NUAEG/CR-1021: PNL-3108

\title{
Models Selected for Calculation of Doses, Health Effects and Economic Costs due to Accidental Radionuclide Releases from Nuclear Power Plants
}

Prepared by D. L. Strenge

Battelle-Pacific Northwest Laboratory

Prepared for

U.S. Nuclear Regulatory

Commission 


\section{NOTICE}

This report was prepared as an account of work sponsored by an agency of the United States Government. Neither the United States Government nor any agency thereof, or any of their employees. makes any warranty, expressed or implied, or assumes any legal liability or responsibility for any third party's use, or the results of such use, of any information, apparatus product or process disclosed in this report, or represents that its use by such third party would not infringe privately owned rights.

\section{Available from}

GPO Sales Program

Division of Technical Information and Document Control

U. S. Nuclear Regulatory Commission

Washington, D. C. 20555

and

National Technical Information Service

Springfield, Virginia 22161 


\section{3}

MODELS SELECTED FOR CALCULATION OF DOSES, HEALTH EFFECTS AND ECONOMIC COSTS

DUE TO ACCIDENTAL RADIONUCLIDE RELEASES

FROM NUCLEAR POWER PLANTS

D. L. Strenge

Contributors:

S. Acharya, NRC

D. A. Baker, PNL

J. G. Droppo, PNL

R. B. McPherson, PNL

B. A. Napier, PNL

L. A. Nieves, PNL

J. K. Soldat, PNL

E. C. Watson, PNL

May 1980

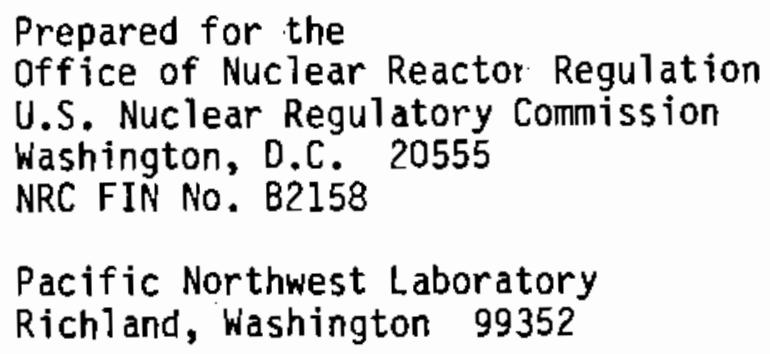




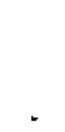

3 


\section{PREFACE}

This report describes work performed under Phase II of a three-phase project. The desired end product of the project is a coherent set of mathematical models and computer codes to be used in performing detailed environmental assessments for reactor accidents of Classes 3 through 9 (USNRC 1976). During Phase I of the project, methodologies currently used for environmental assessment of accidental and routine releases from nuclear facilities were reviewed for the purpose of

- facilitating the use of site-specific meteorological, hydrological, demographic, land and water use, evacuation route, sheltering facility and economic data

- increasing the compatibility between the methodology for evaluating the risks of Class 9 and Classes 3 through 8 reactor accidents

- increasing the compatibility between the methodology for evaluating the risks of accident situations and that used for evaluating risks of routine (chronic) releases.

Also, areas were identified where further modeling effort was needed (Strenge et al. 1978). This report presents the results of model selection efforts under Phase II. This project is part of a larger NRC program (generic Task Action PIan TAP A-33) designed to

- facilitate a decision on whether to revise or re-issue as a Regulatory Guide a proposed Annex to 10 CFR 50, Appendix $D(a)$, which is currently used for assessing environmental impacts of reactor accidents in applicant's Environmental Report or NRC's Environmental Statement on a site-specific basis, and/or

- provide NRC staff with the capability for performing environmental impacts of reactor accidents on a generic basis by appropriate averaging of sitespecific results for a number of selected real sites.

The larger NRC program is intended to provide the staff with additional insight and an enhanced capability for assessing environmental impacts of reactor accidents. Phase I was originally sponsored by the Office of Standards Development (SD) whose personne T laid the groundwork and shaped the initial efforts. During Phase I, however, the project was transferred to the Radiological Assessment Branch (RAB) of the Office of Nuclear Reactor Regulation (NRR) with substantial changes in scope.

Dr. Sarbes Acharya of RAB has provided valuable guidance concerning the objectives of this study and its end use within the larger NRC program.

(a) The complete text of the proposed Annex to Appendix D, 10 CFR 50, is given in Appendix I to the Regulatory Guide 4.2 (USNRC 1976). The text was originally published in the Federal Register, December 1, 1971 (36 FR 22851). 



\section{ABSTRACT}

Models are described for use in site-specific environmental consequence analys is of nuc lear reactor accidents of classes 3 through 9. The mode ls presented relate radioactivity released to resulting doses, health effects, and costs of remedial actions. Specific models are presented for the major exposure pathways of airborne releases, waterborne releases and direct irradiation from activity within the facility buildings, such as the containment. Time-dependent atmospheric dispersion parameters, crop production parameters and other variable parameters are used in the mode 15. The environmental effects are analyzed for several accident start times during the year. 



\section{CONTENTS}

PREFACE

ABSTRACT

FIGLRES

TABLES

1.0 INTRODUCTION

1.1 Problem Overview

$1-1$

1.2 Site Description/Land Usage . . . . . . . . 1-3

1.3 Organization of Calculations . . . . . . . . . 1-5

1.4 Model Uncertainty and Accuracy . . . . . . 1-10

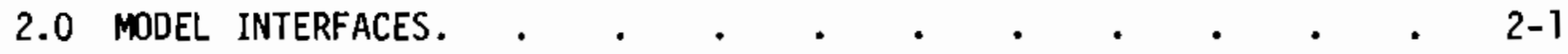

2.1 Source Term/Transport Interface . . . . . . . 2-1

2.2 Transport/Exposure Pathway Interface . . . . . 2-2

2.3 Exposure Pathway/Human Intake Interface . . . . . . 2-2

2.4 Human Intake/Dose Interface . . . . . . . . . 2-4

2.5 Dose/Remedial Action/Dose Interface . . . . . 2-4

2.6 Dose/Health Effects Interface . . . . . . . . 2-5

2.7 Remedial Action/Economic Costs Interface . . . . . . 2-6

3.0 SOURCE TERM . . . . . . . . . . . . . . . . . . . . . .

4.0 TRANSPORT $. \quad . \quad . \quad . \quad . \quad . \quad . \quad . \quad . \quad . \quad . \quad 4-1$

4.1 Atmospheric Dispersion . . . . . . . . . . . . 4-1

4.1.1 Plume Model . . . . . . . . 4-1

4. 1.2 Meteorological Data Requirements . . . . 4-10

4.1.3 Building Wake Correction Model . $:$. $:$. 4-11

4.1.4 Plume Rise . . . . . . . 4-11

4.1.5 Dry Deposition Model . . . . . . . . 4-14

4.1.6 Wet Deposition Mode1 . . . . . . . 4-15

4.1.7 Release Duration . . . . . . . . 4-17 
4.2 Waterborne Dispersion . . . . . . . . 4-18

4.2.1 Dispersion in Rivers . . . . . . . 4-20

4.2.2 Dispersion in Lakes . . . . . . . . 4-24

4.2.3 Dispersion in Estuaries . . . . . . . 4-26

4.2.4 Dispersion Along Open Coasts . . . . . 4-27

4.2.5 Effects of Cooling Ponds . . . . . . . 4-27

4.3 Direct Photon Transport . . . . . . . . 4-32

5.0 EXPOSURE PATHWAYS . . . . . . . . . . . 5-

5.1 External Exposure from Plume Passage . . . . . 5-1

5.2 Externa1 Exposure from Contaminated Ground . . . . 5-1

5.3 Inhalation of Radionuclides during Passage of Plume . . 5-5

5.4 Inhalation of Resuspended Material . . . . . 5-6

5.5 Intake Through Ingestion of Crops . . . . . . 5-9

5.5.1 Air Deposition Mode1 . . . . . . . 5-10

5.5.2 Irrigation Deposition Models $. \quad . \quad . \quad . \quad 5-11$

5.5.3 Resuspension and Deposition to Plant Surfaces : . 5-14

5.5.4 Weathering from Plant Surfaces . . . . . 5-16

5.5.5 Plant Uptake of Radionuclides Through Roots . . 5-17

5.5.6 Consumption after Harvest . . . . . . 5-18

5.6 Ingestion of Released Contamination in Animal Products . 5-21

5.6.1 Animal Ingestion of Water . . . . . . 5-22

5.6.2 Animal Ingestion of Pasture Grass : $: \quad \cdot \quad 5-27$

5.6.3 Animal Ingestion of Feed Crops . . . . . 5-34

5.6.4 Summary: Animal Product Pathway. . . . . 5-37

5.7 Ingestion of Aquatic Foods . . . . . . . . 5-41

5.8 Ingestion of Contaminants in Drinking Water . . . . 5-47

5.9 External Exposure from Waterborne Contamination . . . 5-48

5.10 External Exposure to Material Contained Within Facility
Buildings. . . . . . . . 5-51

6.0 DOSIMETRY $. \quad . \quad . \quad . \quad . \quad . \quad . \quad . \quad . \quad . \quad .6-1$

6.1 External Exposure . . . . . . . . . $6-1$ 
6.1 .1 Air Submersion . . . . . . . . . 6-1

6.1 .2 Ground Contamination . . . . . . . . 6-4

6.1 .3 Direct Irradiation . . . . . . . . 6-6

6.1 .4 Swiming and Boating . . . . . . . . 6-7

6.2 Internal Dosimetry . . . . . . . . . . . . 6-9

6.2.1 Respiratory System . . . . . . . . 6-11

6.2.2 Gastrointestinal Tract . . . . . . 6-12

6.2.3 Body Organs . . . . . . . . . 6-13

6.3 Sumary of Dose Conversion Factors . . . . . . 6-13

7.D REMEDIAL ACTION . . . . . . . . . . . . . . . . .

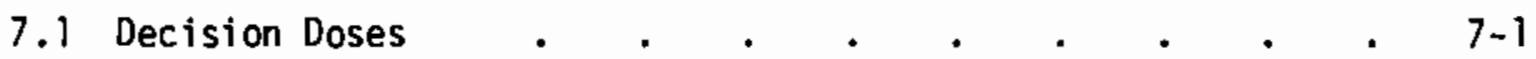

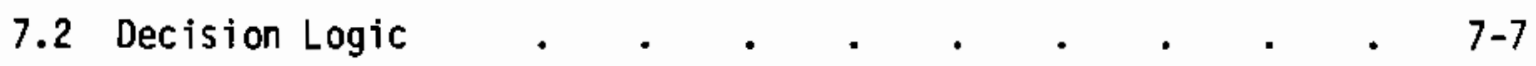

7.3 Evacuation and Sheltering Model . . . . . . . . . . . . . . . .

7.3.1 External Exposure from the Plume . . . . . 7-21

7.3.2 Inhalation of Contaminated Air $. \quad . \quad . \quad . \quad$ 7-23

7.3.3 External Exposure to Contaminated Ground . . . 7-23

7.3.4 Direct Irradiation from Contained Materials : . 7-24

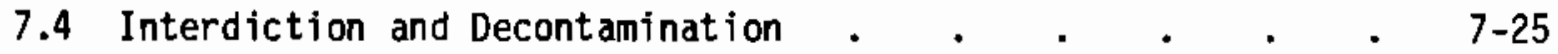

8.0 ECONOMIC COSTS . . . . . . . . . . . . . . . $8-1$

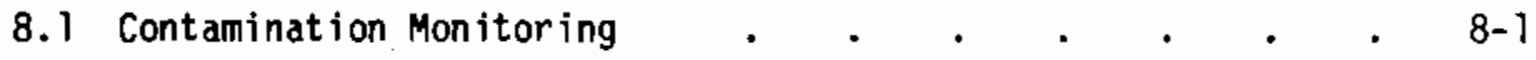

8.2 Sheltering and Evacuation . . . . . . . . . 8-2

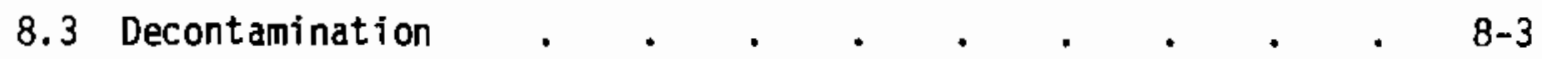

8.4 Interdiction . . . . . . . . . . . 8-3

9.0 HEALTH EFFECTS . . . . . . . . . . . . . . . . . $9-1$

9.1 Early Somatic Effects . . . . . . . . . . 9-1

9.2 Late Somatic Effects . . . . . . . . . . 9-3

9.3 Genetic Effects $\quad$. . . . . . . . . 9-7

10.0 COMPARISON WITH REACTOR SAFETY STUDY MODELS . . . . . . 10-1

10.1 Source Terms . . . . . . . . . . . . . 10-1 


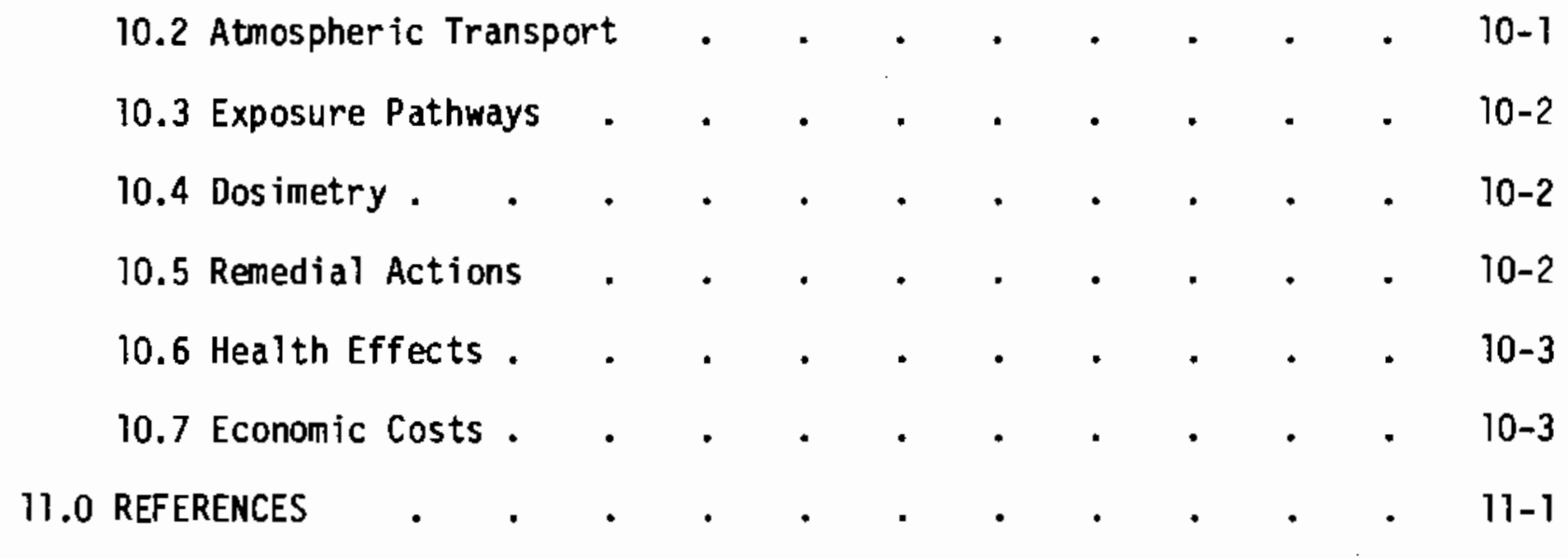




\section{FIGURES}

1.1-1 Problem Overview Diagram . . . . . . . . 1-2

1.2-1 Site Data Definition Grid . . . . . . . 1-3

1.3-] Calculation Logic - Part I . . . . . . . . 1-7

1.3-2 Calculation Logic - Part II . . . . . . . 1-8

1.3-3 Calculation Logic - Part III . . . . . . . . 1-9

4.2-1 Partially Mixed Cooling Pond . . . . . . . 4-30

5.5-1 Food Crop Pathway Diagram . . . . . . . . . 5-9

5.6-1 Routes by Which Animal Products are Contaminated . . . 5-22

6.2-1 Internal Dosimetry Model . . . . . . . . 6-9

7.2-1 Remedial Action Control Logic . . . . . . . 7-7

7.2-2 Remedial Action Logic for Type 1 Exposures . . . . 7-8

7.2-3 Remedial Action Logic for Plume Passage Exposures . . . 7-9

7.2-4 Remedial Action Logic for Direct Irradiation Exposure . . 7-10

7.2-5 Remedial Action Logic for Contaminated Ground External

7.2-6 Remedial Action Logic for Type 2 Exposures . . . . 7-12

7.2-7 Remedial Action Logic for Liquid Release Ingestion . . . 7-13

7.2-8 Remedial Action Logic for Airborne Release
Ingestion Exposures . . . . 7-14

7.2-9 Remedial Action Logic for Second-Year Ingestion . . . 7-15

7.3-1 Normalized Plume Concentration Function . . . . . 7-22

7.3-2 Normalized Ground Concentration Function . . . . . 7-24

7.3-3 Direct Irradiation Dose Rate Function $\mathrm{D}(\mathrm{t})$. . . . 7-25 


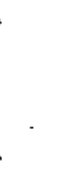




\section{TABLES}

1.3-1 Parameter Dimensions . . . . . . . . 1-6

1.4-1 Areas of Uncertainty in Models and Parameters for

Evaluation of Environment Releases . . . . . . 1-10

2.1-1 Source Term/Transport Model Interface . . . . . 2-1

2.2-1 Transport/Exposure Pathway Interface . . . . . 2-2

2.3-1 Exposure Pathway/Human Intake . . . . . . . 2-3

2.4-1 Human Intake/Dose Interface . . . . . . . 2-4

2.5-1 Dose/Remedial Action/Dose Interface . . . . . . 2-5

2.6-1 Dose/Health Effects Interface . . . . . . . 2-6

4.1-1 Constants for Dispersion Parameter Equation . . . . 4-3

4.3-1 Photon Energy Groupings . . . . . . . . 4-34

6.1-1 Finite-Cloud Dose Correction Factor . . . . . . 6-3

6.2-1 Gastrointestinal Tract Compartment Data . . . . . 6-12

6.3-1 Dose Conversion Factor Surmary . . . . . . 6-14

6.3-2 Time Periods for Internal Dose Conversion Factors . . . 6-15

7.1-1 Dose Categories and Dose Criteria Used by Reactor Safety Study. 7-2

7. 1-2 Time Periods for Inhalation Dose Contribution to the Seven-day Dose . . . . . . . . . 7-3

7.1-3 Protective Action Guides for Exposure of the General
Population to Radionuclides in a Passage Plume. . . 7-3

7.1-4 Protective Actions Recommended by the Environmental Protection Agency to Avoid Whole-Body and Thyroid Dose from Exposure to a Gaseous Plume . . . . . 7-5

7.1-5 Decision Doses . . . . . . . . . . . . 7-6

9.1-1 Early Death Probability Functions: Fraction of Population Expected to Die by Radionuclide Exposure to Various Organs . . . . . . . . 9-3 
9.2-1 Expected Latent Cancer (Excluding Thyroid) Deaths per Million Man-rem of External Exposure . . . . . 9-4

9.2-2 Expected Latent Cancer (Excluding Thyroid) Deaths per Million Man-rem from Internal Radionuclides Delivered During Specified Periods . . . . . . 9-5

9.2-3 Dose-Effectiveness Factors . . . . . . . . . 9-6

9.2-4 Expected Thyroid Nodules . . . . . . . . 9-6

9.3-1 Disorders and Spontaneous Abortions Attributable to Radiation from External Sources Derived from Releases at the Time of the Hypothetical Accident . . . 9-9

9.3-2 Disorders and Spontaneous Abortions Due to Radiation from Internal Sources Incorporated at the time of the Hypothetical Accident . 


\subsection{INTRODUCTION}

This report presents the results of Phase II of a three-part study of the modeling of environmental exposure pathways and consequent radiation doses in reactor accident situations. During Phase I, current methodologies for environmental consequence assessment of nuclear facilities were reviewed and areas were identified where further modeling effort was required. Under Phase II, mathematical models were selected and developed for the areas defined in Phase I. This report describes the models selected for all aspects of the calculations. Under Phase II the models are also to be incorporated into a computer program. Phase III of the study will use the computer program to perform environmental consequence analyses for selected sites and sensitivity analyses.

The following sections provide an overview of the calculational problem and a discussion of the site description used by the various models involved in the analysis.

\subsection{PROBLEM OVERVIEW}

The purpose of Phase II is to prepare a computer program for calculation of doses, health effects and economic costs resulting from specified radionuclide source terms. Three major sources are considered:

1. releases via effluent air

2. releases via effluent liquids

3. releases to facility buildings such as the containment.

The pathways by which these releases can contribute to doses, health effects and economic costs are illustrated in the diagram of Figure $1,1-1$.

The source terms are defined as activity released in a given time period. The release is converted to activity in the environment by appropriate transport models. Exposure to humans may result through several pathways. For airborne release the exposure modes considered include

- external dose from the passing cloud

- internal dose from radionuclides inhaled during cloud passage

- external dose from material deposited on the ground

- internal dose from ingestion of farm products contaminated by deposition

- internal dose from inhalation of resuspended radionuclides. modes:

Releases via liquid effluents can contribute by the following exposure

- external dose from swimming and boating

- external dose from shoreline deposition

- internal dose from ingestion of drinking water

- internal dose from ingestion of aquatic foodstuffs 


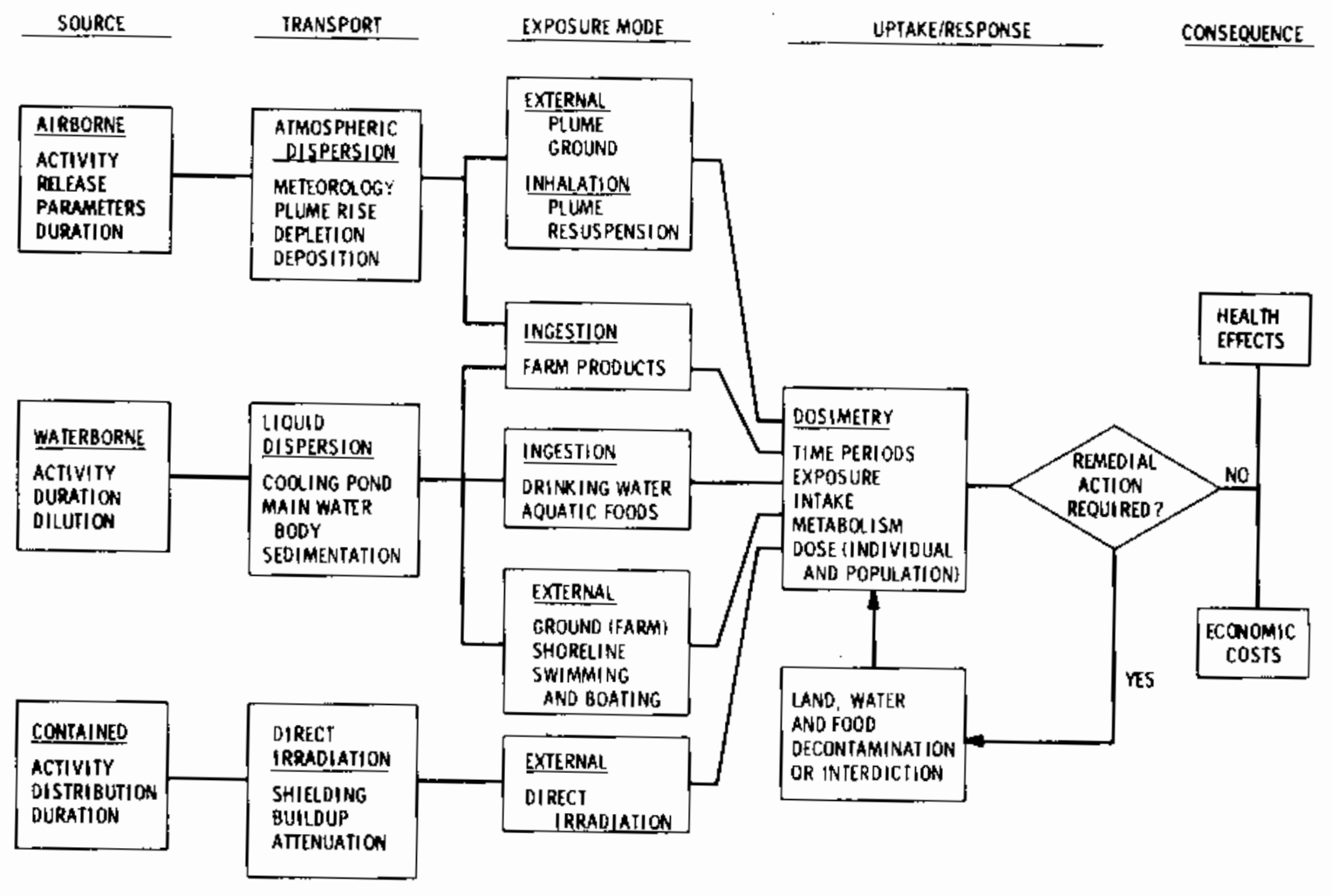

FIGURE 1.1-1. Problem Overview Diagram

- internal dose from ingestion of drinking water

- internal dose from ingestion of aquatic food

- internal dose from ingestion of irrigated farm products

- external dose from irrigated farmlands.

The direct irradiation pathway involves only external exposure to photon radiation from activity contained within the facility buildings.

The pathway models determine the intake of each radionuclide by the exposed population. The intake is converted to radiation dose by use of precalculated dose conversion factors. For the direct irradiation pathway the photon flux at the exposure point is converted to dose rate. The total direct irradiation dose is calculated as the time integral of dose rate.

The results of dose calculation consist of dose received from the several pathways for each organ of interest. These doses are compared to specified dose criteria to determine if any protective actions are warranted. Doses are reevaluated for any pathway involving a required protective action. When all actions have been accounted for, the final dose levels are used to calculate health effects. Economic costs are calculated for the required protective actions. 


\subsection{SITE DESCRIPTION/LAND USAGE}

Land usage and people at a site must be distributed in such a manner as to be compatible with calculations for all three major exposure modes (direct, air and liquid). For dose calculations involving air releases and direct radiation, it is necessary to define parameters as a function of compass directions in an outward direction from the site as illustrated in Figure 1.2-1. The usual method is to define 16 equal compass-direction sectors of $22-1 / 2^{\circ}$ each. The radial distances (selected for each site) are defined to account for irregularities in site parameters, such as high population centers or crop production areas. The resulting grid provides a spatial reference for definition of land usage parameters and a framework about which to organize calculations (see Section 1.3).

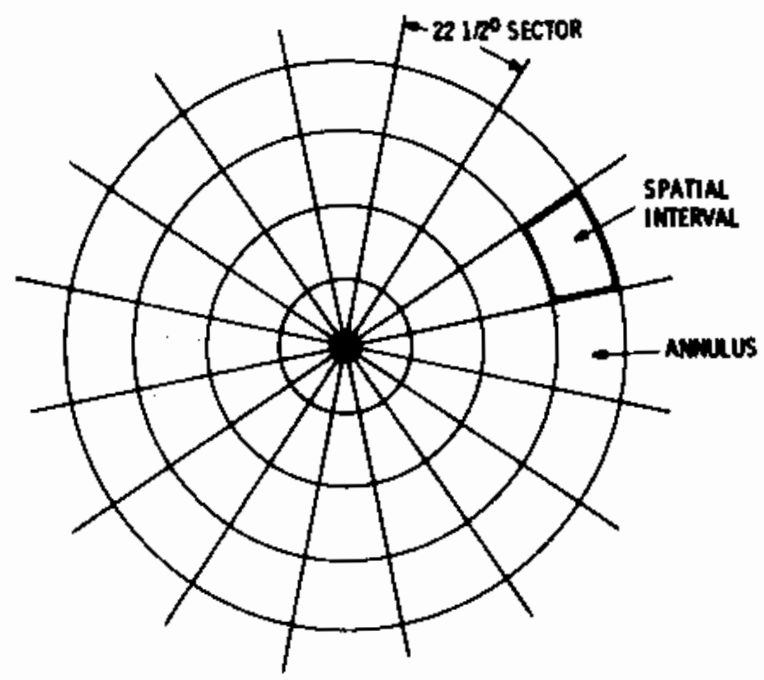

(FACILITY AT CENTER OF GRIO)

\section{FIGURE 1.2-1. Site Data Definition Grid}

Included in the site description is information on water bodies which are potential receptors for liquid effluents. While the actual location of the water bodies is not especially significant, it is important to know the usages of the water for each element of the spatial grid. This information is needed for the water usage exposure pathways. 

usage:

The $l$ and usage model presented here defines three categories of 1 and

- residential

- commercial

- farml and.

The area used for each of the three categories is defined for each spatial interval by

$$
\begin{array}{ll}
\text { residential area: } & A_{r i}=A_{j} F_{r i} \\
\text { commercial area: } & A_{c i}=A_{j} F_{c i} \\
\text { farmland area: } & A_{f i}=A_{j} F_{f i}
\end{array}
$$

where

$A_{j}$ - total habitable land area in spatial interval $i, m^{2}$

$$
A_{j}=a_{j} F_{h i}
$$

$a_{j}$ - total area within boundaries of spatial interval $i, m^{2}$

$F_{\text {hi }}$ - fraction of habitable land in spatial interval $i$

Ari - total residential land area in spatial interval $i, \mathrm{~m}^{2}$

$F_{r i}$ - fraction of habitable land in residential use in spatial interval $i$

$A_{c j} \cdot$ total commercial land area in spatial interval $i, \mathrm{~m}^{2}$

$\mathrm{F}_{\mathrm{ci}}$ - fraction of habitable land in commercial use in spatial interval i

$A_{f i}$ - total farmland area in spatial interval $i, \mathrm{~m}^{2}$

$F_{f i}$ - fraction of habitable land in use as farmlands in spatial interval i.

Definition of farmland usage requires additional information on crop production. The production area for each type of farm product is necessary for calculation of radionuclide intake.

The farmland usage is represented by

$$
A_{f i k}=A_{f i} F_{k i}
$$

where 
Afik - area of farmland used for farm product $k$ as defined for spatial interval i

$F_{k i}$ - fraction of $f a r m l$ and used for farm product $k$ in spatial interval i.

Health effects are dependent on radiation dose, which are in turn dependent on radionuclide uptake. Because production of farm produce has a direct relation to uptake, estimating farmiand usage is important in estimating heaith effects.

Economic costs are based on value per unit area defined for each major 7 and usage category, and on farm product values per unit area defined for each farm product. The economic data is defined by major land usage category and farm product along with the land fraction data. Use of economic data is described in the economic model discussion.

\subsection{ORGANIZATION OF CALCULATIONS}

The many models selected for use in the computer program must be organized and interfaced properly before they will be of use in accident consequence analysis. General organization and flow of the calculations is described here. Mode1 interface parameters are discussed in Section 2.0.

To organize the calculations, the number of parameters and features desired in the computer program must be considered. The present study requires the features listed in Table 1.3-1. Because of the large number of calculations required by using dimensioned variables, the calculations must be organized to eliminate redundant calculations. This can be done by calculation of intermediate values and by efficient use of temporary storage files and data arrays. Below are listed methods for reducing the complexity of the calculations and for reducing computing time requirements.

- For each accident involving direct irradiation, calculate dose as a function of distance and direction with and without evacuation and sheitering for required time periods. When more than one accident is considered, this information may be stored on a temporary file.

- For food crop pathways and animal product pathways, precalculate unit transfer factors to find the activity ingested by humans per unit activity concentration on the soil and per unit activity concentration initially deposited on plant surfaces. These unit transfer factors are calculated monthly and are used for all start times during the given month.

- Start times are determined at the start of each run and are arranged in chronological order. This is done to make efficient use of the unit transfer factors for food.

- Atmospheric dispersion is calculated for a release for one start time at a time. The normalized dispersion values are applied to each accident's airborne source term to generate air and ground contamination levels as a function of distance and direction fram the site. 
- The air concentrations and ground contamination levels are stored on temporary files when more than one accident is involved with airborne releases.

- The air concentration and ground contamination levels are applied to each sector toward which the wind blew after the start of the accident and until the plume tail passed beyond the farthest radial distance.

- Initial dose criteria tests for remedial actions are performed for each major pathway. After dose reductions are applied, the sum of specific pathway doses is tested against the dose criteria to determine if further actions are necessary.

TABLE 1.3-1. Parameter Dimensions

\begin{tabular}{lr}
\multicolumn{1}{c}{ Parameter } & \multicolumn{1}{c}{ Variability } \\
\cline { 3 - 3 } Sites & 1 per run \\
Accidents & 10 per run \\
Release Types (airborne, & 3 per accident \\
waterborne, direct) & \\
Radionuclides & 60 per run \\
Radionuclide Classes & 10 per release type \\
Radial Distances & 20 \\
Sectors & $16\left(22-1 / 2^{\circ}\right.$ each) \\
Start Times & 365 per accident \\
Food Crops & 9 \\
Animal Products & 4 \\
Aquatic Foodstuffs & 4 \\
Organs & 13 \\
Acute Health Effects & 8 \\
Latent Health Effects & \\
From Early Exposure & 8 \\
From Chronic Exposure & 8 \\
Genetic Effects & 4
\end{tabular}

All site parameters must, of course, be defined before calculations are begun. For all major release modes, the site grid (distances) must be defined and the population within each spatial interval given. If air or liquid releases are considered, it is also necessary to def ine parameters which describe crop production/usage and economic costs.

Calculation of effects for a particular release are based on the grid structure of Figure 1.2-1. For direct irradiation the dose may be calculated as a function of distance and direction for specified time periods after release. It is assumed that the resulting doses are independent of the time of year in which the accident happens, so that this calculation need be done only once for each accident. If population data were supplied as a function of time of year then population doses from direct irradiation would also be a function of time of year. 
The contribution to ingestion dose from liquid pathways is independent of wind direction. However, it is dependent on time of year because contamination via irrigation will occur only during the crop growing season. The liquid concentration is also a function of time of year because of seasonal or monthly variations of water dispersion parameters. The water concentration can be calculated for each uptake point for each month of the year prior to performing the dose calculations for each start time. The appropriate concentration array will then be available and will not need to be calculated for each start time.

The general organization of calculations is shown in the logic diagrams of Figures 1.3-1, 1.3-2 and 1.3-3. These diagrams reflect the methods suggested above for reduction of computing efforts.

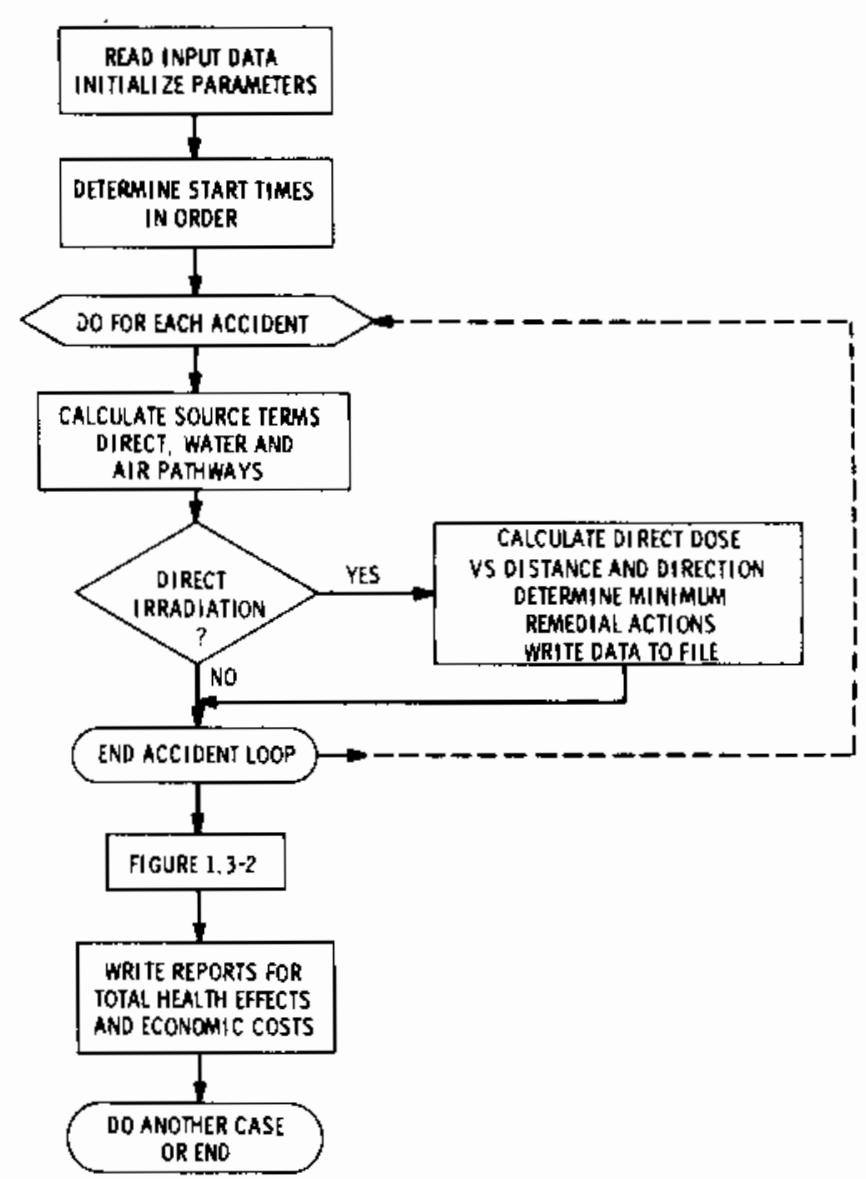

FIGURE 1.3-]. Calculation Logic - Part I 
FROM FIGURE 1.3-1

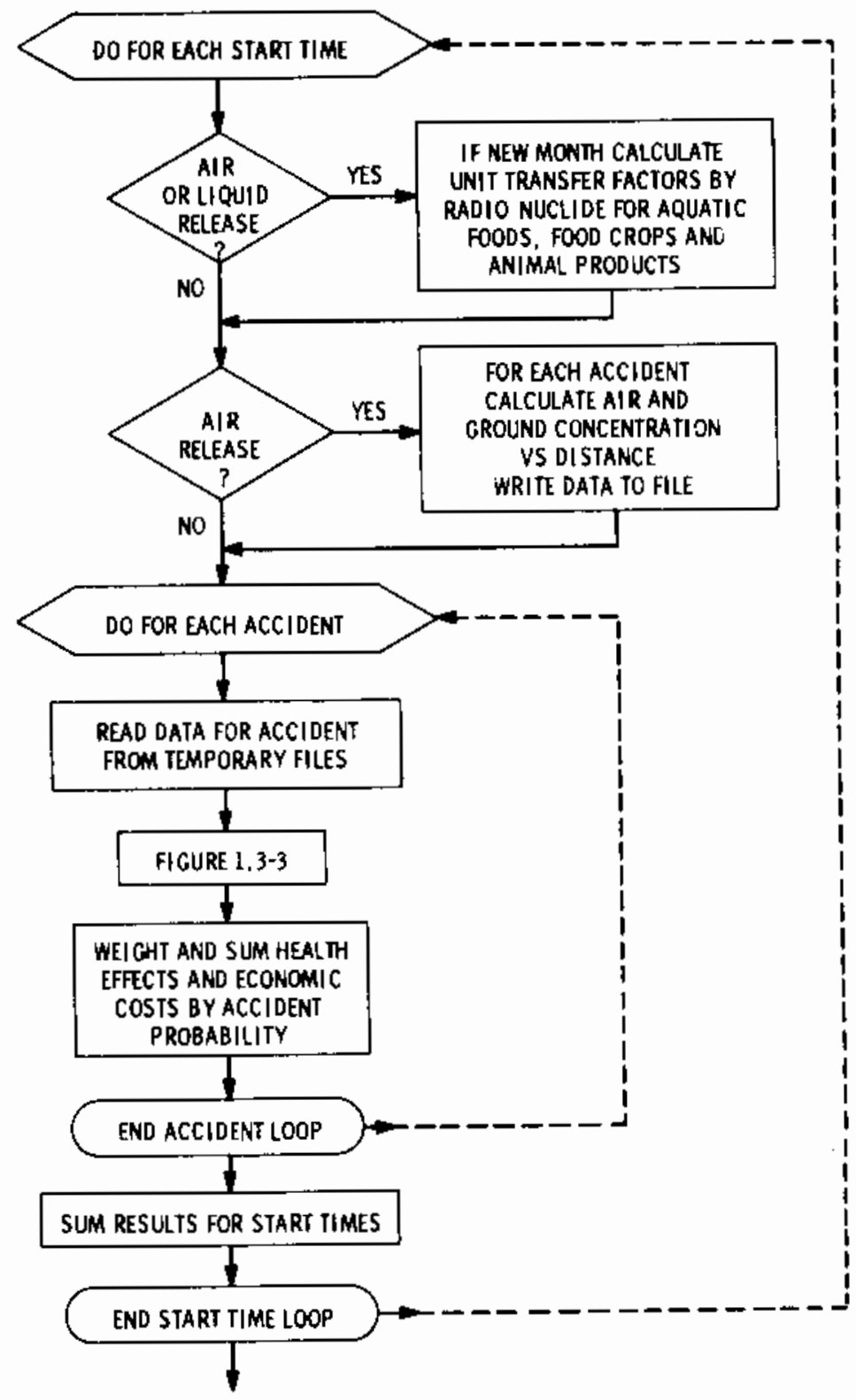

TO FIGURE 1.3-1

FIGURE 1.3-2. Calculation Logic - Part II 


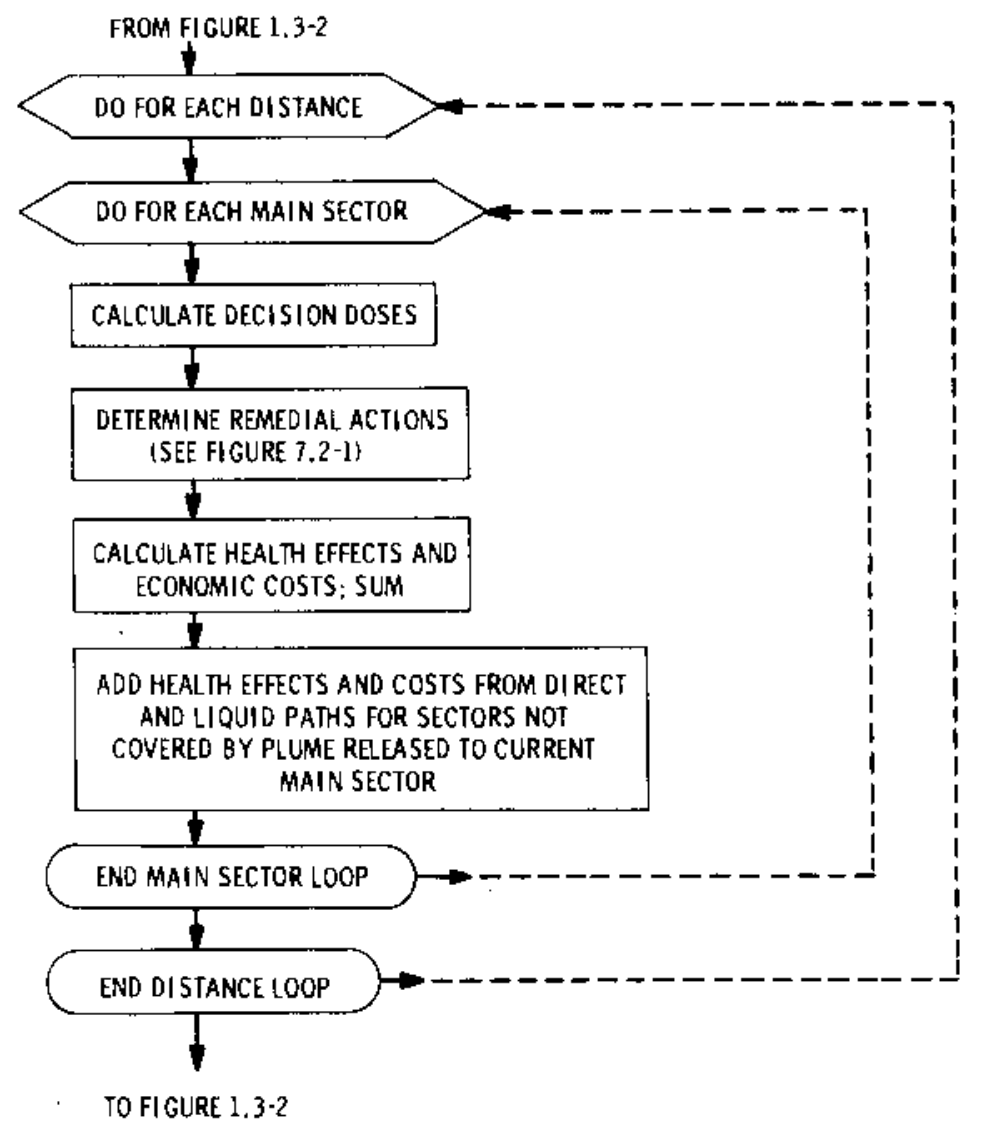

FIGURE 1.3-3. Calculation Logic - Part III 


\subsection{Model Uncertainty and Accuracy}

Any comprehensive system of models designed to trace materials released to the environment from the source to the ultimate receptor involves a large number of uncertainties. Most of the uncertainties can be identified, but few can be quantified. Each model or submodel in the system involves its own individual uncertainties. One possible scheme of categorizing the models and identifying the major areas of uncertainty is presented in Table 1.4-1.

TABLE 1.4-1. Areas of Uncertainty in Models and Parameters for Evaluation of Environmental Releases

\section{ATMOSPHERIC TRANSPORT}

A. Meteorological Data

1. Numerical Accuracy

2. Geographical Coverage

B. Terrain

1. Mountains/Valleys

2. Forests/Vegetation/Water

3. Ocean/Land Interface

C. Deposition and Depletion

1. Dry

2. Washout/Rainout

3. Vegetation Cover

4. Stability/Wind Speed

II. HYDROLOGIC TRANSPORT

A. Hydrologic Data

1. Numerical Accuracy

2. Fluctuations--Seasona 1, Diurna 1

B. Rivers--Channeling, Mixing

C. Large Lakes, Oceans--Winds/Tides

D. General

1. Sediment/Water Interactions

2. Channel and Physical Changes After Release

III. AQUATIC FOODS

A. Food Types Available 
TABLE 1.4-1. Contd.

B. Concentration Ratios

1. Species

2. Season

3. Chemical and Physical Form of Contaminant

C. Exposure History

1. Timing of Exposure

2. Timing of Harvest

3. Timing of Consumption

D. Orinking Water

1. Water Treatment Facilities

2. Delay in Water System

IV. TERRESTRIAL FOODS

A. Deposition

1. Onto Soil/Plant from Air

2. Onto Soil/Plant from Irrigation

3. Resuspension from Soil to Plant

4. Transfer to Edible Parts

B. Long-Term Accumulation

1. Residence Time on Plant

2. Soil Removal Mechanisms

C. Uptake From Soil

1. Species Dependence

2. Chemical and Physical Form

3. Change in Availability with Time

4. Transfer to Edible Parts

D. Exposure History

1. Timing of Plant Growth

2. Timing of Plant Harvest

3. Timing of Plant Consumption

E. Animal Products

1. Animal Diet

2. Animal Metabolism

3. Transfer to Edible Product

V. EXTERNAL EXPOSURE

A. Exposure History

1. Timing

2. Location 
TABLE 1.4-1. Contd.

B. Dosimetry

1. Shielding

2. Environmental factors (Scattering)

VI. INTERNAL EXPOSURE

A. Inhalation

1. Timing and Location of Exposure

2. Particle Size

3. Chemical Form

4. Ventilation Rate (Age, Sex, Time of Day)

5. Metabolism and Transfer from Lungs

6. Behavior of Daughter Products

7. Dosimetry

B. Ingestion

1. Timing and Location of Production

2. Diet (Age)

3. Metabolism (Age)

4. Losses of Contaminant in Food Preparation

5. Dosimetry

\section{HEALTH EFFECTS}

A. Conversion of Dose to Heaith Effects

1. Linearity

2. Threshold

3. Dependence on Dose/Dose Rate

4. Dependence on Age/Sex

A detailed discussion of each of the areas of uncertainty in the table is not warranted here, partly because most of them cannot be quantified at this time. A general discussion of environmental transport and dose models was conducted at a workshop held in Gatlinburg, Tennessee, September 6 through 9, 1977 (Hoffman et al. 1977). As expected, very little quantitative information was available on uncertainties, but it was apparent that most persons felt that models yielded order-of-magnitude assessments, which tended to err on the conservative side more of ten than not. The following quotation from the portion of the proceedings covering the working group on terrestrial food chain models illustrates this point of view.

Conservative estimates are generally used for those parameter values which are not well defined or which have a wide range of possible values. This leads to calculated dose values which are likely to be higher than the true doses. Because of the possibility of unidentified errors in some other parameter values, the magnitude of the overestimate cannot be quantified. The net 
result is calculated dose values which are order-of-magnitude estimates of the true doses. In certain specific applications, such as transfer of radioiodine from air to grass to milk, the models predict the true values within factors of 3 to 5 (Hoffman et a1. 1977, p. 85).

Some members of the working group on atmospheric transport concluded that the application of models to relatively flat terrain using accurate meteorological input data could yield calculated air concentrations within a factor of 4 of measured concentrations out to distances as great as $100 \mathrm{~km}$. 0thers felt that a factor of 10 was more realistic.

The working group on internal and external dosimetry discussed several causes of uncertainty and concluded that validation and accuracy could be estimated, at least initially, only for certain parts of the overall metabolism and dosimetry schema. No quantitative assessment of the uncertainty was made, but dosimetry should be one of the least inaccurate portions of the overall modeling system.

Oak Ridge National Laboratory (ORNL) is currently evaluating the uncer= tainty in the output of environmental transport and dose models and has recentiy reported on a statistical analysis of parameters involved in such models (Hoffman and Baes, 1979).

Very few parameters have sufficient data to permit the generation of a probability distribution function (PDF), so the assumption was made that the parameter values would be distributed log-normally.

The limited data available do not seriously contradict the log-normal assumption.

Stochastic calculations have been made of the PDF of the model output values using the log-nomal PDF for certain selected nuclide/pathway combinations.

In a later report on the ORNL uncertainty study, Little and Miller (1979) have concluded, in part:

Aquatic transport models are divided into one-dimensional, longitudinal-vertical and longitudinal-horizontal models.

The one-dimensional models considered predict observed concentrations to within a factor of 2, but they underpredicted in a research flume and overpredicted in a natural environment. Longitudinal-transverse models were available with and without sorption. The sorption model, FETRA, underpredicted pollutant concentrations by $40 \%$ and sediment concentrations by $70 \%$ (p. vii).

The Gaussian plume atmospheric dispersion model predicts (under certain conditions) ground-level centerline concentrations within $10 \mathrm{~km}$ of a continuous point release to within $20 \%$ of the observation. 
Predictions of concentration at a specific time and place within $10 \mathrm{~km}$ over flat terrain from the release point under steady meteorological conditions could be within an order of magnitude of the observations. The long-term average for a specific point up to $10 \mathrm{~km}$ from the release over flat terrain could be predicted within a factor of 2 . Monthly and seasonal averages over flat terrain up to $100 \mathrm{~km}$ away from the release could be predicted to within a factor of 4 . The uncertainties of predicting over complex terrain or during complex meteorology are unquantifiable at this point.

No validation study has been conducted to test the predictions of either aquatic or terrestrial food chain models. Using the aquatic pathway from water to fish to an adult for ${ }^{137} \mathrm{Cs}$ as an example, a 95\% one-tailed confidence limit interval for the predicted exposure is calculated by examining the distributions of the input parameters. Such an interval is found to be 16 times the value of the median exposure, A similar one-tailed limit for the air-grass-cow-milk-thyroid for $131_{I}$ and infants was 5.6 times the median dose (p. viii). 


\subsection{MODEL INTERFACES}

The proposed consequence models cover many topics from source term generation to dosimetry, health effects and cost to man. To be of use in consequence analys is the models must interface with each other properly. This section defines the intermediate parameters at each major mode 1 interface point. The following interfaces are discussed:

- source term/transport

- transport/exposure pathway

- exposure pathway/human intake

- human intake/dose

- dose/remedial action/dose

- dose/health effects

- remedial action/economic costs.

The interfaces consist of parameters generated by models from specified input data and previous models in the calculational chain.

\subsection{SOURCE TERM/TRANSPORT INTERFACE}

The starting point in the calculation of source terms is the activity of each important radionuclide in the reactor core at the time of the accident. The release fractions defined for each radionuclide class and each pathway are used to generate the source term for each transport pathway. These secondary source terms are represented as the activity of each radionuclide to be considered for the particular transport path. Table 2.1-1 gives the source term/ transport interface parameters for airborne, waterborne and direct irradiation.

TABLE 2.1-1. Source Term/Transport Mode1 Interface

\begin{tabular}{|c|c|c|c|}
\hline Transport Path & Parameter & Symbol & Units \\
\hline \multirow[t]{2}{*}{ Airborne } & $\begin{array}{l}\text { Activity of each radionuclide released } \\
\text { decayed to the start of release. One set } \\
\text { of activities must be specified for each } \\
\text { accident involving airborne releases. }\end{array}$ & $\mathrm{O}_{\mathrm{a}}$ & $\mathrm{Ci}_{\mathrm{i}}$ \\
\hline & $\begin{array}{l}\text { Time period over which the activity } \\
\text { is released }\end{array}$ & $\mathrm{t}_{\mathrm{a}}$ & sec \\
\hline \multirow[t]{2}{*}{ Waterborne } & $\begin{array}{l}\text { Activity of each radionuclide released } \\
\text { via liquid effluents decayed to the } \\
\text { start of release. One set of activities } \\
\text { must be specified for each accident } \\
\text { involving waterborne releases. }\end{array}$ & $O_{2}$ & $\mathrm{Ci}$ \\
\hline & $\begin{array}{l}\text { Time period over which the activity } \\
\text { is released }\end{array}$ & $\mathrm{t}_{2}$ & $\sec$ \\
\hline \multirow[t]{2}{*}{$\begin{array}{l}\text { Direct } \\
\text { Irradiation }\end{array}$} & $\begin{array}{l}\text { Activity of each radionuclide released } \\
\text { to the conf inement spaces decayed to } \\
\text { the time of release. One set of } \\
\text { activities must be defined for each } \\
\text { accident involving direct irradiation. }\end{array}$ & $a_{d}$ & $\mathrm{Ci}$ \\
\hline & $\begin{array}{l}\text { Time period over which material in } \\
\text { confinement spaces is available as } \\
\text { a source of radiation (cleanup } \\
\text { processes may reduce potential exposure). }\end{array}$ & $t_{d}$ & $\sec$ \\
\hline
\end{tabular}




\subsection{TRANSPORT/EXPOSURE PATHWAY INTERFACE}

The source terms described in Table 2.1-1 are used by transport models to generate input to exposure pathway models. The airborne and waterborne transport models use the initial release activity $\left(0_{a}, Q_{l}\right)$ and parameters affecting transport to estimate radionuclide activities at specified points in the environment. The direct irradiation source term is used to generate dose rates as a function of time, distance and direction from the reactor building. For this pathway the interface is from transport to dosimetry. The interface parameters are listed in Table 2.2-1.

\section{TABLE 2.2-1. Transport/Exposure Pathway Interface}

\begin{tabular}{|c|c|c|c|}
\hline Transport Path & Parameter & Symbol & Units \\
\hline \multirow[t]{2}{*}{ Airborne } & $\begin{array}{l}\text { Time-integrated air concentration for } \\
\text { each nuclide and spatial interval }\end{array}$ & $c$ & $\mathrm{Ci} \cdot \mathrm{sec} / \mathrm{m}^{3}$ \\
\hline & $\begin{array}{l}\text { Ground contamination level for each } \\
\text { nuclide and spatial interval }\end{array}$ & G & $\mathrm{Ci} / \mathrm{m}^{2}$ \\
\hline \multirow[t]{2}{*}{ Waterborne } & $\begin{array}{l}\text { Average water concentration (radio- } \\
\text { active decay accounted for) for } \\
\text { each nuclide and each intake } \\
\text { location }\end{array}$ & $c_{w}$ & $\mathrm{Ci} / \mathrm{l}$ \\
\hline & $\begin{array}{l}\text { Time period over which the average } \\
\text { water concentration persists }\end{array}$ & $T_{\text {wa }}$ & sec \\
\hline \multirow[t]{2}{*}{$\begin{array}{l}\text { Direct } \\
\text { Irradiation }\end{array}$} & $\begin{array}{l}\text { Whole-body external dose rate at each } \\
\text { spatial interval for specified times }\end{array}$ & $\mathrm{D}_{\mathrm{d}}$ & $\mathrm{rem} / \mathrm{sec}$ \\
\hline & $\begin{array}{l}\text { Maximum distance interval where direct } \\
\text { irradiation is calculated (for each } \\
\text { direction) }\end{array}$ & $M_{d}$ & (none) \\
\hline
\end{tabular}

\subsection{EXPOSURE PATHWAY/HUMAN INTAKE INTERFACE}

The airborne and waterborne pathways result in human exposure through external, inhaled and ingested intake. (Direct irradiation results in external exposure, $D_{d}$, but this pathway's interfaces have been considered under the Transport/Exposure Pathway Interface section above.) The external exposure is calculated for each location and is represented as a dose received in a specified time period. Exposures by inhalation and ingestion are represented as the activity of each radionuclide taken in by humans for the several pathways (inhalation, food crops, potable water, etc.) at a given spatial interval. The intake is calculated for each of several time periods after the accident as required for the health effects model. The exposure pathway/human intake interface parameters are listed in Table 2.3-1. 
TABLE 2.3-1. Exposure Pathway/Human Intake

\begin{tabular}{|c|c|c|c|}
\hline $\begin{array}{l}\text { Exposure } \\
\text { Pathway }\end{array}$ & Parameter ${ }^{\star}$ & Symbol & Units \\
\hline Direct Irradiation & $\begin{array}{l}\text { Whole-body dose from direct } \\
\text { irradiation from activity con- } \\
\text { tained within reactor confinement } \\
\text { barriers for the current spatial } \\
\text { interval and accident }\end{array}$ & $\mathrm{D}_{\mathrm{d}}$ & rem \\
\hline External from Plume & $\begin{array}{l}\text { Whole-body dose for plume passage } \\
\text { for the current spatial interval } \\
\text { and accident }\end{array}$ & $\mathrm{D}_{\mathrm{e}}$ & rem \\
\hline External from Ground & $\begin{array}{l}\text { Whole-body dose for specified } \\
\text { time periods for the current } \\
\text { spatial interval and accident }\end{array}$ & $\mathrm{D}_{\mathrm{g}}$ & rem \\
\hline $\begin{array}{l}\text { External from Aquatic } \\
\text { Activities }\end{array}$ & $\begin{array}{l}\text { Whole-body dose for specified } \\
\text { time periods for the current } \\
\text { spatial interval and accident }\end{array}$ & $\mathrm{D}_{\mathrm{S}}$ & rem \\
\hline Inhalation of Plume & $\begin{array}{l}\text { Average individual intake for } \\
\text { plume passage for the current } \\
\text { spatial interval and accident }\end{array}$ & $\mathrm{C}_{i}$ & $\mathrm{Ci}$ \\
\hline $\begin{array}{l}\text { Inhalation of Resus- } \\
\text { pended Material }\end{array}$ & $\begin{array}{l}\text { Average individual intake for } \\
\text { specified time periods for the } \\
\text { current spatial interval and } \\
\text { accident }\end{array}$ & $\mathrm{C}_{r}$ & $\mathrm{Ci}$ \\
\hline $\begin{array}{l}\text { Ingestion of Drinking } \\
\text { Water }\end{array}$ & $\begin{array}{l}\text { Average individual intake for } \\
\text { specified time periods for the } \\
\text { current spatial interval and } \\
\text { accident }\end{array}$ & $C_{d}$ & $\mathrm{Ci}$ \\
\hline $\begin{array}{l}\text { Ingestion of Aquatic } \\
\text { Foodstuffs }\end{array}$ & $\begin{array}{l}\text { Average individual int ake for } \\
\text { specified time periods for the } \\
\text { current spatial interval and } \\
\text { accident }\end{array}$ & $c_{q}$ & $\mathrm{C} i$ \\
\hline \multirow[t]{2}{*}{$\begin{array}{l}\text { Ingestion of Farm } \\
\text { Products }\end{array}$} & $\begin{array}{l}\text { Average individual intake for } \\
\text { specified time periods for the } \\
\text { current spatial interval and } \\
\text { accident }\end{array}$ & $C_{f i}$ & $\mathrm{Ci}$ \\
\hline & $\begin{array}{l}\text { Total intake of farin products for } \\
\text { specified time periods by persons } \\
\text { outside the current spatial } \\
\text { interval }\end{array}$ & $C_{f t}$ & $\mathrm{Cj}$ \\
\hline
\end{tabular}

*Parameters $\bar{D}_{d}, D_{e}, D_{g}$ and $D_{s}$ are totals over all radionuclides and other parameters are defined for each radionuclide. 


\subsection{HUMAN INTAKE/DOSE INTERFACE}

The dosimetry model uses the intake values to determine doses to various organs for each pathway and dose period of significance. The doses are used as input to the remedial action model which determines necessary actions for the spatial interval of interest. The internal doses are calculated by using unit intake dose conversion factors for ingestion and inhalation. External doses are calculated from environmental concentrations using dose conversion factors for each exposure situation (i.e., ground contamination, swiming, boating, etc.; see Table 2.4-1).

\section{TABLE 2.4-1. Human Intake/Dose Interface}

\begin{tabular}{|c|c|c|}
\hline $\begin{array}{l}\text { Exposure } \\
\text { Pathway }\end{array}$ & Symbol & Description \\
\hline $\begin{array}{l}\text { External: } \\
\text { Ground and } \\
\text { Shoreline }\end{array}$ & $\mathrm{D}_{g_{\gamma} i}(5)$ & $\begin{array}{l}\text { Dose rate conversion factor at a } \\
\text { tissue depth of } 5 \mathrm{~cm} \text { for exposure } \\
\text { to radionuclide } i \text {, rem per } \\
\mathrm{Ci} / \mathrm{m}^{2} / \text { day }\end{array}$ \\
\hline $\begin{array}{l}\text { Direct from } \\
\text { Contained Activity }\end{array}$ & $\mathrm{D}_{\mathrm{C} 5}(\mathrm{E})$ & $\begin{array}{l}\text { Dose rate conversion factor for } \\
\text { Equation } 4 \cdot 3-1 \text { for photons of } \\
\text { energy } E\left(m^{2} \cdot \text { rad } \cdot \text { dis }\right) \text { per } \\
(\mathrm{MeV} \cdot \mathrm{C} i \cdot \text { day })\end{array}$ \\
\hline $\begin{array}{l}\text { Swimming and } \\
\text { Boating }\end{array}$ & $\mathrm{D}_{\mathrm{S}_{\gamma} \mathrm{i}}(5)$ & $\begin{array}{l}\text { Dose rate conversion factor for } \\
\text { radionuclide } i \text { at a tissue depth } \\
\text { of } 5 \mathrm{~cm} \text {, rem per } \mathrm{C} i \cdot d a y / \mathrm{m}^{3}\end{array}$ \\
\hline $\begin{array}{l}\text { Internal: } \\
\text { Inhalation }\end{array}$ & $D_{h i}$ & $\begin{array}{l}\text { Inhalation dose conversion factor } \\
\text { for radionuclide } i \text { defined for } \\
\text { necessary uptake and dose commit- } \\
\text { ment periods, rem } / \mathrm{C} i \text { inhaled }\end{array}$ \\
\hline Ingestion & $\mathrm{D}_{\mathrm{e} i}$ & $\begin{array}{l}\text { Ingestion dose conversion factor } \\
\text { for radionuclide } i \text { defined for } \\
\text { necessary uptake and dose commit- } \\
\text { ment periods, rem/Ci ingested }\end{array}$ \\
\hline
\end{tabular}

\subsection{DOSE/REMEDIAL ACTION/DOSE INTERFACE}

The need for remedial action is based on dose levels calculated for each pathway and body organ in a particular spatial interval. Remedial actions include evacuation, sheltering, crop, land and water interdiction and decontamination, and other actions that may reduce radiation exposure. If any remedial action is deemed necessary by specified criteria, the corresponding 
doses must be reevaluated. Table 2.5-1 presents the interface parameters needed in the remedial action model. Further definition of the dose values is given in Section 7.1 .

TABLE 2.5-1. Dose/Remedial Action/Dose Interface

Renedial Action Model
Evacuation, Sheltering,
Decontamination,
Interdiction,
Administration of
Potassium I odide
Tablets

Interdiction and Decontamination of Farmlands, Crops and Animal Products

Interdiction and Decontamination of Aquatic Foodstuffs

Interdiction and Decont amination of Water Supply

\begin{tabular}{|c|c|c|}
\hline Parameter & Symbol & Units \\
\hline $\begin{array}{l}\text { Organ doses from inhalation } \\
\text { during cloud passage }\end{array}$ & $D_{i}$ & rem \\
\hline $\begin{array}{l}\text { Whole-body dose from external } \\
\text { radiation during cloud passage }\end{array}$ & $\mathrm{D}_{\mathrm{e}}$ & rem \\
\hline $\begin{array}{l}\text { Whole-body dose from external } \\
\text { exposure to contaminated ground } \\
\text { for specified time periods }\end{array}$ & $\mathrm{D}_{\mathrm{g}}$ & rem \\
\hline $\begin{array}{l}\text { Individual dose to organs for } \\
\text { crop consumption for specified } \\
\text { time period }\end{array}$ & $D_{f}$ & rem \\
\hline $\begin{array}{l}\text { Individual dose to organs for } \\
\text { aquatic food consumption }\end{array}$ & $\mathrm{D}_{\mathrm{q}}$ & rem \\
\hline $\begin{array}{l}\text { Individual dose to organs for } \\
\text { consumption of farm products } \\
\text { resulting from irrigation }\end{array}$ & $D_{w i}$ & rem \\
\hline $\begin{array}{l}\text { Individual dose to organs from } \\
\text { drinking contaminated water }\end{array}$ & $D_{\text {wd }}$ & $r$ \\
\hline
\end{tabular}

\subsection{DOSE/HEALTH EFFECTS INTERFACE}

The remedial action model determines reduction in radiation exposure for any remedial actions that are warranted (based on criteria specified by the user). The human intake parameters and doses are modified by the remedial action model to generate corrected dose values. These corrected dose values form the basis of the health effects calculation. Specific dose pathways and dose types are summed to provide parameters for direct conversion to health effects. Table 2.6-1 presents the dose/health effects interface parameters. 
TABLE 2.6-1. Dose/Health Effects Interface

\begin{tabular}{lllll} 
Health Effect Type & & \multicolumn{1}{c}{ Parameter } & Units \\
\cline { 1 - 3 } Acute Effects & $\begin{array}{l}\text { Sose received in short time } \\
\text { Leriod by critical organ for } \\
\text { each acute health effect }\end{array}$ & $D_{A}$ & rem \\
Latent Effects & $\begin{array}{l}\text { Dose received in specified } \\
\text { time periods by critical organ } \\
\text { for each latent health effect }\end{array}$ & $D_{L}$ & rem \\
& $\begin{array}{l}\text { Dose received in specified } \\
\text { time periods by critical organ } \\
\text { for each genetic effect }\end{array}$ & $D_{G}$ & rem
\end{tabular}

\subsection{REMEDIAL ACTION/ECONOMIC COSTS INTERFACE}

The economic costs of an accident are determined by the remedial actions required. Remedial action requirements are based on comparison of calculated doses with specified criteria. The interfaces between the remedial action model and the cost model consists of a series of parameters that indicate required action. Costs are then generated only for required actions for each spatial interval. Land usage and cost data are supplied through input to the cost mode 1 . 


\subsection{SOURCE TERM}

The activity of each important radionuclide released to the environment is the starting point for each accident calculation. The released activity is calculated from the activity in the core at the time of the accident. Release fractions are defined for each radionuclide class. These classes are defined for elements or groups of elements that exhibit similar physical behavior. The release fractions give the fraction of the core inventory released. For each accident, a set of release fractions is necessary for each major pathway (direct irradiation, airborne release and liquid effluent release). For accidents in which one or two pathways are not considered, the corresponding release fractions are zero. This is the method used by the Reactor Safety Study (USNRC 1975) consequence computer progran CRAC.

In addition to the activity released, other parameters need to be specified, depending on the pathway involved. For the direct irradiation pathway, it is necessary to define the delay time between the start of the accident and the time offsite irradiation begins. This corresponds to the time of transport from the reactor primary, secondary or auxiliary systems to the relatively less shielded regions in the facility buildings. The time at which irradiation stops must also be given.

The parameters necessary for calculating effects of airborne releases include 1) delay time until release begins, 2) duration of release, 3) effluent stream velocity and heat content and 4) stack height and diameter. Those necessary to represent liquid effluent releases are release delay time, duration of release, volume of dilution and other parameters for the transport model.

The source terms for each release pathway are calculated from the core inventory. The release fractions are defined for each accident. For a given accident the initial source terms are yielded by

$$
\begin{aligned}
& Q_{a j}=A_{i} f_{a i} \\
& Q_{1 i}=A_{i} f_{j i} \\
& Q_{d i}=A_{i} f_{d i}
\end{aligned}
$$

where

\footnotetext{
$Q_{a j}$ - activity of radionuclide $i$ in airborne release source term, $\mathrm{C} i$

Q1i - activity of radionuclide $i$ in waterborne release source term, $\mathrm{Ci}$

$Q_{d i}$ - activity of radionuclide in direct irradiation source term, $\mathrm{Ci}$

$A_{i}$ - activity of radionuclide $i$ in the core at the time of the the accident, $\mathrm{C} i$
} 
$f_{a j}$ - fraction of radionuclide $i$ core inventory in airborne source term

$f_{1 j}$ - fraction of radionuclide $i$ core inventory in liquid release source term

$f_{d i}$ - fraction of radionuclide $i$ core inventory in direct irradiation source term.

When release for a particular pathway involves an initial delay time, the inventory must be corrected for radioactive decay between the start of the accident and the beginning of release. The general decay equations for a parent radionuclide $i$ and a daughter radionuclide $k$ in a decay chain are

$$
Q_{a i}\left(T_{a h}\right)=Q_{a i}(0) e^{-\lambda_{j} T_{a h}}
$$

and

$$
Q_{a k}\left(T_{a h}\right)=Q_{a i}(0)\left[\prod_{j=2}^{k} \lambda_{j}\right] \sum_{h=1}^{k} \frac{e^{-\lambda_{h} t}}{\prod_{\substack{p=1 \\ p \neq h}}^{k}\left(\lambda_{p}-\lambda_{h}\right)}
$$

where

$Q_{a i}\left(T_{a h}\right) \cdot$ activity of parent radionuclide $i(i=l$ in $3.0-5$ ) after decay for holdup time $\mathrm{T}_{\mathrm{ah}}, \mathrm{Ci}$

$Q_{a k}\left(T_{a h}\right) \cdot$ activity of daughter radionuclide $k$ after decay for holdup time $\mathrm{T}_{\mathrm{ah}}, \mathrm{C} \mathrm{i}$

$T_{\text {ah }}$ - holdup time for airborne releases, days

$\lambda_{j}, \lambda_{j}$ - radiological decay constant for parent radionuclide $i$ or daughter radionuclide $j$, days ${ }^{-1}$.

Equations 3.0-4 and 3.0-5 are written for the air release pathway. These equations may also be used for the direct irradiation and iquid release pathways by substituting appropriate symbols in place of $Q_{a j}, Q_{a k}$ and Tah.

Equation 3.0-5 is applicable to a series of radioactive daughter products. However, it is anticipated that consideration of one daughter radionuclide will be sufficient for the majority of radionuclide releases. For this reason the remaining sections present equations for the parent radionuclide and one daughter. 
When one daughter is considered, Equation 3.0-5 can be written as follows, with the addition of the decay branching fraction, $f_{i k}$, and inclusion of contributions from initial daughter product activity:

$$
\begin{aligned}
Q_{a k}\left(T_{a h}\right) & =Q_{a k}(0) e^{-\lambda_{k} T_{a h}} \\
& +\frac{f_{i k} \lambda_{k} Q_{a j}(0)}{\lambda_{k}-\lambda_{j}}\left[e^{-\lambda_{i} T_{a h}}-e^{\lambda_{k} T_{a h}}\right]
\end{aligned}
$$

where

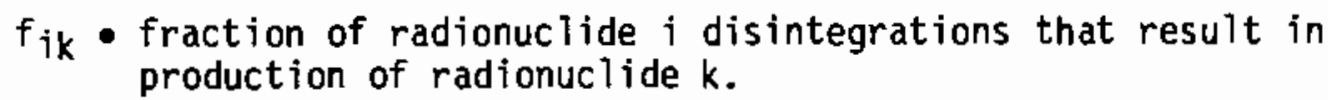

Several additional parameters are required as part of the source term description. These parameters include stack parameters, evacuation warning time, time behavior of material conf ined to reactor buildings, and others. These parameters are described in the following sections as they are used.

When a prolonged atmospheric release (lasting longer than eight hours) is considered, the release duration is described by a succession of eight-hour time steps (the last time step may be less than eight hours). The time variation of release is described by a normalized release function, $f g(t)$, which is the fraction (of the total release) that is actually released during the time step $t$. The function $f q(t)$ satisfies the equation:

$$
\sum_{t=1}^{\text {Time steps }} f q(t)=?
$$

Values for $f q(t)$ are to be defined for each accident and for each radionuclide class. Equation 3.0-7 is satisfied for each set of $f q(t)$ values (by accident and radionuclide class). Effects of radioactive decay are not included in $f q(t)$. 


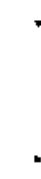




\subsection{TRANSPORT}

The transport of activity and radiation from the site to the environment is described in this section. The released activity for airborne and liquid pathways is supplied as input to transport models and converted to activity concentrations at selected points in the environment. These activity concentrations are then used to determine exposure to man via the important pathways. The transport model for direct irradiation from activity contained within the reactor buildings considers photon transport through shielding materials and air to the exposure location. The sections below describe methods and models selected to represent transport for the three principal release modes.

\section{1 ATMOSPHERIC DISPERSION}

The purpose of the atmospheric dispersion model is to estimate the transport of released material downwind from the reactor site. The model also considers the variation of dispersion with variation in accident start time. The selected model uses as a basis the methods developed for the Reactor Safety Study, with modification of some of the submodels. The following sections describe the selected dispersion model and submodels for building wake effects, plume rise, dry deposition, wet deposition and release duration. The atmospheric dispersion model assumes that atmospheric releases are described by straight-line trajectories over relatively flat terrain. Effects of terrain variations on dispersion patterns are not considered here because implementation of available models would greatly increase computer requirements with limited increase in modeling accuracy. The development of new models may be warranted to describe effects of major terrain features such as valleys, coastlines or mountain ranges. However, these features are not included in the models presented in the following sections.

\subsubsection{Plume Model}

The estimation of atmospheric dispersion of airborne releases is based on the method developed for the Reactor Safety Study. This method uses hourly onsite meteorological observation data to establish downwind concentration patterns for each accident start time. The meteorological data base consists of one year of sequential hourly observations collecting the following information:

- wind direction (compass sector)

- wind speed

- stability (Pasquill category A-G; see Slade 1968)

- precipitation.

The wind speed, stability and precipitation data are used to establish the downind air concentrations and ground concentrations, assuming that the wind direction is constant. For each start time, the number of hourly observations 
required is determined by the time required for the tail of the plume to pass beyond the last distance interval. This time is determined by the hourly windspeed data and the release duration. As the downwind plume is being generated, the wind direction data is used to establish a wind direction frequency array for the time period involved in the plume passage. The direction frequency array is used to determine the effective air concentration and ground contamination levels as a function of distance and direction for each accident.

The dispersion model presented in this section is to be applied to releases lasting $8 \mathrm{hr}$ or less. When longer releases are considered, the accident is divided into a series of successive $8-\mathrm{hr}$ time steps with effective air concentrations and ground contamination levels determined by repeated application of the short-term release plume model for each time step. Appropriate source-term and directional frequency weighting is performed as described in Section 4.1.7. The width of the plume is determined as described below. When the plume width overlaps into adjacent $22.5^{\circ}$ sectors, the concentration in those sectors affected are incremented by the fraction of the sector area covered, multiplied by the plume concentration.

The Gaussian bivariant dispersion model equation to determine timeintegrated ground level air concentrations is:

$$
E_{i}(x)=\frac{Q_{a j}(x)}{\pi \sigma_{y} \sigma_{z} \bar{u}} \exp \left[\left(-y^{2} / 2 \sigma^{2} y\right)+\left(-h_{e}{ }^{2} / 2 \sigma_{z}{ }^{2}\right)\right]
$$

where

$E_{i}(x)$ - time-integrated ground level air concentration at $x, \mathrm{Ci} \cdot \mathrm{sec} / \mathrm{m}^{3}$

$Q_{a j}(x)$ - total activity $(C i)$ of nuclide $i$ released via the airborne path corrected for radioactive decay and depletion by ground deposition and precipitation in transit to the current downwind location

$x$ - downwind distance from release point, m

$\sigma_{y}$ - crosswind horizontal standard deviation of plume concentration at the downwind distance, $m$

$\sigma_{z}$ - crosswind vertical standard deviation of plume concentration at the downwind distance, m

$\bar{u}$ - average wind speed at the release elevation, $\mathrm{m} / \mathrm{sec}$

$y$ - crosswind horizontal distance from plume centerline to exposure location, $m$

$h_{e}$ - effective height of plume centerline at the downwind location, m (see Section 4.1.4). 
The horizontal and vertical dispersion parameters $\sigma_{y}$ and $\sigma_{z}$ are evaluated by emperical expressions suggested by Powell et al. (1977). The expressions are

$$
\begin{aligned}
& \sigma_{y}=a x^{b} \\
& \sigma_{z}=c x^{d}+e
\end{aligned}
$$

where

$$
\begin{aligned}
& a, b, c \\
& d, e \cdot \text { empirical constants. }
\end{aligned}
$$

Values of the empirical constants $a, b, c, d$ and $e$ are given in Table 4.1-1 for the seven Pasquili stability categories. Equations 4.1-2 and 4.1-3 are to be applied at distances beyond $100 \mathrm{~m}$. The $100-\mathrm{m}$ value is used at shorter distances. The maximum distance for applicability of Equations 4.1-2 and 4.1-3 is about $100 \mathrm{~km}$.

\begin{tabular}{|c|c|c|}
\hline \multirow{2}{*}{$\begin{array}{l}\text { Pasquill } \\
\text { Stability } \\
\text { Category }\end{array}$} & \multicolumn{2}{|c|}{$\sigma_{y}$ constants } \\
\hline & $a$ & b \\
\hline $\begin{array}{l}A \\
B \\
C \\
D \\
E \\
F \\
G\end{array}$ & $\begin{array}{l}0.3658 \\
0.2751 \\
0.2089 \\
0.1471 \\
0.1046 \\
0.0722 \\
0.0481\end{array}$ & $\begin{array}{l}0.9031 \\
0.9031 \\
0.9031 \\
0.9031 \\
0.9031 \\
0.9031 \\
0.9031\end{array}$ \\
\hline
\end{tabular}

TABLE 4.1-7. Constants for Dispersion Parameter $\left(\sigma_{y}\right.$ and $\left.\sigma_{z}\right)$ Equation

\begin{tabular}{|c|c|c|c|c|c|c|}
\hline Pasquiा & & $x<1000 m$ & & & $>1000 \mathrm{~m}$ & \\
\hline $\begin{array}{c}\text { Category } \\
\text { A } \\
\text { B } \\
\text { C } \\
\text { D } \\
\text { E } \\
\text { F } \\
\text { G }\end{array}$ & $\begin{array}{l}c \\
0.0015 \\
0.028 \\
0.113 \\
0.222 \\
0.211 \\
0.086 \\
0.052\end{array}$ & \begin{tabular}{l}
\multicolumn{1}{c}{$d$} \\
1.941 \\
1.149 \\
0.911 \\
0.725 \\
0.678 \\
0.74 \\
0.74
\end{tabular} & $\begin{array}{l}\frac{\mathrm{e}}{9.27} \\
3.3 \\
0 \\
-1.7 \\
-1.3 \\
-0.35 \\
-0.21\end{array}$ & $\begin{array}{l}c \\
0.00024 \\
0.055 \\
0.113 \\
1.26 \\
6.73 \\
18.05 \\
10.83\end{array}$ & \begin{tabular}{l}
\multicolumn{1}{c}{$\mathrm{d}$} \\
2.094 \\
1.098 \\
0.911 \\
0.516 \\
0.305 \\
0.18 \\
0.18
\end{tabular} & $\begin{array}{c}e \\
-9.6 \\
+2.0 \\
0 \\
-13.0 \\
-34.0 \\
-48.6 \\
-29.6\end{array}$ \\
\hline
\end{tabular}

Lateral Dispersion

Vertical Dispersion

(a) $\begin{aligned} & \sigma_{y}=a x^{b} \\ & \text { (b) } \sigma_{z}=c x^{d}+e\end{aligned}$ 
The method of the Reactor Safety Study is based on Equation 4.1-1 with two modifications: 1) the crosswind horizontal dispersion is represented by a rectangular function and 2) a plume expansion factor is applied to account for effects of increased lateral dispersion for prolonged releases (greater than a half hour). The first modification replaces the Gaussian crosswind shape with a uniform function by the following substitution:

$$
\frac{1}{(2 \pi)^{1 / 2} \sigma_{y}} \exp \left(-y^{2} / 2 \sigma_{y}^{2}\right)=\frac{1}{3 \sigma_{y}}
$$

This representation provides an average concentration over a lateral width of $3 \sigma_{y}$, which is within $20 \%$ of the Gaussian peak value.

The dispersion parameters represented by Equations 4,1-2 and 4. 1-3 are for short duration releases (<10 min). These equations are used for releases from zero to $30 \mathrm{~min}$ in duration. For releases lasting from $30 \mathrm{~min}$ to $8 \mathrm{hr}$, an expansion factor is applied to account for effects of meander. The expansion factor is represented by

$$
E_{t}=\left(2 T_{r}\right) 1 / 3
$$

where

$E_{t}$ - expansion factor to correct for prolonged release times, dimensionless

$T_{r}$ - release duration for airborne releases, $\mathrm{hr}$.

The expansion factor is applied to the denominator of the dispersion Equation (4.1-1). Applying the above modifications to Equation 4.1-1 results in the following expression:

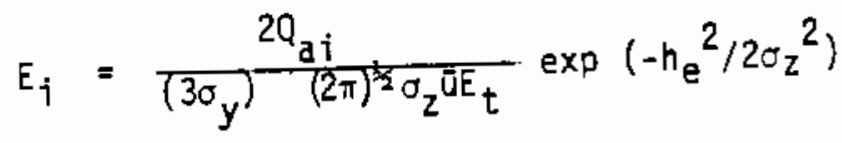

This equation is the basis of the plume dispersion calculation. For releases lasting less than $30 \mathrm{~min}, \mathrm{Et}_{\mathrm{t}}$ is unity.

The downwind plume is established sequentially by applying Equation 4.1-6 to each spatial interval, starting with the interval nearest the source. The initial values for the dispersion parameters $\sigma_{y}$ and $\sigma_{z}$ are set to zero unless building wake effects are to be considered. Building wake effects are modeled by initializing the dispersion parameters of Equation 4.1-6 as follows:

$$
\begin{aligned}
& \sigma_{y}=B_{w} / 3 \\
& \sigma_{z}=B_{H} / 2.15
\end{aligned}
$$


where

$$
\begin{aligned}
& B_{W} \text { - characteristic building width for the building wake model, m } \\
& B_{H} \text { - characteristic building height for the building wake model, m. }
\end{aligned}
$$

In practice, the building wake model is not allowed to reduce the calculated air concentration by a factor of more than 3 lower than the air concentration calculated without building wake considerations within a distance of $2.3 \mathrm{~km}$.

To establish the downwind plume, one must:

- determine the average wind speed for the period during passage of the plume front across the distance interval

- calculate, for each stability occurring during plume passage:

1. the value of $\sigma_{y}$ at the midpoint of the interval

2. the value of $\sigma_{y}$ at the end of the interval (for use with the next interval)

3. the increment to $\sigma_{z}$

- calculate the stability-weighted value of $\sigma_{y}$ and $\sigma_{z}$ at the midpoint and the end of the interval

- calculate the effective plume height, including plume rise effects at the midpoint of the distance interval (weighted by stability frequency as for $\sigma_{y}$ and $\sigma_{z}$ )

- calculate the normalized time-integrated air concentration, $\mathrm{E}_{\mathbf{j}} / \mathrm{Q}_{\mathrm{a}}$, at the interval midpoint, using Equation 4. 1-6

- calculate the fractional reduction in plume radionuclide concentration due to wet and dry deposition for the current distance interval

- correct the release inventory $Q_{a j}$ for decay in transit to the midpoint of the interval

- calculate the air concentration and ground deposition concentration at the midpoint of the interval.

These steps are repeated sequentially for each distance interval until all intervals have been processed. Details of the above steps are given below and in the sections on plume rise (4.1.4), dry deposition (4.1.5) and wet deposition (4.1.6).

The average wind speed for a distance interval is calculated as the arithmetic average of the hourly observations occurring during plume front passage across the interval: 


$$
\bar{u}_{j}=\frac{1}{N_{j}} \sum_{i=1}^{N_{j}} u_{i}
$$

where

$\bar{u}_{j}$ - average wind speed for distance interval $j, \mathrm{~m} / \mathrm{sec}$

$N_{j}$ - number of hours of data required for the plume front to cross interval $f\left(N_{j}\right.$ is an integer, $\left.N_{j} \geq 1\right)$

$u_{i}$ - wind speed for the $i-t h$ hour from the time the plume front reaches the start of the distance interval, $\mathrm{m} / \mathrm{sec}$.

The expansion of the plume across each spatial interval is estimated using a derivative approximation for $\sigma_{y}$ and $\sigma_{z}$. The value for each parameter at the start of the interval is incremented for the distance to the midpoint of the interval.

For lateral dispersion under stability s

$$
\Delta \sigma_{y s}=\left.\Delta x \frac{d \sigma_{y s}}{d x}\right|_{x+\frac{\Delta x}{2}}
$$

where

$$
\begin{gathered}
\Delta \sigma_{y s} \cdot \begin{array}{l}
\text { increment to } \sigma_{y} \text { for stability s across the first half of } \\
\text { the current interval, m }
\end{array} \\
\Delta x \cdot \text { half of the interval length, m } \\
\frac{d \sigma_{y s}}{d x} x+\frac{\Delta x}{2} \text { - rate of change of } \sigma_{y} \text { for stability s evaluated at half the }
\end{gathered}
$$

The derivative is evaluated from Equation 4.1-2 as

$$
\frac{d \sigma_{y s}}{d x}=a_{s} b_{s} x^{b}{ }^{-1}
$$

where $a_{s}, b_{s}$ e empirical constants of Equation 4.1-2 for stability, s.

The increment to the vertical dispersion parameter $\sigma_{z}$ for a stability $s$ is estimated in a similar manner with the differential evaluated by

$$
\frac{d \sigma_{2 s}}{d x}=c_{s} d_{s} x^{d s-1}
$$


where $c_{s}, d_{s}$ - empirical constants of Equation 4.1-3 for stability s.

The values of the dispersion parameters at the midpoint of the interval are calculated as

$$
\sigma_{y j}=\sigma_{y o} \sum_{s=1}^{7} f_{s j} \Delta \sigma_{y s}
$$

and

$$
\sigma_{z j}=\sigma_{z 0}+\sum_{s=1}^{7} f_{s j} \Delta \sigma_{z s}
$$

where

$$
\begin{aligned}
& \sigma_{y j} \text { - lateral dispersion parameter, } \sigma_{y} \text {, at the midpoint of spatial } \\
& \text { interval } j, m
\end{aligned}
$$

The vertical dispersion parameter is limited by the mixing depth, $L_{s}$, which is stability-dependent. Mixing depth values are defined by season and for stable and unstable atmospheric conditions. When the calculated increment to $\sigma_{z}$ would increase $\sigma_{z}$ above the mixing depth, the increment is limited to the mixing depth or to zero, whichever is larger.

$$
\Delta \sigma_{z S}=L_{s}-\sigma_{z 0} \text { or zero }
$$



where $L_{s} \cdot$ mixing depth for stability $s$ for the season in which the accident
started, m.

The calculation of the effective plume height is based on the stack height and the plune rise:

$$
h_{S}=h_{x}+\Delta h
$$

where

$h_{e}$ - effective height of the plume centertine at the midpoint of the current distance interval, $m$

$h_{s}$ - height of stack above ground level, $m$

$\Delta h$ - increment to release height due to plume rise, $m$.

The calculation of the plume rise increment is described in Section 4.1.4. The value of $\Delta h$ is stability/frequency-weighted:

$$
\Delta h=\sum_{s=1}^{7} \Delta h_{s} f_{s}
$$

where

$\Delta h_{s}$ - plume rise increment for stability, s, at the current interval midpoint, $m$.

Plume rise is limited by the inversion lid $L_{s}$ as defined above. The maximum increment to plume rise for a given spatial interval and stability, $\Delta h_{S}$, is such that $\Delta h_{S} \leq L_{S}-\left(h_{S}+\sigma_{z}\right)$. The method limits the plume rise when the upper edge of the plume (defined as $\sigma_{2}$ above the centerline) reaches the inversion ijd.

The fractional reduction in air concentration due to dry and wet deposition is calculated using the equations in Sections 4.1.5 and 4.1.6. The total reduction (from both wet and dry deposition processes) is calculated as a reduction factor from start to midpoint of each interval. This reduction factor is used to calculate the average air concentration for the interval:

$$
c_{i j}=\left(E_{i j}\right)_{j} f_{r i j}
$$

where $\mathrm{C}_{i j} \cdot \mathrm{time-integrafed} \mathrm{air} \mathrm{concentration} \mathrm{of} \mathrm{radionuclide} i$ for interval $_{j, \mathrm{C} i \cdot \mathrm{sec} / \mathrm{m}^{3}}$

$\left(E_{i}\right)_{j}$ - time-integrated air concentration of radionuclide $i$ for the start of interval $\mathrm{j}$ as calculated by Equation $4.1-6, \mathrm{Ci} \cdot \mathrm{sec} / \mathrm{m}^{3}$ 
$f_{r i j}$ - fractional reduction of air concentration (to give amount remaining) for half of interval $j$ for radionuclide $i$.

The ground concentration is calculated from the midpoint air concentration as follows:

$$
G_{i j}=C_{i j} \bar{Z}_{j}\left(1-f_{r i j}^{2}\right) / t_{j}
$$

where

$G_{i j}$ - ground concentration after plume passage for radionuclide $i$ in interval $\mathrm{j}, \mathrm{Ci} / \mathrm{m}^{2}$

$t_{j}$ - time for plume front to pass interval $j$, sec

$\bar{Z}_{j}$ - effective thickness of the plume at the midpoint of interval $j, m$.

$\left(1-f_{r i j}^{2}\right) \cdot$ fraction of activity of radionuclide $i$ deposited in interval $j$.

The effective plume thickness (USNRC 1975) is defined by

$$
z_{j}=\left(\frac{\pi}{2}\right)^{1 / 2} \sigma_{z j} \exp \left(h_{e}^{2} / 2 \sigma_{z j}{ }^{2}\right)
$$

The expression $C_{i j} \bar{Z}_{j} / t_{j}$ (in Equation 4.1-19) represents the average concentration $\left.(\mathrm{C}) \mathrm{m}^{2}\right)$ above the current interval. When multiplied by the fraction deposited $\left(1-f_{F} f_{j}\right)$, the ground deposition is obtained.

The air and ground concentrations are assumed to be uniform over the area of the plume coverage for the current interval. The area of plume coverage is based on the lateral dispersion parameter value $\left(\sigma_{y}\right)$ at the midpoint of the interval and the downwind distance across the interval.

$$
a_{p j}=3 \sigma_{y}\left(r_{j}\right)\left[R_{j}-R_{j-1}\right]
$$

where

$$
\begin{aligned}
& { }_{a_{p j}} \text { - area of plume coverage for distance interval } j, m^{2} \\
& \sigma_{y}\left(r_{i}\right) \text { - lateral dispersion parameter evaluated at a distance } r_{i}, m \\
& r_{j} \text { - midpoint of downwind distance intervals } j, m \\
& R_{j}, R_{j-l} \text { - endpoint of downwind distance intervals } j \text { and } j-1 \text {. } \\
& \text { The values of apj represent the trapezoidal area defined by a width of } 3 \sigma_{y} \\
& \text { across each interval } j \text {. }
\end{aligned}
$$


As the plume concentrations are being generated, several other parameters are also defined. These are

$T_{j}$ - time of transit from the release point to the midpoint of the current interval $j$, sec

$t_{j}$ - time of transit across the downwind length of the interval $j$, sec

$v_{j}$ - average velocity in traveling from the release point to the midpoint of interval $\mathrm{j}, \mathrm{m} / \mathrm{sec}$.

These parameters are used in other mode1s as needed.

The effective air concentrations and ground contamination levels are calculated as a function of distance and direction by weighting the values of $C_{i j}$ and $G_{i j}$ by the wind direction frequency values $f_{\Theta}$.

$$
c_{i j \Theta}=f_{\Theta} c_{i j}
$$

and

$$
G_{i j \Theta}=f_{\Theta} G_{i j}
$$

where

$C_{i j \Theta}$ - effective time-integrated air concentration for radionuclide in interval $\mathrm{j}$ in direction $\theta$, in $\mathrm{C} i \cdot \mathrm{sec} / \mathrm{m}^{3}$

$G_{j j \theta}$ - effective ground contamination level for radionuclide $i$ in direction $\theta, \mathrm{Ci} / \mathrm{m}^{2}$

$f_{\Theta}$ - wind direction frequency for direction $\theta$ over the total time for plume passage across the last interval boundary.

\subsubsection{Meteorological Data Requirements}

The atmospheric dispersion model described in the previous section requires as input a data file containing sequential observations of onsite meteorological data. The file should contain hourly data covering a period of at least one year because it is assumed that the accidents may start at any time during the year. Each hourly observation should provide information on wind direction, wind speed, stability type, and precipitation rate.

The wind direction is expressed as a compass sector index corresponding to the standard sixteen directions (22-1/2 ${ }^{\circ}$ per sector), and wind speed would be the average for the hour of observation $(\mathrm{m} / \mathrm{sec})$. The average Pasquill stability type is expressed as an integer from one to seven (Pasquill types $A$ to $G$ ). Total precipitation during the hour is recorded as millimeters of rain. Values for each parameter must be given for each hour of the observation period. Assumptions must be made for calm periods and unknown periods 
(i.e., instruments out of service) so that a continuous set of meteorological data is available. The wind speed for calm periods may be set to half the starting speed for wind speed measurements. Wind direction and stability may be based on data for adjacent periods.

\subsubsection{Building Wake Correction Model}

Material released at ground level or from building vents or short stacks may be subject to enhanced dispersion due to the turbulent wake caused by air flow around the building. Several models for estimating the effects of building wake on dispersion have been presented in the literature (Gifford 1972, Slade 1968, Sagendorf and Goll 1977, Powell et al. 1977). These models account for building wake through modification of the Gaussian dispersion equation. The general way to handle building wake is to add a term to the plume size parameters to account for enhanced mixing in the wake of the building. The model selected adds a characteristic building width to the lateral dispersion parameter, $\sigma_{y}$, and a characteristic building height to the vertical dispersion parameter, $\sigma_{z}$. This is the model used in the Reactor Safety Study. It is thought to be sufficient for the current application because the building wake only affects results for 1 or $2 \mathrm{~km}$ out from the release point. The characteristic building dimensions are defined"by the user and may be set to zero to bypass building wake consideration. In practice, the building wake model is not allowed to reduce the calculated air concentration by a factor of more than 3 lower than the air concentration calculated without building wake considerations within a distance of $2.3 \mathrm{~km}$.

Building wake effects are modeled by initializing the dispersion parameters as follows:

$$
\begin{aligned}
& \sigma_{y}=B_{W} / 3 \\
& \sigma_{z}=B_{H} / 2.15
\end{aligned}
$$
repeated) repeated)

where

BW - characteristic building width for the building wake model, m

BH - characteristic building height for the building wake model, $\mathrm{m}$.

The factor $B_{W} / 3$ corresponds to the top hat plume width of $3 \sigma_{y}$. The factor $B_{H} / 2.15$ corresponds to the height at which the plume concentration reaches $70 \%$ of the centerline value.

\subsubsection{Plume Rise}

In determining the effective height of release for use in the atmospheric dispersion equation, the plume rise models presented here are used to account 
for buoyancy and momentum. These plume rise models can be used to describe releases from stacks and building vents. The plume rise correction to stack height (see Equation 4.1-17) is defined as

$$
\Delta h_{S}=h_{b} \quad \text { (buoyancy) }
$$

or

$$
\Delta h_{S}=h_{m} \quad \text { (momentum) }
$$

where

$\Delta h_{S}$ - the plume rise increment to be added to the release height, $m$

$h_{b} \cdot$ the plume rise increment due to thermal buoyancy, m

$h_{m}$ - the plume rise increment due to momentum, corrected as necessary for downwash, $m$.

The correction for plume buoyancy is a function of stability, wind speed, source heat content and downwind distance. Two sets of equations are needed to describe plume rise due to buoyancy: one for stable conditions, and one for neutral and unstable conditions. The following equation (Briggs 1975) applies for all stabilities out to a distance $x^{*}$.

$$
h_{b}=1.6 \mathrm{Fl}^{1 / 3} \mathrm{u}^{-1} \times 2 / 3
$$

where

$$
\begin{aligned}
& F \text { • buoyancy flux parameter } \\
& F=3.7 \times 10^{-5} Q_{H} \\
& Q_{H} \cdot \text { thermal energy release rate, calories/sec } \\
& u \cdot \text { wind speed at the release height, } \mathrm{m} / \mathrm{sec} \\
& x \cdot \text { downwind distance, } m .
\end{aligned}
$$

The distance to which this equation appiies is a function of atmospheric stability. For stable conditions,

$$
x^{\star}=2.1 \cup(S)^{-1 / 2}
$$

where

$S$ - restoring acceleration per unit vertical displacement for adiabatic motion in the atmosphere $\left(\sec ^{-2}\right)$. For Pasquill $E$, stability $S$ is $8.7 \times 10^{-4}$ and for Pasquill $F$ stability $S$ is $1.75 \times 10^{-3}$, and for Pasquill $G$ stability $S$ is $2.45 \times$ $10^{-3}$. 


$$
S=\frac{g}{f} \frac{\partial \theta}{\partial z}
$$

g. acceleration of gravity, $\mathrm{m} / \mathrm{sec}^{2}$

$T$ - ambient temp̣erature, $K^{\circ}$

$\partial \Theta / \partial z$ - vertical potential temperature gradient $\mathrm{k} / \mathrm{m}$.

Beyond $x^{*}$, plume rise for stable conditions is constant at

$$
h_{b}=2.6(F / U S)^{1 / 3}
$$

For neutral and unstable conditions,

$$
x^{\star}=14 F^{5 / 8} \text { for } F \leq 55
$$

and

$$
x^{*}=34 \mathrm{~F} 2 / 3 \text { for } F>55
$$

Between $x^{*}$ and $5 x^{*}$, plume rise for neutral and unstable conditions is given by

$$
h_{b}=1.6 \mathrm{~F}^{1 / 3} \mathrm{u}^{-1} \mathrm{x} \star 2 / 3 \mathrm{~K}
$$

where

$$
k=\left[\frac{2}{5}+\frac{16}{25} \frac{x}{x^{\star}}+\frac{11}{5} \frac{x}{x^{\star}} \quad 2\right]\left(1+\frac{4 x}{5 x^{\star}}\right)^{-2}
$$

$K$ may be approximated by a linear interpolation between $x^{\star}$ and $5 x^{*}$. At distances beyond $5 x^{*}$ plume rise is constant at the value of the above equation evaluated at $x=5 x^{\star}$.

Plume $r$ ise due to momentum is described below by models recommended by Briggs (1969). A correction for downwash is included, as given by Gifford (1972).

For neutral and unstable conditions, plume rise is calculated by

$$
h_{m}=1.44\left(\frac{w_{0}}{u}\right)^{2 / 3}\left(\frac{x}{D}\right)^{1 / 3} D
$$

where

$W_{0}$ - the stack or vent exit velocity, $\mathrm{m} / \mathrm{sec}$

D - the interrial stack diameter, m. 
Other terms are as previously defined.

When the exit velocity $W_{0}$ is less than 1.5 times the wind speed $u$ a correction for downwash may be applied. This correction (Gifford 1972) is calculated as

$$
h_{d}=3\left(1.5-\frac{W_{0}}{u}\right)_{D}
$$

where

$h_{d}$ - the value to be subtracted from $h_{m}$.

The result from Equation 4.1-32 after correction as necessary for downwash is compared with

$$
h_{m}=3\left(\frac{w_{0}}{u}\right) D
$$

and the smaller value of $h_{m}$ is used as the momentum plume rise correction.

For stable conditions, the results from Equations 4.1-32 and 4.1-34 are compared with values calculated from the following two equations:

$$
\begin{aligned}
& h_{m}=4\left(\frac{F_{m}}{s}\right)^{1 / 4} \\
& h_{m}=1.5\left(\frac{F_{m}}{v}\right)^{1 / 3} \mathrm{~s}^{-1 / 6}
\end{aligned}
$$

where

$$
F_{m}=\left(W_{0} D / 2\right)^{2}
$$

The smallest value of $h_{\pi}$ from equations $4.1-32,-34,-35$, and -36 is used. For each postulated accident the plume rise will be defined for the controlling mechanism, which is either buoyancy or momentum. The mechanism will be selected by the user. Appropriate paraneters are provided by input to the computer.

\subsubsection{Dry Deposition Model}

The removal of a material from the plume by dry deposition processes can be described by source depletion models and surface depletion models. Source depletion models allow for uniform removal of activity from the cloud at progressive downwind distances. The dry deposition model used in the Reactor Safety Study (USNRC 1975) is an example of a source depletion model.

Surface depletion models consider nonuniform vertical concentration profiles resulting from activity removal at the air-ground interface. Horst 
(1978) developed a model for correction of the Gaussian plume model for the surface depletion of nonsettling particles. This model reduces the source strength in the Gaussian model as a function of downwind distance to account for both the loss of airborne material and for the change in vertical profiles.

The source depletion model has been selected to describe dry deposition; it should prove sufficient for the current application. Future effort could include adaptation of Horst's hybrid surface depletion/source depletion model.

The dry deposition model is used to estimate the fraction of the material remaining after removal during transport across a given spatial interval. This fraction is combined with the wet deposition fraction (section 4.1.6) to determine the total fraction remaining, $f_{r i j}$, for use in Equations $4.1-18$ and $4.1-19$.

$$
f_{r i j}=f_{r i j}^{d} f_{r i j}^{w}
$$

where

$f_{\text {rij }}$ - fractional reduction factor for air concentration due to dry and wet deposition for half of interval $j$ for radionuclide $i$

$f_{\text {rij }}$ - dry deposition fraction remaining after transport across half of interval $j$ for radionuclide $i$

$\mathrm{f}_{\mathrm{W}}^{\mathrm{W}} \mathrm{ij}$ - wet deposition fraction remaining after transport across half of interval $j$ for radionuclide $i$ (see Section $4,1,6$ ).

The source depletion model of the Reactor Safety Study calculates the fraction remaining at the midpoint of the current internal (relative to the start of the interval) as

$$
f_{r i j}^{d}=e^{-V_{d i} t_{j} /\left(2 Z_{j}\right)}
$$

where

$V_{d i}$ - effective deposition velocity for radionuclide $i, \mathrm{~m} / \mathrm{sec}$.

$t_{j} / 2$ - transport time for half of interval $j, s e c$.

$\bar{Z}_{j}$ - effective plume thickness at the interval $j$ midpoint, $m$.

The effective plume thickness is calculated using Equation 4.1-20.

\subsubsection{Wet Deposition Mode]}

The model selected for estimation of wet removal of airborne material is based on use of time-integrated washout coefficients. The depletion of the plume is estimated using the Engleman equation:

$$
x=x_{0} \bar{e}^{\Omega} j t
$$


where

$\chi$ - air concentration of contaminant at the location of interest after wet removal, $\mathrm{Ci} / \mathrm{m}^{3}$

$\chi_{0}$ - initial air concentration of contaminant at the location of interest, $\mathrm{Ci} / \mathrm{m}^{3}$

$\Omega_{j}$ - washout coefficient for the removal period $t$ and contaminant $i$, $\mathrm{sec}^{-1}$

$t$ - duration of wet removal period (based on transport across half of the current interval), sec.

The fraction remaining is calculated as

$$
F_{r i j}^{W}=x / x_{0}
$$

where

$f_{r i j}$ - fraction of radionuclide $i$ remaining after wet removal processes during transport across half of interval $j$.

This fraction is used with the dry deposition fraction to estimate the total fraction remaining, $f_{r i j}$, as indicated in Equation 4.1-37.

The estimation of the washout coefficient is important to proper application of the model. Hourly precipitation rate data should be used when available. These data are used to define the washout coefficient as

$$
\Omega_{j}=\Omega_{i 1} \operatorname{Pr} \mathrm{Pr}
$$

where

$\Omega_{j}$ - washout coefficient for radionuclide $i, \mathrm{sec}^{-1}$

$\Omega_{i 1}$ - washout coefficient for radionuclide $i$, when the precipation rate is $1 \mathrm{~mm} / \mathrm{hr}, \frac{\mathrm{hr}}{\mathrm{mm} \mathrm{sec}}$

Pr - actual precipitation rate for the period of interest, $\mathrm{mm} / \mathrm{hr}$

$p_{r}$ - exponent to describe washout coefficient rate dependence on precipitation rate, dimensionless.

Slinn (1975) has suggested a linear relationship between the washout coefficient and rain rate $\left(p_{r}=1\right)$. 
At sites where hourly data are not available, assumptions about rainfall should be based on local precipitation climatology. Davis (1979) has shown that use of the actual fraction of time that precipitation occurs provides wet removal values that are comparable to those obtained with actual hourly data. This method will indicate rain for all start times at the average rate for a fraction of the plume front transit time. The fraction remaining is given by

$$
f_{r i j}=\exp \left(-\Omega_{i} \bar{P}_{r} f_{t r} t\right)
$$

where

$$
\begin{aligned}
& \overline{\mathrm{P}}_{\mathrm{r}} \text { - average annual precipitation rate, } \mathrm{mm} / \mathrm{hr} \\
& \mathrm{f}_{\mathrm{tr}} \text { - fraction of the time during a year that precipitation occurs, } \\
& \text { dimensionless. }
\end{aligned}
$$

Other terms are as previously defined.

The models suggested above are applied to particulates and gases other than noble gases. Although the actual computation techniques may be identical, wet removal processes for gases are significantly more complex than for particulates. Wet removal of gases depends on chemical and physical properties of the gases. The complexity of the processes makes washout coefficients difficult to define for other than perfectly soluble gases. By making reasonable assumptions, washout coefficients may be derived for specific gases (Dana 1978). Such derivations would be useful for defining the nomalized washout coefficients for a particular radionuclide, $\Omega_{i}$.

\subsubsection{Release Duration}

The models presented in Section 4.1.1 are used to estimate effective air concentrations and ground contamination levels for releases of $8 \mathrm{hr}$ duration or less. When longer releases are considered, the effective values are determined by repeated application of the short duration models to successive 8-hr time steps until the entire release duration has been considered. The effective concentrations are calculated as

\section{time steps}

$$
c_{i j \Theta}=\sum_{t=1} f_{\ominus t} c_{i j} t
$$

and

time steps

$$
G_{i j \Theta}=\sum_{t=1} f_{\Theta t} G_{i j t ~} e^{-\lambda_{i}(T i m e ~ s t e p s-t) * 8 h r}
$$


where

$$
\begin{aligned}
& C_{i j \Theta} \cdot \text { effective time-integrated air concentration for } \\
& \text { radionuclide } i \text { in interval } j \text { in direction } \theta, \mathrm{C} i \cdot \mathrm{sec} / \mathrm{m}^{3} \\
& C_{i j t} \cdot \text { time-integrated air concentration for radionuclide } j \text { in } \\
& \text { interval } j \text { for } 8-\mathrm{hr} \text { period } t \text { (by Equation } 4.1-18 \text { ), } \mathrm{Ci} \cdot \mathrm{sec} / \mathrm{m}^{3} \\
& f_{\Theta t} \text { - wind direction frequency for direction } \theta \text { and } 8-h r \text { period } t \\
& G_{i j \theta} \text { - effective ground contamination level for radionuclide } i \text { in } \\
& \text { interval } \mathrm{j} \text { in direction } \theta, \mathrm{Ci} / \mathrm{m}^{2} \text { evaluated at the end of } \\
& \text { the deposition period }
\end{aligned}
$$

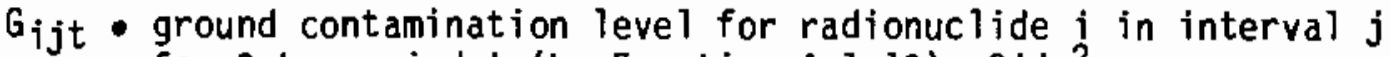

$$
\begin{aligned}
& \text { for 8-hr period } t \text { (by Equation 4.1-19), } \mathrm{Ci} / \mathrm{m}^{2} \text {. }
\end{aligned}
$$

The exponential term represents decay from time step $t$ until the end of the deposition period. The resulting value for $G_{i j \Theta}$ is the ground concentration at the end of the deposition period.

The values for $f_{\Theta t}$ are based on the time required for the 8 -hr plume tail to travel beyond the last distance interval. For example, if the travel time were $10 \mathrm{hr}$ from the source to the last interval, the total time would be $18 \mathrm{hr}$. Values for $C_{i j t}$ and $G_{i j t}$ are calculated using release activity $Q_{a j}$ (see Equation $3.0-1)$ multiplied by the normalized release fraction $f_{q}(t)$ for the 8-hr time step $t$ and decayed to the beginning of time step $t$.

\subsection{WATERBORNE DISPERSION}

The method selected to represent waterborne dispersion in surface waters is discussed in this section. Models to represent movement of ground water have not been considered for reasons stated in the Phase I report (Strenge et al. 1978). However, when analyzing extreme core melt accidents, the possibility of contamination of groundwater aquifers in the vicinity of the reactor should be considered. Movement of ground water under these accident conditions can be estimated using the computer program developed for the Liquid Pathway Generic Study (USNRC 1978). The consequences resulting from the ground water pathway should be reported separately from the other pathway resuits, because the slowness of groundwater transport extends the consequences far into the future. Almost no near-term effects would be expected.

The method selected calculates radionuclide activity concentrations at selected usage points in the aquatic environment. Use of the selected method requires definition of three parameters for each water usage location:

$W_{j}$ - average water concentraztion per unit activity release for water usage location $\mathrm{j}, \mathrm{Ci} / \mathrm{m}^{3}$ per $\mathrm{C} i$ released

$\mathrm{T}_{\text {waj }}$ - time period over which the average water concentration persists, sec 
$T_{t j}$ - mean transit time measured from start of release until the contamination first reaches the usage location $j$, sec.

The dispersion factor, $w_{j}$, is used to estimate the average water concentration without consideration of radioactive decay. When site data does not provide information to determine $W_{j}$ directly, simple models described in Regulatory Guide 1.113 (USNRC, 1977) may be used. These models are described in Sections 4.2.1 through 4.2.4 for rivers, lakes, estuaries and open coasts, respectively. The effect of holdup by cooling ponds is described in Section 4.2.5. When multiplied by the liquid effluent source term, $Q_{1 j}$, the result is the nondecayed average water concentration at the usage location. Decay is considered for the average transit time to the location and for the time period of contamination. In practice, the initial water concentration at the beginning of the contamination period $T_{\text {waj }}$ is calculated first as

$$
C_{w i j}(0)=Q_{1 i}\left(T_{t j}+T_{w h}\right) \quad W_{j}
$$

where

$$
\begin{aligned}
& C_{w i j}(0) \cdot \text { activity concentrajon of radionuclide } i \text { at location } j \\
& \text { at the beginning of the contamination period, } \mathrm{Ci} / \mathrm{m}^{3} \\
& Q_{1 i}\left(T_{t j}+T_{w h}\right) \text { - total activity of radionuclide } i \text { to be released to the } \\
& \text { liquid environment, corrected for decay to the time indicated, } \\
& \mathrm{Ci} \text { (see Equations 3.0-4 and 3.0-5) }
\end{aligned}
$$

The average water concentration corrected for decay over the time period $T_{\text {waj }}$ is evaluated for parent radionuclide $i$ and its first daughter radionuclide $k$ by

and

$$
\bar{C}_{w i j}\left(T_{w a j}\right)=\frac{1}{T_{w a j}} \int_{0}^{T_{w a j}} c_{w i j}(0) e^{-\lambda i t} d t
$$

$$
\begin{aligned}
\bar{c}_{w k j}\left(T_{w a j}\right)= & \frac{1}{T_{w a j}} \int_{0}^{T}{ }_{w a j}\left[c_{w k j}(0) e^{-\lambda} k^{t}+\frac{c_{w j j}(0) f_{i k} \lambda_{k}}{\lambda_{k}-\lambda_{j}}\right. \\
& \left.\left(e^{-\lambda_{j} t}-e^{-\lambda k^{t}}\right)\right] d t
\end{aligned}
$$


where

$\bar{C}_{w i j}\left(T_{\text {waj }}\right)$ - average water concentration of parent nuclide $i$ at usage location $j$, averaged for radioactive decay over time period $\mathrm{T}_{w a j}, \mathrm{C} i / \mathrm{m}^{3}$

$\bar{C}_{w k j}\left(T_{w a j}\right)$ - average water concentration of daughter nuclide $k$ at usage location $j$ averaged for radionuclide decay over time period $\mathrm{T}_{w a j}, \mathrm{Ci} / \mathrm{m}^{3}$

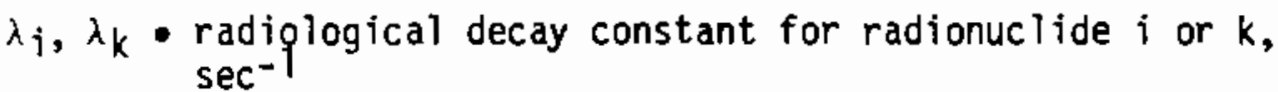

$f_{i k}$ - fraction of nuclide $i$ disintegration resulting in production of radionuclide $k$.

The average water concentration is used as the starting parameter for all aquatic exposure pathways. For each spatial interval, a water usage location is assigned for each liquid pathway to be considered. These usage points are used for each accident to be analyzed. The data arrays containing the average concentration, $C_{w j j}\left(T_{w a j}\right)$, and time period $T_{w a j}$ are calculated for each accident and saved on a temporary data file. The above equations are evaluated for parent radionuclide $i$ and daughter radionuclide $k$ by

$$
\bar{C}_{w i j}\left(T_{w a j}\right)=\frac{C_{w i j}(0)}{T_{w a j}}\left(\frac{1-e^{\lambda_{i} t}}{\lambda_{i}}\right)
$$

and

$$
\begin{aligned}
& \vec{c}_{w k j}\left(T_{w a j}\right)=\frac{C_{w k j}(0)}{T_{w a j}}\left(\frac{1-e^{-\lambda_{k} t}}{\lambda_{k}}\right) \\
& +\frac{C_{w i k}(0)_{f i k} \lambda_{k}}{T_{w a j}\left(\lambda_{k}-\lambda_{j}\right)}\left[\frac{1-e^{-\lambda_{i} t}}{\lambda_{j}}-\frac{1-e^{-\lambda_{k} t}}{\lambda_{k}}\right]
\end{aligned}
$$

where all terms are as defined above.

\subsubsection{Dispersion in Rivers}

Effluent transport from reactors located on nontidal rivers can be estimated using the transient release model of Regulatory Guide 1.113 (USNRC, 1977). This model represents a vertical Tine source in a straight rectangular channel. Parameters required for this model are the lateral and longitudinal 
turbulent diffusion coefficient, stream channel geometry and a definition of stream discharge. The model predicts concentration as a function of time at a selected downstream location. The time integral of the water concentration is used to estimate the water dilution factor $w_{j}$ (see Section 4.2) as follows:

$$
w_{j}=\frac{1}{\left(t_{2}-t_{1}\right)} \int_{t_{1}}^{t_{2}} c_{j} d t
$$

where

$C_{j}$ - instantaneous normalized water concentration at location $j$,

$t_{1}$ - time front of contamination plume reaches location $j$, days

$t_{2}$ - time last contamination has past location $j$, days.

Evaluation of the time integral is dependent on the flow conditions and on the distance from the release point to the location $j$. Three equations are given below: 1) a general equation, 2) an equation for points near the source and 3) an equation for points for downstream. The general equation includes effects of the far shore in the region where complete mixing is not yet attained.

$$
\begin{aligned}
& w_{j}=\frac{1}{\left(t_{2}-t_{1}\right) A\left(4 \pi E_{x}\right) I_{2}} \int_{t_{1}}^{t_{2}} \frac{1}{t \frac{1}{2}} \exp \left\{-\frac{\left(x_{j}-u t\right)^{2}}{4 E_{x} t}\right\} \\
& {\left[1+2 \sum_{n=1}^{\infty} \exp \left(-\frac{n^{2} \pi^{2} E y t}{B^{2}}\right) \cos \frac{n_{\pi} y s}{B} \cos \frac{n_{\pi} y}{B}\right] d t}
\end{aligned}
$$


where

A - river cross-sectional area, $\mathrm{m}^{2}$

B - width of river, $m$

$\mathrm{u}$ - downstream water speed, $\mathrm{m} / \mathrm{sec}$

$x_{j}$ - distance from source downstream to location $j, m$

$y_{s}$ - distance of the source from shore, $m$

$y$ - distance of the uptake point from the shore, m

t - time since release occurred, sec

$E_{x} \cdot$ vertically integrated dispersion coefficient in the $x$ direction, $\mathrm{m}^{2} / \mathrm{sec}$

$E_{y}$ - vertically integrated dispersion coefficient in the cross-stream direction, $\mathrm{m}^{2} \mathrm{sec}$.

The integration time limits are selected to include all significant contributions. The limits are determined from the condition

$$
\frac{(x j-u t)^{2}}{4 E_{x} t} \leqq k
$$

where $K$ is a constant.

Tests have shown that a value of 4.0 for $K$ gives good results. Solving the above relation for $t$ (assuming equality) results in the following expression for the time limits:

$$
t_{1}, t_{2}=\left(\frac{-b \pm \sqrt{b^{2}-4 c}}{2}\right)^{2}
$$

where

$$
\begin{aligned}
& b=\frac{\left(4 E_{x} K\right)^{\frac{1}{2}}}{u} \\
& c=-\frac{x_{j}}{u}
\end{aligned}
$$


The above dispersion equation applies at all points in the river. However, at points near the source, the equation is difficult to evaluate because of convergence problems in the summation term. Another equation is suggested in Regulation Guide 1.113 (USNRC 1977) at points near the source. This is the equation for open coasts with a constant longshore current. The equation is applicable to rivers where far-shore effects are not important. The equation is given below with a slight modification to include far-shore effects near the source. The modification has been included to allow for situations where the water intake is on the side of the river opposite the source.

$$
\begin{aligned}
& W_{j}=\frac{1}{\left(t_{2}-t_{1}\right) 4 d E_{x} E_{y}} \int_{t_{1}}^{t_{2}} \frac{1}{t} \exp \left[-\frac{\left(x_{j}-u t\right)^{2}}{4 E_{x} t}\right] \\
&\left\{\exp \left[-\frac{\left(y-y_{s}\right)^{2}}{4 E_{y} t}\right]+\exp \left[-\frac{\left(y+y_{s}\right)^{2}}{4 E_{y} t}\right]\right. \\
&\left.+\exp -\left[\frac{\left(2 B-y_{s}+y\right)^{2}}{4 E_{x} t}\right]+\exp \left[-\frac{\left(2 B-y_{s}-y\right)^{2}}{4 E_{y} t}\right]\right\} d t
\end{aligned}
$$

where

$$
\begin{aligned}
& d \text { - average river depth, m } \\
& d=A / B \text {. }
\end{aligned}
$$

The last exponential includes effects of the far shore for intake points located near the far shore and for sources located near midstream.

At distances far from the release point, complete mixing may be assumed. At these distances, the time-integrated water concentration is given by

$$
w_{j}=\frac{1}{\left(t_{2}-t_{1}\right) A u}
$$

The equation used for river concentration is selected by a series of tests on parameters for each location. 


\subsubsection{Dispersion in Lakes}

Transient and steady-state models which describe dispersion along shoreline sites on the Great Lakes are presented in the Liquid Pathway Generic Study (USNRC 1978). Three lake regimes are considered: nearshor:, offshore and totally mixed.

For the nearshore regime, a vertically integrated diffusion model is used which considers discharge into a lake having only an alongshore current. For an instantaneous release at time $t=0$ of a unit quantity of activity as a vertical line source at $x=0$ and $y=y_{5}$, the dilution factor is

$$
\begin{aligned}
& w_{j}=\frac{1}{\left(t_{2}-t_{1}\right) \frac{1 \pi d \sqrt{E_{x} E_{y}}}{t_{2}}} \int_{t_{1}}^{t_{t}} \frac{1}{t} \exp \left[-\frac{\left(x_{j}-U_{\ell} t\right)^{2}}{4 E_{x} t}\right] . \\
& \left\{\exp \left[-\frac{\left(y-y_{s}\right)^{2}}{4 E_{y} t}\right]+\exp \left[-\frac{\left(y+y_{s}\right)^{2}}{4 E_{y} t}\right]\right\} d t
\end{aligned}
$$

$W_{j}$ - average water concentration per unit activity released for water usage location $j, \mathrm{Ci} / \mathrm{m}^{3}$ per $\mathrm{C} i$ released

d average nearshore lake depth, $m$

$E_{x}$ - vertically integrated dispersion coefficient in the $x$ (1ongshore) direction, $\mathrm{m}^{2} / \mathrm{sec}$

$E_{y}$ - vertically integrated dispersion coefficient in the $y$ direction, $\mathrm{m}^{2} / \mathrm{sec}$

$t$ - time since release occurred, sec

$x_{j}$ - distance from source longshore to location $j, m$

$U$ - net longshore water velocity, $\mathrm{m} / \mathrm{sec}$

$y$ - distance of the uptake point from shore, m

$y_{s}$ - distance of the source from shore, $m$

The integration time limits are calculated using Equations 4.2-8 and 4.2-9 with $U_{\ell}$ in $p$ lace of $u$.

The intermediate offshore model is used for dispersion estimates after the activity has left the nearshore zone but before total mixing throughout the lake has occurred. These are the assumptions applying to the model: 
- Activity movement is described by a symmetric Gaussian diffusing patch.

- None of the activity leaves the lake (by flowthrough).

- Shoreline interaction is not important.

- Dispersion is confined to the upper layer of stratification.

For an instantaneous unit activity release, the average concentration in the patch is

$$
C(t)=\frac{1}{A(t) h}
$$

where

$c(t) \cdot$ average concentration at time $t$ (radioactive decay not considered), $\mathrm{m}^{-3}$

$h$ - depth of upper stratification layer, $m$

$A(t)$ - area of the patch at time $t, m^{2}$.

Based on data for Lake Ontario, an expression was presented for $A$ as

$$
A(t)=9.98 \times 10^{-8} t^{2.86}
$$

Using this expression in Equation 4.2-13 results in

$$
c(t)=\frac{1.00 \times 10^{7} t^{-2.86}}{h}
$$

The dilution factor is then given by

$$
w_{j}=\frac{1}{\Delta t} \int_{t_{1}}^{t_{2}} c(t) d t=\frac{5.4 \times 10^{6}}{\left(t_{2}-t_{1}\right) h}\left(t_{1}^{-1.86}-t_{2}^{-1.86}\right)
$$

Selection of the integration time limits $\left(t_{1}\right.$ and $\left.t_{2}\right)$ should be based on the period over which the model applies to the portion of the lake of interest.

When the lake becomes totally mixed, the concentration is described by a mixed-tank model. Assuming constant 7 ake volume and constant inflow equal to outflow, the dilution factor is given by

$$
w_{j}=\frac{1}{\left(t_{2}-t_{1}\right) q_{L}}\left(e^{-\frac{q_{L}}{V_{L}} t_{1}}-e^{-\frac{q_{L}}{V_{L}} t_{2}}\right)
$$

where 
qL - lake flowthrough rate, $\mathrm{m}^{3} / \mathrm{sec}$

$V_{L}$ - lake volume, $m^{3}$

$t_{1}$ - time at which the lake becomes uniformly mixed, sec

$t_{2}$ - time selected for end of contamination period, sec.

Selection of $t_{2}$ may be based on the time for the concentration to be reduced to some fraction $F_{m}$ of the concentration at time $t_{1}$.

$$
F_{m}=\frac{c\left(t_{2}\right)}{c\left(t_{1}\right)}=e^{-\frac{q_{L}}{V_{L}}\left(t_{2}-t_{1}\right)}
$$

Then

$$
t_{2}=t_{1} \frac{V_{L} \text { in } F_{m}}{q}
$$

\subsubsection{Dispersion in Estuaries}

The dispersion model presented here is essentially that described in the Liquid Pathway Generic Study (USNRC 1978). This simple model does not consider tidal currents as an advective mechanism because potable water intakes (or irrigation water intakes) are not likely to be located on estuaries where there is a possibility of sait water contanination during high tides. For an instantaneous release at time $t=0$ of a unit quantity of activity distributed uniformly over the estuary cross-sectional area, the dilution factor is

$$
W_{j}=\frac{1}{\left(t_{2}-t_{1}\right)} \frac{1}{A \sqrt{4 \pi} E_{L}} \int_{t_{1}}^{t_{2}} \frac{1}{t} \exp \left[-\frac{\left(x_{j}-u_{f} t^{2}\right)}{4 E_{L} t}\right] d t
$$

where

$$
\begin{aligned}
& W_{j} \text { - average water concentration per unit activity released for water } \\
& \text { usage location } \mathrm{j}, \mathrm{Ci} / \mathrm{m}^{2} \text { per } \mathrm{Ci} \text { released } \\
& A \text { - estuary cross-sectional area, } \mathrm{m}^{2} \\
& x_{j} \text { - downstream distance from release to location } \mathrm{j} \text {, m } \\
& \mathrm{u}_{\mathrm{f}} \text { - net downstream freshwater velocity, } \mathrm{m} / \mathrm{sec} \\
& \mathrm{E}_{\mathrm{L}} \text { - longitudinal dispersion coefficient, } \mathrm{m}^{2} / \mathrm{sec}
\end{aligned}
$$


$\mathrm{t}$ - after release.

The time integration limits are determined in a manner similar to that used in the river model. The time limits are

$$
t_{1}, t_{2}=\left(\frac{-b \pm \sqrt{b^{2}-4 c}}{2}\right)^{2}
$$

where

$$
\begin{aligned}
& b=\frac{\left(4 E_{L} K\right)^{\frac{1}{2}}}{u_{f}} \\
& c=-\frac{x_{j}}{u_{f}} \\
& K=4.0 \text { (as for the river model). }
\end{aligned}
$$

The main differences between this model and the river model are that far-shore effects are not considered here and the initial dispersion is uniform over the flow cross-section rather than being considered a vertical line source.

\subsubsection{Dispersion Along Open Coasts}

Dispersion along open coasts can be described by the nearshore lake model in Section 4.2.2. Care must be taken to account for the greater temporal and spatial variability of coastal systems in defining the dispersion coefficients.

\subsubsection{Effects of Cooling Ponds}

Release of activity to cooling ponds results in delayed release to the main receiving water body. This delay results in lower concentrations because of radionuclide decay. Also, the release duration is of ten extended, causing lower concentrations over longer time periods.

Three cooling pond models are described here which estimate the effect of holdup on release to the receiving water bodies. These models represent a completely mixed system, a plug-flow system and a partially mixed system.

For a closed loop system in which the pond is represented as a completely mixed tank, all inputs are instantaneously mixed so that the concentration is homogeneous. The activity of a radionuclide at time $t$ following a quantity of release at time zero is

$$
c_{i}(t)=c_{j}(0) e^{-\left(\lambda_{j}+\lambda_{v}\right) t}
$$


where

$C_{j}(t)$ - pond activity of radionuclide $i$ at time $t, C_{i}$

$C_{i}(0)$ - initial quantity of radionuclide $i$ in the pond, $C_{i}$

$\lambda_{i}$ - radiological decay constant for radionuclide $i, \mathrm{sec}^{-1}$

$\lambda_{\mathrm{v}} \cdot$ pond time constant, sec

$\lambda_{V}=\frac{q}{V}$

$q=$ pond flowthrough rate, $\mathrm{m}^{3} / \mathrm{sec}$

$V=$ pond volume, $\mathrm{m}^{3}$.

The total activity released to the receiving water body is given by

$$
Q_{j}(t)=\frac{C_{j}(0) \lambda_{v}}{\lambda_{v}+\lambda_{i}} \quad\left[1-\mathrm{e}^{-\left(\lambda_{i}+\lambda_{v}\right) t}\right]
$$

where $Q_{j}(t)$ - total activity $(C i)$ of radionuclide $i$ leaving the pond by time $t$.

The maximum fraction leaving is given by the above equation evaluated at large times:

$$
\frac{Q_{j}(\max )}{C_{j}(0)}=\frac{\lambda_{v}}{\lambda_{v}+\lambda_{i}}
$$

This reduction factor can be applied to each radionuclide released as an estimate of the effect of the cooling pond releases. To estimate the reduction of the dilution factors $w_{j}$ due to extension of the release period, consider Equation 4.2-23 without decay to determine the time at which a fraction $F_{m}$ of the activity has been flushed from the system.

$$
T_{m}=\frac{-\ln F_{m}}{\lambda v}
$$

where

$$
\begin{aligned}
& F_{m} \text { - fractional reduction of activity (ignoring decay) } \\
& T_{m} \text { - time to reach the fractional reducton } F_{m}, s e c \text {. }
\end{aligned}
$$

The time period can be used to modify the values for $w_{j}$ reported in the previous sections as follows:

$$
w_{j}=\frac{w_{j}\left(t_{2}-t_{1}\right)}{t_{2}-t_{1}+T_{m}}
$$


where

$$
\begin{aligned}
& W_{j}^{\prime}: \text { corrected dilution factor, } m^{-3} \\
t_{2}-w_{j} & \text { : dilution factor without the cooling pond, } m^{-3} \\
& \text { timed over which the dilution factor } W_{j} \text { applies, sec. }
\end{aligned}
$$

The new dilution factor $W_{j}^{\prime}$ now applies over the extended time period $t_{2}-t_{1}+T_{m}$.

For cooling ponds in which plug-flow is a representative model, the reduction in activity results from radioactive decay in transit through the pond. The delay time through the pond is given by

where

$$
t_{p}=\frac{v}{q}
$$

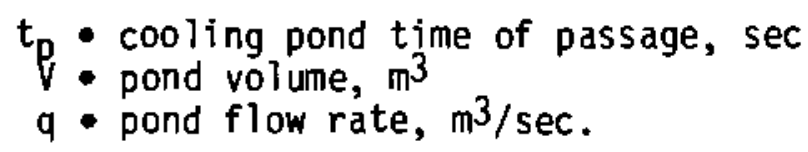

The decay correction for passage through the pond is then given by the following equations for parent radionuclide $i$ and daughter radionuclide $k$ :

$$
Q_{j}\left(t_{p}\right)=Q_{i}(0) e^{-\lambda_{i} t_{p}}
$$

and

where

$$
Q_{k}\left(t_{p}\right)=Q_{k}(0) e^{-\lambda_{k} t_{p}}+\frac{Q_{j}(0) f_{i k} \lambda_{k}}{\lambda_{k}-\lambda_{j}}\left(e^{-\lambda_{i} t_{p}}-e^{-\lambda_{k} t_{p}}\right)
$$

$$
\begin{aligned}
& Q_{j}\left(t_{p}\right), Q_{k}\left(t_{p}\right) \cdot \begin{array}{l}
\text { activity of radionuclides } i \text { and } k \text { leaving the cooling } \\
\text { pond at time } t_{p}, C j
\end{array} \\
& Q_{j}(0), Q_{k}(0) \cdot \begin{array}{l}
\text { activity of radionuclides } i \text { and } k \text { entering the cooling } \\
\text { pond at time zero, } C_{j}
\end{array}
\end{aligned}
$$

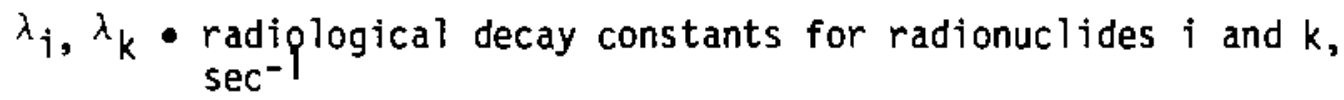

$$
\begin{aligned}
& f_{i k} \text { - fraction of radionuclide } i \text { disintegrations that result in }
\end{aligned}
$$

No modification to the dilution factor, $W_{j}$, is necessary for the plug-flow cooling pond model since the dilution period is not expanded. 
For cooling ponds described by plug-flow with partial recycle through the reactor, the partially mixed model should be used. Consider the pond system illustrated in Figure 4.2-1. For an initial impulse of $Q_{j}(0), \mathrm{Ci}_{i}$, released from the reactor, the activity reaching the end of the pond after the first pass is

$$
Q_{j}\left(t_{p}\right)=Q_{j}(0) e^{-\lambda_{j} t_{p}}
$$

where

$$
\begin{aligned}
Q_{i}\left(t_{p}\right) & - \text { activity at the end of the pond after the first pass, } C i \\
t_{p} & \cdot \text { time of passage through the pond, sec } \\
t_{p} & =\frac{v}{q_{b}+q_{p}} \\
q_{b} & \bullet \text { blowdown rate, } \mathrm{m}^{3} / \mathrm{sec} \\
q_{p} & - \text { recycle flow rate, } \mathrm{m}^{3} / \mathrm{sec} \\
v & \bullet \text { pond volume, } \mathrm{m}^{3} .
\end{aligned}
$$

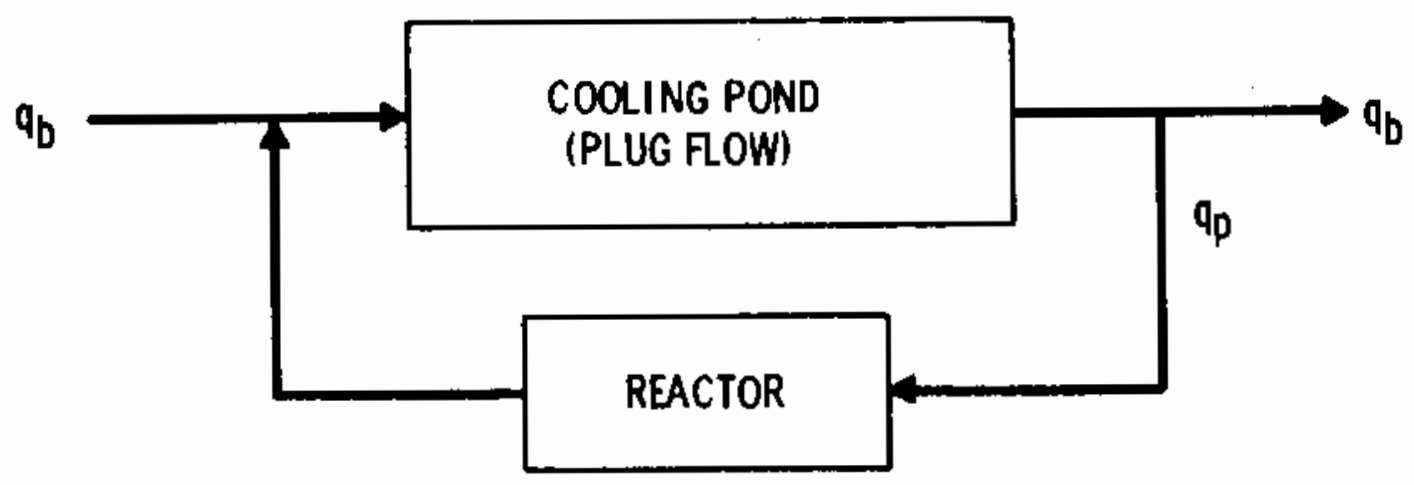

FIGURE 4.2-1. Partially Mixed Cooling Pond

The activity recycled for the start of the second pass is

$$
Q_{i}\left(t_{p}\right) R
$$

where $R$ - recycle fraction.

$$
R=\frac{q_{p}}{q_{p}+q_{b}}
$$


At the end of the second pass the activity remaining is

$$
Q_{j}\left(2 t_{p}\right)=Q_{j}(0) R\left(e^{-\lambda_{j} t_{p}}\right)^{2}
$$

After $n$ passes, the activity remaining is

$$
Q_{i}\left(n t_{p}\right)=Q_{j}(0) R^{n-1}\left(e^{-\lambda_{j} t_{p}}\right) n
$$

At the end of each pass the fraction of activity released to the receiving water body is $(1-R) Q_{i}\left(n t_{p}\right)$. The total activity released after $n$ passes is

$$
A_{j}\left(n t_{p}\right)=(1-R) Q_{i}(0) \sum_{k=1}^{n} R^{k-1}\left(e^{-\lambda_{j} t_{p}}\right)^{k}
$$

where $A_{i}\left(n t_{p}\right)$ - total activity of radionuclide $i$ released after $n$ passes, Ci.

An estimate of the maximum time required is obtained by ignoring radionuclide decay. Then

$$
A_{j}\left(n t_{p}\right)=(1-R) c_{j}(0) \sum_{k-1}^{n} R^{k-1}
$$

This expression can be solved by trial and error for the value of $n$ to find the time at wich $A_{j}\left(n t_{p}\right)$ is within a desired fraction of $C_{j}(0)$. This time can be used in Equation 4.2-26 to estimate the effect on the dilution factor $W_{j}$. 


\subsection{DIRECT PHOTON TRANSPORT}

In the direct irradiation pathway, people near the plant are exposed to radionuclides that have escaped from the reactor core and spread to regions of the containment or other buildings having less shielding. The dose received by persons near the plant will depend on their distance from the contaminated buildings, the source term, and the amount and type of shielding material. The magnitude of the source term will vary with time because of radioactive decay, settling, and cleanup efforts. The intensity of the direct radiation reaching points exterior to the plant is anisotropic because the degree of shielding varies with the nature and location of adjacent structures. Hence, the dose distribution will be a function of direction, distance and time.

The dose rate can be represented mathematically by the following expression:

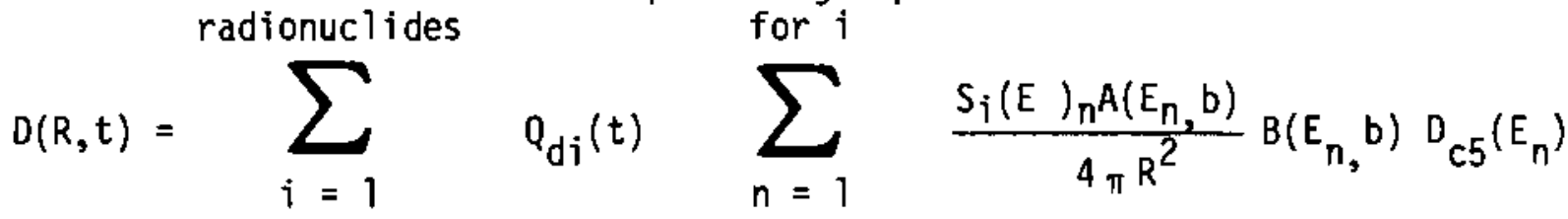

where

$D(R, t)$ - dose rate at time $t$ at a distance $R$ for a tissue depth of $5 \mathrm{~cm}, \mathrm{rem} / \mathrm{sec}$

$R$ - distance from source reference point to exposure point, m

$Q_{d i}(t)$ - activity of radionuclide $i$ in the direct irradiation source term at time $t, \mathrm{C} i$

$S_{i}\left(E_{n}\right)$ - photon energy from radionuclide $i$ in energy group $n$, MeV/ disintegration

$E_{n}$ - average photon energy for energy group $n, M e V$

$A\left(E_{n}, b\right)$ - attenuation factor for photons of initial energy $E_{n}$ and for shielding by $b$ mean free paths, dimensionless

$B\left(E_{n}, b\right)$ - the buildup factor representing the contribution from scattered radiation for photons of initial energy $E_{n}$ and effective shielding of $b$ mean free path lengths between the source and exposure point, dimensionless

$D_{c 5}\left(E_{n}\right)$ - the flux-to-dose conversion factor as a function of photon energy, $\left(\mathrm{rem} / \mathrm{m}^{2}\right)$ per $(\mathrm{MeV} \cdot \mathrm{day} \cdot \mathrm{C} \mathrm{i})$. 
The initial radionuclide activity, $Q_{d i}(0)$, is defined by Equations $3.0-4$ and 3.0-6. The activity at other times is calculated assuming

- cleanup is described by a radionuclide-dependent half-time

- radioactive decay

- after a given time, $T_{d r}$, all material is unavailable for causing exposure.

With these assumptions, the following equations yield the time-dependence for activity for parent radionuclide $i$ and daughter radionuclide $k$ :

$$
O_{d i}(t)=O_{d i}(T) e^{-\lambda_{d i} t}
$$

and

where

$$
\begin{aligned}
Q_{d k}(t) & =Q_{d k}(T) e^{-\lambda_{d k} t} \\
& +\frac{f_{i k} \lambda_{k} Q_{d j}(0)}{\lambda_{k}-\lambda_{j}}\left[e^{-\lambda_{d i} t}-e^{-\lambda_{d k} t}\right]
\end{aligned}
$$

$Q_{d i}(t)$ - activity of parent radionuclide $i$ in the direct irradiation source term at time $t, \mathrm{C}^{i}$

$Q_{d k}(t)$ - activity of daughter radionuclide $k$ in the direct irradiation source term at $t$ ime $t, \mathrm{C} i$

$T_{d h}$ - holdup time for release of activity into the containment vessels

$\lambda_{d i}, \lambda_{d k}$ - effective removal constant for the direct irradiation source term for parent radionuclide $i$ and daughter radionuclide $k$, days -1

$\lambda_{i}, \lambda_{k} \cdot$ radiological decay constant for parent radionuclide $i$ and daughter radionuclide $k$, days ${ }^{-1}$

$f_{i k}$ - fraction of radionuclide $i$ disintegrations that results in production of radionuclide $k$

$t$ - time after irradiation begins ( since $T_{d h}$ ), days

At times beyond the source term cutoff period, $T_{d r}$, the activity (and dose rate) is zero.

The summation over energy groups is a close approximation to an energy integration. Preliminary investigations have shown that photons with energy 
Tess than $0.5 \mathrm{MeV}$ are essentially eliminated by the amount of shielding expected for the present application. Also, attenuation and buildup coefficients for air are slowly varying functions of energy. Therefore, a coarse energy grouping is adequate. The groups suggested for use in this study are presented in Table 4.3-1.

\section{TABLE 4.3.1. Photon Energy Groupings}

Group
1
2
3
4
5

\begin{tabular}{|c|c|}
\hline $\begin{array}{c}\text { Energy } \\
\text { Limits (MeV) }\end{array}$ & $\begin{array}{l}\text { Averag } \\
\text { Energy (1 }\end{array}$ \\
\hline $\begin{array}{l}0.5-1.0 \\
1.0-1.5 \\
1.5-2.0 \\
2.0-2.5 \\
2.5-5\end{array}$ & $\begin{array}{l}1.25 \\
1.75 \\
2.25 \\
3.0\end{array}$ \\
\hline
\end{tabular}

The dose rate is calculated at several times after the accident with decay of the initial inventory considered for each time. Build-in of daughter products is accounted for, with chains of up to three members allowed.

The photon probability and energy data are stored in an external data file. Data in the file are derived from that used by the code ISOSHLD (Engle et al. 1966). Gamma energies and probabilities per disintegration are stored by the five energy groups. Many of the nuclides considered have beta-particle decay modes, but the distances and anounts of shielding present in reactor accident cases prevent direct beta irradiation. However, bremsstrahlung (Hine and Brownell 1956) from the slowing down of high-energy betas can contribute up to $5 \%$ of the total photon dose (Blizard 1962). Therefore, photons from bremsstrahlung are included in the ganma probability file. Spectral distributions for internal and external bremsstrahlung (photons/beta) are derived from the computer code BREMRAD ( $V$ an Tuyl 1964). The derivation is based upon the beta end-point energies, beta production probabilities, and the absorption characteristics of air, which is the dominant absorbing medium for radionuclides released into the containment building. BREMRAD uses the KnippUhlenbeck ( $\mathrm{Knipp}$ and Uhlenbeck 1936) approximation to calculate the internal bremstrahlung spectrum, and the Bethe-Heitler (Bethe and Heitler 1934) approximation for the external spectrum.

The attenuation factor as a function of distance, shielding and photon energy is calculated (Engle et al. 1966, Jaeger 1968) as

$$
A(E, b)=e^{-b(E)}
$$


where

$$
b(E)=\sum_{j=1}^{m} \mu_{j}(E) t_{j}
$$

$b(E)$ - the effective mean free path length

$m$ - the number of shields

$j(E)$ - the linear energy attenuation coefficient for shield material $j$, for photons of initial energy $E, m^{-1}$

$t_{j}$ - the thickness $(m)$ of shield material $j$. The thicknesses $t_{j}$ are related to the total source to receptor distance by

$$
R=\sum_{j=1}^{m} t_{j}
$$

the largest $t_{j}$ is usually that of air.

Since attenuation is a function of direction fram the reactor, provisions are made for up to five different shielding configurations. Default values are provided for the attenuation coefficients and densities of air, steel and concrete. Addition of one or two more sets of shield materials is allowed through input to the computer code. Standard requirements beyond those for the source term are the thicknesses of steel and concrete for each of the desired shielding configurations. The remainder of the standard distances from source to detectors are assumed to be air. If other materials are desired in the shields, attenuation coefficients and thicknesses must be added a)so.

The buildup factor is calculated for all of the materials between the source point and the dose point. Buildup is calculated using Taylor's equation (Blizard 1962, Jaeger 1968):

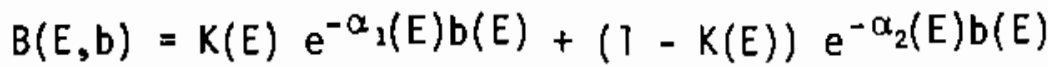

where $K, \alpha_{1}, \alpha_{2}$. Taylor's coefficients as functions of energy and attenuating medium.

The parameters $K, \alpha_{1}$, and $a_{2}$ are dependent on the energy of the photons and also on the effective atomic number of the scattering medium. Engle et al. (1966) have discussed treatment of buildup for multi-region shields. The approach they used, which is probably sufficient for the current application, was to consider all the mean free paths in material between the source and detector, using only the bujldup coefficients of the last shield region. For accident cases, this last region will be air. Taylor's formulation of the buildup factor is good for distances of more than a few mean free paths (Jaeger 1968). For air, Taylor's coefficients give a good approximation for up to 20 mean free paths, which corresponds to a distance of over $3000 \mathrm{~m}$. 
The model described above is a simple point-source, slab shield direct irradiation dose rate model. For locations near the source, it will overestimate the dose rate, since the size of the reactor building and distribution of nuclides will make the point source approximation conservative. Preliminary calculations have shown, however, that the point-source model overestimates the dose rate by only a factor of 3 at $100 \mathrm{~m}$. Much beyond 100 $m$, the point-source and distributed-source results tend to converge. Since very few people will be within $1000 \mathrm{~m}$ of a reactor, the point source is felt to be an adequate model. It will yield useful results with a minimum of computational time and effort.

The above equations provide an estimate of the energy-dependent ganma field at selected distances and directions from the source. Multiplicative flux-to-dose rate conversion factors are used to estimate the total-body dose rate as described in Section 6.1 .

The model described above does not consider exposure from radiation scattered around shields. It is assumed that shields are relatively continuous (no large open spaces) and extend over the top of the source as well as around it. For situations where scatter around shields (sky shine) may be significant, a special analysis must be made to estimate the effective shielding available in each direction. This effective thickness would then be used as input to the above model. 


\subsection{EXPOSURE PATHWAYS}

This section describes models for relating environmental activity concentrations to human uptake through inhalation and ingestion. Also discussed are external exposure pathways which relate environmental concentrations to timeintegrated exposures. The inhalation and ingestion uptake and external timeintegrated exposures are converted to dose by appropriate conversion factors as described in Section 6.0.

\subsection{EXTERNAL EXPOSURE FROM PLUME PASSAGE}

The external exposure to activity in the plume during passage is based on the time-integrated air concentration at the location of interest, calculated for a ground-level release. The dose conversion factor for air submersion (see Section 6.1) gives the dose at the midpoint of the spatial interval, assuming the plume to be infinite and of uniform concentration. A correction is applied to account for the elevation of the plume and for plume size based partiy on the recommendations in the Reactor Safety Study as described in Section 6.1.1. The dose is calculated from the time-integrated air concentration corresponding to ground-level release after correction for finite plume dimensions. The time-integrated air concentration is given by

$$
c_{0 i j}=c_{i j} \quad\left[\exp \left(-h_{e}^{2} / 2 \sigma_{z}^{2}\right)\right]-1
$$

where

$C_{0 i j}$ - time-integrated ground-level air concentration of radionuclide $i$ for external exposure to plume at location $j, \mathrm{Ci} \cdot \mathrm{sec} / \mathrm{m}^{3}$

$C_{i j}$ - time-integrated air concentrations for radionuclide $i$ for interval j, $\mathrm{Ci} \cdot \mathrm{sec} / \mathrm{m}^{3}$

$h_{e}$ - effect plume height at location $j, m$

$\sigma_{z} \cdot$ vertical dispersion parameter, $m$.

Values of $C_{0 i j}$ are used with dose conversion factors described in Section 6.1 .1 to give dose during plume passage. The $C_{i j}$ values are calculated by Equation 4.1-22, where the directional dependence, $\theta$, is now included in the spatial interval index $j$.

\subsection{EXTERNAL EXPOSURE FROM CONTAMINATED GROUND}

The atmospheric dispersion model provides ground contamination levels resulting from passage of the plume for each radionuclide at each downwind 
location. External exposure to the contaminated ground is calculated using dose-rate conversion factors for exposure to an infinite plane uniformly contaminated (See Section 6.1). The dose is calculated as the product of the dose-rate conversion factor and the time-integrated ground contanination level, integrated over the exposure period of interest. The time-integrated contamination level is calculated by

$$
\bar{G}_{i j}\left(T_{g}\right)=\int_{0}^{T_{g}} G_{i j}(t) d t
$$

where

$G_{i j}\left(T_{g}\right)$ - time-integrated ground contamination level for radionuclide $i$, location $j$ and exposure time $\mathrm{T}_{\mathrm{g}}, \mathrm{C} i \cdot$ days $/ \mathrm{m}^{2}$

$T_{g}$ - duration of exposure to contaminated ground, days

$G_{i j}(t)$ - ground contamination level at location $j$ for radionuclide $i$, corrected for decay from the time of deposition to time $t$, $\mathrm{Ci} / \mathrm{m}^{2}$.

Values of $G_{i j}$ are determined from Equation 4.1-44 for each spatial interval where the direction index $\theta$ is now included in the location index $j$. Equation 5.2-1 is evaluated for continuous exposure periods by the following equations. Here, subscript $i$ refers to a parent radionuclide and subscript $k$ refers to a daughter radionuclide. The equations for time-integrated ground concentrations are

$$
\bar{G}_{i j}\left(T_{g}\right)=\frac{G_{i j}(0)}{\lambda_{j}}\left(1-e^{-\lambda_{j} T_{g}}\right)
$$

and

$$
\begin{aligned}
& G_{k j}\left(T_{g}\right)=\frac{G_{k j}(0)}{\lambda k}\left(1-e^{-\lambda_{k} T_{g}}\right)+ \\
& \frac{G_{i j}(0) f_{i k} \lambda_{k}}{\lambda k-\lambda_{j}}\left[\frac{1-e^{-\lambda j T_{g}}}{\lambda j}-\frac{1-e^{-\lambda k} T_{g}}{\lambda k}\right]
\end{aligned}
$$

where

$G_{i j}\left(T_{g}\right)$ - contamination time integral for parent radionuclide $i$ at location $\mathrm{j}$ for time period $\mathrm{T}_{\mathrm{g}}$ after deposition, $\mathrm{C} i \cdot$ days $/ \mathrm{m}^{2}$

$G_{k j}\left(T_{g}\right)$ - contamination time integral for daughter radionuclide $k$ at location $\mathrm{j}$ for time period $\mathrm{Tg}, \mathrm{C} i$ - days $/ \mathrm{m}^{2}$

$G_{i j}(0)$, contamination levels at the time of deposition as given by $\mathrm{G}_{\mathrm{kj}}(\mathrm{O})$ Equation $4.1-23, \mathrm{Ci} / \mathrm{m}^{2}$

$\lambda_{j}, \lambda_{k}$ - radiological decay constant for parent and daughter, days-l 
$f_{i k}$ - fraction of radionuclide $i$ disintegrations that result in production of a daughter radionuclide $k$.

These equations are used to generate integrals for each exposure period needed for assessment of health effects and costs. Use of the integrals is discussed in Section 6.1.2.

When ground exposure to irrigated farmland is considered, the ground contamination level is given as a function of a time by Equations $5.5-11$ and 5.5-12 for acute irrigation and Equations 5.5-13 and 5.5-14 for chronic irrigation. The time integral of ground concentration is given by the following equations for acute depositions:

$$
\tau_{s a}^{w i}\left(T_{g}\right)=S_{m} c_{s a}^{w i}(0)\left[\frac{1-e^{-\lambda_{i}^{\top} g}}{\lambda_{i}}\right]
$$

and

$$
\begin{aligned}
C_{s a}^{w k}\left(T_{g}\right) & =S_{m} C_{s a}^{w k}(0)\left[\frac{1-e^{-\lambda^{\lambda} g}}{\lambda_{k}}\right] \\
& +\frac{S_{m} f_{j k} \lambda_{k} C_{s a}^{w i}(0)}{\lambda_{k}-\lambda_{j}}\left[\frac{1-e^{-\lambda_{j}{ }^{\top} g}}{\lambda_{j}}-\frac{1-e^{-\lambda_{k}^{\top} g}}{\lambda_{k}}\right]
\end{aligned}
$$

where

$$
\begin{aligned}
& \begin{array}{l}
\bar{C}_{S a}^{w i}\left(T_{g}\right) \text { - time-integrated soil concentration of parent radionuclide } i \text {, } \\
\text { from acute irrigation deposition, } C_{i} \cdot \text { days } / \mathrm{m}^{2}
\end{array} \\
& \bar{C}_{S a}^{W k}\left(T_{g}\right) \text { - time-integrated soil concentration for daughter radionuclide } k \\
& \text { from acute irrigation deposition, } \mathrm{C} i \cdot \text { days } / \mathrm{m}^{2} \\
& C_{S a}^{w i}(0) \text {, - initial soil concentration for parent radionuclide } i \\
& \mathrm{C}_{\mathrm{sa}}^{\mathrm{wk}}(0) \text { and daughter radionuclide } \mathrm{k} \text { from acute irrigation (defined by }
\end{aligned}
$$


The time integral of soil concentration for chronic irrigation is given by the following equations for parent radionuclide $i$ and daughter radionuclide $k$.

$$
\tau_{s c}^{w i}\left(T_{g}\right)=\frac{S_{m} R_{s}{ }^{w i}}{\lambda_{i}}\left[T_{g}-\frac{1-e^{-\lambda_{i} T^{T}}}{\lambda_{i}}\right]
$$

and

$$
\begin{aligned}
& \begin{aligned}
\bar{c}_{s c}^{w k}\left(T_{g}\right) & =\frac{S_{m} R_{s}{ }^{w k}}{\lambda_{k}}\left[T_{g}-\frac{1-e^{-\lambda_{k}{ }^{\top} g}}{\lambda_{k}}\right] \\
& +\frac{S_{m} R_{s}{ }^{w i} f_{i k}}{\lambda_{i}}\left[T_{g}-\frac{1-e^{-\lambda_{k} T_{g}}}{\lambda_{k}}\right]
\end{aligned} \\
& +\frac{s_{m} R^{w i} f_{i k} \lambda_{k}}{\lambda_{i}\left(\lambda_{k}-\lambda_{i}\right)}\left[\frac{1-e^{-\lambda_{k}{ }^{\top} g}}{\lambda_{k}}-\frac{1-e^{-\lambda_{i}{ }^{\top} g}}{\lambda_{i}}\right]
\end{aligned}
$$

where

$\bar{C}_{S C}^{w i}\left(T_{g}\right)$ - time-integrated ground concentration for parent radionuclide $i$ from chronic irrigation deposition, $\mathrm{C} i \cdot$ days $/ \mathrm{m}^{2}$

$\bar{C}_{S d}^{w k}\left(T_{g}\right)$ - time-integrated ground concentration for daughter radionuclide $k$ from chronic irrigation deposition, $\mathrm{C} \cdot$ - days $/ \mathrm{m}^{2}$

$R_{S}^{W i}, R_{S}^{W k}$ - constant deposition rate to soil for parent radionuclide $i$ and daughter radionuclide $k$ from chronic irrigation (defined by Equation 5.5-9), Ci-day/kg.

The above equations for chronic irrigation apply when the irrigation period, $T_{\text {waj }}$, is greater than the ground exposure period, $T_{g}$. When the ground exposure period is greater, the time-integrated ground concentrations are given by

$$
C_{s c}^{w i}\left(T_{g}\right)=\bar{c}_{S c}^{w i}\left(T_{w a j}\right)+C_{s c}^{w i}\left(T_{w a j}\right)\left[\frac{1-e^{-\lambda_{j} t}}{\lambda_{i}}\right]
$$

and 


$$
\begin{aligned}
\bar{C}_{s c}^{w k}\left(T_{g}\right) & =\bar{C}_{s c}^{w k}\left(T_{w a j}\right)+C_{s c}^{w k}\left(T_{w a j}\right)\left[\frac{1-e^{-\lambda_{k} t}}{\lambda_{k}}\right] \\
& +\frac{f_{i k} \lambda_{k} c_{s c}^{w i}\left(T_{w a j}\right)}{\lambda_{k}-\lambda_{i}}\left[\frac{1-e^{-\lambda_{i} t}}{\lambda_{i}}-\frac{1-e^{-\lambda_{k} t}}{\lambda_{k}}\right]
\end{aligned}
$$

where

$\bar{C}_{S C}^{w i}\left(T_{\text {waj }}\right)$ - time integral of parent radionuclide $i$ ground concentration evaluated at the end of the chronic irrigation period, $T_{w a j}$, $\mathrm{Ci} \cdot$ days $/ \mathrm{m}^{2}$

$\bar{C}_{S C}^{W k}\left(T_{w a j}\right) \cdot$ time integral of daughter radionuclide $k$ ground concentration evaluated at the end of the chronic irrigation period $T_{w a j}$, $\mathrm{Ci} \cdot$ days $/ \mathrm{m}^{2}$

$\mathrm{C}_{\mathrm{SC}}^{\mathrm{wi}}\left(T_{w a j}\right) \cdot \mathrm{soil}_{\mathrm{C} i / \mathrm{m}^{2}}$ concentration of parent radionuclide $i$ at time $T_{w a j}$,

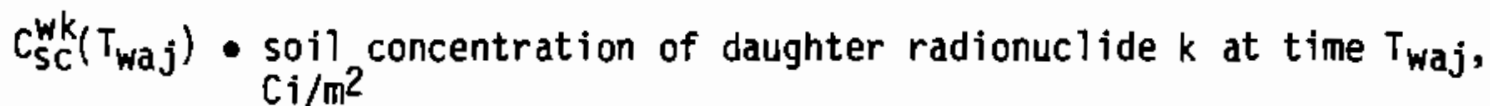
$t$ - time since the end of the chronic irrigation period, days $t=T_{g}-T_{\text {waj }}$.

\subsection{INHALATION OF RADIONUCLIDES DURING PASSAGE OF PLUME}

Persons in the path of the plume are subject to exposure from inhalation of radionuclides during passage of the plume. The inhaled activity will remain in the body and cause radiation exposure beyond the uptake period. The amount of material inhaled is calculated from the time-integrated air concentration at the location of interest:

$$
Q_{h i j}\left(T_{r}\right)=B_{r} / T_{r} \int_{0}^{T_{r}} c_{i j}(t) d t
$$

where

$$
\begin{gathered}
Q_{h i j}\left(T_{r}\right) \text { - total activity of nuclide } i \text { inhaled at location } j \\
\text { during release time } T_{r} \text { (passage of the plume), } C i \\
T_{r} \text { - duration of release for the accident, days }
\end{gathered}
$$


$B_{r}$ - ventilation rate of individual exposed, $\mathrm{m}^{3} /$ day

$C_{i j}(t)$ - time-integrated air concentration at the plume front (with time zero equal to the time the plume front reaches the exposure location), $\mathrm{Cj}$. days $/ \mathrm{m}^{3}$.

Values of $C_{i j}$ are determined from Equation 4.1-22 for each spatial interval. The integral allows for decay of the nuclide over the release time. Equation 5.3-1 may be evaluated for a parent radionuclide $i$ and a daughter radionuctide $k$ by

and

$$
Q_{h i j}\left(T_{r}\right)=\frac{B_{r} C_{i j}(0)}{T_{r} \lambda_{i}}\left(1-e^{-\lambda_{j} T_{r}}\right)
$$

$$
\begin{aligned}
Q_{h k j}\left(T_{r}\right)= & \frac{B_{r}}{T_{r}} \frac{C_{k j}(0)}{\lambda_{k}}\left(1-e^{-\lambda_{k} T_{r}}\right)+ \\
& \frac{C_{j j}(0) f_{i k} \lambda_{k}}{\lambda_{k}-\lambda_{i}}\left[\frac{1-e^{-\lambda_{j} T_{r}}}{\lambda_{j}}-\frac{1-e^{-\lambda_{k} T_{r}}}{k}\right]
\end{aligned}
$$

where

$$
\begin{aligned}
f_{i k} \cdot \begin{array}{l}
\text { fraction of radionuclide } i \text { dis integrations that result } \\
\text { in production of radionuclide } k
\end{array} \\
\lambda_{i}, \lambda_{k} \cdot \begin{array}{l}
\text { radiological decay constants for parent radionuclide } \\
\text { radionuclide } k \text {, sec }-1 .
\end{array} \\
\text { Other terms are as previously defined. }
\end{aligned}
$$

\subsection{INHALATION OF RESUSPENOED MATERIAL}

Material deposited on the ground during plume passage is subject to resuspension and presents a potential inhalation hazard. Inhalation of resuspended material is on ly considered for periods after the passage of the plume; immediately following the accident, resuspension would pose a very small hazard compared to the initial plume. The amount of material resuspended is calculated as a function of time after the accident by use of the resuspension equation of Anspaugh et al. (1975).

$$
R_{f}(t)=10^{-4} e^{-0.15 \sqrt{t}}+10^{-9}
$$

where

$$
\begin{aligned}
& R_{f}(t) \text { - resuspension factor evaluated at time } t, m^{-1} \\
& t \text { - time in days since initial deposition. }
\end{aligned}
$$


The amount of material inhaled by an individual in a time period, Trm, following initial deposition is calculated from the ground contamination level evaluated at the end of plume passage, $G_{j j}\left(T_{r}\right)$. This ground contamination level is calculated for parent radionuclide $i$ and daughter radionuclide $k$ by

$$
G_{i j \Theta}\left(T_{r}\right)=G_{i j \Theta}(0) e^{-\lambda_{i} T_{r}}
$$

and

$$
\begin{aligned}
G_{k j \Theta}\left(T_{r}\right)= & G_{k j \Theta}(0) e^{-\lambda_{k} T_{r}+} \\
& \frac{G_{i j \Theta}(0) f_{i k} \lambda_{k}}{\lambda_{k}-\lambda_{i}}\left(e^{\left.-\lambda_{j} T_{r}-e^{-\lambda_{k} T_{r}}\right)}\right.
\end{aligned}
$$

where

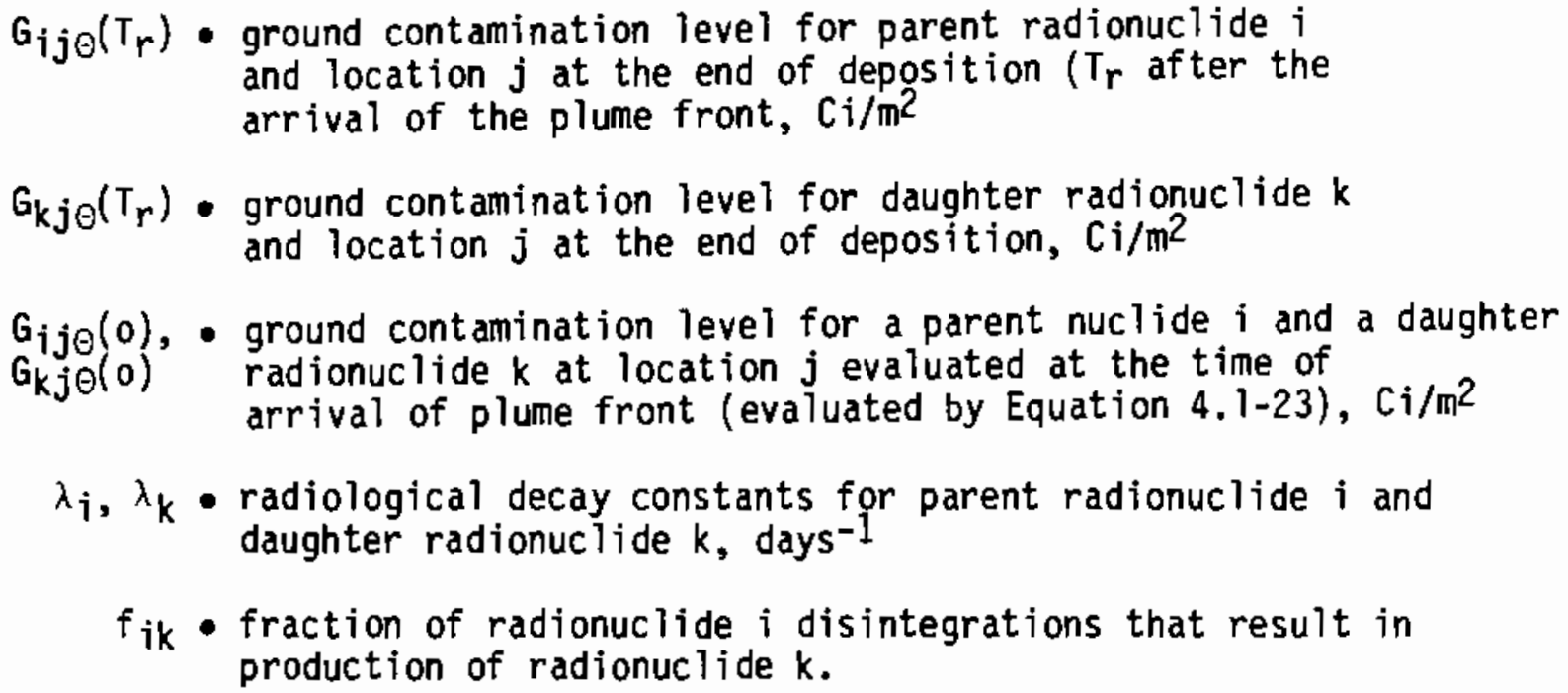

The amount inhaled is calculated using the resuspension factor of Equation 5.4-1 and the initial ground contamination levels of Equations 5.4-2 and 5.4-3 as follows:

$$
Q_{r i}\left(T_{r m}\right)=B_{r} \quad \int_{0}^{T_{r m}} R_{r}(t) G_{i j}\left(T_{r}\right) e^{-\lambda_{j} T} d t
$$

and

$$
\begin{aligned}
Q_{r k}\left(T_{r m}\right) & =B_{r} \quad \int_{0}^{T_{r m}} R_{f}(t) G_{k j}\left(T_{r}\right) e^{-\lambda_{k} t} d t \\
& +B_{r} \int_{0}^{T_{r m}} \frac{R_{f}(t) G_{j j}\left(T_{r}\right) f_{j k} \lambda_{k}}{\lambda_{k}-\lambda_{j}}\left(e^{-\lambda_{j} t}-e^{k t}\right)^{\lambda_{d} t}
\end{aligned}
$$


where

$Q_{r i}\left(T_{r m}\right) \cdot$ total activity of parent radionuclide $i$ inhaled during the period $\mathrm{T}_{\mathrm{rm}}$ due to resuspension, $\mathrm{Ci}$

$Q_{r k}\left(T_{r m}\right) \cdot$ total activity of daughter radionuclide $k$ inhaled during the period $\mathrm{T}_{\mathrm{rm}}$ due to resuspension, $\mathrm{Ci}$

$T_{r m}$ - time period in days after deposition for calculation of resuspension

$\mathrm{B}_{\mathrm{r}}$ - ventilation rate for an individual, $\mathrm{m}^{3} /$ day.

The above equations can be partially integrated to give the expressions below. The remaining integrals can be precalculated for selected time periods to reduce computing time.

$$
\begin{aligned}
Q_{r i}\left(T_{r m}\right) & =B_{r} G_{i j}\left(T_{r}\right) \quad\left[10^{-9}\left(\frac{1-e^{-\lambda_{j} T_{r m}}}{\lambda_{i}}\right)\right. \\
& \left.+10^{-4} \int_{0}^{T_{r m}} e^{-\left(\lambda_{j} t+0.15 \sqrt{t}\right)} d t\right]
\end{aligned}
$$

and

$$
\begin{aligned}
Q_{k 1}\left(T_{r m}\right) & =B_{r} G_{k j}\left(T_{r}\right)\left[10^{-9}\left(\frac{1-e^{-\lambda_{k} T_{r m}}}{\lambda_{k}}\right)\right. \\
& \left.+10^{-4} \int_{0}^{T_{r m}} e^{-\left(\lambda_{k} t+0.15 \sqrt{t}\right)} d t\right] \\
& +\frac{B_{r} G_{i j}\left(T_{r}\right) f_{j k} \lambda_{k}}{\lambda_{k}-\lambda_{j}}\left\{\left[\frac { 1 0 ^ { - 9 } } { \lambda _ { j } } \left(1-e^{\left.-\lambda_{j} T_{r m}\right)}\right.\right.\right. \\
& \left.+10^{-4} \int_{0}^{T_{r m}} e^{-\left(\lambda_{j} t+0.15 \sqrt{t}\right)} d t\right] \\
& -\left[\frac{10^{-9}}{\lambda_{k}}\left(1-e^{-\lambda_{k} T_{r m}}+10^{-4} \int_{0}^{T_{r m}} e^{-\left(\lambda_{k} t+0.15 \sqrt{t}\right)} d t\right]\right\}
\end{aligned}
$$




\subsection{INTAKE THROUGH INGESTION OF CROPS}

Both airborne and waterborne releases can contaminate crops and be ingested with them by humans. Airborne activity may settle on plants or soil as a result of dry and wet atmospheric deposition processes, as described in Sections 4.1.5 and 4.1.6. Waterborne activity may reach food crops through irrigation with contaminated water. The general model for calculating food crop contamination as a function of time is illustrated in Figure 5.5-1. For accidents occurring before the plant emerges from the soil, contamination will only be deposited on the soil. After the plant has emerged, it will receive

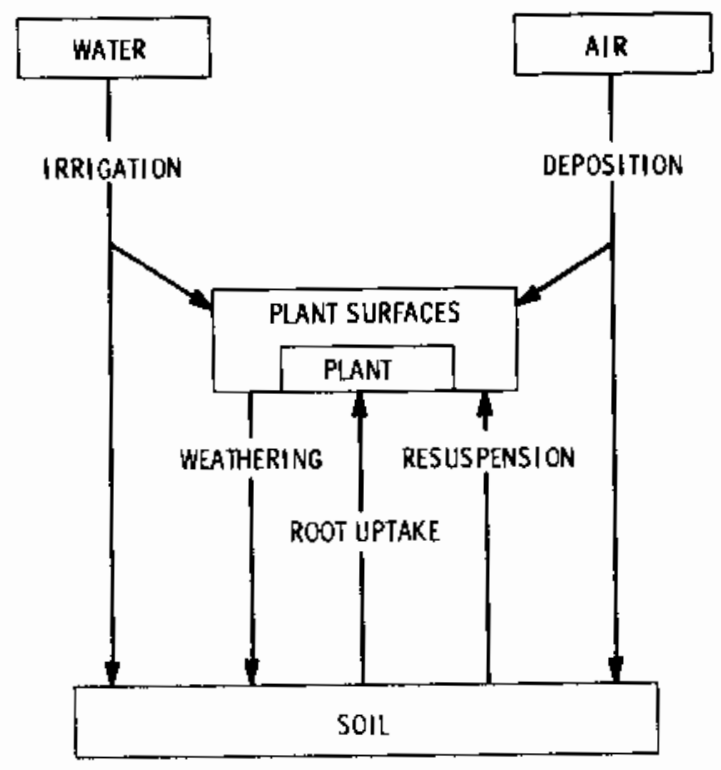

FIGURE 5.5-1. Food Crop Pathway Diagram

direct deposition from the air and from overhead irrigation. When crops are irrigated by canals, contaminants are only deposited on the soil.

The initial retention on plant surfaces is assumed to be a constant fraction of deposition. Transfer from the plant foilage to the soil by weathering is described by a constant weathering half-time of 14 days. Transfer from soil to the plant occurs by two routes: redeposition of resuspended particles and root uptake. These routes are particularly significant when deposition occurs before plant emergence. Activity in the soil can be a potential source of exposure for as long as the land is used for crop production or until the radionuclides decay away. Therefore, the soil pathway is considered a chronic source for subsequent years.

The important parameter in calculating human consumption by food crop pathways is the radionuclide concentrations in edible portions of the plant at the time of harvest. In the models described below, the contribution to plant concentrations by the several modes indicated in Figure 5.5-1 are considered 
separately when possible. The independent transfer paths are characterized as follows:

- air deposition onto plant surfaces; weathering from plant

- air deposition onto soil; resuspension and deposition onto plant surfaces; weathering from plant

- air deposition onto soil; root uptake by plant

- irrigation deposition onto plant surfaces; weathering from plant

- irrigation deposition onto soil; resuspension to plant surfaces; weathering from plant

- irrigation deposition onto soil; root uptake by plant.

Because resuspension and root uptake remove only a small fraction of the soil concentration, the soil concentration is assumed to be constant except for radiological decay.

The following sections contain equations for calculation of these items:

- initial plant and soil concentration from air deposition (5.5.1)

- initial plant and soil concentration fron irrigation deposition (5.5.2)

- resuspension to plant surfaces (5.5.3)

- weathering from plant surfaces $(5.5 .4)$

- root uptake to edible parts of the plant (5.5.5)

- consumption after harvest (5.5.6).

\subsubsection{Air Deposition Model}

In the air deposition pathway model, the initial ground concentration is used to estimate the starting soil concentration and plant surface concentration. The ground concentration for a nuclide $i$ in spatial interval $j$ is calculated at the time of the arrival of the plume front as $G_{i j}(0)$ by Equation 4.1-23. The concentration at the end of plume passage (as given by Equations 5.4-2 and 5.4-3) is used as the starting point for the crop pathway calculations. Initial deposition results in a fraction, $R_{p}$, of activity reaching plant surfaces (if plants have emerged from the soil by the time of the accident). The plant and soil concentrations due to initial deposition from the air pathway are given by

$$
C_{p}^{a j}(0)=R_{p}^{i} T_{p}^{j} G_{i j}\left(T_{r}\right) / Y_{p}
$$


and

$$
C_{s}^{a \dot{\top}}(0)=G_{i j}\left(T_{r}\right) / S_{m}
$$

where

$$
\begin{aligned}
& \begin{array}{l}
c_{p}^{a i}(0) \text { - initial plant concentration for plant type } p \text { and radionuclide } i \\
\text { from air deposition, } C i / k g
\end{array} \\
& C_{S}^{a}(0) \text { - initial soil concentration from air deposition for radionuclide } i \text {, }
\end{aligned}
$$

The crop yield factors, $Y_{p}$, represent the production rate for edible parts of the plant.

The fraction of radionuclide $i$ actually reaching the ground is $1-R_{R}$. However, for purposes of ground concentration estimation, all material is assumed to reach the ground in a short time because of the relatively short weathering half-time of 14 days assumed for transfer from plant surfaces to soil (see Section 5.5.4).

\subsubsection{Irrigation Deposition Models}

The contributions to initial concentrations of radionuclides in plants and soil from irrigation deposition are calculated from the average water concentration, $\bar{C}_{w i j}$, as given by Equations $4.2-2$ and $4.2-3 . \bar{C}_{w i j}$ is the average water concentration for nuclide $i$ over the period, $T_{\text {waj }}$, during which contamination persists in the water supply as measured at the water intake plant $j$. Two models are used to describe application of contaminated irrigation water to crops. The first model assumes that the contamination period, $T_{\text {waj }}$, is short, so that application is essentially an acute deposition at time zero. Release of activity to a fast-moving river would be an acute contamination case. The other model assumes that $T_{w a j}$ is long, so that application is essentially chronic and extends from time zero until the end of crop production for the first year after the accident. Release to a lake or reservoir would be a chronic contamination case. 
The water intake plant may purify and partially remove some radionuclide activity. The activity concentration of each radionuclide present after purification is given by

$$
A_{w i}(0)=\bar{C}_{w i j} \cdot K_{w i j}
$$

where

$A_{w i}(0)$ average water concentration of radionuclide $i$ after purification at the water intake $\mathrm{plant}, \mathrm{Ci} / \mathrm{m}^{3}$

$K_{w i j}$ - purification factor for radionuclide $i$ at water intake plant $j$

$\bar{C}_{W i j}$ - average water concentration over the period $T_{w a j}$ for nuclide $i$ supplied to water plant $\mathrm{j}, \mathrm{Ci} / \mathrm{m}^{3}$.

The average concentration reaching the irrigated fields is calculated from the concentration leaving the intake plant corrected for decay in transit to the fields. For parent radionuclide $i$ and daughter radionuclide $k$, the average concentrations are

$$
A_{w i}\left(T_{h j}\right)=A_{w i}(0) e^{-\lambda i T_{h j}}
$$

and

$$
\begin{aligned}
A_{w k}\left(T_{h j}\right) & =A_{w k}(0) e^{-\lambda k T_{h j}} \\
& +\frac{A_{w j}(0) f_{i k} \lambda_{k}}{\lambda_{k}-\lambda_{j}}\left(e^{-\lambda i T_{h j}}-e^{-\lambda k T_{h j}}\right)
\end{aligned}
$$

where

$A_{w i}\left(T_{h j}\right)$, average water concentration of parent radionuclide $i$ or $A_{w k}\left(T_{h j}\right)$ daughter radionuclide $k$ for the period of irrigation with contaminated water, $\mathrm{Ci} / \mathrm{m}^{3}$

$\lambda_{i}, \lambda_{k} \cdot$ radiological decay constant for parent radionuclide $i$ and daughter radionuclide $k$, days ${ }^{-1}$

$f_{i k}$ - fraction of radionuclide $i$ disintegrations that result in production of radionuclide $k$ 
$T_{h j}$ - holdup time for transit from the water intake plant $j$

to the location of irrigation, days.

The deposition to plant surfaces and soil from irrigation for the acute deposition model is given by

and

$$
C_{p a}^{w i}(0)=R_{p}^{i} T_{p}^{i} A_{w i}\left(T_{h j}\right) T_{w a j} E_{w} / Y_{p}
$$

$$
C_{s a}^{w i}(0)=A_{w i}\left(T_{h j}\right) T_{w a j} E_{w} / S_{m}
$$

where

$$
\begin{aligned}
& C_{p a}^{w i}(0) \text { - initial concentration for radionuclide } i \text { (parent } \\
& \text { or daughter) from acute irrigation, } \mathrm{C} i / \mathrm{kg}
\end{aligned}
$$

$E_{w}$ - usage rate for contaminated irrigation water, $m^{3} / d a y / m^{2}$.

Other terms are as defined above.

When irrigation water is contaminated over a prolonged period (several months), the chronic model is used to estimate food crop contamination. The irrigation water is assumed to have a constant radionuclide concentration over the irrigation period. Deposition to plants and soil is at a constant rate; radioactive decay and daughter buildup is included in the average water concentration term $A_{w i}\left(T_{h j}\right)$. The average deposition rates to $p$ lant and soil surfaces for any radionuclide $i$ are given by

$$
R_{p}^{w i}=A_{w j}\left\langle T_{h j}\right) R_{p}^{i} T_{p}^{i} E_{w} / Y_{p}
$$

and

$$
R_{s}^{w i}=A_{w i}\left(T_{h j}\right) E_{w} / S_{m}
$$

where

$R_{p}^{w i}$ - constant deposition rate to plants for radionuclide $i$ activity from irrigation water, $\mathrm{Ci} / \mathrm{day} / \mathrm{kg}$

$\mathrm{R}_{\mathrm{s}} \mathrm{i}$ - constant deposition rate to soil for radionuclide $i$ activity from irrigation water, $\mathrm{Ci} / \mathrm{day} / \mathrm{kg}$.

other terms are as previously defined. 


\subsubsection{Resuspension and Deposition to Plant Surfaces}

Transfer from soil to plant surfaces is considered for the period between initial deposition and harvest. Resuspension is modeled using Anspaugh's (1975) expression for the resuspension factor, as given in Equation 5.4-1. Using this expression, the air concentration above the contaminated soil is given by

$$
C_{r}^{i}(t)=\left(10^{-4} e^{-0.15 \sqrt{t}}+10^{-9}\right) C_{s}^{i}(t) S_{m}
$$

where

$$
\begin{aligned}
& C_{r} \text { - air concentration for radionuclide } i \text { (parent or daughter) due to } \\
& \text { resuspension at a time } t \text { after intitial deposition, } \mathrm{C} i / \mathrm{m}^{3} \\
& C_{s}(t) \text { - concentration of radionuclide } i \text { in the soil at time } t, \mathrm{C} i / \mathrm{kg} \text {. } \\
& S_{m} \text { is as previously defined. }
\end{aligned}
$$

The soil concentration from acute depositions is given below for parent radionuclide $i$ and daughter radionuclide $k$ :

$$
c_{s}^{j}(t)=c_{s}^{i}(0) e^{-\lambda i t}
$$

and

$$
c_{s}^{k}(t)=c_{s}^{k}(0) e^{-\lambda_{k} t}+\frac{f_{i k^{\lambda}} c_{s}^{i}(0)}{\lambda_{k}-\lambda_{j}}\left(e^{-\lambda_{j} t}-e^{-\lambda k t}\right)
$$

where

$$
\begin{aligned}
& c_{S}^{i}(t) \text {, - soil concentration of parent radionuclide } i \text { or daughter } \\
& C_{S}^{k}(t) \text { radionuclide } k \text { at time } t, C_{i} / \mathrm{kg} \text {. For air deposition, } C_{s}^{j} \\
& \text { represents Cgi (Equation 5.5-2); for acute irrigation } \\
& \text { deposition, Cs represents Cya (Equation 5.5-7) } \\
& t \text { - time in days since initial deposition. } \\
& \text { Other terms are as previously defined. }
\end{aligned}
$$

The soil concentrations are given as a function of time for chronic deposition by the following equations for parent radionuclide $i$ and daughter radionuclide $k$ : 


$$
C_{s c}^{w i}(t)=\frac{R_{s}^{w i}}{\lambda_{i}}\left(1-e^{-\lambda_{i} t}\right)
$$

and

$$
\begin{aligned}
C_{s c}^{w k}(t) & =\frac{R_{s}^{w k}}{\lambda_{k}}\left(1-e^{\lambda_{k} t}\right)+\frac{R_{s}^{w i} f_{i k}}{\lambda_{j}}\left(1-e^{-\lambda} k^{t}\right) \\
& +\frac{\lambda_{k} R_{s}^{w i} f_{i k}}{\lambda_{i}\left(\lambda_{k}-\lambda_{i}\right)}\left(e^{-\lambda k t}-e^{-\lambda_{j} t}\right)
\end{aligned}
$$

where

$$
\begin{aligned}
& c_{S c}^{w i}(t) \text { - soil concentration of parent radionuclide } i \text { at } t \text { ime } t \\
& \text { from chronic irrigation, } \mathrm{Ci} / \mathrm{kg} \\
& \mathrm{C}_{\mathrm{SC}}^{\mathrm{Wk}}(\mathrm{t}) \text { - soil concentration of daughter radionuclide } k \text { at time } t \\
& \text { from chronic irrigation, } \mathrm{Ci} / \mathrm{kg} \text {. }
\end{aligned}
$$

0ther terms are as previously defined. In Equations 5.5-11 through 5.5-14, removal from the soil by downward movement (leaching) is not considered. To include loss from soil described by a removal half-time, the radiological decay constants $\lambda_{j}$ and $\lambda_{k}$ must be replaced by an effective rate constant (the sum of the radiological decay constant and the removal rate constant).

The rate of deposition to edible parts of the plant is assumed to be constant as evaluated at the endpoint of plant growth, $T_{m}$.

$$
R_{p}^{r i}=\frac{R_{p}^{j} T_{p}^{i} v_{d}^{i}}{Y_{p}} C_{r}^{i}\left(T_{m}\right)
$$

where

$$
\begin{aligned}
& \mathrm{R}_{\mathrm{p}}^{\mathrm{r}} \text { - constant average rate of deposition to } \mathrm{plants} \text { for radionuclide } \\
& \text { i, } \mathrm{Ci} / \mathrm{kg} / \text { day } \\
& v_{d}^{i} \text { - air deposition velocity for radionuclide } i, m / \text { day } \\
& c_{r}^{i}\left(T_{m}\right) \text { - air concentration due to resuspension and redeposition for }
\end{aligned}
$$


Other terms are as previous $1 y$ defined.

The deposition rate is evaluated at the endpoint of the growing period because the short weathering half-time (14 days) is the controlling factor in determining the plant concentration at harvest.

\subsubsection{Weathering from Plant Surfaces}

Material deposited on plant surfaces due to initial air or irrigation deposition or from resuspension is assumed to be removed from plant surfaces by weathering with a 14-day half-time. Plant concentrations after initial air deposition and acute irrigation deposition are described by simple exponential removal, as follows:

$$
C_{p}^{i}(t)=C_{p}^{i}(0) e^{-\lambda} E_{1} t
$$

and

$$
\begin{aligned}
C_{p}^{k}(t) & =C_{p}^{k}(0) e^{-\lambda E k t} \\
& +\frac{C_{D}^{i}(0) f_{i k} \lambda_{k}}{\lambda_{E k}-\lambda_{E i}}\left(e^{-\lambda_{E} t}-e^{-\lambda_{E k} t}\right)
\end{aligned}
$$

where

$c_{p}^{j}(t)$ - concentration on $p$ lant at time $t$ for parent radionuclide $i$,

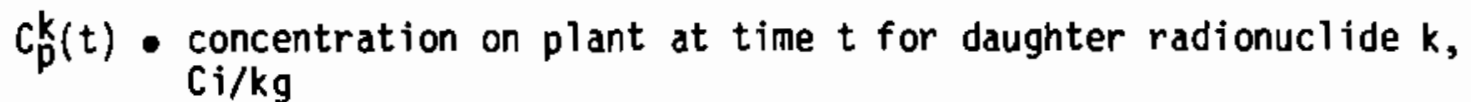

$\lambda_{E i}, \lambda_{E k}$ - effective half-time for parent radionuclide $i$ and daughter radionuclide $\mathbf{k}$ on the $\mathbf{p l a n t .}$

$\lambda_{E i}=\lambda_{p}+\lambda_{i}$

$\lambda_{E k}=\lambda_{p}+\lambda_{k}$

$\lambda_{p}$ - removal time constant for weathering at a 14-day half-time $\lambda_{p}=4.95 \times 10^{-2}$ days $^{-1}$.

The concentration parameter $C_{p}^{j}$ represents $C_{\beta}^{i}$ (Equation 5.5-1) for air deposition and C $\mathrm{pl}_{\mathrm{a}}$ (Equations 5.5-6) for acute irrigation deposition. 
When chronic (long-term) irrigation or resuspension from soil are considered, the weathering equation is applied continuously to estimate the plant concentration as a function of time. The plant concentrations for parent radionuclide $i$ and daughter radionuclide $k$ are given by

$$
C_{p}^{j}(t)=\frac{R^{i}}{{ }{ }_{E i}}\left(1-e^{-\lambda} E_{i} t\right)
$$

and

$$
\begin{aligned}
C_{p}^{k}(t) & =\frac{R^{k}}{\lambda_{E k}}\left(1-e^{-\lambda} E k t\right)+\frac{f_{i k} \lambda_{k} R^{i}}{\lambda_{E i}}\left[\left(\frac{1-e^{-\lambda} E k t}{\lambda_{E k}}\right)\right. \\
& \left.+\frac{e^{-\lambda} E k t-e^{-\lambda} E i t}{\lambda_{E k}-\lambda_{E i}}\right]
\end{aligned}
$$

where

$$
\begin{aligned}
& \mathrm{R}^{\mathrm{i}}, \mathrm{R}^{\mathrm{k}} \text { - constant deposition rate to } \mathrm{plants} \text { for parent radionuclide } i \\
& \text { and daughter radionuclide } \mathrm{k}, \mathrm{C} i / \text { day/kg } \\
& t \text { - time since plant emergence or start of contamination period } \\
& \text { (whichever is later), days. }
\end{aligned}
$$

other terms are as previously defined.

The deposition rate parameters $R^{i}$ represent $R^{\prime}{ }^{i}$ (Equations 5.5-8) for chronic irrigation deposition and $R_{p}^{i}$ (Equation 5.5-15) for resuspension from soil. The $\mathrm{plant}$ concentration parameter, $\mathrm{C}_{\mathrm{p}}^{\mathrm{d}}$, represents $\mathrm{C}_{\mathrm{pC}}^{\mathrm{W}}$ for chronic irrigation and $\mathrm{C}_{\mathrm{p}}^{\mathrm{i}}$ for resuspension from soil.

\subsubsection{Plant Uptake of Radionuclides Through Roots}

The root uptake pathway is modeled by use of transfer factors giving plant concentration per unit soil concentration. Use of these factors assumes that uptake by plants is rapid and elimination from plants is slow. The contribution to plant concentration at a time $t$ is given by

$$
C_{p}^{u i}(t)=B_{p}^{i} C_{s}^{i}(t)
$$


where

$c_{p} i(t)$ - the plant concentration for radionuclide $i$ (parent or daughter) at time $t$ due to uptake via $\mathrm{plant}$ roots, $\mathrm{Ci} / \mathrm{kg}$

$B_{p}^{i}$ - the plant transfer factor for plant type $p$ and radionuclide $i$, $\mathrm{Ci} / \mathrm{kg}$ plant per $\mathrm{Ci} / \mathrm{kg}$ soil

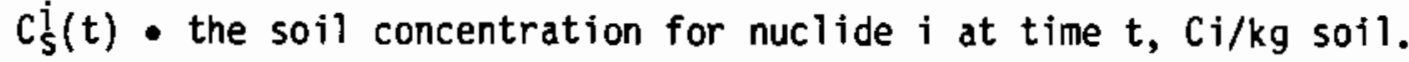

The soil concentration parameter $C_{S}^{i}$ represents soil concentration $C_{S}^{i}$ or Cwi (Equations 5.5-11 and 5.5-12) for acute depositions and Cwi (Equations 5.5-13 and 5.5-14) for chronic irrigation deposition.

\subsubsection{Consumption after Harvest}

Concentration of contaminants in plants at the time of harvest is the sum of the plant concentration from each pathway as defined in the previous sections. The total plant concentration at harvest $c^{f i}(0)$ is the sum of the following:

$C_{p}^{a i}(t)$ - initial deposition from air to plant surfaces (Equations 5.5-16, $5.5-17)$

$c_{p}^{i}(t)$ - resuspension from soi] after air or irrigation deposition (Equations 5.5-20, 5.5-21)

$C_{p a}(t)$ - acute irrigation deposition to plant surfaces (Equations 5.5-16, 5.5-17)

$\mathrm{Cw}_{\mathrm{pc}} \mathrm{i}(\mathrm{t})$ - chronic irrigation deposition to plant surfaces (Equations $5.5-20,5.5-21)$

$\mathrm{Cu}_{\mathrm{p}}^{\mathrm{i}}(\mathrm{t})$ - root uptake by plants (Equations $5.5-22$ ).

Because only one type of irrigation is considered for a given location, only one of the concentration parameters $c p_{a}(t)$ or $C b d(t)$ is required. As mentioned previously, acute irrigation refers to situations in which the irrigation water is contaminated for a short period of time (days), and chronic irrigation is irrigation with contaminated water for much of the plant growing season (weeks to months).

The concentration in each plant type at harvest is used to estimate the uptake by individuals in the spatial interval and by the offsite population served by the crop production area. The concentration of parent radionuclide $i$ in plant type $p$ consumed by an individual is given by

$$
C_{p}^{T i}\left(T_{p h}\right)=F_{p j} C_{p}^{T i}(0) e^{-\lambda i T p h}
$$


where

$C_{p}^{T} i\left(T_{p h}\right)$ - concentration of parent radionuclide $i$ in consumed plant type, $p$, at time of consumption, $\mathrm{C} i / \mathrm{kg}$

$C_{p}^{T i}(0)$ - total plant concentration for radionuclide $i$ in $p l a n t$ type $p$, at time of harvest, $\mathrm{Ci} / \mathrm{kg}$

$F_{p i}$ - fraction of radionuclide $i$ remaining on plant type $p$ after processing

$T_{p h}$ - holdup time between harvest and consumption for plant type $p$, days

$\lambda_{j}$ - radiological decay constant for radionuclide $i$, days ${ }^{-1}$.

The concentration of daughter radionuclide $k$ in consumed $p l a n t$ types is given by

$$
\begin{aligned}
C_{p}^{T k}\left(T_{p h}\right) & =F_{p k} C_{p}^{T k}(0) e^{-\lambda} k^{T} p h \\
& +\frac{F_{p k} C_{p}^{T i}(0) f_{i k} \lambda_{k}}{\lambda_{k}-\lambda_{j}}\left(e^{-\lambda_{j} T p h}-e^{-\lambda} k^{T} p h\right)
\end{aligned}
$$

where $C^{T k}\left(T_{p h}\right)$ - concentration of daughter radionuclide $k$ in consumed
plant type $p$ at time of consumption, $\mathrm{C} i / \mathrm{kg}$

$c^{T k}(0)$ - total plant concentration for radionuclide $k$ in plant type $p$ at time of harvest, $\mathrm{Ci} / \mathrm{kg}$

$\lambda_{k}$ - radiological decay constant for radionuclide $k$, days -1

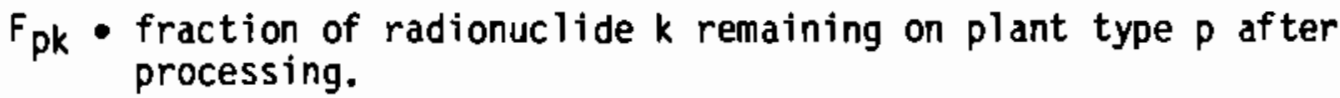

Note that the contribution to radionuclide $k$ from radionuclide $i$ is modified by the food processing factor for radionuclide $k, F_{p k}$. This results from assuming that food processing renoval occurs near the time of consumption.

The total activity of radionuclide $i$ consumed by an individual from one crop is given by

$$
Q_{p j \ell}^{i}=C_{p}^{T i}(T p h) U p \ell
$$


where

$$
\begin{aligned}
& Q_{p j \ell}^{i} \text { - activity of radionuclide } i \text { consumed from } p \text { lant type } p \text { grown } \\
& \text { in interval } j \text { for current crop harvest period } \ell, C i / \text { person) } \\
& U_{p_{\ell}} \text { - average consumption rate by individuals for plant type } p \\
& \text { for each crop, } \mathrm{kg} / \mathrm{crop} / \mathrm{person} \\
& U_{p l}=U_{p} / N_{p c} \\
& U_{p} \text { - annual consumption rate by individuals for plant type } p \text {, } \\
& \mathrm{kg} / \mathrm{yr} / \mathrm{person} \\
& N_{p c} \text { - number of successive crops per year for crop } p \text {. }
\end{aligned}
$$

The total consumption in the first year for food crop $p$ is the sum of the consumptions for each crop harvest

$$
Q_{p}^{i}=\sum_{j=1}^{N} Q_{p j}^{i}
$$

where

$$
\begin{aligned}
& Q_{p j}^{j} \text { - activity of radionuclide } i \text { consumed from } p l a n t \text { type } p \\
& \text { in interval } j \text { for the one-year period, } \mathrm{C} i / \text { person/yr. }
\end{aligned}
$$

When more food is produced in a spatial interval than can be consumed locally, it is assumed that the excess is transported for consumption elsewhere. The transported food is used to estimate population doses outside the current spatial interval. The anount of plant type p produced in a spatial interval $j$ is given by

$$
P_{p j}=A_{f j p} P_{P}
$$

where

$P_{p j}$ - total production of food crop $p$ in spatial interval $j, \mathrm{~kg} / \mathrm{yr}$

$A_{f j p}-$ area of spatial interval $j$ used for production of food
crop $p, m^{2}$

$$
P_{p} \text { - production rate of food crop } p, \mathrm{~kg} / \mathrm{m}^{2} \mathrm{yr} \text {. }
$$

The amount consumed in spatial interval $j$ per year is calculated as

$$
H_{p j}=P_{j} U_{p}
$$


where

$$
\begin{aligned}
& H_{p j} \text { - amount of food crop p consumed in spatial interval } \mathrm{j}, \mathrm{kg} / \mathrm{yr} \\
& \mathrm{P}_{\mathrm{j}} \text { - number of persons in spatial interval } \mathrm{j} \text {. }
\end{aligned}
$$

The ratio of total production to total consumption is used to determine distribution of plant type $p$. When the ratio is equal to one, the production equals consumption and all produce is assumed to be consumed within the spatial interval. When the ratio is greater than one, excess food has been produced. This excess is transported outside the spatial interval. The number of people served at the annual consumption rate $U_{p}$ is given by

$$
P_{p o j}=\frac{\left(P_{p j}-H_{p j}\right)}{U_{p}}
$$

where $P_{p o j}$ - number of persons served by excess food crop p grown in spatial interval $\mathrm{j}$.

0ther terms are as previously defined.

When the production/consumption ratio is less than one, consumption exceeds production. In this case it is assumed that uncontaminated produce is shipped into the spatial interval to make up the shortage. The number of people served by the contaminated local produce is calculated as

$$
P_{p j \ell}=P_{j} \frac{P_{p j}}{H_{p j}}
$$
where $P_{p_{\ell}}$ - number of persons in interval $\ell$ served by local production of
food crop $\mathrm{p}$.

\subsection{INGESTION OF RELEASED CONTAMINATION IN ANIMAL PRODUCTS}

Airborne and waterborne releases may contaninate animal produce and thus enter the food chain pathway to man. Animals become contaninated by ingesting contaminated feed crops, forage and/or animal drinking water. Models for these pathways are presented in the following sections. The drinking water pathway (Section 5.6.1) is only considered for liquid releases. The other two pathways (pasture grass and feed crops, Sections 5.6.2 and 5.6.3) are considered for both air and liquid releases. Section 5.6.4 gives a summary of contributions for all animal product pathways. The general model used for calculation of animal product contamination is illustrated in Figure $5.6-1$. 


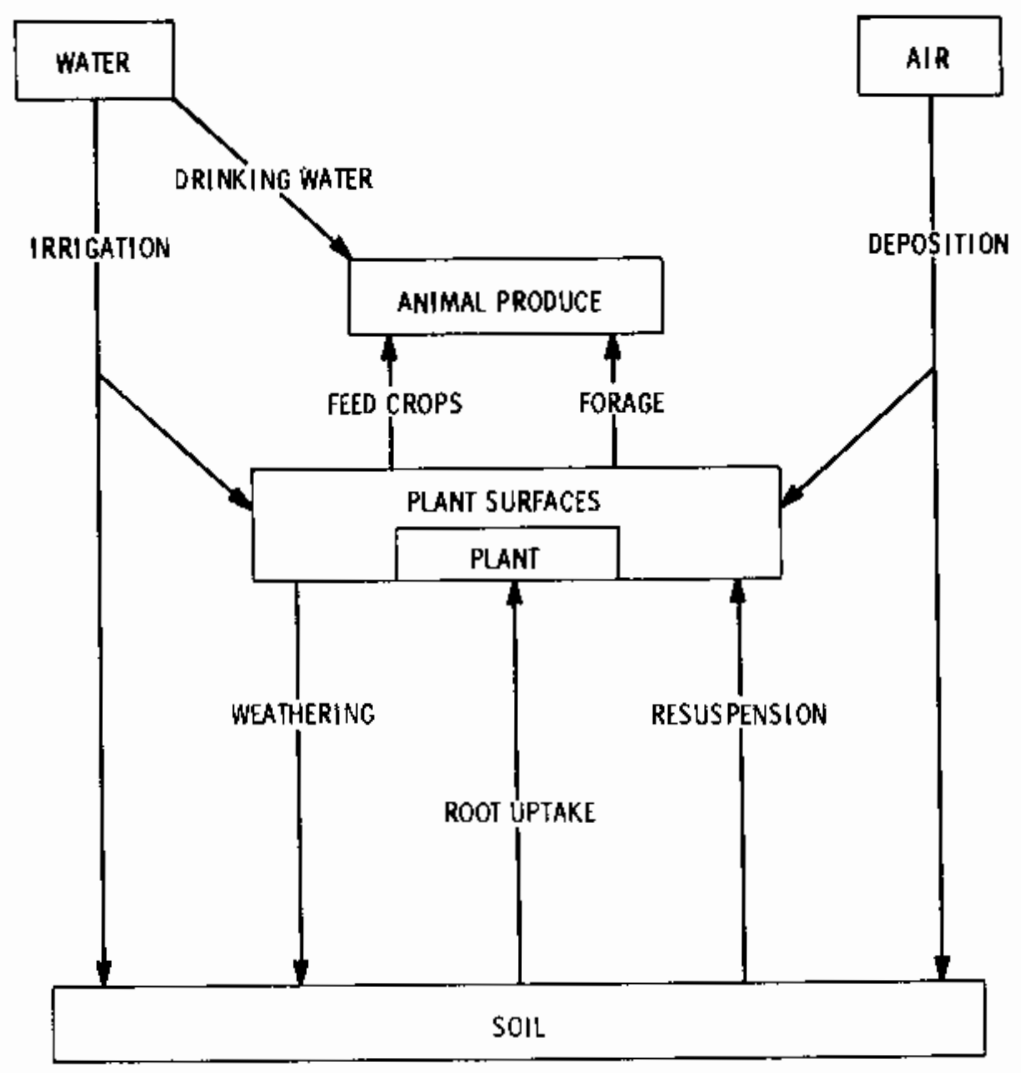

FIGURE 5.6-1. Routes by which Animal Products are Contaminated

Two human consumption situations are considered in these models: consumption by an individual and consumption by the population. The animal produce/ human consumption pathway is complicated by the transport of animal feed crops to areas away from where it is grown. The consumption of contaminated animal products by an individual living in the spatial intervat in which the contaminated animal produce is grown (using contaminated feed from the same spatial interval) is assumed to be the highest consumption situation. This consumption is used to estimate the need for remedial actions associated with the particular spatial interval. Consumption by the population exposed to the entire mass of contaminated food products is used to estimate potential health effects.

\subsubsection{Animal Ingestion of Water}

Contamination of animal products may occur when animal drinking water is taken from a contaminated supply. The concentration in the animal product as a function of time after initial contamination begins is calculated as 


$$
c_{a p}^{d i}(t)=\frac{B_{a}^{j} U_{a}^{w} C_{w i j}}{\lambda_{a i}}\left[1-e^{-\lambda_{a i} t}\right]
$$

and

$$
\begin{aligned}
C_{a p}^{d k}(t) & =\frac{\beta_{a}^{k} U_{a}^{w} C_{w k j}}{\lambda_{a}}\left[1-e^{-\lambda a k t}\right] \\
& +\frac{\beta_{a}^{i} U_{a} f_{i k} \lambda_{k} C_{w i j}}{\lambda_{a j}}\left[\frac{1-e^{-\lambda a k}}{\lambda_{a k}}+\frac{e^{-\lambda_{a j} t} \cdot-e^{-\lambda_{a k} t}}{\lambda_{a j}-\lambda_{a k}}\right]
\end{aligned}
$$

where

$$
\begin{aligned}
& c_{a p}^{d i}(t) \text { - concentration of parent radionuclide } i \text { in animal product } p \\
& \text { from the animal drinking water path at time } t, \mathrm{Ci} / \mathrm{kg} \\
& C_{\mathrm{ap}}^{\mathrm{dk}}(t) \text { - concentration of daughter radionuclide } k \text { in animal product } p \\
& \text { from the animal drinking water path at time } t, \mathrm{Ci} / \mathrm{kg} \\
& \beta_{\mathrm{a}}^{i}, B_{\mathrm{a}}^{k} \text { - transfer factor from ingestion intake to animal product } \\
& \text { concentration for parent radionuclide } i \text { or daughter radionuclide } k \text {, } \\
& \mathrm{Ci} / \mathrm{kg} \text { per } \mathrm{Ci} \text { ingested } \\
& u_{a}^{W} \text { - water consumption rate for animal, } \mathrm{m}^{3} / \text { day } \\
& \lambda_{\mathrm{a} i}, \lambda_{\mathrm{ak}} \text { - effective removal constant for animal product } \mathrm{p} \text { and parent } \\
& \text { radionuclide } i \text { or daughter radionuclide } k \text {, day }-1 \\
& \lambda_{\mathrm{aj}}=\lambda_{\mathrm{a}}+\lambda_{j} \\
& \lambda_{a k}=\lambda_{a}+\lambda_{k} \\
& \lambda \text { a, } \lambda_{a}^{k} \cdot \text { biological removal constant for animal product } p \text { and } \\
& \text { parent radionuclide } i \text { or daughter radionuclide } k \text {, day- } 1 \\
& \lambda_{j}, \lambda_{k} \text { - radiological decay constant for parent nuclide } i \text { and } \\
& \text { daughter nuclide } k \text {, days }{ }^{-1} \\
& C_{w i j} \text {, average water concentration for parent nuc Tide } i \text { or } \\
& C_{w k j} \text { daughter nuclide } k \text {, during the period of water contamination, } \\
& T_{w a j} \text {, at water uptake location } j, \mathrm{Ci} / \mathrm{m}^{3} \text {. }
\end{aligned}
$$


The steady-state solution to Equation 5.6-1 (i.e., as $t$ becomes large) gives the following expression:

$$
C_{a p}^{d i} \text { (steady-state) }=\frac{B_{a}^{i}}{\lambda_{a i}} U_{a}^{w} C_{w i j}
$$

This equation shows that the animal product bioaccumulation factor for radionuclide $i$ is given by

$$
B_{a}^{i}=\frac{B_{a}^{i}}{\lambda_{a i}}
$$

Applying this result to Equation 5.6-1 and 5.6-2 yields the following expressions:

and

$$
C_{a p}^{d i}(t)=B_{a}^{i} U_{a}^{w} C_{w i j}\left(1-e^{-\lambda_{a} i t}\right)
$$

$$
\begin{aligned}
& C_{a p}^{d k}(t)=B_{a}^{k} U_{a}^{w} C_{w k j}\left(1-e^{-\lambda a k t}\right) \\
& +B_{a}^{i} U_{a}^{W} f_{j k} \lambda_{k} C_{w i j}\left[\frac{1-e^{-\lambda_{a k} t}}{\lambda_{a k}}+\frac{e^{-\lambda} a i t-e^{-\lambda} a k t}{\lambda_{a j}-\lambda_{a k}}\right]
\end{aligned}
$$

where

$$
\begin{aligned}
\mathrm{B}_{\mathrm{a}}^{i}, \mathrm{~B}_{\mathrm{a}}^{k} \text { - bioaccumulation factor for parent radionuclide } \mathrm{i} \text { and } \\
\text { daughter radionuclide } \mathrm{k} \text { for animal product } \mathrm{a}, \mathrm{C} / \mathrm{kg} \\
\text { per } \mathrm{C} i / \text { day ingested. }
\end{aligned}
$$

other terms are as previously defined.

Equations 5.6-5 and 5.6-6 represent the concentrations in animal product from ingestion of contaminated water during the period of water contamination, $T_{\text {waj. At times after }} T_{\text {waj }}$, the concentrations are given by

$$
c_{a p}^{d i}\left(t^{-}\right)=c_{a p}^{d i}\left(T_{w a j}\right) e^{-\lambda_{a i} t^{-}}
$$

and

$$
c_{a p}^{d k}\left(t^{\prime}\right)=c_{a p}^{d k}\left(T_{w a j}\right) e^{-\lambda a k t^{\prime}}
$$




$$
+\frac{f_{i k} \lambda_{k} c_{a p}^{d j}\left(T_{w a j}\right)}{\lambda_{a k}{ }^{-\lambda} a j}\left[e^{-\lambda_{a j} t^{\prime}} \cdot e^{-\lambda_{a k} t^{\prime}}\right]
$$

where

$$
t^{\prime} \text { - time after } T_{w a j} \text {, days. }
$$

The above equations describe concentration in animal products at any time after contamination of the animal drinking water path. Because consumption by humans is assumed to be continuous (i.e., animal products are generated and harvested continuously), it is calculated as the time integral of the animal product concentration. The consumption (based on the time of harvest) is given by

$$
Q_{a p}^{d i}(0)=v_{p} \int_{0}^{t_{d}} c_{a p}^{a i}(t) d t
$$

where

$$
\begin{aligned}
& Q_{a p}(0) \text { - consumption (for animal drinking water path) of nuclide } i \text { from } \\
& \text { animal product } p \text { during one year, based on the time of harvest }
\end{aligned}
$$
$(0), \mathrm{Ci}$

$U_{p}$ - consumption by humans of animal product $p, \mathrm{~kg} /$ day

$t_{d}$ - consumption period, days.

Decay during the period from harvest to consumption is calculated by

$$
Q_{a p}^{d i}\left(T_{p h}\right)=Q_{a p}^{d i}(0) e^{-\lambda^{\top} p h}
$$

and

$$
\begin{aligned}
Q_{a p}^{d k}\left(T_{p h}\right) & =Q_{a p}^{d k}(0) e^{-\lambda_{k} T^{T} p h} \\
& +\frac{f_{j k} \lambda_{k} Q_{a p}^{d i}(0)}{\lambda_{k}-\lambda_{j}}\left[e^{-\lambda_{j} T_{p h}}-e^{-\lambda_{k} T^{T} p h}\right]
\end{aligned}
$$


where

$$
\begin{aligned}
& T_{p h} \text { - average holdup time from harvest to consumption for } \\
& \text { animal product } p \text {,. days. }
\end{aligned}
$$

Evaluation of the integral Equation 5.6-9 is performed by the equation below. It is assumed that the period of contaminated water usage $T_{w a j}$ is less than the consumption period $t_{d}$.

$$
Q_{a p}^{d i}(0)=U_{p}\left[\int_{0}^{T_{w a j}} c_{a p}^{d i}(t) d t+\int_{0}^{t_{d^{-T}} w a j} c_{a p}^{d i}\left(t^{-}\right) d t^{-}\right]
$$

The first integral uses the concentration defined by Equations 5.6-5 and 5.6-6 while the second integral uses the concentration defined by Equations 5.6-7 and 5.6-8. The resulting equations are

$$
\begin{aligned}
Q_{a p}^{d i}(0) & =U_{p} B_{a}^{j} U_{a} C_{w i j}\left[T_{w a j}-\frac{1-e^{-\lambda} a j T_{w a j}}{\lambda_{a j}}\right] \\
& +U_{p} C_{a p}^{d i}\left(T_{w a j}\right)\left[\frac{1-e^{-\lambda} a t_{2}}{\lambda_{a i}}\right]
\end{aligned}
$$

and

$$
\begin{aligned}
Q_{a p}^{d k}(0) & =B_{a}^{k} U_{a} C_{w k j} U_{p}\left[T_{w a j}-\frac{1-e^{-\lambda}{ }^{-\lambda} T_{w a j}}{\lambda_{a k}}\right] \\
& +U_{p} C_{a p}^{d k}\left(T_{w a j}\right)\left[\frac{1-e^{-\lambda} a k^{t} 2}{\lambda_{a k}}\right]
\end{aligned}
$$$$
+B_{a}^{i} U_{a} f_{j k} \lambda_{k} C_{w i j} U_{p}\left[\frac{T_{w a j}}{\lambda_{a k}}-\frac{1-e^{-\lambda} a k T_{w a j}}{\lambda^{2} a k}\right.
$$$$
\left.+\frac{1-e^{-\lambda_{a i} T_{w a j}}}{\lambda_{a j}\left(\lambda_{a i}-\lambda_{a k}\right)}+\frac{1-e^{-\lambda_{a k} T_{w a j}}}{\lambda_{a k}\left(\lambda_{a f}-\lambda_{a k}\right)}\right]
$$$$
+\frac{f_{i k}{ }_{k} C_{a p}^{d i}\left(T_{w a j}\right)_{U p}}{\lambda_{a k}-\lambda_{a j}}\left[\frac{1-e^{-\lambda_{a j} t_{2}}}{\lambda_{a j}}-\frac{1-e^{-\lambda_{a k} t_{2}}}{\lambda_{a k}}\right]
$$ 
where

$t_{2}=t_{d} \cdot T_{\text {waj }}$ and other terms are as previously defined.

Consumption by humans after the first period may be calculated using the above equations and subtracting the results for successive uptake periods.

\subsubsection{Animal Ingestion of Pasture Grass}

Pasture grass may be contaminated by both airborne and waterborne releases. The pathways considered for contamination of grass are initial deposition (air or irrigation), uptake by roots and redeposition of resuspended radionuclides. Removal from grass by weathering is also considered. Models for estimating concentration on grass as a function of time use the initial deposition equations of Sections 5.5.1 and 5.5.2, the weathering model of Section 5.5.4, the resuspension model of Section 5.5 .3 and the root uptake model of Section 5.5.5. The grazing model assumes a mean time of 30 days for animals to graze an area. After 30 days, the animals return to the initial area and begin the second pass over it. Grazing is only considered for the specified portion of the year that pasture grass is available.

The contribution from initial air deposition onto pasture grass is given by Equations 5.5-16 and 5.5-17 for parent radionuclide $i$ and daughter radionuclide $k$, respectively. The concentration on grass from the initial deposition is assumed to be zero after the first grazing period (thirty days). The concentration in the animal product from air deposition is calculated by the following equations for the 30-day grazing period:

$$
C_{p i}^{g}(t)=\frac{\varepsilon_{a}^{i} u_{a}^{g} C_{p}^{a j}(0)}{\lambda_{E j}-\lambda_{a i}}\left(e^{-\lambda_{a i} t}-e^{-\lambda_{E i} t}\right)
$$

and

$$
\begin{aligned}
& C_{p k}^{g}(t)=\beta_{a}^{k} U_{a}^{g}\left\{C_{p}^{a k}(0)\left[\frac{e^{-\lambda} a k^{t}-e^{-\lambda} E k^{t}}{{ }^{\lambda} E k-{ }^{\lambda} a k}\right]\right. \\
& \left.+\frac{C_{p}^{a i}(0) f_{i k} \lambda_{k}}{\left(\lambda_{E k}-\lambda_{E i}\right)}\left[\frac{e^{-\lambda} a k^{t}-e^{-\lambda_{E i} t}}{\lambda_{E k}-\lambda_{a k}}-\frac{e^{-\lambda} a k^{t}-e^{-\lambda} E k^{t}}{{ }^{\lambda} E k-\lambda_{a k}}\right]\right\} \\
& +\frac{{ }^{B} U_{a}^{g} C_{p}^{a i}(0) f_{i k} \lambda_{k}}{{ }^{\lambda_{E K}}-\lambda_{a j}}\left[\frac{e^{-\lambda_{a k}}-e^{-\lambda_{a i} t}}{\lambda_{a i}-\lambda_{a k}}-\frac{e^{-\lambda} a k^{t}-e^{-\lambda} E k^{t}}{\lambda_{E k}-\lambda_{a k}}\right]
\end{aligned}
$$


where

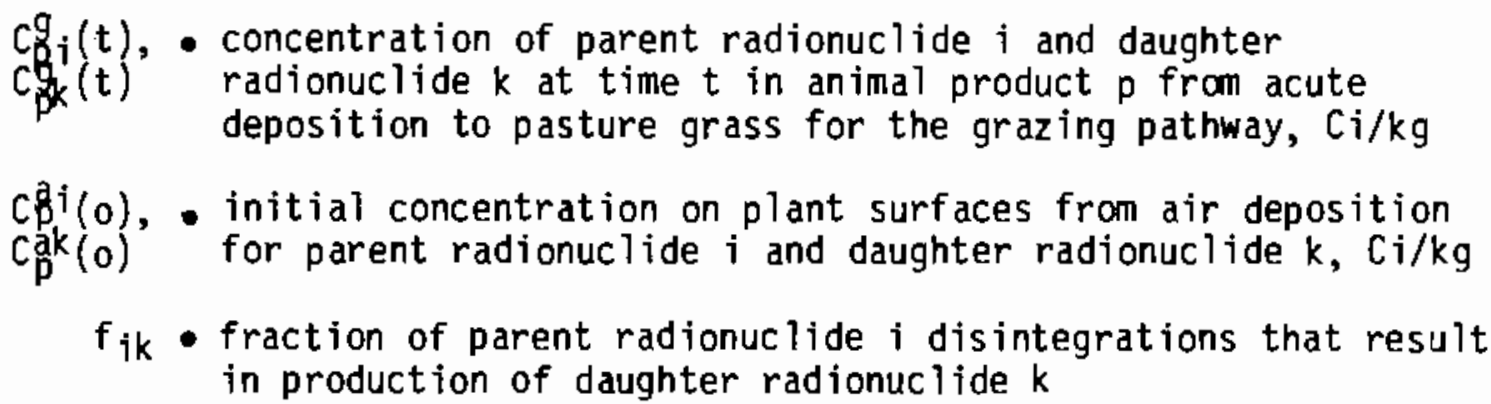

$\lambda_{E j}, \lambda_{E k}$ - effective removal constant for weathering from plants as defined in Section 5.5.4, days $^{-1}$

$\lambda_{a j}, \lambda_{a k}$ - effective removal constant for animal product $p$ as defined in Section 5.6.1, days

$\lambda_{k}$ - radiological decay constant for radionuclide $k$, days ${ }^{-1}$

$B_{a}^{j}, B_{a}^{k}$ - transfer factor from ingestion intake to animal product concentration for parent radionuclide $i$ or daughter radionuclide $k$, $\mathrm{Ci} / \mathrm{kg}$ per $\mathrm{Ci}$ ingested. (Note: This is the transfer factor used to estimate the bioaccumulation factor defined by Equation 5.6-4.)

$\mathrm{U}_{\mathrm{a}}^{\mathrm{g}}$ - animal consumption rate of pasture grass, $\mathrm{kg} / \mathrm{day}$.

The above equations apply for the 30-day grazing period. When deposition occurs before the animals start grazing, the initial deposition concentrations $\mathrm{Ca}_{\mathrm{B}}(0)$ and $\mathrm{C}_{\mathrm{K}}(0)$ must be modified for radioactive decay and weathering from deposition until grazing starts. This decay calculation is represented by Equations 5.5-16 and 5.5-17 of Section 5.5.4.

When initial deposition is from acute irrigation, the above equations are used, but $c_{p} i(0)$ is substituted for $c_{p}^{a}(0)$ and $C_{p a}^{w k}(0)$ for $C_{p}^{a k}(0)$.

The animal product concentration from chronic irrigation is not calculated as a function of time as is done for acute deposition. The required parameter is the total consumption by humans. Because deposition is continuous over the period of contamination and grazing is also continuous, it is assumed that all material deposited will be subject to 30 days of grazing. Therefore, the total amount of material deposited during the grazing period is assumed to be deposited at the start of the grazing period. Note that radioactive decay is already included in the irrigation source terms over the period of water contamination. The initial deposition is calculated for the start of the grazing period as

$$
C_{p}^{w i}(0)=C_{p c}^{w i}(t)+R_{p}^{w i}\left(T_{w a j}-t\right)
$$


where

$\mathrm{C}_{\mathrm{pC}} \mathrm{i}(\mathrm{t})$ - plant concentration of radionuclide $i$ at the start of grazing ( $t$ ) due to chronic irrigation calculated by Equations $5.5-20$ and $5.5-21, \mathrm{Ci} / \mathrm{kg}$

$R_{\mathrm{p}}^{w^{i}}$ - deposition rate to $\mathrm{plants}$ from irrigation for radionuclide $i$ as calculated by Equation $5.5-8, \mathrm{Ci} /$ day $/ \mathrm{kg}$

$T_{\text {waj }}$ - period during which irrigation water is contaminated, days

$t$ - time from start of irrigation until start of grazing, days.

Equation 5.6-17 applies when grazing starts, during irrigation. When grazing starts after irrigation ends, the initial concentration is calculated by Equations 5.5-20 and 5.5-21 evaluated for $t=T_{w a j}$, with the result further decayed and weathered (according to Equations 5.5-16 and 5.5-17) from the end of irrigation until the start of grazing. The calculation may be represented as

$$
C(0)=C_{p C}^{W i}\left(T_{w a j}\right) \text { by } 5.5-20 \text { or } 21
$$

and

$$
C_{p}^{w i}(0)=C\left(t-T_{w a j}\right) \quad \text { by } 5.5-16 \text { or } 17
$$

When irrigation starts after grazing has started, the initial deposition is given by

$$
C_{p}^{w i}(0)=R_{p}^{w i} T_{w a j}
$$

The initial deposition, as determined by Equations 5.6-17, 5.6-19 and 5.6-20, is used in Equations 5.6-15 and 5.6-16 to estimate the effective animal product concentration. The use of Equations 5.6-15 and 5.6-16 in this manner does not give the true time-dependence for chronic irrigation. However, the time integral of the representation will closely approximate the consumption by humans when all factors are included as described below.

The consumption by humans is calculated as the time integral of animal product concentration. The consumption (based on the time of "harvest") is given by

$$
Q_{a p}^{9 i}(0)=u_{p} \int_{0}^{T^{g}} c_{p i}^{g}(t) d t
$$


where

$\mathrm{Qgi}_{\mathrm{ap}}^{\mathrm{i}}(0)$ - consumption by humans of nuclide $i$ by ingestion of animal product $\mathrm{p}$ contaminated via ingestion, $\mathrm{Ci}$

$T_{g} \cdot$ grazing period (assumed to be 30 days), days

$U_{p}$ - consumption rate by humans of animal product $p, \mathrm{~kg} /$ day.

$C_{p j}(t)$ is as previously defined.

The evaluation of Equation 5.6-21 is not given here because it is easily derived from Equations 5.6-15 and 5.6-16 by replacing each exponential with its time integral over $T_{g}$. For example,

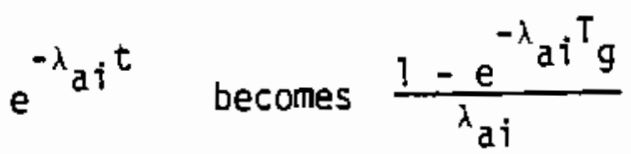

The actual consumption by humans is determined from the results of Equation 5.6-2 by accounting for radioactive decay over the delay time between harvest and consumption. This is represented by Equations 5.6-10 and 5.6-11 with $Q_{a p}{ }_{a p}$ in $p l a c e$ of $Q_{a p}^{d i}$ and $Q Q_{a p}^{g k}$ in $p l a c e$ of $Q \frac{d k}{a p}$.

When more than one pathway is considered (i.e., air and irrigation deposition) Equation 5.6-2l must be evaluated for each path and the results summed. The equations above only consider initial deposition and weathering from plants. The pathways involving deposition to soil with subsequent root absorption or resuspension to grass surfaces are discussed in the following paragraphs. The initial deposition to soil is calculated by Equation 5.5-2 for air deposition and by Equation 5.5-7 for acute irrigation deposition. The soil concentration after deposition is the initial deposition modified for radioactive decay. For chronic irrigation, the soil concentration is calculated as a function of time by Equations 5.5-13 and 5.5-14.

The resuspension model of Section 5.5.3 is used to estimate the rate of deposition to grass for each consecutive 30-day grazing period. The resuspension rate (Equation 5.5-10) is evaluated at the midpoint of each grazing period for use in Equation 5.5-15 to determine the rate of deposition to grass. This resuspension rate is also used in Equations 5.5-20 and 5.5-2l to estimate the concentration on grass as a function of time. To reduce the complexity in subsequent equations for animal products and human consumption, the average concentration on grass for each 30-day grazing period is calculated. The subsequent equation for animal product concentration is then estimated for constant uptake rate based on the average concentration on grass. The average concentrations on grass for parent radionuclide $i$ and daughter radionuclide $k$ are given by 


$$
\vec{C}_{p}^{r i}\left(t_{1}, t_{2}\right)=\frac{\vec{R}_{p}^{+i}}{\lambda_{E j}\left(t_{2}-t_{1}\right)}\left[\left(t_{2}-t_{1}\right)-\frac{\left(e^{-\lambda E i^{t}}-e^{-\lambda E i t_{2}}\right)}{\lambda_{E j}}\right]
$$

and

$$
\begin{aligned}
& \bar{c}_{p}^{r k}\left(t_{1}, t_{2}\right)=\frac{\bar{R}_{p}^{r k}}{\lambda_{E k}\left(t_{2}-t_{1}\right)}\left[\left(t_{2}-t_{1}\right)-\frac{e^{-\lambda_{E k} t_{1}}-e^{-\lambda_{E k} t_{2}}}{\lambda_{E k}}\right] \\
& +\frac{f_{i k} \lambda_{k} \bar{R}_{p}^{r i}}{\lambda_{E j}\left(t_{2}-t_{1}\right)}\left\{\frac { 1 } { \lambda _ { E k } } \left[\left(t_{2}-t_{1}\right)-\frac{\left(e^{-\lambda_{E k} t_{1}}-e^{-\lambda_{E k} t_{2}}\right)}{\lambda_{E k}}\right.\right. \\
& \left.+\frac{1}{\lambda_{E k}-\lambda_{E i}}\left[\frac{e^{-\lambda E k^{t} 1}-e^{-\lambda} E k^{t_{2}}}{\lambda_{E k}}-\frac{e^{-\lambda E_{i} t_{T}}-e^{-\lambda_{E i} t_{2}}}{{ }^{\lambda_{E i}}}\right]\right\}
\end{aligned}
$$

where

$\bar{c}_{p}^{r i}\left(t_{1}, t_{2}\right)$ - average concentration on grass for parent radionuc 1 ide $i$ from resuspension during the period from $\mathrm{t}_{1}$ to $\mathrm{t}_{2}, \mathrm{Ci} / \mathrm{kg}$

$\bar{c}_{p}^{r k}\left(t_{1}, t_{2}\right)$ - average concentration on grass for parent radionuclide $k$
from resuspension during the period from $t_{1}$ to $t_{2}, c i / k g$

$\bar{R}_{p}^{r i}, \bar{R}_{p}^{r k}$ - average resuspension rate to grass for parent radionuclide $i$ and daughter radionuclide $k$ evaluated at the midpoint in time between $t_{1}$ and $t_{2}, \mathrm{Ci} / \mathrm{kg} /$ day

$t_{1}$ - time since initial deposition until the start of the current grazing period, days

$t_{2}$ - time since initial deposition until the end of the current grazing period, days.

Other terms are as previously defined.

The average uptake rate by animals is calculated for any radionuclide as

$$
\bar{R}_{\mathrm{a}}^{r i}=U_{a} \bar{C}_{p}^{r i}
$$


where

$\bar{R}_{a}^{r i}$ - average uptake rate by animal from resuspension for radionuclide $\mathrm{i}, \mathrm{Ci} / \mathrm{day}$.

Other terms are as previously defined.

The concentration in animal products during a given grazing period is estimated for a constant uptake rate by the following equations for parent radionuclide $i$ and daughter radionuclide $k$ :

$$
C_{a p}^{r i}(t)=C_{a p}^{r i}\left(t_{1}\right) e^{-\left(t-t_{1}\right) \lambda_{a i}}+B_{a}^{i} \bar{R}_{a}^{r i}\left(1-e^{-\left(t-t_{1}\right) \lambda_{a i}}\right)
$$

and

$$
\begin{aligned}
& c_{a p}^{r k}(t)=c_{a p}^{r k}\left(t_{1}\right) e^{-\left(t-t_{1}\right) \lambda} a k+B_{a}^{k} \bar{R}_{a}^{r k}\left(1-e^{-\left(t-t_{1}\right) \lambda_{a k}}\right) \\
& +f_{i k} \lambda_{k} c_{a p}^{r i}\left(t_{1}\right)\left[\frac{e^{-\left(t-t_{1}\right) \lambda_{a i}-e^{-\left(t-t_{1}\right) \lambda_{a k}}}}{\lambda_{a k}-\lambda_{a i}}\right] \\
& +f_{i k} k^{g} a_{a}^{i-r i}\left[\frac{1-e^{-\left(t-t_{1}\right) \lambda_{a k}}}{\lambda_{a k}}-\frac{e^{-\left(t-t_{1}\right) \lambda_{a i}-e^{-\left(t-t_{1}\right) \lambda_{a k}}}}{\lambda_{a k}-\lambda_{a j}}\right]
\end{aligned}
$$

where

$$
\begin{aligned}
& \mathrm{crp}_{\mathrm{ap}}^{\mathrm{j}}(\mathrm{t}) \text { - concentration of parent radionuclide } \mathrm{i} \text { in animal product } \\
& \text { from resuspension to grazing feed at time } \mathrm{t} \text { after initial } \\
& \text { deposition, } \mathrm{C} i / \mathrm{kg}
\end{aligned}
$$

Crkp $(t)$ - concentration of daughter radionuclide $k$ in animal product from resuspension to grazing feed at time $t$ after initial deposition, $\mathrm{Ci} / \mathrm{kg}$

$\bar{R}_{\mathrm{a}}^{r i}, \bar{R}_{a}^{r k}$ - average uptake rate by animal of feed containing parent radionuclide $i$ and daughter radionuclide $k$ for the current grazing period

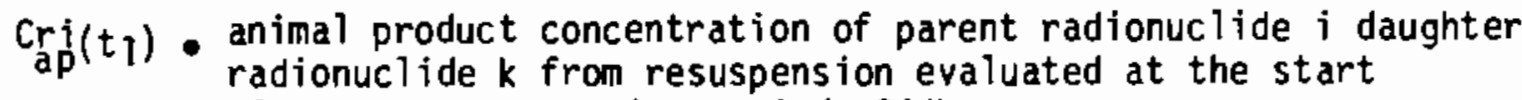
of the current grazing period, $\mathrm{Ci} / \mathrm{kg}$. 
Other terms are as previously defined.

The animal product concentration equations are integrated over each 30 day grazing period to estimate the activity consumed by individuals from anjmal products generated during each period. This time integral represents the activity present at the time of harvest (slaughter, milking, egg gathering, etc.). To get the actual human uptake quantities, the harvest activities are decayed for the average holdup time for the particular animal product. The human consumption (evaluated at the time of harvest, $t=0$ ) is given by the following equations for parent radionuclide $i$ and daughter radionuclide $k$ :

$$
\begin{aligned}
& Q_{a p}^{r i}(0)=U_{p} c_{a p}^{r i}\left(t_{1}\right)\left[\frac{1-e^{-\left(t_{2}-t_{1}\right) \lambda_{a i}}}{\lambda_{a j}}\right]
\end{aligned}
$$

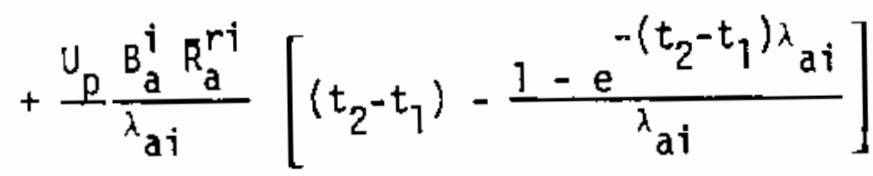

and

$$
\begin{aligned}
Q_{a p}^{r k}(0)= & u_{p} c_{a p}^{r k}\left(t_{1}\right)\left[\frac{1-e^{-\left(t_{2}-t_{1}\right) \lambda_{a k}}}{\lambda_{a k}}\right] \\
& +\frac{U_{p} B_{a}^{k} \vec{R}_{a}^{r k}}{\lambda_{a k}}\left[\left(t_{2}-t_{1}\right)-\frac{1-e^{-\left(t_{2}-t_{1}\right) \lambda_{a k}}}{\lambda_{a k}}\right] \\
& +\frac{U_{p} f_{i k} \lambda_{k} c_{a p}^{r i}\left(t_{1}\right)}{\lambda_{a k}-\lambda_{a j}}\left[\frac{1-e^{-\left(t_{2}-t_{1}\right) \lambda_{a i}}}{\lambda_{a i}}-\frac{1-e^{-\left(t_{2}-t_{1}\right) \lambda_{a k}}}{\lambda_{a k}}\right] \\
& +\frac{U_{0} f_{i k} \lambda_{k} B_{a}^{i} k_{a}^{r i}}{\lambda_{a i}}\left\{\frac{\left(t_{2}-t_{1}\right)}{\lambda_{a k}}-\frac{1-e^{-\left(t_{2}-t_{1}\right) \lambda_{a k}}}{\left(\lambda_{a k}\right)^{2}}\right. \\
& \left.-\frac{1}{\lambda_{a k}-\lambda_{a i}}\left[\frac{1-e^{-\left(t_{2}-t_{1}\right) \lambda_{a j}}}{\lambda_{a i}}-\frac{1-e^{-\left(t_{2}-t_{1}\right) \lambda_{a k}}}{\lambda_{a k}}\right]\right\}
\end{aligned}
$$


where

$$
\begin{aligned}
& Q_{a p}^{r j}(0) \text { - total consumption by humans of parent radionuclide } i \text { from animal } \\
& \text { products due to resuspension onto grazing feed measured at the time } \\
& \text { of harvest for the current } 30 \text {-day grazing period, } C i
\end{aligned}
$$

Qrk $(0)$ - total consumption by humans of daughter radionuclide $k$ from animal products due to resuspension onto grazing feed measured at the time of harvest for the current 30-day grazing period, $\mathrm{Ci}$.

other terms are as previously defined.

Decay during the holdup period between harvest and consumption is calculated using Equations 5.6-10 and 5.6-11 by replacing odj with Q orj. The total consumption during each yearly period is calculated as the sum of contributions for each grazing period during that year.

\subsubsection{Animal Ingestion of Feed Crops}

Animals fed on contaminated harvested feed crops will produce contaminated animal products. Contamination levels in the feed are determined by the models of Section 5.5 for the food crop specified as feed for a particular animal product. The concentration of a nuclide in the feed at harvest is given by

$$
c_{p f}^{i}(0)=F_{p i}^{a} C_{p}^{T i}(0)
$$

where

$$
\begin{aligned}
& C_{p f}^{j}(0) \text { - concentration of nuclide } i \text { in animal feed at the time of harvest, } \\
& \mathrm{Ci} / \mathrm{kg} \\
& C_{p}^{T i}(0) \text { - concentration of nuclide } i \text { in plant type } p \text { to be used for animal } \\
& \text { feed (see Section 5.5.6), Ci/kg } \\
& F_{p i}^{a} \text { - fraction of nuclide } i \text { remaining in animal feed crop } p \text { after } \\
& \text { processing. }
\end{aligned}
$$

The feed crop concentration is assumed to vary with time after harvest because of radioactive decay. Radioactive decay is estimated with Equations 5.6-10 and 5.6-Tl by replacing $Q d j$ with $C_{p f}^{j}$, $0_{a p}^{d}$ with $C_{p f}^{k}$, and $T_{p h}$ with $T_{g a}-T_{h p}$ where $T_{\mathrm{ga}}$ is the time of year when grazing stops and $T_{h p}$ is the time of year when feed crop $p$ is harvested.

The contaminated feed is assumed to be used during the period of the year when grazing on fresh crops is not possible. When feed crop harvest comes at or after the end of the grazing period, Equation 5.6-29 gives the initial feed crop concentration. If feed crop is harvested before the end of grazing, then the concentrations at harvest must be modified for radioactive decay during 
storage until being fed to animals. The concentration of parent radionuclide $i$ and daughter radionuclide $k$ fed to animals is estimated as

$$
c_{p}^{f i}(t)=c_{p f}^{i}\left(T_{g a}-T_{h p}\right) e^{-\lambda_{i} t}
$$

and

$$
\begin{aligned}
C_{p}^{f k}(t) & =C_{p f}^{k}\left(T_{g a}-T_{h p}\right) e^{-\lambda_{k} t} \\
& +\frac{f_{i k} \lambda_{k} C_{p f}^{i}\left(T_{g a}-T_{h p}\right)}{\lambda_{k}-\lambda_{i}}\left(e^{-\lambda_{j} t}-e^{-\lambda_{k} t}\right)
\end{aligned}
$$

where $\mathrm{C}_{p}^{f k}(t)$ - concentration of parent radionuclide in animal feed
at time $t, c_{i} / \mathrm{kg}$ $c_{p}^{f k}(t)$ - concentration of daughter radionuclide $k$ in animal
feed at time $t, c i / k g$

$C_{p f}^{i}\left(T_{g a}-T_{h p}\right) \cdot$ initial concentration of parent of parent radionuclidein animal feed at the time grazing ends, $\mathrm{Ci} / \mathrm{kg}$

$C_{p f}^{k}\left(T_{g a}-T_{h p}\right) \cdot$ initial concentration of daughter radionuclide $k$ in animal feed at the time grazing ends, $\mathrm{Ci} / \mathrm{kg}$

$t$ - time since grazing ended, days

$T_{\text {ga }}$ - time of the year when grazing stops, days

$T_{h p}$ - time of the year when feed crop is harvested, days.

other terms are as previously defined.

The above equations give the time variation of radionuclide concentrations in stored feeds. These concentrations are used to determine the concentration in animal products by assuming a constant uptake (kg/day) by animals. The resulting equations for parent radionuclide $i$ and daughter radionuclide $k$ are

$$
c_{a p}^{f i}(t)=\beta_{a}^{i} U_{a}^{f} c_{p f}^{i}\left(T_{g a}-T_{h p}\right) \quad\left[\frac{e^{-\lambda_{a i} t}-e^{-\lambda_{i} t}}{\lambda_{i}-\lambda_{a i}}\right]
$$


and

$$
\begin{aligned}
c_{a p}^{f k}(t) & =\beta_{a}^{k} v_{a}^{f} c_{p f}^{k}\left(T_{g a}-T_{h p}\right)\left[\frac{e^{-\lambda} a k t-e^{-\lambda_{k} t}}{\lambda_{k}-\lambda_{a k}}\right] \\
& +\frac{f_{j k} \lambda_{k} \beta_{a}^{i} v_{a}^{f} C_{p f}^{i}\left(T_{g a}{ }^{-T_{h p}}\right)}{\lambda_{k}-\lambda_{i}}\left[\frac{e^{-\lambda_{a k} t}-e^{-\lambda_{i t}}}{\lambda_{i}-\lambda_{a k}}\right. \\
& \left.-\frac{e^{-\lambda_{a k} t-e^{-\lambda_{k} t}}}{\lambda_{k}-\lambda_{a k}}\right]
\end{aligned}
$$

where

$c_{a p}^{f i}(t)$ - concentration of parent radionuclide $i$ in animal product at time $t$ after grazing stops, $\mathrm{Ci} / \mathrm{kg}$

$C_{a p}^{f f}(t)$ - concentration of daughter radionuclide $k$ in animal product at time $t$ after grazing stops, $\mathrm{Ci} / \mathrm{kg}$

$\beta_{\mathrm{a}} \mathrm{i}, \beta_{\mathrm{a}} \mathrm{k}$ - transfer factor from ingestion intake to animal product concentration for parent radionuclide $i$ and daughter radionuclide $k$, $\mathrm{Ci} / \mathrm{kg}$ per $\mathrm{Ci}$ ingested.

$\mathrm{U}_{\mathrm{a}}^{f}$ - animal consumption rate of stored feed, $\mathrm{Ci} / \mathrm{kg}$.

Other terms are as previously defined.

The animal products are assumed to be harvested and eaten continuously by humans. The total activity present at harvest is given by the time integral of animal product concentration. As before, this time integral represents the activity present at harvest and must be modified for decay for the holdup time between harvest and consumption by humans. The total activity (at the time of harvest) for parent radionuclide $i$ and daughter radionuclide $k$ is given by

$$
Q_{a p}^{f i}(0)=\frac{B_{a}^{j} u_{a}^{f} C_{p f}^{j}\left(T_{g a}-T_{h p}\right)}{\lambda_{i}-\lambda_{a i}}\left[\frac{\left(1-e^{-\lambda_{a i} t_{3}}\right)}{\lambda_{a i}}-\frac{\left(1-e^{-\lambda_{i} t_{3}}\right)}{\lambda_{i}}\right]
$$


and

$$
\begin{aligned}
& Q_{a p}^{f k}(0)=\frac{B_{a}^{k} U_{a}^{f} c_{p f}^{k}\left(T_{g a} T_{h p}\right)}{\lambda k-\lambda_{a k}}\left[\frac{1-e^{-\lambda_{a k} t_{3}}}{\lambda_{a k}}-\frac{1-e^{-\lambda_{k} t_{3}}}{\lambda k}\right] \\
& +\frac{f_{i k} \lambda_{k} B_{a}^{j} U_{a}^{f} c_{p f}^{i}\left(T_{g a} T_{h p}\right)}{\lambda_{k}-\lambda_{i}}\left\{\frac{1}{\lambda_{j}-\lambda_{a k}}\left[\frac{1-e^{-\lambda_{a k} t_{3}}}{\lambda_{a k}}-\frac{1-e^{-\lambda_{j} t_{3}}}{\lambda_{j}}\right]\right. \\
& \left.-\frac{1}{\lambda_{k}-\lambda_{a k}}\left[\frac{1-e^{-\lambda_{a k} t_{3}}}{\lambda_{a k}}-\frac{1-e^{-\lambda_{k} t_{3}}}{\lambda_{k}}\right]\right\}
\end{aligned}
$$

where

$$
\begin{aligned}
& \mathrm{Q}_{\mathrm{fi}}^{\mathrm{i}}(0) \text { - total consumption by humans of parent radionuclide } i \text { from } \\
& \text { animal products due to use of contaminated feed crops measured at } \\
& \text { the time of animal product harvest, } \mathrm{C} i
\end{aligned}
$$

Other terms are as previously defined.

Radioactive decay during holdup between harvest and consumption is calculated using Equations 5.6-10 and 5.6-11 with $Q Q_{a p}^{j}$ in place of $Q \mathrm{~d}_{\mathrm{ap}}^{\mathrm{i}}$ and $Q_{\mathrm{ap}}^{\mathrm{fk}}$ in place of Qdk.

\subsubsection{Summary: Animal Product Pathway}

The total human consumption from animal product pathways is the sum of the contribution from each pathway as defined in the above sections. Exposure pathways for waterborne releases are animal drinking water, grazing on irrigated 1 and and use of stored feed produced with contaminated irrigation water. For airborne releases, exposure pathways are from direct deposition to land used for grazing and production of stored feed. The total human consumption is given by

$$
Q_{a p}^{i}=Q_{a p}^{d i}+Q_{a p}^{g i}+Q_{a p}^{f i}
$$


where

$Q_{a p}^{i}$ - activity of radionuclide $i$ consumed from animal product $p, C i$.

Other terms are as previously defined.

The consumption is calculated for given periods as required by remedial action models and health effects models. The total consumption given by Equation 5.6-36 is used to describe exposure to an individual in the current spatial interval. This exposure is used to determine remedial action requirements. In determining the total population exposure for health effects estimates, transport of contaminated feed crops and animal products must be considered. These considerations are made under the following assumptions:

- The animal drinking water path contributes to the local individual dose and population doses from transported animal products.

- The animal grazing path contributes to the local individual dose and the population doses from transported animal products.

- The contaminated feed path contributes to the

a) loca 1 individual dose

b) population dose from transported animal products

c) population doses from animal feed crops used outside the local interval.

When more animal product is harvested in a spatial interval than can be consumed lacally, it is assumed that the excess is transported elsewhere. The amount of animal product p produced in a spatial interval $j$ is given by

where

$$
P_{p j}=A_{f j p} P_{p}
$$

$P_{p j}$ - total production of animal product $p$ in spatial interval $j$, $\mathrm{kg} / \mathrm{yr}$

$A_{f j p}$ - farmland area in spatial interval $j$ devoted to production of animal product $p, m^{2}$

$\mathrm{P}_{\mathrm{p}}$ - production rate of animal product $\mathrm{p}, \mathrm{kg} / \mathrm{m}^{2} / \mathrm{yr}$.

The amount consumed in spatial interval $j$ per year is calculated as

$$
H_{p j}=P_{j} U_{p}
$$

where

$\mathrm{H}_{\mathrm{pj}}$ - amount of animal product $\mathrm{p}$ consumed in spatial interval $\mathbf{j}, \mathrm{kg} / \mathrm{yr}$ 
$\mathrm{Pj}$ - number of persons in spatial interval $j$

$U_{p}$ - average consumption rate by individuals for animal product $p$, $\mathrm{kg} / \mathrm{yr} /$ person.

With an excess in production, it is assumed that people outside the spatial interval will receive contaminated animal produce. The number of people served outside interval $j$ is given by

$$
P_{p o}=P_{j p}-P_{j}
$$

where

$P_{p o}$ - number of persons outside of interval $j$ served by excess production of animal product $\mathbf{p}$

$P_{j p}$ - number of persons served (as calculated by Equation 5.6-35) for product $p$ in interval $j$.

The total activity consumed by local population and populations outside interval $j$ are given by

$$
\begin{aligned}
& Q_{p j}^{i}=p_{j s} u_{p} \\
& q_{p o}^{i}=p_{p o} u_{p}
\end{aligned}
$$

where

$$
\begin{aligned}
& Q_{p j} \text { - total activity of nuclide } i \text { consumed from animal product } p \\
& \text { by the local population of spatial interval } j, C
\end{aligned}
$$

(Note: $P_{P P}$ is zero when there is a shortage of animal product $p$ for interval 3 ).

When the amount produced is less than the amount consumed, animal produce is being shipped into the spatial interval from elsewhere. The produce shipped in is considered uncontaminated and does not contribute to local individual or population doses. The local population dose calculation must, however, 
account for use of less contaminated animal product. This is done by the following equation, which estimates the number of people served by the locally produced contaminated animal product $p$ :

$$
P_{j p}=P_{j} P_{p j} / H_{p j}
$$

where

$P_{j p}$ - number of persons in spatial interval $j$ served by contaminated
animal product $p$.

Other terms are as previously defined.

Equations 5.6-37 through 5.6-42 apply to animal product contamination via drinking water and grazing. When contamination is from stored feed crops, it is necessary to consider the amount of feed crop produced in relation to consumption by animals locally and outside the interval. Consumption by animals outside the spatial interval is assumed to result only in exposure of populations outside the interval. The production of feed in the spatial interva] $j$ for use with animal product $p$ is given by

$$
P_{f j p}=A_{f j f} P_{f} R_{p j f}
$$

where

$$
\begin{aligned}
& P_{f j p} \text { - production rate of feed crop } f \text { for use with animal product } p \\
& \text { in interval } j, \mathrm{~kg} / \mathrm{yr}
\end{aligned}
$$

The factor Rpjf allows for multiple use of one feed crop for production of several animal products. The usage of feed crop $f$ in interval $j$ for animal product $p$ is calculated as

$$
H_{f p j}=A_{f j p} U_{p f} .
$$

where

\footnotetext{
$H_{f p j}$ - total consumption of feed crop $f$ necessary to sustain animal product $p$ in interval $j, \mathrm{~kg} / \mathrm{yr}$

$A_{f j p}-f a r m l a n d$ area devoted to production of animal product $p$ in interval $\mathrm{j}, \mathrm{m}^{2}$
} 
Upf - usage rate by animal product $\mathrm{p}$ for feed crop $\mathrm{f}, \mathrm{kg} / \mathrm{m}^{2} / \mathrm{yr}$.

When less feed is produced than needed, supplementary feed shipped into the interval is assumed to be uncontaminated. The animal product concentration for the feed crop path is modified to account for use of uncontaminated feed as follows:

$$
Q_{a p}^{f i}=Q_{a p}^{f j} \frac{P_{f j}}{H_{f p j}}
$$

When there is an excess of animal feed, the extra is shipped outside the interval and is assumed to be used for production of animal products of all types. The total excess feed crop is calculated as

$$
E_{f j}=\sum_{p}{ }_{f j p}-\sum_{p} H_{f p j}
$$

where $E_{f j}$ - total excess $(\mathrm{kg} / \mathrm{yr})$ feed crop $f$ produced in spatial interval $j$.

other terms are as previously defined.

The excess feed crop is assumed to be used for animal product production of each type by a defined ratio. The concentration in each animal product is calculated using the equations of Section 5.6.3 with the resulting animal products being used totally offsite. Only population doses are calculated for this production mode.

\subsection{INGESTION OF AQUATIC FOODS}

Releases of radioactivity to aquatic environments may reach man by ingestion of contaminated aquatic organisms used for human foods. The water contamination level is described by the average concentration functions of Equations 4.2-2 and 4.2-3. This average concentration is as sumed to persist for a period $T_{w a j}$ after the accident. The concentration is assumed to be zero after $T_{\text {waj. In }}$ In this section the subscript $j$ refers to water usage location. Uptake of radionuclides by aquatic organisms during the contamination period is described by

$$
\frac{d C_{q i}(t)}{d t}=\beta_{q i}^{\prime} \vec{C}_{w i j}-\beta_{q i} C_{q i}(t)-\lambda_{i} C_{q i}(t)
$$

and

$$
\frac{d C_{q k}(t)}{d t}=8_{q k}^{\prime} \bar{C}_{w k j}+\lambda_{k} f_{i k} C_{q i}(t)-8_{q k} C_{q k}(t)-\lambda_{k} C_{q k}(t)
$$


where

$C_{q j}(t)$ - concentration of parent radionuclide $i$ in aquatic food of $\mathrm{q}$ at a time $\mathrm{t}, \mathrm{Ci} / \mathrm{kg}$

$C_{q k}(t)$ - concentration of daughter radionuclide $k$ in aquatic food $q$ at time $\mathrm{t}, \mathrm{Ci} / \mathrm{kg}$

$B_{q j}, B_{q k}$ - uptake rate constant for radionuclide $i$ or $\mathbf{k}$ from water to aquatic food $q$, days ${ }^{-1}$

$\beta_{q j}, \beta_{q k}$ - biological elimination rate constant for radionuclide $i$ or $k$ for aquatic food $q$, days -1

$\lambda_{i}, \lambda_{k}$ - radiological decay constant for radionuclide $i$ or $k$, days $s^{-1}$

$\overline{\mathrm{C}}_{w i j}$ - average water concentration of parent radionuclide $j$ at water location $j$ over the contamination period $\mathrm{T}_{w a j}, \mathrm{Ci} / \mathrm{m}^{3}$

$\vec{C}_{w k j}$ - average water concentration of daughter radionuclide $k$ at water location $j$ over the contanination period $\mathrm{T}_{w a j}, \mathrm{C} i / \mathrm{m}^{3}$

$f_{i k}$ - fraction of parent radionuclide $i$ disintegrations that result in production of daughter radionuclide $k$.

The solutions to the above equations are given by the following equations for al1 times before the end of the contanination period:

$$
C_{q i}(t)=\frac{B_{q i}^{\prime}}{\lambda_{q j}} \bar{C}_{w i j}\left(1-e^{-\lambda_{q i t}}\right)
$$

and

$c_{q k}(t)=\frac{\beta_{q k}^{\prime} \vec{C}_{w k j}}{\lambda_{q k}}\left(1-e^{-\lambda q k t}\right)+\frac{\lambda_{k} f_{i k} \beta_{q i}^{t}}{\lambda_{q j}} \bar{c}_{w i j}\left[\frac{1-e^{-\lambda} q k t}{\lambda_{q k}}-\frac{e^{-\lambda} q j t-e^{-\lambda} q k t}{\lambda_{q k}-\lambda_{q i}}\right]$

where

$$
\begin{gathered}
\lambda_{q i}, \lambda_{q k} \text { - effective elimination rates from aquatic organism } \\
q \text { for parent radionuclide } i \text { and daughter radionuclide } k, \\
\text { days }-1 \\
\lambda_{q i}=\beta_{q i}+\lambda_{i}
\end{gathered}
$$




$$
\lambda_{q k}=\beta_{q k}+\lambda_{k}
$$

Other terms are as previously defined.

The steady-state solution to Equation $5.7-3$ is found by evaluating the equation as $t$ becomes large. The result is

$$
C_{q i} \text { (steady-state) }=\frac{\beta_{q i}^{1}}{\lambda_{q i}} \bar{C}_{w i j}
$$

This equation reveals that the commonly used bioaccumulation factor for radionuclide $i$ is equal to the coefficient on the right side of the equation:

$$
s_{q}^{i}=\frac{\beta_{q i}^{\prime}}{\lambda_{q i}}
$$

Applying this resuit to Equations $5.7-3$ and $5.7-4$ yields the following expressions:

and

$$
c_{q i}(t)=B_{q}^{i} \bar{c}_{w i j}\left(1-e^{-\lambda q_{i} t}\right)
$$

$C_{q k}(t)=B_{q}^{k} \bar{C}_{w k j}\left(1-e^{-\lambda} q k^{t}\right)+\lambda_{k} f_{i k} B_{q}^{i} \bar{C}_{w i f}\left[\frac{1-e^{-\lambda} q k^{t}}{\lambda_{q k}}-\frac{e^{-\lambda} q i^{t}-e^{-\lambda} q k^{t}}{\lambda_{q k}-\lambda_{q i}}\right]$

where

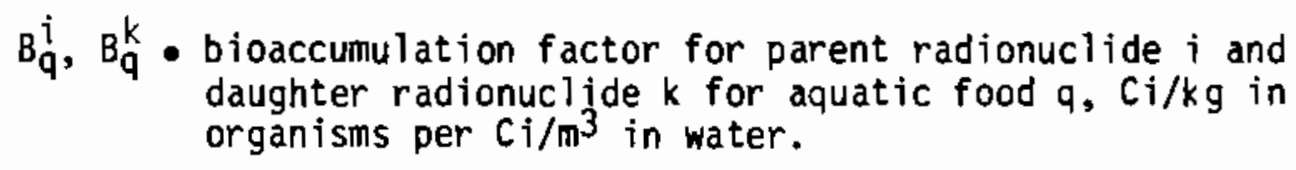

Other terms are as previousiy defined.

The concentration in the aquatic food after the end of the water contamination period $T_{w a j}$ is given by the following equations:

$$
C_{q i}\left(T_{w a j}+t\right)=C_{q i}\left(T_{w a j}\right) e^{-\lambda} q i t
$$


and

$$
C_{q k}\left(T_{w a j}+t\right)=C_{q k}\left(T_{w a j}\right) e^{-\lambda q k}+\frac{f_{i k} \lambda_{k} C_{q k}\left(T_{w a j}\right)}{\lambda_{q k}-\lambda_{q k}}\left[e^{-\lambda q i^{t}}-e^{-\lambda q k t}\right]
$$

where

$t$ - time since the end of the contaminated water period, days.

Harvest of aquatic food is assumed to be continuous. The consumption by humans is calculated from the time integral of Equations 5.7-9, 5.7-10, 5.7-11 or 5.7-12 as appropriate. The time integral is taken over the duration of the harvest period after contamination has begun. The following equations for parent radionuclide $i$ and daughter radionuclide $k$ give the time integrals evaluated at the time of continuous harvest. For times before the end of the contamination period,

$$
H_{q i}(t)=8_{q}^{i} \bar{C}_{w i j}\left(t-\frac{1-e^{-\lambda} q i^{t}}{\lambda_{q i}}\right)
$$

and

$$
\begin{aligned}
H_{q k}(t) & =B_{q}^{k} \bar{C}_{w k j}\left(t-\frac{1-e^{-\lambda} q k t}{\lambda_{q k}}\right)+\frac{\lambda_{k} f_{i k} B_{q}^{i} \bar{C}_{w i j}}{\lambda_{q k}}\left(t-\frac{1-e^{-\lambda q k t}}{\lambda_{q k}}\right) \\
& +\frac{{ }^{\lambda} k^{f}{ }_{j k} B_{q}^{i} \bar{C}_{w i j}}{\lambda_{q k}-\lambda_{q i}}\left[\frac{1-e^{-\lambda q i t}}{\lambda_{q i}}-\frac{1-e^{-\lambda q k t}}{\lambda_{q k}}\right]
\end{aligned}
$$

where

$\mathrm{H}_{\mathrm{q}}(\mathrm{t})$ - time integral of parent radionuclide $\mathrm{i}$ concentration harvested as aquatic food $q$ during the period of water contamination, $\mathrm{Ci}$ days/kg

$H_{q k}(t)$ - time integral of daughter radionuclide $k$ concentration harvested aquatic food q during the period of water contamination, $\mathrm{Ci}$ days $/ \mathrm{kg}$

$t$ - time since beginning of contamination period, days 
$0 \leq t \leq T_{\text {waj }}$

Other terms are as previously defined.

The time integrals are given by the following equations for times after the end of the contamination period:

$$
H_{q i}\left(T_{w a j}+t\right)=H_{q i}\left(T_{w a j}\right)\left(\frac{1-e^{-\lambda} q i t}{\lambda_{q i}}\right)
$$

and

$$
\begin{aligned}
H_{q k}\left(T_{w a j}+t\right) & =H_{q k}\left(T_{w a j}\right)\left(\frac{1-e^{-\lambda} q k t}{\lambda_{q k}}\right)+\frac{f_{i k} \lambda_{k} H_{q k}\left(T_{w a j}\right)}{\lambda_{q k}-\lambda_{q j}}\left[\frac{1-e^{-\lambda_{q i} t}}{\lambda_{q t}}\right. \\
& \left.-\frac{1-e^{-\lambda_{q k} t}}{\lambda_{q k}}\right]
\end{aligned}
$$

where

$t$ - time since end of contamination period, days

$H_{q i}\left(T_{\text {waj }}+t\right)$ - time integral of parent radionuclide $i$ harvested as aquatic foodstuff $q$ evaluated at time $t$ after the contamination of water ends, $\mathrm{Ci} \cdot$ days $/ \mathrm{kg}$

$H_{q k}\left(T_{\text {waj }}+t\right)$ - time integral of daughter radionuclide $k$ harvested as aquatic foodstuff $q$ evaluated at time $t$ after contamination of water ends, $\mathrm{C} i \cdot$ days $/ \mathrm{kg}$

$\mathrm{H}_{\text {qi }}\left(\mathrm{T}_{\text {wak }}\right)$, - time integral of harvested aquatic foodstuff evaluated by

$H_{q k}\left(T_{\text {wak }}\right)$ Equations 5.7-13 and 5.7-14 over the water contamination period $T_{\text {waj }}, \mathrm{Ci} \cdot$ days $/ \mathrm{kg}$.

other terms are as previously defined.

The consumption by individuals is calculated from the above equations modified to account for 1) decay during holdup between harvest and consumption and 2) removal of activity from the foodstuff during processing and preparation. The resulting equations are given below for parent radionuclide $i$ and daughter radionuclide $k$ :

$$
Q_{q i}\left(T_{h q}\right)=U_{q} K_{q i} H_{q i}(t) e^{-\lambda{ }_{j} T_{h q}}
$$


and

$$
Q_{q k}\left(T_{h q}\right)=U_{q} K_{q k} H_{q k}(t) e^{-\lambda_{k}{ }^{T} h q}+\frac{U_{q} K_{q k} H_{q j}(t) f_{i k} \lambda_{k}}{\lambda_{k}-\lambda_{j}}\left(e^{-\lambda_{j} T h q}-e^{-\lambda_{k} k^{\top} h q}\right)
$$

where

$$
\begin{aligned}
& Q_{q i}\left(T_{h q}\right) \text { - total consumption by humans of parent radionuclide } i \text { aquatic } \\
& \text { food q evaluated after holdup for a time } T_{h q}, C i
\end{aligned}
$$

The individual consumption values are used to determine doses to an individual from consumption of each aquatic food. Aquatic food usage is assumed to be essentially independent of production site; therefore, a 11 people within the spatial grid of the site are potential users of the aquatic foods. The individual doses from.aquatic food production are therefore added to individual dose from other pathways for all spatial intervals.

The exposure is estimated from the annual production of each aquatic food from each defined production location. The total amount of radionuclide $i$ in aquatic food q production is described by

$$
P_{q j i}(0)=h_{q j} \int_{0}^{t} c_{q j}(\tau) d \tau
$$

$P_{q j i}(0)$ - total activity of radionuclide $i$ in aquatic food $q$ measured at the time of harvest (represented by zero') at production location $\mathrm{j}, \mathrm{C} i$ 
$h_{q j}$ - production rate of aquatic food $q$ from production location $j$, $\mathrm{kg} /$ day

$t$ - time over which contaminated harvest is taken, days

$C_{q j}(t)$ - concentration of a radionuclide $i$ (parent or daughter) in aquatic food $q$ at a time $\mathrm{t}, \mathrm{Ci} / \mathrm{kg}$.

Note that the time integral may be evaluated from the equations for $\mathrm{H}_{q} i$ and $\mathrm{H}_{\mathrm{qk}}$. Equation 5.7-19 then becomes

$$
P_{q j i}(0)=h_{g j} H_{q j}(t)
$$

This is the total activity as measured at harvest time. The total consumption by humans after decay holdup and food processing is calculated by

$$
P_{q j j}\left(T_{h q}\right)=K_{q i} P_{q j i}(0) e^{-\lambda j} T_{h q}
$$

$P_{q j k}\left(T_{h q}\right)=k_{q k} p_{q j k}(0) e^{-\lambda_{k} T_{h q}}+\frac{k_{q k} p_{q j j}(0) f_{i k} \lambda_{k}}{\lambda_{k}-\lambda_{j}}\left(e^{-\lambda_{j} T_{h q}}-e^{-\lambda_{k} T_{h q}}\right)$

where

$P_{q j i}\left(T_{h q}\right)$ - total consumption of parent radionuclide $i$ from ingestion of aquatic food q produced in water location $j, \mathrm{Cj}$

$P_{q j k}\left(T_{h q}\right)$ - total consumption of daughter radionuclide $k$ from ingestion of aquatic food $q$ produced in water location $j, \mathrm{C} i$.

The total consumption as defined by the above two equations is used to estimate the population dose from aquatic food production.

\subsection{INGESTION OF CONTAMINANTS IN DRINKING WATER}

The model for the drinking water ingestion pathway is based on the average water concentration at the water intake plant, corrected for $p l a n t$ purif $i-$ cation factors and decay during transit from the plant to individuals consuming the water. The activity concentration of each nuclide present after purification is given by 


$$
A_{w i}(0)=C_{w i j} \cdot K_{w i j}
$$

where

$A_{w i}(0)$ - average concentration of nuclide $i$ after purification at the water intake plant, $\mathrm{Ci} / \mathrm{m}^{3}$

$K_{w i j}$ - purification factor for nuclide $i$ at water intake $p l a n t ~ j$

$C_{w i j}$ - average water concentration for nuclide $i$ supplied to water plant $\mathrm{j}, \mathrm{Ci} / \mathrm{m}^{3}$.

The consumption by individuals is calculated by

$$
Q_{w i}=T_{w a j} \cup A_{w i}\left(T_{h j}\right)
$$

where

Q $Q_{\text {wi }}$ - total activity consumed by an individual during the period $\mathrm{T}_{\text {waj }}$ from the drinking water pathway, $\mathrm{C} i$ /person

$U$ - water consumption rate by individuals, $\mathrm{m}^{3} /$ day

$A_{w i}\left(T_{h j}\right) \cdot$ average activity in the drinking water supply, correcteed for decay in transit to the consumption location, $\mathrm{Ci} / \mathrm{m}^{3}$

$T_{h j}$ - holdup time for transit from the water intake plant $j$ to the location of consumption, days.

The total activity consumed is used to calculate ingestion doses. (Dose conversion factors are discussed in Section 6.2.) The drinking water pathway is used to calculate acute and latent health effects from early (first-year) exposure. Doses and health effects from chronic exposure are not considered because it is assumed the water supply will not be contaminated over a long period of time, i.e., greater than one year.

\subsection{EXTERNAL EXPOSURE FROM WATERBORNE CONTAMINATION}

Humans can be externally exposed to waterborne contamination while swimming, boating or participating in shoreline activities. Swimming and boating involve partial or total immersion in the contaminated water. Shorel ine exposure comes from radionuclides in shoreline sediments and is similar to external exposure to contaminated ground. The dose from aquatic activities is calculated from the time-integrated concentration in water (for boating and swiming) and shoreline sediments (for shorel ine activities). The effective exposure concentrations are calculated by 


$$
\bar{c}_{b i j}\left(T_{g}\right)=\bar{C}_{w i j}\left(T_{g}\right) F_{b s}
$$

and

$$
\tilde{C}_{s i j}\left(T_{g}\right)=\bar{C}_{w i j}\left(T_{g}\right) F_{s a} S_{c}^{j}
$$

where

$$
\begin{aligned}
\bar{C}_{b i j}\left(T_{g}\right) \cdot & \text { time-integrated water concentration for boating and swimming } \\
& \text { exposure, } C i \cdot \text { days } / m^{3}
\end{aligned}
$$

$\bar{C}_{\text {sij }}\left(T_{g}\right)$ - time-integrated shoreline sediment concentration for shoreline activities, $\mathrm{Ci} \cdot$ days $/ \mathrm{m}^{2}$

$\bar{C}_{w i j}$ - average water concentration for radionuclide $i$ (parent or daughter) at water usage location $j$ over the period of water contamination $T_{\text {waj }}$ (calculated by Equations $4.2-4$ or $4.2-5$ ), $\mathrm{Ci} / \mathrm{m}^{3}$

$T_{g}$ - time period over which exposure occurs, days

Fbs - fraction of time an individual spends boating or swimming

Fa - fraction of time an individual spends in shoreline activities

$S_{C}^{i}$ - shoreline concentration factor for radionuclide $i, \mathrm{Ci} / \mathrm{m}^{2}$ per $\mathrm{Ci} / \mathrm{m}^{3}$.

The shoreline concentration factor relates water concentration to shoreline concentration. The factor is dependent on shoreline sediment properties such as porosity, composition and absorption characteristics. Absorption is also element-dependent. An estimate of the shoreline concentration factor can be obtained using the equation below (5.9-3) and the following assumptions:

- Uptake of activity by the sediments is rapid.

- Removal of activity from the sediment is slow.

- The effective active sediment layer for radionuclide retention and external exposure can be defined.

- Distribution coefficients relating equilibrium soil-to-water concentrations are available.

$$
s_{c}^{i}=d_{s} K_{d s}^{i}\left(1-e^{-\lambda_{s i}{ }^{t}}\right)
$$


where

$d_{s}$ - effective sediment layer depth, m

$K_{d s}^{i} \cdot$ equilibrium sediment distribution coefficient for radionuclide $i$, $\mathrm{Ci} / \mathrm{m}^{3}$ soil per $\mathrm{Ci} / \mathrm{m}^{3}$ water

si - effective remoyal rate constant of radionuclide $i$ from shoreline sediment, day-1

$\lambda_{\mathbf{s}}=\lambda_{\mathbf{s}}^{i}+\lambda_{j}$

$t$ - time since contamination period ended, days

$\lambda_{S}^{i}$ - rate constant for removal of radionuclide $i$ from shoreline sediment, days-

$\lambda_{j}$ - radiological decay constant for radionuclide $i$, days ${ }^{-1}$.

When activity is tightly bound to the sediment, the removal rate constant is small and the shoreline factor is dependent only on radiological decay.

Equation 5.9-1 applies for boating exposure when the period of water contamination, $T_{w a j}$, is greater than the exposure period, $T_{g}$. When the exposure period is greater, Equation 5.9-1 is evaluated with the contamination period, $\mathrm{T}_{\text {waj, }}$, in place of $\mathrm{T}_{\mathrm{g}}$.

Also Equation 5.9-2 applies for shoreline exposure when the period of water contamination, $\mathrm{T}_{\text {waj, }}$, is greater than the exposure period, $\mathrm{T}_{\mathrm{g}}$. When the exposure period is greater, the time-integrated shoreline sediment concentrations are given by

$$
\bar{c}_{s i j}\left(T_{g}\right)=\bar{c}_{s i j}\left(T_{w a j}\right)+d_{s} K_{d s}^{i} c_{w i j}\left(T_{w a j}\right)\left[\frac{1-e^{-\lambda_{s i} t}}{\lambda_{s i}}\right]
$$

and

$$
\begin{aligned}
\bar{c}_{s k j}\left(T_{g}\right) & =\bar{c}_{s k j}\left(T_{w a j}\right)+d_{s} k_{d s}^{k} c_{w k j}\left(T_{w a j}\right) \\
& +\frac{d_{s} k_{d s}^{i} c_{w i j}\left(T_{w a j}\right) \lambda_{k} f_{i k}}{\lambda_{s k}-\lambda_{s i}}\left[\frac{1-e_{s k} t}{\lambda_{s k}}\right]
\end{aligned}
$$


where

$$
\begin{aligned}
& C_{S j j}\left(T_{w a j}\right) \cdot \text { time integral of shoreline concentration of parent radio- } \\
& \text { nuclide } i \text { at water location } j \text { evaluated at the end of } \\
& \text { the water contamination period } \mathrm{T}_{\text {waj }}, \mathrm{C} i \cdot \text { days } / \mathrm{m}^{2} \\
& C_{\text {skj }}\left(T_{\text {waj }}\right) \cdot \text { time integral of shoreline concentration of daughter radio- } \\
& t=T_{g} \cdot T_{\text {waj }} \cdot
\end{aligned}
$$

The average water concentration location may be different for boating and swiming than that used for shoreline activities (i.e., the index $j$ is different). This allows shoreline sediment to be defined as a water concentration through input for specific use in calculating doses for this externa? exposure pathway. The time fractions for use in the above equation are defined through input for each month of the year to allow for seasonal variations. This external exposure pathway is used to calculate acute health effects and population doses for latent health effects.

\subsection{EXTERNAL EXPOSURE TO MATERIAL CONTAINED WITHIN FACILITY BUILDINGS}

Models for calculating external exposure to material contained within reactor buildings at offsite locations are presented in Section 4.3 , Direct Photon Transport. These models describe the time-integrated exposure at each location of interest. The time-integrated exposure is converted to dose by use of appropriate dose conversion factors. No further models are required to relate activity concentration levels to exposure for this pathway. 



\subsection{DOSIMETRY}

This section describes models used to calculate radiation dose to humans from intake of radionuclides and external exposure. These models are used to generate appropriate dose conversion factors for use in data libraries; they are therefore not progranmed explicitly in the computer code. The models for external exposure are discussed first, followed by internal dosimetry models for ingestion and inhalation. Also presented is a summary of the dose conversion factor requirements for the computer code.

\subsection{EXTERNAL EXPOSURE}

Exposure to radiation external to the body is considered here for submersion in contaminated air, exposure to comtaminated ground (or shoreline) and direct irradiation from contained activity. Dose calculations are based on dose conversion factors relating media concentration to dose for the total body. The total-body dose is calculated for a tissue depth of $5 \mathrm{~cm}$, considering photon buildup and attenuation in passing through the tissue. The dose to other internal body organs is assumed to be equal to the total-body dose.

\subsubsection{Air Submersion}

In estimating external exposure from airborne activity, consideration must be given to radionuclide concentration in the air and the spatial distribution of the activity with respect to the receptor location. When the dimensions of the plume are larger than the mean free path length for photons in the air, the concentration may be assumed to be constant. Under these conditions, the external exposure at the body surface is easily calculated as

$$
D_{Y}(0)=0.23 f_{Y} \bar{E}_{Y} C_{0 i j}
$$

where

$D_{\gamma}(0)$ - gamma dose contribution at the surface of the body, rem

$f_{Y}$ - stopping power of tissue relative to air for the gamma energy

$\bar{E}_{Y}$ - effective garma energy released per disintegration, MeV/dis

$C_{o i j}$ - time-integrated air concentration at the receptor location, $\mathrm{Ci} \mathrm{sec/m^{3 }}$

and the 0.23 constant is derived as follows:

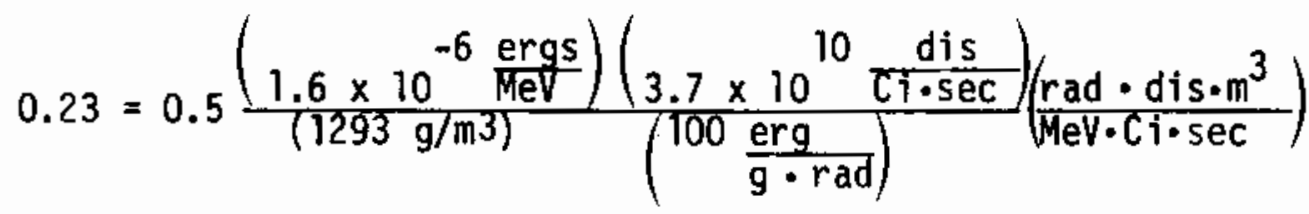


The factor of 0.5 accounts for the ground interface making the air source effectively semi-infinite. The quality factor for gamma radiation is taken as 1.0 so that dose in rads is equivalent to dose in rem. The total body dose (at $5 \mathrm{~cm}$ tissue depth) is calculated from the surface dose by

$$
D_{\gamma}(5)=D_{\gamma}(0)\left[1+5 \mu_{s}\left(E_{\gamma}\right)\right] e^{-5 \mu_{s}}\left(E_{\gamma}\right)
$$

where

$D_{\gamma}(5) \cdot$ total body ganma dose contribution at $5 \mathrm{~cm}$ tissue depth, rem $\mu_{S}\left(E_{\gamma}\right) \cdot$ linear energy attenuation coefficient in tissue for photons of

$E_{Y} \cdot$ initial photon energy, MeV.

other terms are as previously defined.

In practice, the energy-dependent portions of Equations $6.1-1$ and $6.1-2$ are evaluated for each nuclide and each photon energy for that nuclide. The dose factor is then the sum of the contributions from each photon energy normalized to air concentration, $E_{j}$. The dose factor is represented by the symbol $\mathrm{D}_{\mathrm{py}}(5)$, for radionuclide $i$.

The tissue depth correction gives results very close to those calculated by Poston and Snyder (1974) using a Monte Carlo calculation for a geometric phantom. The ratio of their total-body dose to skin dose is nearly equal to the correction factor of Equation 6.1-2 over the energy range of $0.03 \mathrm{MeV}$ and above. Also, the dose factors (except for low-gamma energies) of Poston and Snyder, do not vary a great deal among the organs of interest.

Equation 6.1-1 may also be used to estimate the dose to surface tissue from beta radiation by replacing the gamma energy, $E_{\gamma}$, with the average beta energy emitted, $E_{\beta}$, MeV/dis. In this case the $f_{\gamma}$ is unity and the factor 0.5 accounts for effective irradiation of surface tissue from one side only.

When the plume is smaller than the mean free path of photons, consideration must be given to the spatial distribution of radionuclide concentration. Effects of plume size are accounted for by applying a "finite plume" correction factor to the total body dose. The correction factors relate dose from a finite plume to dose from a semi-infinite plume of uniform concentration. The concentration of reference in the finite plume is that on the plume centerline at a given downwind distance. This reference concentration is used for ground level and elevated releases. The Reactor Safety Study presented a table of correction factors as a function of the vertical dispersion coefficient, $\sigma_{2}$, and the elevation of the plume centerline above the ground $h_{e}$. These correction factors are presented in Table 6.1-1. The factors are based on calculations by Gamertsfelder (Siade 1968) for a spherical cloud of uniform concentrations emitting photons of 
initial energy of $0.7 \mathrm{MeV}$. The atmospheric dispersion model presented in Section 4.1 predicts plume cross sections that are generally nonsymetric with $\sigma_{y} \geq \sigma_{z}$. To account for the lack of symetry in use of the spherical cloud correction factors, the following procedures have been developed. The method is based on numerical finite plume dose calculations for nonsymmetric clouds using the computer program BIVAR of the SUBDOSA code set (Strenge et al. 1975).

Table $6.7-1$ is used to generate two correction factors as follows:

- $D_{z}$ is based on the values of $\sigma_{z}$ and $h_{e} / \sigma_{z}$

- $D_{y}$ is based on the values of $\sigma_{y}$ and $h_{e} / \sigma_{z}$.

TABLE 6.7-1. Finite-Cloud Dose Correction Factor

Dispersion

Parameter, $\sigma$

3
10
20
30
50
100
200
400
1000

Ratio of Plume Height to Vertical Dispersion Parameter, he/ ${ }^{\prime} z$

\begin{tabular}{ccc}
0 & 1 & 2 \\
\cline { 1 - 1 } 0.020 & 0.018 & 0.011 \\
0.074 & 0.060 & 0.036 \\
0.150 & 0.120 & 0.065 \\
0.220 & 0.170 & 0.088 \\
0.350 & 0.250 & 0.130 \\
0.560 & 0.380 & 0.150 \\
0.760 & 0.511 & 0.150 \\
0.899 & 0.600 & 0.140 \\
0.951 & 0.600 & 0.130
\end{tabular}

\begin{tabular}{cc}
3 & 4 \\
\hline 0.006 & 0.005 \\
0.020 & 0.015 \\
0.035 & 0.024 \\
0.046 & 0.029 \\
0.054 & 0.028 \\
0.045 & 0.016 \\
0.024 & 0.004 \\
0.014 & 0.001 \\
0.011 & 0.001
\end{tabular}

0.004

0.011

0.016

0.017

0.013

0.004

0.001

0.001

0.001

The effective correction factor is then given by

$$
D_{p Y}=\left(D_{y} D_{z}\right)^{1 / 2}
$$

where

$D_{p y}$ - finite plume correction factor for use in modifying results from Equation 6.1-2

Dy - finite plume correction factor based on Table 6.1-1 using the current value of $\sigma_{y}$

$D_{2}$ - finite plume correction factor based on Table 6.1-1 using the current value of $\sigma_{z}$.

Use of the $D_{z}$ value as the correction factor (as was done in the Reactor Safety Study) will generally underestimate external dose when $\sigma_{y}>\sigma_{z}$, as 
is usually the case. The effect is less important as the effective release height, $h_{e}$, increases. The modified correction factor $D_{p \gamma}$ is a better estimate for nonsymetric plumes.

\subsubsection{Ground Contamination}

The mode] presented here for exposure to contaminated ground is used to estimate doses from contaminated shoreline, farmland and other residential ground. Exposure to contaminated ground is calculated by assuming the ground surface to be an infinite disk source with receptor at $1 \mathrm{~m}$ above the surface.

The gamma dose rate at a distance $d$ above an infinite disk source is given by

$$
D_{g \gamma}(5)=1.98 \times 10^{4} G_{i j} \sum_{n}^{\text {photons }} B E_{\gamma}\left(\mu_{n} d\right) \mu_{a n} E_{\gamma n} f_{n}^{f} f_{\gamma n}\left[1+5 \mu_{s}\left(E_{\gamma n}\right)\right] e^{-5 \mu_{s}\left(E_{\gamma n}\right)}
$$

where

$\mathrm{D}_{\mathrm{gr}}(5)$ - gamma dose rate to total body at a distance d meters above ground, rem/day

$G_{i j} \cdot$ ground source strength as defined by Equation $4.1-19, \mathrm{Ci} / \mathrm{m}^{2}$

B - buildup factor for photons of energy $E_{\gamma n}$ in traversing d meters of air ( $B$ is essentially equal to unity),

$E_{1}\left(\mu_{n} d\right)$ - first exponential integral function (Kovalev and Foderaro 1968) evaluated at $\mu_{n} d$

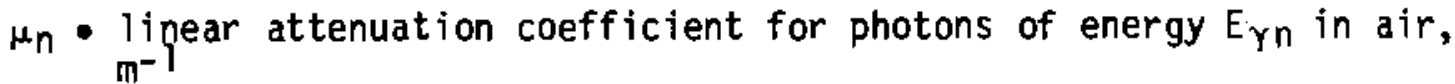

d - distance of receptor above ground (set equal to $1 \mathrm{~m}$ ), $\mathrm{m}$

Han - energy absorption coefficient for photons of energy $E_{\gamma n}$ in air, $\mathrm{m}^{-1}$

$E_{\gamma n} \bullet$ photon energy, MeV/photon

$f_{n}$ - abundance of photons of energy $E_{\gamma n}$ for the source, photons/dis

$f_{Y n}$ - stopping power of tissue relative to air for photons of energy EYn

$1.98 \times 104$ - unit conversion constant, $\frac{\mathrm{rem} \cdot \mathrm{m}^{3}}{\mathrm{Ci} \cdot \mathrm{day} \cdot \mathrm{MeV}}$

$1.98 \times 10^{4}=\frac{1}{2}\left(3.7 \times 10^{10} \frac{\mathrm{dis}}{\mathrm{Ci} \cdot \mathrm{sec}}\right)\left(1.6 \times 10^{-6} \frac{\mathrm{erg}}{\mathrm{MeV}}\right)\left(\frac{\mathrm{g} \mathrm{rad}}{100 \mathrm{erg}}\right)\left(\frac{86400 \mathrm{sec}}{\text { day }}\right)\left(\frac{\mathrm{m}^{3}}{1293 \mathrm{~g}}\right)$ 
The factor of one-half is the constant of integration based on the infinite disk squrce geometry. Equation 6.1-4 is evaluated for a source strength of $1 \mathrm{Ci} / \mathrm{m}^{2}$ for each radionuclide of interest. The resulting dose conversion factors are stored in a data library for use by the computer program. The dose for a time period, $T_{g}$, is calculated as follows, using the dose conversion factors:

$$
D_{g i}\left(T_{g}\right)=D_{g \gamma i}(5) \bar{G}_{i j}\left(T_{g}\right) S_{g}
$$

where

$D_{g i}$ - dose contribution from radionuclide $i$ over the time period $\mathrm{T}_{\mathrm{g}}$ from ground contamination, rem

$D_{g \gamma i}(5)$ - dose conversion factor at a tissue depth of $5 \mathrm{~cm}$ for exposure to radignuclide $i$ from the ground contamination pathway, rem per $\mathrm{Ci} / \mathrm{m}^{2} /$ day

$\bar{G}_{i j}$ - time-integrated ground concentration for radionuclide $i$ in spatial interval $j$ (as defined in Equations 5.2-2 and 5.2-3), $\mathrm{Ci} \cdot$ days $/ \mathrm{m}^{2}$

$T_{g}$ - period of exposure to contaminated ground, days

$S_{g}$ - shielding factor for exposure to ground contamination, dimensionless.

The shielding factor accounts for effects of ground roughness and backscatter for the exposure situation of interest, as discussed in Section 7.3. by

When exposure to contaminated shoreline is considered, dose is calculated

$$
D_{s i}\left(T_{g}\right)=D_{g} i(5) C_{s i j}\left(T_{g}\right) W_{s} S_{g}
$$

where

$D_{s i}\left(T_{g}\right)$ - dose from external exposure to radionuclide $i$ from contaminated shoreline over the exposure period of $\mathrm{T}_{g}$, rem

$\bar{C}_{s i j}$ - time-integrated water concentration for radionuclide $i$ at water

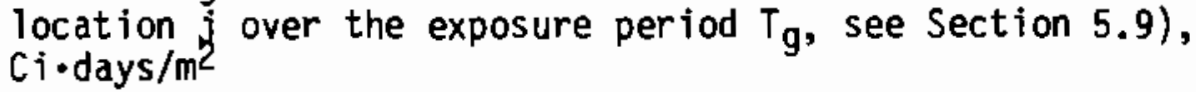

$W_{5}$ - shoreline width factor, dimensionless.

0ther terms are as previously defined. 
The shoreline width factor accounts for shorelines being narrow and not well represented as an infinite disk source.

The dose from exposure to farmland contaminated by irrigation deposition is calculated as

$$
D_{f i}^{w}\left(T_{g}\right)=D_{g Y i}(5) \vec{C}_{s}^{w i}\left(T_{g}\right) S_{f}
$$

where

$$
\begin{aligned}
& D_{f i}^{W}\left(T_{g}\right) \cdot \begin{array}{l}
\text { dose from exposure to contaminated farmlands from irrigation } \\
\text { over the period, } T_{g} \text {, rem }
\end{array} \\
& \begin{aligned}
\bar{C}_{s}^{w i}\left(T_{g}\right) & \text { - time integral of ground concentration over the period } T_{g}, \\
& C i \cdot d a y s / m^{2}
\end{aligned} \\
& S_{f} \text { - shielding factor for exposure to contaminated farmlands, } \\
& \text { dimensionless. } \\
& \text { Other terms are as previously defined. }
\end{aligned}
$$

The parameter $\bar{C}_{S i}\left(T_{q}\right)$ is evaluated as $\bar{C}_{\bar{S}}^{w i}\left(T_{q}\right)$ using Equations 5.2-4 and 5.2-5 when acute irrigation is considered. For chronic irrigation, $\bar{C}_{s}^{W T}\left(T_{g}\right)$ represents $\bar{C}_{S C}^{W i}\left(T_{g}\right)$ of Equations $5.2-6$ and 5.2-7.

When air deposition to farmlands is considered, the external exposure is given by

$$
D_{f i}^{a}\left(T_{g}\right)=D_{g Y i}(5) \bar{G}_{i j}\left(T_{g}\right) S_{f}
$$

where $D_{f i}\left(T_{g}\right)$ - dose from external exposure to contaminated farmland from air
deposition of radionuclide $i$, rem.

Other terms are as previously defined.

\subsubsection{Direct Irradiation}

Dose rate conversion factors which relate photon flux to dose are defined for the direct irradiation pathway. The dose rate conversion factors are calculated for tissue at a depth of $5 \mathrm{~cm}$. A linear buildup factor (Jaeger 1968) is included to account for scattering in the body. The dose conversion factor (for use in Equation 4.3-1) can be described mathematically as

$$
D_{c 5}\left(E_{n}\right)=51.2 e^{-5 \mu_{s}\left(E_{n}\right)}\left[1+5 \mu_{s}\left(E_{n}\right)\right] \mu_{a}\left(E_{n}\right)
$$


where the parameters are

$$
\begin{aligned}
& \mathrm{D}_{\mathrm{c} 5}\left(\mathrm{E}_{\mathrm{n}}\right) \text { - direct irradiation } 5 \mathrm{~cm} \text { tissue dose conversion factor for } \\
& \text { photons of energy } E_{n},\left(m^{2} \cdot\right. \text { rad.dis) per (MeV*Ci.day) } \\
& \mu_{s}\left(E_{n}\right) \text { - the linear energy attenuation coefficient for tissue for } \\
& \text { photons of initial energy } E_{n} \mathrm{~cm}^{-1} \\
& \mu_{a}\left(E_{n}\right) \text { - the linear coefficient of true absorption in tissue for } \\
& \text { photons of initial energy } E_{n} m^{-1} \\
& 5 \text { - average tissue depth for calculation of dose, } \mathrm{cm} \\
& 51.2 \text { - unit conversion factor } \\
& 51.2=\frac{3.7 \times 10^{10}(\mathrm{dis} / \mathrm{sec} \cdot \mathrm{Ci}) 1.6 \times 10^{-6}(\mathrm{erg} / \mathrm{MeV}) 86400(\mathrm{sec} / \mathrm{day})}{100(\mathrm{erg} / \mathrm{g} \cdot \mathrm{rad}) 10^{6}\left(\mathrm{~g} / \mathrm{m}^{3}\right)}
\end{aligned}
$$

The quality factor for gamma radiation is 1 , so the results may be expressed as rem instead of rad. Values of $D_{c 5}\left(E_{n}\right)$ are provided for each of the five energy groups discussed in Section 4.3 .

\subsubsection{Swiming and Boating}

The dose from swiming and boating in contaminated water is calculated for immersion in an infinite volume source of gamma-emitting material. The dose conversion factors for the infinite volume source are calculated by assuming that the energy deposited per unit volume is equal to the energy emitted per unit volume. For exposure to total body at $5 \mathrm{~cm}$ tissue depth the dose conversion factor is given by

$$
D_{S Y \dot{f}}(5)=51.2 \sum_{n}^{\text {photons }} f_{n} f_{Y n} E_{Y n}\left[1+5 \mu_{S}\left(\varepsilon_{Y n}\right)\right] e^{-5 \mu_{S}}\left(E_{Y n}\right)
$$

where

$D_{S Y i}(5) \cdot$ dose conversion factor for radionuclide $i$ for external dose from swimming, rem per $\mathrm{C} i \mathrm{day} / \mathrm{m}^{3}$

$E_{\gamma n} \cdot$ gamma energy for photon $n$ of radionuclide $i$

$f_{n} \cdot$ abundance of photon $n$, photons/disintegration

$f_{Y n}$ - stopping power of tissue relative to air for photons of energy EYn

$\mu_{s}\left(E_{\gamma n}\right) \cdot$ linear energy attenuation coefficient for photons of energy EYn,cm-1 


$$
\begin{aligned}
& \text { 51.2 - unit conversion constant, } \frac{\mathrm{rem} \cdot \mathrm{m}}{\mathrm{C} i \cdot \text { days } \cdot \mathrm{MeV}} \\
& 51.2=\frac{\left(1.6 \times 10^{6} \mathrm{ergs} / \mathrm{MeV}\right)\left(3.7 \times 10^{10} \mathrm{dis} / \mathrm{sec} \mathrm{Ci}\right)(86400 \mathrm{sec} / \mathrm{day})}{(100 \mathrm{ergs} / \mathrm{g}-\mathrm{rad})\left(10^{6} \mathrm{~g} / \mathrm{m}^{3}\right)}
\end{aligned}
$$

The dose from swimming is calculated from the time-integrated water concentration of Section 5.9 as

$$
D_{s i}\left(T_{g}\right)=D_{s Y i}(5) \bar{C}_{s i j}\left(T_{g}\right)
$$

where

$$
\begin{aligned}
& D_{s i}\left(T_{g}\right) \cdot \begin{array}{l}
\text { dose contribution from radionuclide } i \text { for boating during } \\
\text { the time period } T_{g}, \text { rem }
\end{array} \\
& \bar{C}_{s i j}\left(T_{g}\right) \cdot \text { time integral of radionuclide } i \text { water concentration at location } \\
& j, \text { Ci.days/m }
\end{aligned}
$$

The water concentration is calculated from Equation 5.9-2.

The dose from the boating pathway is calculated from the swimming dose conversion factor, applying an additional factor of one-half because the exposed person is above the half-infinite water source:

where

$$
D_{b i}\left(T_{g}\right)=0.5 D_{s \gamma i}(5) \bar{C}_{b i j}\left(T_{g}\right)
$$

$$
\begin{aligned}
& \mathrm{D}_{\mathrm{bi}}\left(\mathrm{T}_{\mathrm{g}}\right) \cdot \begin{array}{l}
\text { dose contribution from radionuclide } \mathrm{i} \text { for swimming during } \\
\text { the time period } \mathrm{T}_{\mathrm{g}} \text {, rem }
\end{array} \\
& \overline{\mathrm{C}}_{\mathrm{bij}}\left(\mathrm{T}_{\mathrm{g}}\right) \cdot \begin{array}{l}
\text { time-integrated water concentration for radionuclide } i \text { at } \\
\text { location } \mathrm{j} \text { for boating exposure, } \mathrm{C} i \cdot \text { days }^{3} / \mathrm{m}^{3}
\end{array}
\end{aligned}
$$

The water concentration parameter is calculated as described in Section 5.9. 


\subsection{INTERNAL DOSIMETRY}

The pathway models discussed in Section 5 provide total radionuclide intake via the air and foods reaching the population. Internal dosimetry models are used to calculate radiation dose to body organs from a given intake and dose period. In order to determine dose from intake, it is necessary for models to describe organ uptake, translocation, deposition and elimination of radioactivity within the body. The two modes of entry to the body illustrated in Figure 6.2-1 are ingestion (to the gastrointestinal tract) and inhalation (to the lungs). Other internal organs receive radionuclides from the gastrointestinal (GI) tract and the lungs via transport through the blood. Models are recommended in the following sections to describe uptake and transport of activity through the GI tract, respiratory system and body organs. These models are well documented; therefore, detailed mathematical representations are not provided here.

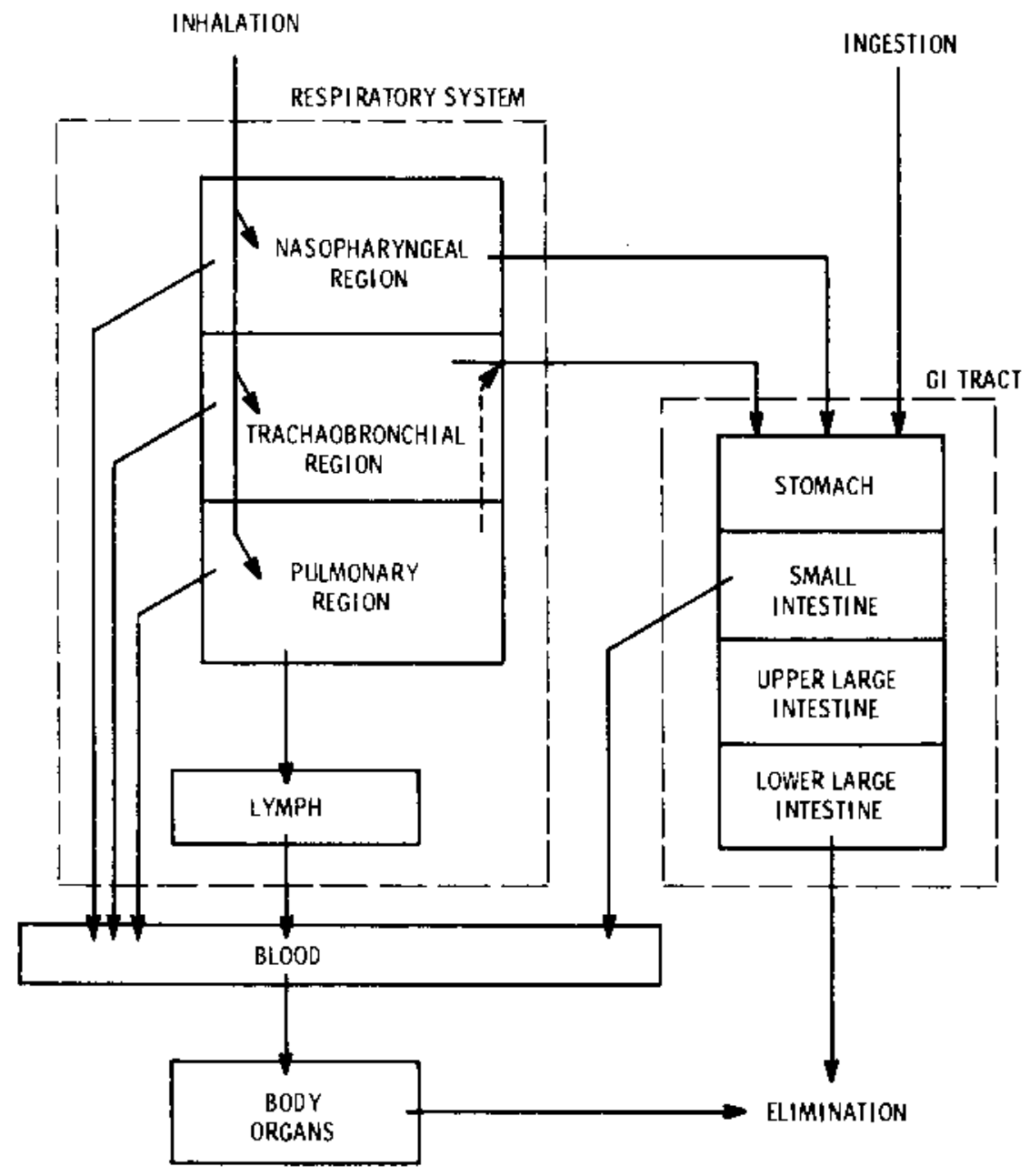

FIGURE 6.2-1. Internal Dosimetry Mode1 
The dose to a given organ is calculated using dose conversion factors generated by the metabolism models described in the next sections. Use of the dose conversion factors is indicated below.

The dose from inhalation of activity during plume passage is calculated by

$$
\text { Dose }=D_{h i} Q_{h i j}\left(T_{r}\right)
$$

where

$D_{\text {hi }}$ - single intake inhalation dose conversion factor for radionuclide $i$ and the desired dose period, $\mathrm{rem} / \mathrm{Ci}$ inhaled

$Q_{h i j}\left(T_{r}\right) \cdot$ total activity of radionuclide $i$ inhaled at location $j$ during release time $T_{r}$ (passage of the plume), Ci/person

$T_{r}$ - duration of release for the accident, sec.

Values for $Q_{h i j}\left(T_{r}\right)$ are determined by Equations 5.3-2 and 5.3-3.

The dose from inhalation of resuspended material is calculated as

$$
\text { Dose }=D_{h i} Q_{r i j}\left(T_{r m}\right)
$$

where

$D_{\text {hi }}$ - inhalation dose conversion factor for radionuclide $i$ over the uptake period (resuspension period), $\mathrm{T}_{\mathrm{rm}}$, and for the desired dose period, rem/Ci inhaled

$Q_{\text {rij }}\left(T_{m}\right)$ - total activity of radionuclide $i$ inhaled during the period $T_{m}$ due to resuspension in spatial interval $\mathrm{j}, \mathrm{C} i /$ person

$T_{\text {rm }} \cdot$ resuspension period, days.

Values for $Q_{r i}\left(T_{r m}\right)$ are determined by Equations 5.4-6 and 5.4-7.

The dose from ingestion of food crops is calculated as

$$
\text { Dose }=D_{e j} Q_{p j}
$$

where

$D_{e j}$ - ingestion dose conversion factor for the appropriate uptake and dose period, rem/ $\mathrm{C}$ ingested

$Q_{p j}^{j}$ - total activity of radionuclide $i$ ingested in $p l a n t$ type $p$ at location $\mathrm{j}, \mathrm{Ci} /$ person 
Values for $Q_{p j}^{i}$ are calculated by Equation 5.5-26.

The dose from ingestion of contaminated animal products is given by

$$
\text { Dose }=D_{e i} Q_{a p j}^{i}
$$

where

$Q_{a p j}^{i}$ - activity of radionuclide $i$ consumed in animal product $p$ for interval $\mathbf{j}, \mathrm{Ci}$ person.

$D_{e i}$ is as previously defined.

The ingested activity, $Q_{a p j}^{i}$, is calculated by Equation 5.6-36.

The dose from ingestion of aquatic foods is

$$
\text { Dose }=D_{e i} Q_{q i j}
$$

where

$Q_{q i j} \cdot$ total consumption of radionuclide $i$ in aquatic food $q$,
$C i /$ person.

$\mathrm{D}_{\mathrm{e} i}$ is as previously defined.

Equations 5.7-17 and 5.7-18 are used to evaluate the consumption parameter, $Q_{q i j}$.

Ingestion of drinking water results in a dose calculated as

$$
\text { Dose }=D_{e i} Q_{w i j}
$$

where

$Q_{w i j}$ - total activity consumed in drinking water by an individual during the period of water contamination, $\mathrm{C} i /$ person.

$\mathrm{D}_{\mathrm{e} i}$ is as previously defined.

Equation 5.8-2 is used to evaluate the drinking water consumption parameter Q wij.

\subsubsection{Respiratory System}

The model recommended for representation of respiratory system metabo' ism and for calculation of lung dose is the ICRP Task Group Lung Model (TGLM) as developed by the ICRP Task Group on Lung Dynamics (Morrow 1966, ICRP 1972). In the TGLM, the respiratory tract is divided into three regions: the nasopharyngeal (NP), the tracheobronchial (TB), and the pulmonary (P), as indicated in Figure 6.2-1. Deposition is assumed to vary with the aerodynamic 
properties of the aerosol distribution and is described by the three parameters $D_{3}, D_{4}$ and $D_{5}$. These parameters represent the fraction of the inhaled material initially deposited in the NP, TB and P regions, respectively. Each of the three regions of deposition are further subdivided into two or more subcompartments, each representing the fraction of material initially in a compartment that is subject to a certain clearance process. The rate of clearance is determined by the translocation class assigned to a particular radionuclide. Material is cleared from the subcompartments to the blood, lymphatic systems, and GI tract. Translocation to other organs and tissues where accumulations of the inhaled radionuclide occur is assumed to take place via the blood. This translocation from the respiratory tract and lymphatic system to the blood has been described in considerable detail (Morrow 1966). A constant fraction of any "soluble" material clearing from the respiratory tract through the GI tract is assumed to be taken up by the blood while passing through the small intestine, as described in Section 6.2.2.

\subsubsection{Gastrointestinal Tract}

The recommended method for calculating dose to tract compartments is to use the initial ICRP model (ICRP 1959) with updated mean transit times of Eve (1968) and mass values from ICRP Publication 23 (ICRP 1975). Table 6.2-1 gives the masses of the contents and average travel time through each compartment of the GI tract. The ICRP GI tract model considers four distinct compartments: stomach, small intestine, upper large intest ine and lower large intestine. The ingested material enters through the stomach and travels sequentialiy through each compartment. Absorption of material into the blood is only considered to occur in the small intestine. Material entering the stomach is assumed to reside there for one hour and then moves collectively to the small intestine. Flow through the small intestine and large intestine is assumed to be continuous and linear. The tissue considered critical in the intestine is the wall. The dose is therefore calculated as one-half the dose to the mass of the contents. For alpha radiation, a factor of 0.01 is also applied to the effective energy to account for the ineffectiveness of alpha particles in reaching the sensitive cells of the stomach and intestine walls. Table 6.2-1 gives the masses of the contents and average trave 1 time through each compartment of the GI tract as defined in ICRP Publication 23 (ICRP 1975).

TABLE 6.2-1. Gastrointestinal Tract Compartment Data

\begin{tabular}{|c|c|c|}
\hline Compartment & $\begin{array}{l}\text { Mass of } \\
\text { Contents } \\
\end{array}$ & $\begin{array}{l}\text { Mean Resident } \\
\text { Time, Hours }\end{array}$ \\
\hline Stomach & $250 \mathrm{~g}$ & $T$ \\
\hline Small Intestine & $400 \mathrm{~g}$ & 4 \\
\hline $\begin{array}{l}\text { Upper Large } \\
\text { Intestine }\end{array}$ & $220 \mathrm{~g}$ & 13 \\
\hline $\begin{array}{l}\text { Lower Large } \\
\text { Intestine }\end{array}$ & $135 \mathrm{~g}$ & 24 \\
\hline
\end{tabular}


The GI tract metabolic model is used for direct ingestion and also for inhaled material that is subsequently swallowed. The fraction of material absorbed through the small intestine into the blood is transferred to other body organs. This transfer is assumed to be immediate (blood transport is not considered to be a time-dependent mechanism). The metabolism of other organs is described in the next section.

\subsubsection{Body Organs}

All organs other than the lung and GI tract compartments are described by a multiple exponential model. Time-dependent input to each organ is considered with removal described by a single effective rate constant defined for each exponential retention function. The differential equation describing the organ concentration for a specific retention term $j$ is

$$
\frac{d Q_{0 j}^{j}(t)}{d t}=R_{0 j}^{j}(t)-\left(\lambda_{i}+\lambda_{o j}^{j}\right) Q_{0 i}^{j}(t)
$$

where

$Q_{0 j}^{j}(t) \cdot$ activity of radionuclide $i$ in organ o described by retention term $j$ at a time $t, C i$

$R_{0 i}^{j}(t)$ - time-dependent uptake rate of radionuclide $i$ by organ 0 and retention term $j$ from the GI tract and respiratory system, Ci/day

$\lambda_{j}$ - radiological decay constant for radionuclide $i$, days ${ }^{-1}$

$\lambda_{o j}^{j}$ - biological removal constant for radionuclide $i$ in organ 0 for retention term $j$, days ${ }^{-1}$.

The total activity in an organ is the sum of the contributions for each retention term. When daughter radionuclides are considered, the above equation is modified to include contributions from parent radionuclides.

This organ model is similar to the initial organ model presented in ICRP Publication 2 (ICRP 1959). The initial model, however, did not allow for timedependent uptake rates by the organ. The time-dependence is included here for use with the respiratory system model described in the preceding section.

\subsection{SUMMARY OF DOSE CONVERSION FACTORS}

Dose conversion factors must be provided to estimate all doses required by the remedial actions model and health effects model. The remedial action model requires doses to be calculated over the first year and second year after the accident. Inhalation dose factors must be provided for acute uptake (inhalation during plume passage) and chronic uptake (inhalation of resuspended 
activity). Ingestion dose factors are needed for acute uptake and also chronic uptake (drinking water, food crops, animal products and aquatic foods).

Table 6.3-1 presents a summary of dose factors to be provided. External dose rate factors for exposure to the contaminated plume, ground and water are dependent only on the radionuclides present. The total-body dose calculated at a tissue depth of $5 \mathrm{~cm}$ is used as the dose for all internal organs. The direct irradiation dose rate factors are determined for each average photon energy as specified by the energy groupings of Table 4.3-1. These energydependent dose rate factors are coupled with photon emission data for each nuclide to estimate dose.

TABLE 6.3-1. Dose Conversion Factor Summary

Exposure Pathway

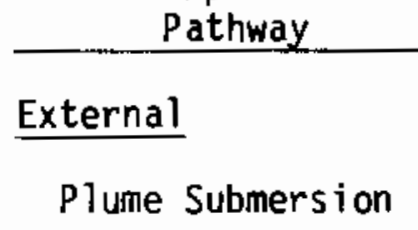

Ground Contamination

Water Immersion

Direct Irradiation

Interna]

Ingest $i$ on

Inhalation: acute
Symbol

$$
\text { Dpri (5) }
$$

$D_{s \gamma j}(5)$

$D_{c 5}\left(E_{n j}\right)$

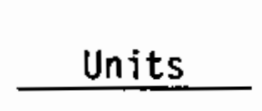

Functional

Dependence radionuclide

$\frac{\text { rem } m^{3}}{c i \cdot s e c}$

$\frac{\text { rem } m^{2}}{c j \cdot d a y}$

$\frac{\text { rem } m^{3}}{c j \cdot d a y}$

$\frac{\text { rem } m^{2} d i s}{C i \cdot d a y \cdot M e V}$ photon energy

radionuclide

radionuclide

Internal dose factors for ingestion and inhalation are specified for each radionuclide, organ, uptake period and dose period required by the remedial action model and health effects model. A suggested set of uptake and dose periods is presented in Table 6.3-2. The one- and two-year periods are for use in estimating remedial action decision doses as defined in Section 7.7. The longer uptake periods are for estimating doses used to calculate health effects from chronic exposures. The time periods for chronic exposure $>2$ years are tentative at this time and may be changed to meet requirements of the health effects calculations. It is only necessary that the time periods selected for the dose conversion factor data library be sufficient for the health effects calculation model. 
TABLE 6.3-2. Time Periods for Internal Dose Conversion Factors

Uptake Period

Single Intake

1 year

10 years
Dose Period

1,2 , and 10 years

1,2 , and 10 years

$10,20,30,40,50,60$, and 70 years 


\section{•}

. 


\subsection{REMEDIAL ACTION}

This section describes the remedial action model used to assess the effects of various actions on radiation dose and economic costs. Costs are incurred when specific actions are taken to reduce potential radiation exposure below predetermined dose criteria for specified exposure pathways. The reduction of dose in turn results in a reduction of deleterious effects on health. Situations may exist, however, wherein the maximum effort will still not eliminate the possibility of health effects. The logic for determining which remedial actions should be taken is discussed in this section.

There are two types of exposures for which remedial actions are defined: 1) inhalation and external exposures and 2) food pathway exposures. Remedial actions for the first exposure type involve evacuation, sheltering, land interdiction, decontamination, condemnation (land interdiction for longer than two years) and the administration of potassium iodide tablets. Remedial actions for food pathway exposures include crop, land and water usage interdiction and crop, land and water decontamination. The specific actions employed in a given situation are determined by comparing dose levels with dose criteria. When no dose criteria are exceeded, the model indicates that no remedial actions need be taken. If any criteria are exceeded, the minimum action will be to monitor the environment for a period of time after the accident.

Input information to the remedial action decision model includes

- dose levels for each pathway and exposure time resulting from the accident under consideration

- remedial action dose criteria for each pathway and exposure time

- potential dose reduction for specific remedial actions; i.e., evacuation, relocation and decontamination.

The sections below describe the dose values used as a basis for each action (Section 7.1) and the logic used in determining the actions to be taken (Section 7.2).

\subsection{DECISION DOSES}

This section describes doses which must be calculated for application of the remedial action decision logic. These are referred to as decision doses. The pathways contributing to each dose and the period of exposure to be considered are given. The decision doses are compared to their respective dose criteria to determine which actions are necessary. Numerical values for the dose criteria are not specified here because these are meant to be defined by the user of the computer code.

The decision dose categories in the Reactor Safety Study were based on reconmendations of the Federal Radiation Council and the Medical Radiation 
Council of Great Britain. The Federal Radiation Council defined "protective action guides" (PAG's) to determine necessary actions (FRC 1964, 1965). The PAG's are defined for three categories which cover the following areas:

- Category I--the immediate transmission of radionuclides through the pasture-cow-milk-man pathway

- Category II--the transmission of radionuclides to man through dietary pathways other than that specified as Category I during the first year after an acute contaminating event

- Category III--the long-term transmission of strontium-90 through the soil into plants in the years following a contaminating event.

Categories I and II relate to intake during the first year after early deposition, and Category III considers intake after the first year. The Medical Radiation Council guidelines are expressed as "energency reference Tevels" (ERL's), which are the total radiation dose received by a tissue from external and internal sources as a result of an accident, regardless of the period over which the dose is accumulated. Based on details of these guidelines, the Reactor Safety Study selected the dose criteria shown in Table 7.1-1. These criteria were used to determine actions for long-term exposure. For shortterm actions such as evacuation or relocation, the decision was based on the "seven-day" dose, defined as the sum of

- external dose received during cloud passage

- external dose received during the first seven days from contaminated ground

- internal dose from inhalation.

TABLE 7.1-7. Dose Categories and Dose Criteria Used by Reactor Safety Study

\begin{tabular}{|c|c|c|}
\hline xposure Pathway/Radionuclides & $\begin{array}{c}\text { Dose } \\
\text { Criteria } \\
\end{array}$ & Organ/Dose Time \\
\hline $\begin{array}{l}\text { External Irradiation } \\
\text { Low population areas } \\
\text { Urban areas }\end{array}$ & $\begin{array}{l}10 \mathrm{rem} \\
25 \mathrm{rem}\end{array}$ & $\begin{array}{l}\text { Whole body in } 30 \text { years } \\
\text { whole body in } 30 \text { years }\end{array}$ \\
\hline $\begin{array}{l}\text { Ingestion via Milk } \\
\text { Strontium } \\
\text { Cesium } \\
\text { Iodine }\end{array}$ & $\begin{array}{l}3.3 \mathrm{rem} \\
3.3 \mathrm{rem} \\
10 \mathrm{rem}\end{array}$ & $\begin{array}{l}\text { bone marrow in first year } \\
\text { whole body } \\
\text { thyroid }\end{array}$ \\
\hline $\begin{array}{l}\text { Ingestion via 0ther Paths } \\
\text { Strontium } \\
\text { Cesium }\end{array}$ & $\begin{array}{l}2 \mathrm{rem} \\
2 \mathrm{rem}\end{array}$ & $\begin{array}{l}\text { bone marrow in first year } \\
\text { whole body }\end{array}$ \\
\hline
\end{tabular}


The inhalation contribution was considered differently for each organ by the Reactor Safety Study. The time periods for the inhalation contribution are given in Table 7.1-2.

\author{
TABLE 7.1-2. Time Periods for Inhalation Dose Contribution \\ to the Seven-Day Dose

$\begin{array}{ll}\text { Organ of Reference } & \text { Inhalation Dose Periodt } \\ \text { Bone Marrow } & \begin{array}{l}\text { Seven days, plus half of dose } \\ \text { from day 8 through day } 30\end{array} \\ \text { Lungs } & \begin{array}{l}\text { One year } \\ \text { Gastrointestiona1 Tract }\end{array} \\ \text { Seven days }\end{array}$

*Time after inhalation for exposure from internally deposited activity

In 1975, the EPA published PAG's for nuclear incidents (EPA, 1975). The report included a general discussion of PAG's and their implementation, followed by PAG values for two exposure pathways (both from exposure to a passing plume): external whole body exposure and inhalation thyroid dose. The intent was to generate PAG values for other pathways, but this has not been done to date. Table 7.1-3 summarizes the PAG values given by EPA for the general public.

TABLE 7.1-3. Protective Action Guides for Exposure of the General Population to Radionuclides in a Passage Plume(a)

Organ

Whole Body (external)

Thyroid (inhalation)

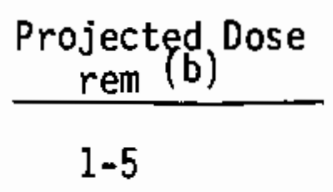

$5-25$

(a)Adapted from EPA 1975

(b) The lowest value shown should be used if there are no major local constraints in providing protection at that level, especially to sensitive populations. Local constraints may make lower values impractical to use, but in no case should the higher value be exceeded in determining the need for protective action. 
The EPA cautioned that

the projected dose does not include dose that may have been received prior to the time of estimating the projected dose. For protective actions to be most effective, they must be instituted before exposure to the plume begins. PAG's should be considered mandatory values for purposes of planning; but under accident conditions, the values are guidance subject to unanticipated conditions and constraints such that considerable judgment may be required for their application.

The EPA also recommended a graded series of actions corresponding to various projected doses. Those applicable to the general population are summarized in Table 7.1-4. The EPA PAG's are "projected" doses, but it is obvious that all of the whole-body external exposure and the thyroid dose from radioiodine inhalation will be received during or within a short time (weeks) after the passage of the plume.

The Food and Drug Administration (FDA, 1978) has recommended PAG's to determine actions for the reduction of radiation exposure to the public via the food pathway. For an exposed person in the population, the preventive PAG is 1.5 rem projected dose commitment to the thyroid, or 0.5 rem projected dose commitment to the whole body, bone marrow or any other body part. The projected dose commitment is defined as the dose that would be received in the future if no protective action were taken. The FDA also defines emergency PAG's at a factor of 10 higher than the above preventive PAG's. Note that the FDA limits are based on long (lifetime) dose commitment periods, while the Reactor Safety Study dose criteria are based on shorter exposure periods.

The present study will use dose conmitments for specified uptake periods in determining remedial action requirements. The dose conmitment represents the total dose received by a person during his lifetime (such as 50 years) from radionuclides taken in during the uptake period. For external exposures the dose cormitment period is equal to the uptake period.

Table 7.1-5 summarizes the decision doses to be used to determine which remedial actions will be taken. The calculated decision doses are compared to the appropriate dose criteria for each organ and exposure type to determine necessary actions. In addition to decision doses listed in Table 7.1-5, the doses from iodine for ingestion and inhalation pathways must be calculated for consideration of administration of potassium iodide tablets. 
TABLE 7.1-4. Protective Actions Recommended by the Environmental Protection Agency to Avgid Whole-Body and Thyroid Dose from Exposure to a Gaseous Plume (a)

Projected Dose (rem) to the Population

Whole Body, <1

Thyroid

$<5$

ín

Whole Body, 1 to $<5$

\author{
Recommended Actions (b) \\ - No protective action required. \\ - State may issue an advisory to seek \\ and await further instructions or to \\ voluntarily evacuate. \\ - Monitor environmental radiation levels \\ - Seek sheiter and await further instruc- \\ tions. \\ - Consider evacuation, particularly for \\ children and pregnant women. \\ - Monitor environmental radiation leve?s. \\ - Control access.
}

Thyroid, 5 to $<25$

Whole Body, 5 and Above

Thyroid, 25 and Above
- Conduct mandatory evacuation of populations in the predetermined area.

- Monitor environmental radiation levels and adjust area for mandatory evacuation based on these levels.

- Control access.

\author{
Coments \\ Previously recommended \\ protective actions may \\ be reconsidered or \\ terminated.
}

\footnotetext{
(a) Adapted from EPA 1975

(b) These actions are recommended for planning purposes. Protective action decisions at the time of the
} incident must take into consideration the impact of existing constraints.

Seeking shelter would be an alternative if evacuation were not immediately possible. 


\section{TABLE 7.1-5. Decision Doses}

\begin{tabular}{|c|c|c|}
\hline Dose Type & Pathways & Uptake Periods \\
\hline Total Dose & A 11 & First year \\
\hline Inhalation/External & All inhalation and external & First year \\
\hline Ingestion & All ingestion & $\begin{array}{l}\text { First year } \\
\text { Second year }\end{array}$ \\
\hline External & Direct irradiation & $\begin{array}{l}\text { Seven days* (and with } \\
\text { sheltering) } \\
\text { Day B to one year } \\
\text { First year }\end{array}$ \\
\hline Inhalation/External & $\begin{array}{l}\text { Inhalation and external } \\
\text { during plume passage }\end{array}$ & $\begin{array}{l}\text { Seven days } \\
\text { (and with sheltering) }\end{array}$ \\
\hline Inhalation/External & $\begin{array}{l}\text { Ground contamination and } \\
\text { resuspension }\end{array}$ & $\begin{array}{l}\text { Seven days } \\
\text { (and with sheltering) } \\
\text { Day } 8 \text { to one year } \\
\text { (and with decontamination) } \\
\text { Second year } \\
\text { (and with decontamination) }\end{array}$ \\
\hline Inhalation & $\begin{array}{l}\text { Iodine inhalation dose to } \\
\text { thyroid during plume } \\
\text { passage }\end{array}$ & Seven days \\
\hline Inhalation & $\begin{array}{l}\text { Iodine inhalation dose to } \\
\text { thyroid from resuspension }\end{array}$ & First year \\
\hline Ingestion & All waterborne ingestion & First year \\
\hline Ingestion & All airborne ingestion & First year \\
\hline Ingestion & Aquatic foods & $\begin{array}{l}\text { First year } \\
\text { Second year }\end{array}$ \\
\hline Ingestion & Drinking water & $\begin{array}{l}\text { First year } \\
\text { Second year }\end{array}$ \\
\hline Ingestion & $\begin{array}{l}\text { Irrigation-contaminated } \\
\text { food crops }\end{array}$ & $\begin{array}{l}\text { First year } \\
\text { Second year }\end{array}$ \\
\hline Ingestion & $\begin{array}{l}\text { Irrigation-contaminated } \\
\text { animal products (including } \\
\text { animal drinking water) }\end{array}$ & $\begin{array}{l}\text { First year } \\
\text { Second year }\end{array}$ \\
\hline Ingestion & $\begin{array}{l}\text { Airborne-contaminated food } \\
\text { crops }\end{array}$ & $\begin{array}{l}\text { First year } \\
\text { (and with decontamination) } \\
\text { Second year } \\
\text { (and with decontamination) }\end{array}$ \\
\hline Ingestion & $\begin{array}{l}\text { Airborne-contaminated } \\
\text { animal products }\end{array}$ & $\begin{array}{l}\text { First year } \\
\text { (and with decontamination) } \\
\text { Second year. } \\
\text { (and with decontamination) }\end{array}$ \\
\hline
\end{tabular}

*For accidents lasting longer than seven days, the uptake period is the duration of the release. 


\subsection{DECISION LOGIC}

The selection of specific remedial actions is based on comparison of dose criteria with the calculated decision doses as defined in the previous section. This section defines the logic by which the calculated decision doses and dose criteria are compared. Figure 7.2-1 presents the logic used to determine minimum action (no criteria exceeded) and to distinguish between the two types of action mentioned in Section 7.0:

- Type 1--actions to reduce external and inhalation exposure

- Type 2--actions to reduce ingestion exposure.

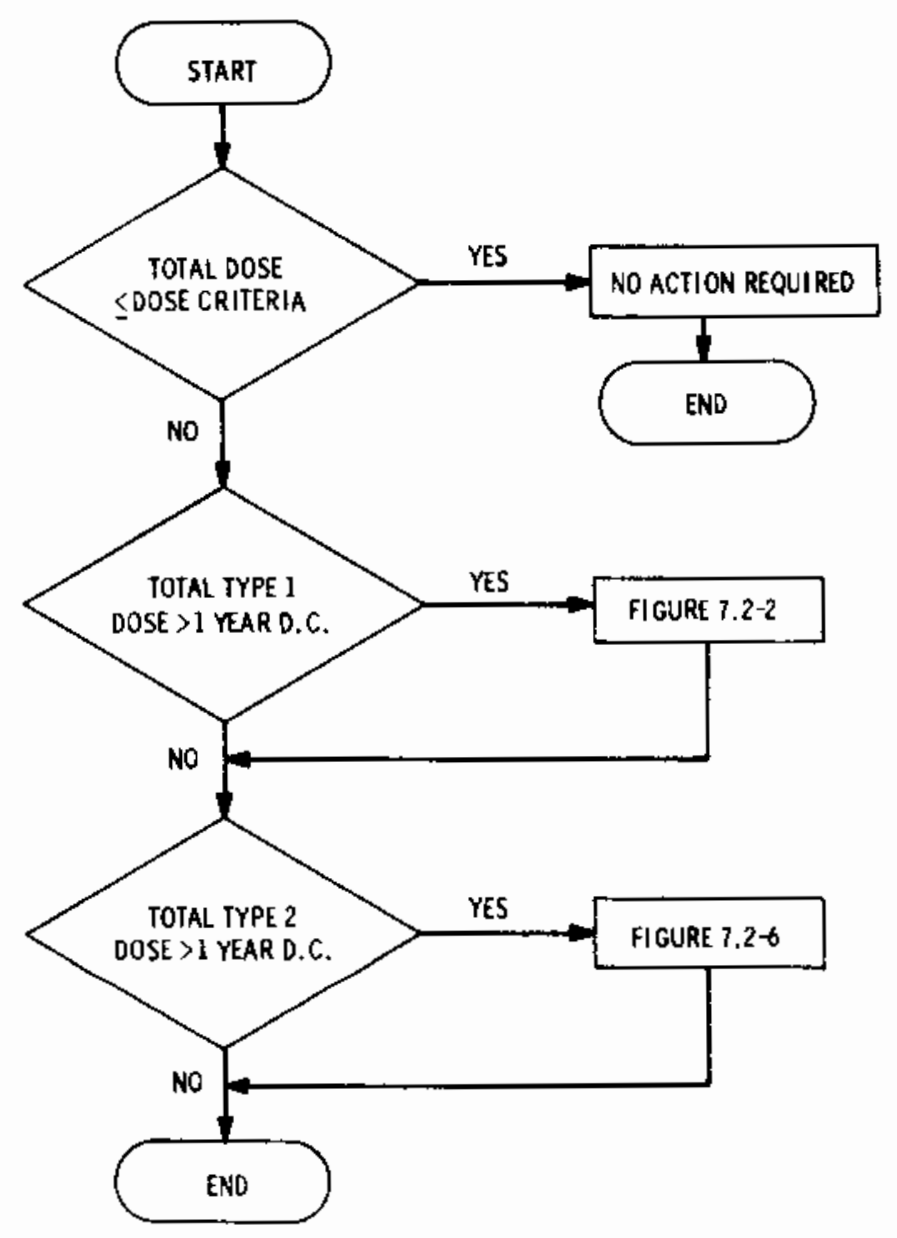

FIGURE 7.2-1. Remedial Action Control Logic

Reference to these types is made in the logic diagrams. The term decision dose is abbreviated in the logic diagrams as "D.C." Each test of the logic diagram is performed for all specified organs. If one or more organ criteria are exceeded, then the action is taken. The logic for Type 1 exposures is shown in Figure 7.2-2. Each decision in this figure is based on a fraction of the 


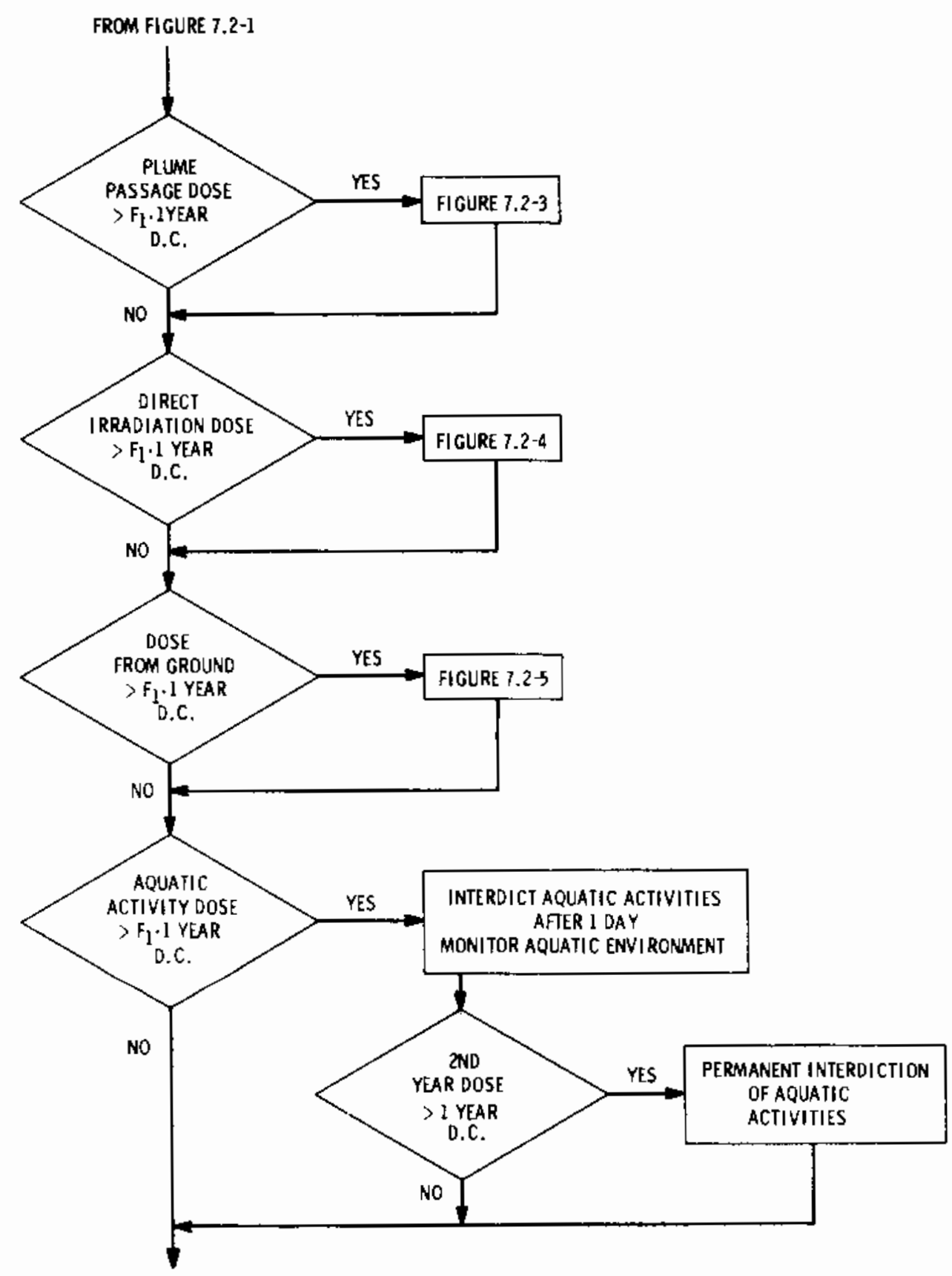

RETURN TO FIGURE 7.2-1

FIGURE 7.2-2. Remedial Action Logic for Type 1 Exposures

total criteria for Type 1 exposures. This is done to ensure that the total of the major exposure pathways is reduced to below the dose criteria. The fraction value is determined as follows: 


\section{Exposure Modes}

airborne, liquid and direct
airborne and liquid or direct
airborne only
direct and liquid
direct only or liquid only

\author{
Fraction $\mathrm{F}_{7}$ \\ one-fourth \\ one-third \\ one-half \\ one-half \\ one
}

Figure 7.2-3 presents the logic used for the short-term uptake received during plume passage from inhalation and external exposure to the activity in the plume. This diagram considers administration of potassium iodide (KI) tablets and emergency actions. Special dose criteria are defined for these actions.

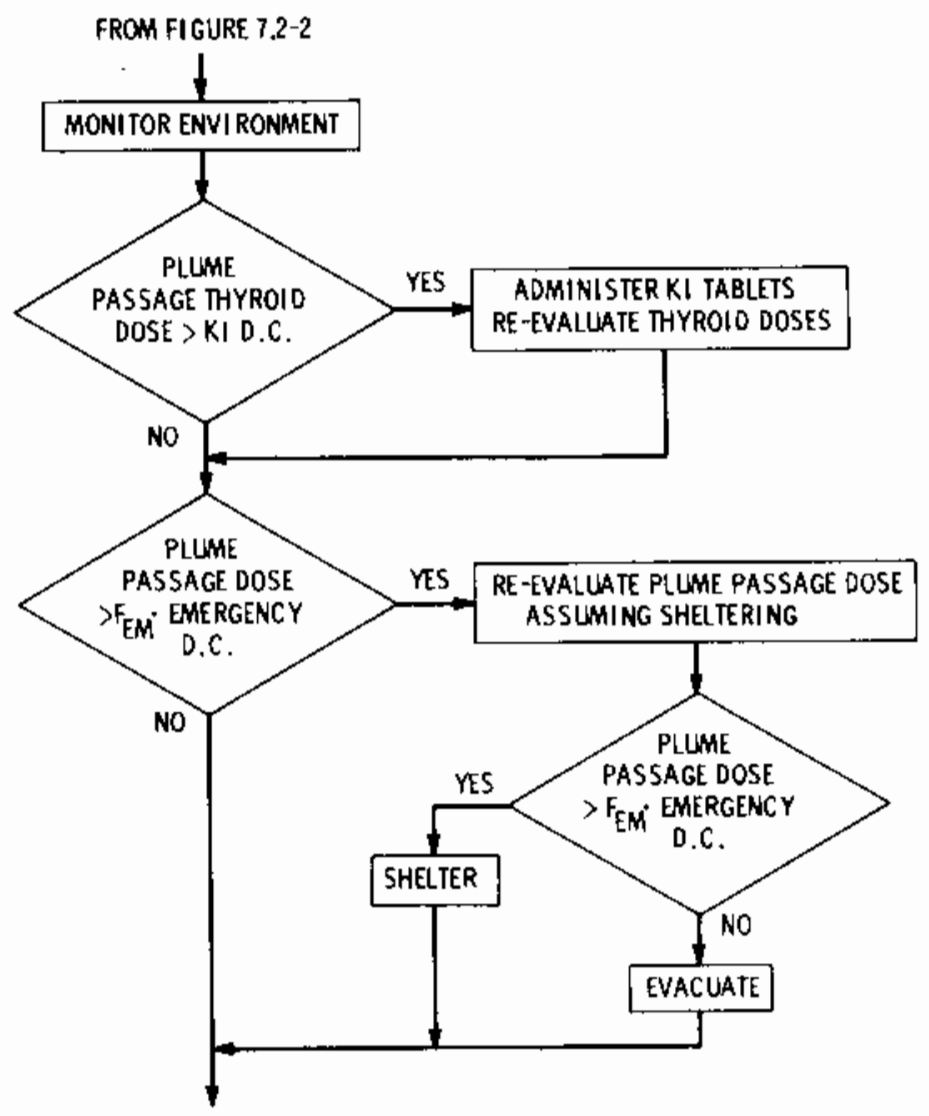

RETURN TO FIGURE $72-2$

\section{FIGURE 7.2-3. Remedial Action Logic for Plume Passage Exposures}

The use of KI tablets is only considered for reduction of inhalation exposure to the thyroid. Emergency actions (evacuation or sheltering) may be needed for plume passage, direct irradiation from contained activity or exposure to contaminated ground. A factor similar to $F_{1}$ is defined for emergency actions: 


$\begin{array}{ll}\frac{\text { Exposure Modes }}{\text { airborne and direct }} & \frac{\text { Fraction, FFM }}{\text { one-third }} \\ \begin{array}{l}\text { airborne only } \\ \text { direct only }\end{array} & \text { one }\end{array}$

Note that liquid releases are not considered in determining $F_{E M}$. Sheltering is in order if it will reduce the dose commitment below the emergency dose criteria; otherwise, evacuation of the spatial interval will be conducted. It should be noted that evacuation is only considered within a given distance from the release. At larger distances, such as 10 miles (USNRC/EPA, 1978b), evacuation is not undertaken, regardless of the dose levels.

Decisions related to reduction of direct irradiation doses are shown in Figure 7.2-4. The minimum action for this diagram is monitoring and sheltering for seven days. Evacuation is possible if dose levels are high enough.

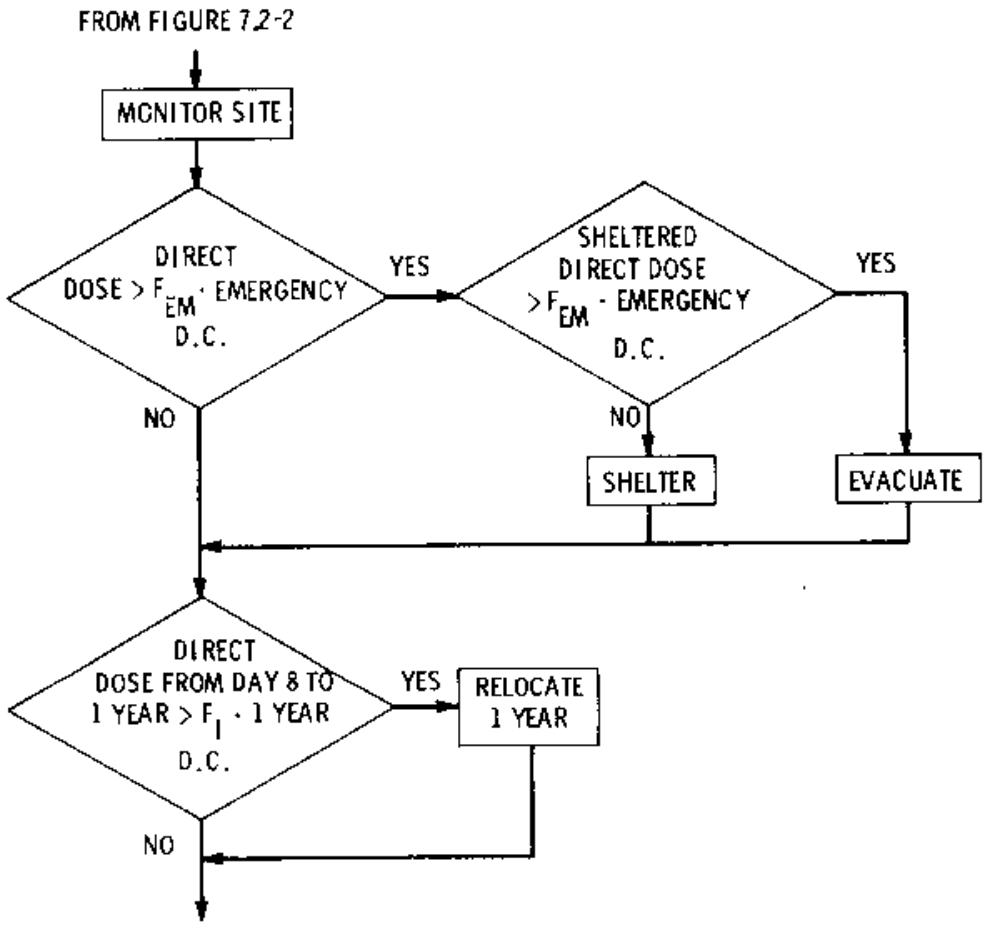

RETURN TO FIGURE 7.2-2

FIGURE 7.2-4. Remedial Action Logic for Direct Irradiation Exposure

Logic for remedial action due to ground contamination exposure is shown in Figure 7.2-5. The decision dose includes inhalation of resuspended material after the accident is over. A one-year uptake period is used for the inhalation dose calculation. In addition to relocation and administration of KI tablets, decisions about sheltering and evacuation are made for land decontamination and condemnation. If decontamination will allow use of the land 


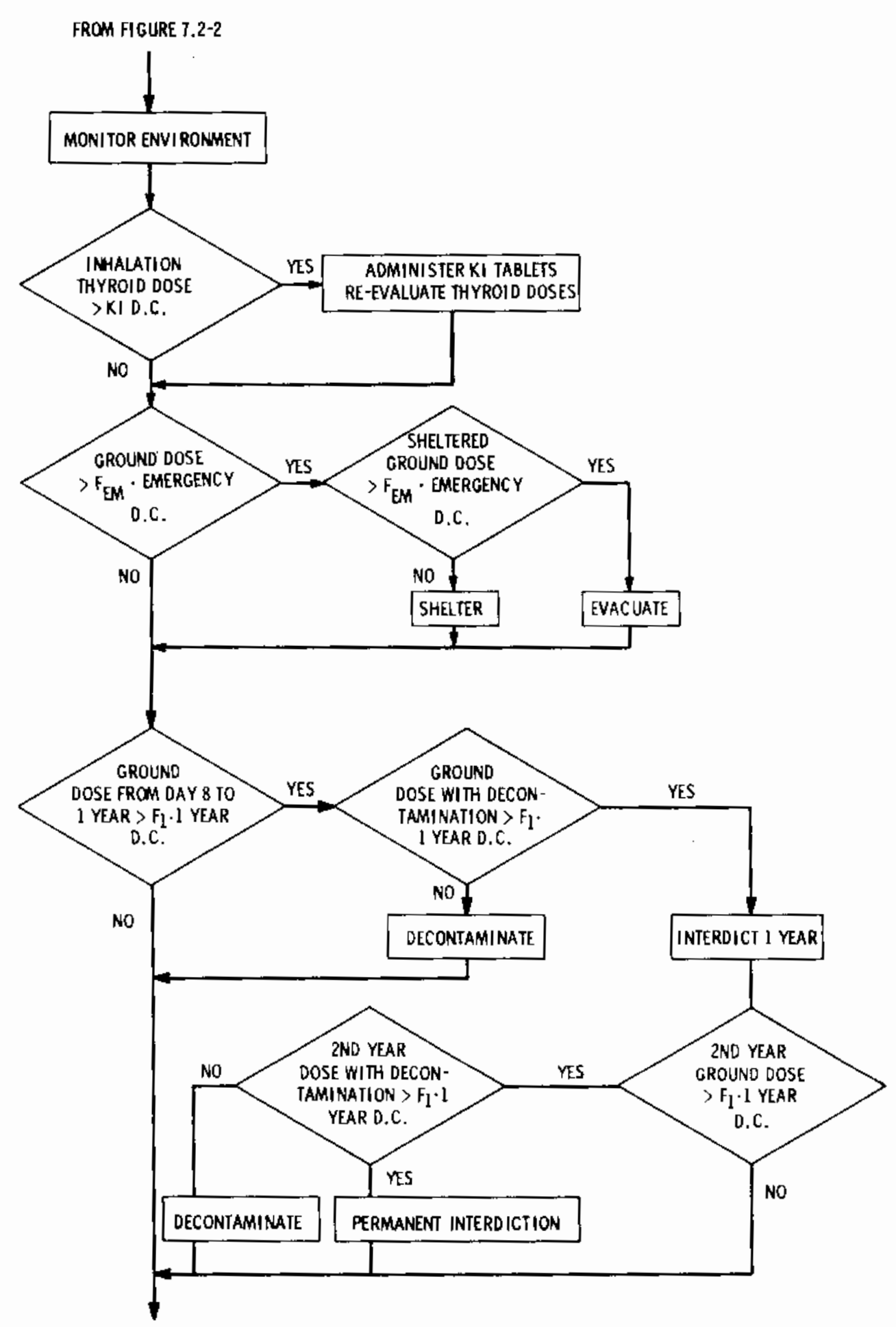

RETURN TO FIGURE 7.2-?

\section{FIGURE 7.2-5. Remedial Action Logic for Contaminated Ground External Exposure and Resuspension Inhalation Exposure}


(based on dose from the eighth day through the first year), it may be undertaken. However, if decontamination will not sufficiently reduce the dose or if it costs less to interdict usage of the 1 and, then the land will be interdicted for the first year. The second-year dose comitment is tested if the first-year dose commitment with decontamination was over the dose criteria. If the second-year dose commitment is also over the dose criteria, permanent interdiction (condemnation) is assumed in evaluating the economic cost.

When the dose from the combined aquatic activities of swiming, boating and shoreline use is excessive, the proper response is to interdict these activities for one year as indicated in Figure 7.2-2. Permanent interdiction is required if the second-year dose level is too high. Decontamination of shorelines may be undertaken if the dose level will be reduced below the one-year criterfa (not shown in Figure 7.2.2).

Type 2 actions are related to reduction of ingestion pathway dose commitments, as indicated in Figure 7.2-6. The first two tests indicate the release modes that contributed significantly to ingestion dose comitments.

FROM FIGURE 7.2-1

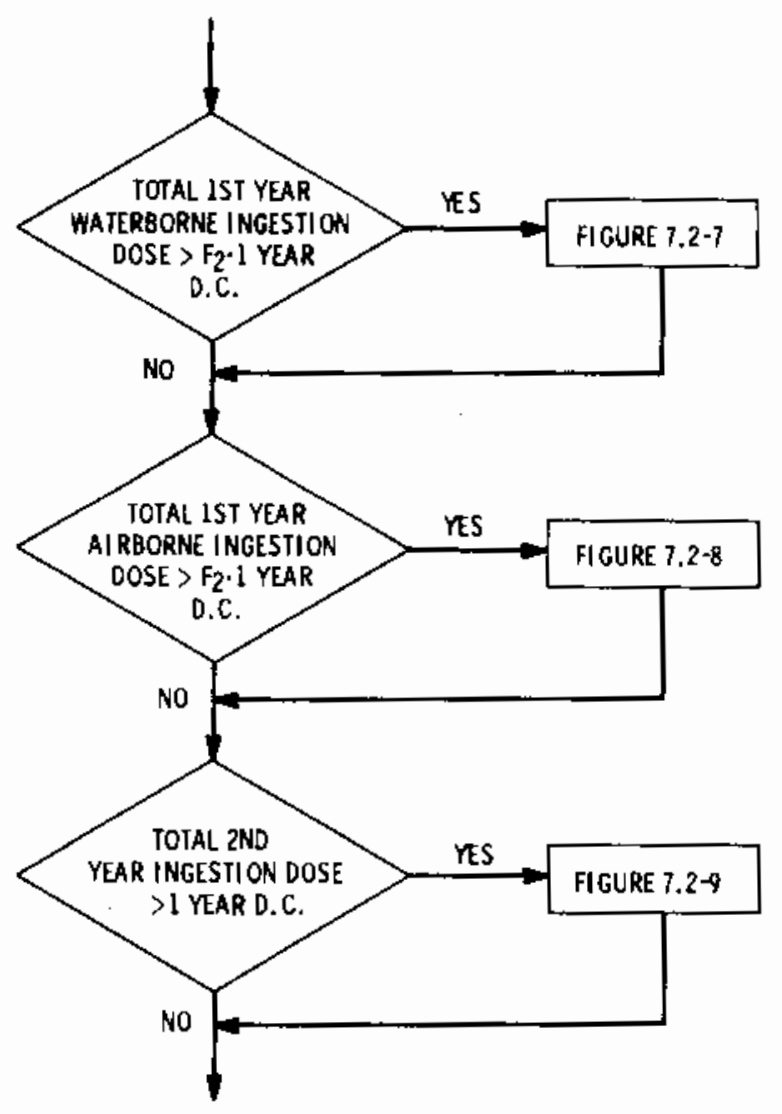

RETURN TO FIGURE $7,2-1$

FIGURE 7.2-6. Remedial Action Logic for Type 2 Exposures 
The limit for comparison is modified by a factor depending on the release modes involved in the particular accident. When both air and liquid releases are considered, the factor is one-half. When only one mode of release is considered, the factor is one.

The logic of Figure 7.2-7 compares each of the four liquid release ingestion pathways with one-fourth of the Type 2 dose criteria. Actions are taken as indicated for those pathways which exceed the dose criteria. Figure 7.2-8 presents the logic for the two airborne release ingestion pathways where comparisons are with one-half of the Type 2 dose criteria.

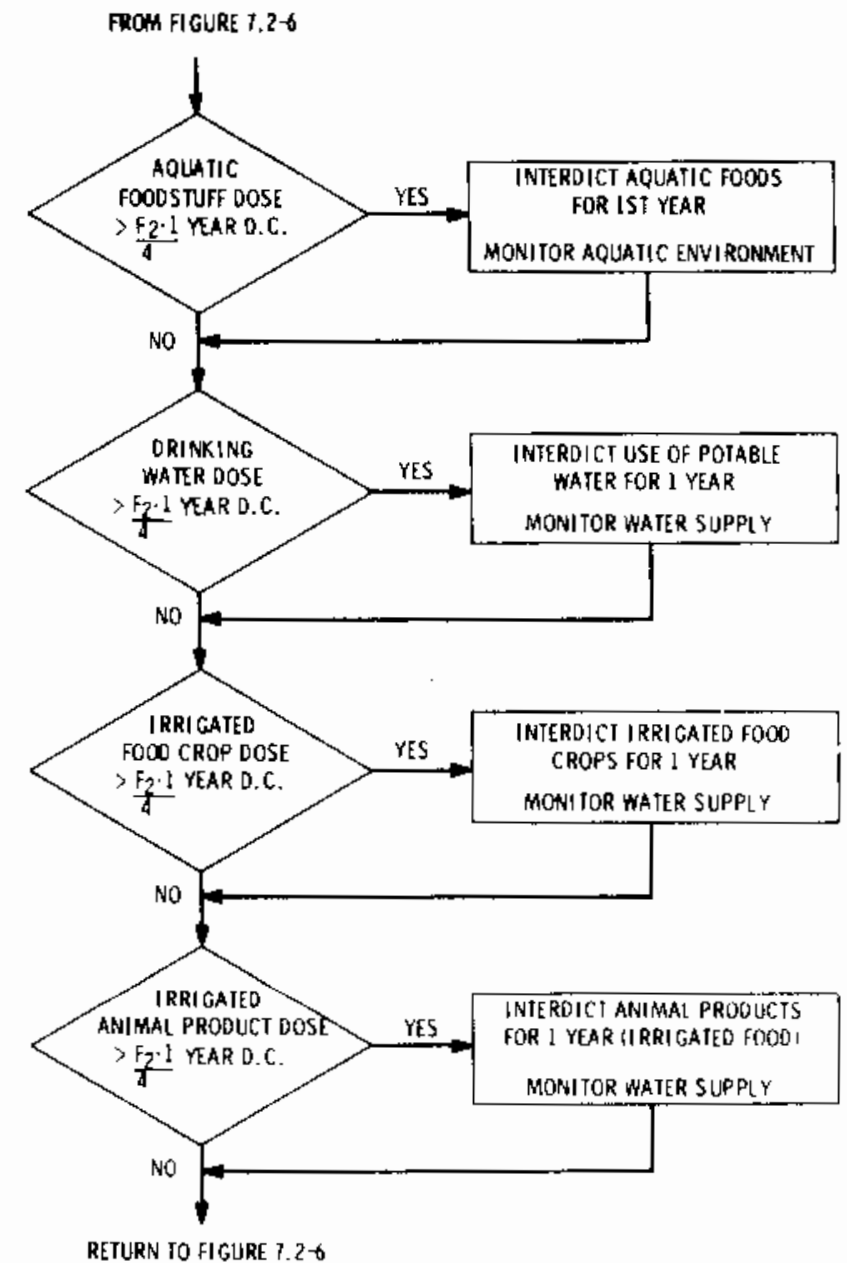

FIGURE 7.2-7. Remedial Action Logic for Liquid Release Ingestion 


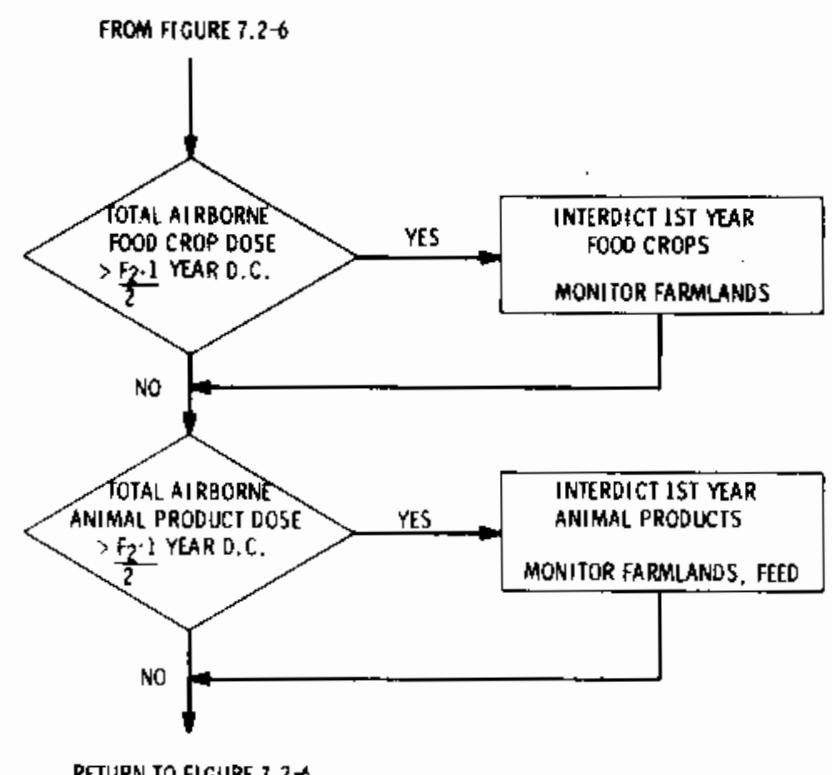

RETURN TO FIGURE $7.2-6$

\section{FIGURE 7.2-8. Remedial Action Logic for Airborne} Release Ingestion Exposures

The dose commitment received from uptake during the second year is calculated after consideration of any first-year remedial actions taken. If the second-year dose is below the Type 2 dose limit, the land is usable and no further action is taken (except possibly monitoring). The logic of Figure 7.2-9 is used to determine necessary actions when the second-year dose commitment is above the limit. If decontamination will not reduce the second-year dose commitment below the limit, then the farmiand is assumed to be permanently interdicted (condemned) for purposes of estimating economic costs.

The remedial action model is used in conjunction with the health effects model and the economic cost model. Whenever an action is necessary, the health effects and costs of the action are determined. 


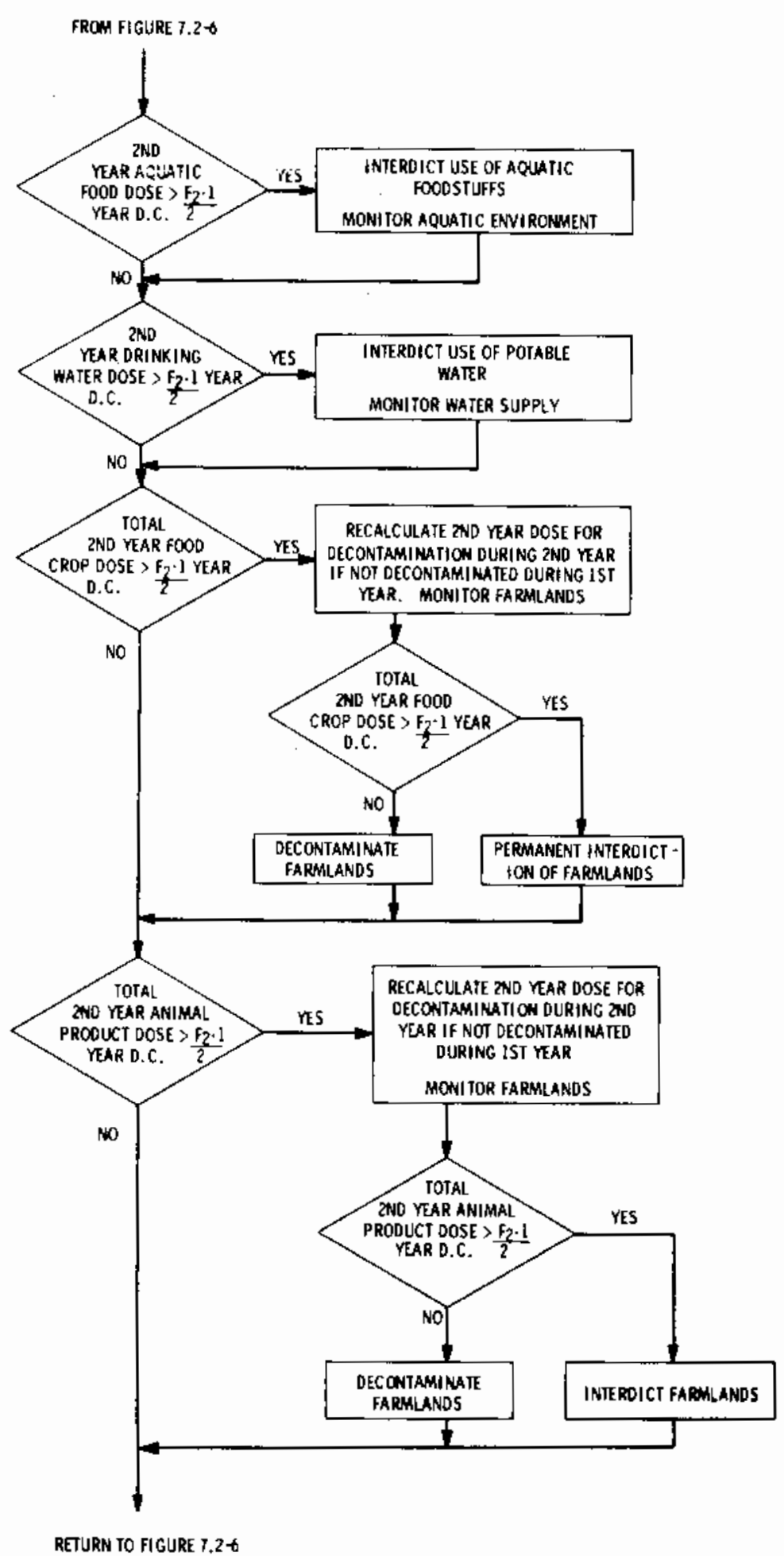

FIGURE 7.2-9. Remedial Action Logic for Second-Year Ingestion 


\subsection{EVACUATION AND SHELTERING MODEL}

In the event of a major accident at a nuclear power plant, evacuation or sheltering of the population may be necessary. The evacuation and sheltering models oriented toward emergency planning which are presented here were developed for estimating the effect of these activities on exposure received by the local populations. The mode 7 relies mainly on the information supplied by the user and avoids detailed time-motion models. In the proposed models, the user provides the start time and end time for evacuation and sheltering. For evacuation, the start is the point at which the first person leaves the area (receiving no further radiation exposure); the end time is when the last person has left. For time between these points, a function is defined for estimating the fraction of people remaining within the range of exposure. For sheltering, the start time is when the first person enters a shelter and the end time is when the last person has entered. A function is also defined for sheltering to estimate the fraction of people within the shelter at a given time.

For situations involving persons who neither evacuate the area nor enter shelters, exposure will be received over the entire period that radiation is present. Such a stationary population may include individuals conf ined to hospitals or prisons and those who refuse to move. When evacuation and sheltering are not called for, the entire local population will be in this category.

The proposed model defines two population groups at a given location: 1) those who will be evacuated and 2) those who will enter shelters. The stationary population is the difference between the total population and the moving population. The remedial action model does not allow sheltering and evacuation to occur simultaneously for the same spatial interval. Therefore, the non-moving population is based on either sheltering or evacuation for each spatial interval. The moving population groups are represented by functions normalized to the total population. The remedial action model allows for no movement, sheltering or evacuation depending on dose levels calculated. When sheltering is called for, the input sheltering fraction represents the fraction of the population in the spatial interval that will enter shelters. Those who do not enter shelters are treated as a stationary population. The evacuation fraction represents the fraction of the population that will evacuate when necessary. A shelter is defined as a structure that provides protection from radiation exposure. A potential sheltering action would be to have all people remain indoors.

The dose to local population groups during the early period following an accident is dependent on transport of radiation and radioactive materials to the exposure area. Four exposure pathways are considered: 1) external exposure from the contaminated plume, 2) inhalation of contamination while in the plume, 3) external exposure from ground contaminated by cloud passage and 4) direct irradiation from materials contained within the reactor buildings. To estimate population dose for each of these pathways, it is necessary to evaluate the time integral of the product of exposure rate and the number of persons exposed. 


$$
\text { Population Dose }=\underset{\text { Factor }}{(\text { Exposure Conversion })} \int_{\text {Time }}(\text { Concentration }) \text { (Population) } d t
$$

The evaluation is simplified by the use of normalized concentration functions and normalized population functions. The concentration functions are normalized to maximum air and ground concentrations of 1 and are dimensionless. The population functions are normalized to total population. The normalized functions are used to calculate dose by multiplying by the actual concentration and total population at a location of interest.

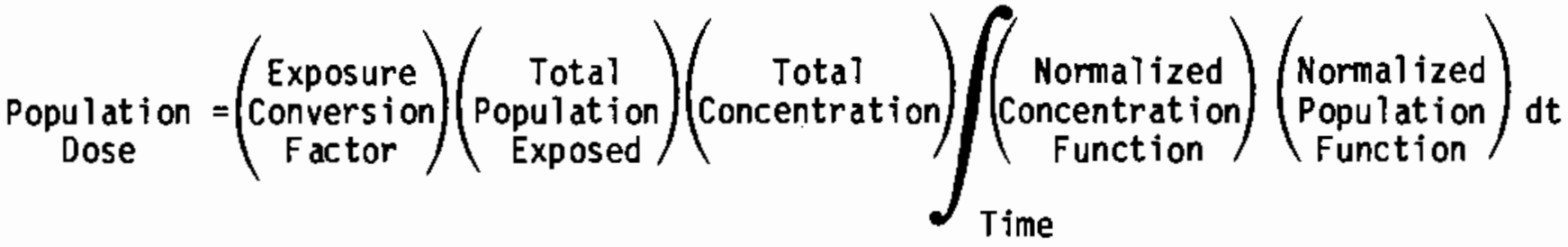

The "total concentration" is calculated by Equation 4.1-22 for air exposures and by Equation 4.1-23 for ground exposures. The normalized integrals are a function of distance, since plume travel time is involved in their calculation (except for direct irradiation). Direct irradiation exposure is based on the actual dose rate at the location of interest because direct dose is a function of both distance and direction.

The parameters used in the equations for the sheltering and exposure model are defined below:

$c(t)$ - normalized air concentration function, dimensionless

$D(t)$ - direct irradiation dose rate function, rem/day

$G(t)$ - normalized ground concentration function, dimensionless

$\mathrm{P}_{\mathrm{e}}(\mathrm{t})$ - normalized population function representing the fraction of the population to be, but not yet, evacuated, dimensionless

$P_{S}(t)$ - normalized population function representing the fraction of the population to enter, but that have not yet entered, shelters, dimension less

$P_{n e}$ - constant fraction of the population that will not be evacuated, dimensionless. Note that $P_{n e}+P_{e}(0)=1$.

$P_{n s}$ - constant fraction of the population that will not be moved to shelters, dimensionless. Note that $P_{n s}+P_{s}(0)=1$.

T - time from start of accident until the plume reaches the mid-point of the current spatial interval, sec 
$T_{r}$ - duration of release for accident, days.

Normalized population time integrals are calculated as intermediate values in evaluating population doses for each spatial interval and for a given dose period, $T_{d}$. These integrals are defined by

$F_{e e}\left(T_{d}\right)$ - integral for external exposure to the plume for the evacuating population, days

$\mathrm{F}_{\text {ed }}\left(\mathrm{T}_{d}\right)$ - integral for direct irradiation for the evacuating population, rem

$F_{e i}\left(T_{d}\right)$ - integral for inhalation for the evacuating population, days

$F_{e g}\left(T_{d}\right)$ - integral for external exposure to contaminated ground for the evacuating population, days

$F_{s e}\left(T_{d}\right)$ - integral for external exposure to the plume for the shelterable population, days

$F_{S d}\left(T_{d}\right)$ - integral for direct irradiation for the shelterable population, rem

$F_{s i}\left(T_{d}\right)$ - integral for inhalation for the shelterable population, sec

$F_{s g}\left(T_{d}\right)$ - integral for external exposure to contaminated ground for the shelterable population, days

$F_{n e}\left(T_{d}\right)$ - integral for external exposure to the plume for the stationary population, days

$F_{n d}\left(T_{d}\right)$ - integral for direct irradiation for the stationary population, rem

$F_{n i}\left(T_{d}\right)$ - integral for inhalation for the stationary population, days

$F_{n g}\left(T_{d}\right)$ - integral for external exposure to contaminated ground for the non-moving population, days.

Shielding factors for each exposure path and population group are defined by

$S_{u e}$ - shielding factor for external exposure to the plume while in transit (relatively unshielded) for the evacuating and shelterable populations, dimensionless

$S_{u i}$ - exposure reduction factor for inhalation while in transit for the evacuating and shelterable populations, dimensionless

Sud - shielding factor for direct irradiation while in transit for the evacuating and shelterable populations, dimensionless 
$S_{\text {ug }}$ - shielding factor for external exposure to contaminated ground while in transit for the evacuating and shelterable populations, dimension less

$S_{s e}$ - shielding factor for external exposure to the plume for the shelterable population while in shelters, dimensionless

$S_{s i}$ - exposure reduction factor for inhalation for the shelterable population while in shelters, dimensionless

$S_{S d}$ - shielding factor for direct irradiation for the shelterable population while in shelters, dimensionless

$\mathrm{S}_{\mathrm{Sg}}$ - shielding factor for external exposure to contaminated ground for the shelterable populations while in shelters, dimensionless

$S_{\text {ne }}$ - shielding factor for external exposure to the plume for the stationary population, dimensionless

$S_{\text {nd }}$ - shielding factor for direct irradiation for the stationary population, dimensionless

$S_{n i}$ - exposure reduction factor for inhalation for the stationary population, dimensionless

$S_{n g} \cdot$ shielding factor for external exposure to contaminated ground for the stationary population, dimensionless

The time frames for evacuation and sheltering in relation to the release and movement of contamination are important to the estimation of dose. Time parameters used in the evacuation and sheltering models are defined below:

$T_{c l}$ - time from start of accident when radiation from contained material is first available for exposure, days

$T_{c 2}$ - time from start of accident when irradiation from contained material stops, days

$T_{d}$ - time from start of accident to the end of the current dose period, days

$\mathrm{T}_{\mathrm{e}}$ - time since start of accident when evacuation starts, days

$\mathrm{T}_{\mathrm{e} 2}$ - time since start of accident when evacuation is completed, days

$\mathrm{T}_{\mathrm{s}} \mathbf{1}$ - time since start of accident when sheltering begins, days

$\mathrm{T}_{\text {s2 }}$ - time since start of accident when all shelterable persons have reached shelters, days. 
Equations for the proposed evacuation model are presented in the following sections by exposure pathway. The equations are presented as time integrals of the appropriate normalized functions for populations and concentrations. The normalized evacuation population function can be represented by Houston's (1976) relation:

$$
P_{e}(t)=1-\alpha_{e}\left[T-\lambda \frac{1}{E}\left(1-e^{-\lambda_{E}{ }^{\top}}\right)\right]
$$

where

$\alpha_{e}$ - limiting fractional evacuation rate, $\mathrm{hr}^{-1}$

$\lambda_{E} \cdot$ evacuation time delay constant, $\mathrm{hr}^{-1}$

T - time since evacuation warning, hr.

The parameters $\alpha$ and $\lambda$ are evaluated as follows:

$$
\alpha_{e}=\bar{n}_{\ell} R^{\prime} \bar{n}_{p} L_{e} / N_{e o}
$$

where

$\bar{n}_{\ell}$ - average number of lanes per route

$R^{\prime}$ - number of cars per hour per lane

$\bar{n}_{p}$ - average number of persons per car

$L_{e}$ - number of routes leaving the area to be evacuated

$N_{\text {eo }}$ - number of persons in the evacuation area that will be evacuated.

$$
\lambda_{E}=1.80 \times 10^{-4} p^{0.54}
$$

where

p - population density in the evacuation area, persons per square mile.

Evaluation of $\alpha_{e}$ and $\lambda_{E}$ is site- and area-dependent. For consideration of a specific spatial interval, $\alpha_{\mathrm{e}}$ and $\lambda_{\mathrm{E}}$ are determined for the area and population in the sector of the spatial interval from the source to the outer boundary of the interval. For each spatial interval, the number of exit routes available to the population must be defined.

Assuming two lanes per route, three persons per car and 2,000 cars per hour, the equation for $\alpha$ becomes

$$
a_{e}=1.20 \times 10^{4} \mathrm{~L}_{\mathrm{e}} / \mathrm{N}_{\mathrm{eo}}
$$


An estimate of the evacuation end time can be made by noting that $\lambda_{E} t$ is normally snall. Then solving Equation 7.2-1 for $P_{e}\left(t_{e}\right)=0$ and $\lambda_{E} t_{e}$ small results in

$$
t_{e}=\frac{2}{\alpha^{\lambda}{ }^{\lambda}}
$$

The evacuation end time, $T_{e 2}$, is $T_{e l}+t_{e}$. The evacuating population is the total population multiplied by the fraction to be evacuated, $P_{s}(0)$.

These equations are based on the model developed by Houston (1976) using historical evacuation data tabulated by Hans and Sell (1974).

When sheltering is considered, the above equations can be used with modified evaluation of $\alpha_{e}$ and $\lambda_{E}$ It is likely that less distance will be traveled during sheltering than for evacuation, and that shelters are available within or near each spatial interval. For sheltering, $\lambda$ is evaluated for the spatial interval population density. Also, $\alpha$ is evaluated for the initial population $\left(N_{s o}\right)$ to be sheltered within the spatial interval (as opposed to the cummulative population to the end of the interval, as for evacuation). The number of routes is larger for sheltering because distances are shorter, and therefore smaller roads can be included in the available number of routes. Assuming, for sheltering, 1.5 lanes per route, three persons per car and 2000 cars per hour,

$$
\alpha_{s}=9.00 \times 10^{3} \mathrm{~L}_{\mathrm{s}} / \mathrm{N}_{\mathrm{so}}
$$

where

$$
\begin{aligned}
& \alpha_{s} \text { - limiting fractional sheltering rate, persons/hr } \\
& L_{s} \text { - number of routes useful for sheltering } \\
& N_{s o} \text { - number of people to be sheltered. }
\end{aligned}
$$

Equations for the proposed evacuation and sheltering model are presented in the following sections by exposure pathway.

The normalized functions for air concentration and ground contamination do not include effects of radioactive decay. If decay is important during the time periods involved, the indicated time integrals need to include the decay exponential in addition to the functions shown.

\subsubsection{Externa] Exposure from the Plume}

The general expressions for external exposure to the overhead plume are defined for each population group by

$$
F_{n e}\left(T_{d}\right)=S_{n e} P_{n} \int_{T}^{T+T r} c(t) d t
$$




$$
\begin{aligned}
& F_{e e}\left(T_{d}\right) \Rightarrow S_{n e} \int_{T}^{T} e l c(t) P_{e}(t) d t+S_{u e} \int_{T}^{T+T_{r}} d(t) P_{e}(t) d t \quad(7.3-8)
\end{aligned}
$$

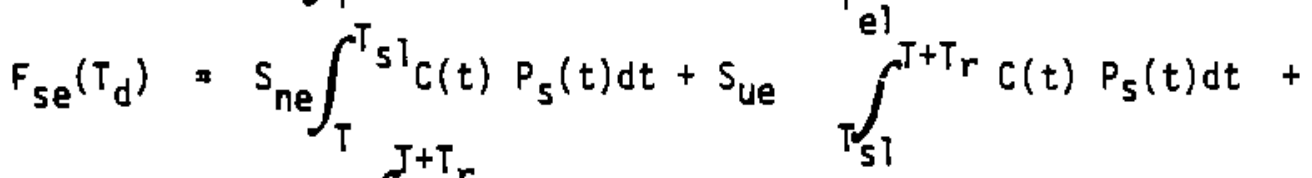

$$
\begin{aligned}
& S_{s e} \int_{T_{s 1}}^{J+T_{r}} C(t) P_{5}^{\prime}(t) d t
\end{aligned}
$$

Where $P_{n}$ represents $P_{n s}$ and $P_{n e}$ as appropriate

$$
\begin{aligned}
& P_{s}(t)=1-P_{n s}-P_{s}(t) \\
& P_{s}(t) \text { - the fraction of the population that has reached the } \\
& \text { shelters. }
\end{aligned}
$$

The assumption is made that, before the start time for evacuation or sheltering, the appropriate shielding factor is that for the stationary population,

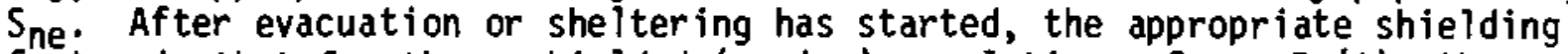
factor is that for the unshielded (moving) populations, $S_{n e} \cdot P_{s}(t)$, the population that has reached the shelter, is shielded by the shielding factor for sheltered persons, $\mathrm{S}_{\mathrm{se}}$.

A suggested normalized function for air concentration is shown in Figure 7.3-1. An alternate definition would be to use the normalized release fraction $\mathrm{fq}(\mathrm{t})$ as described in Section 3.0.

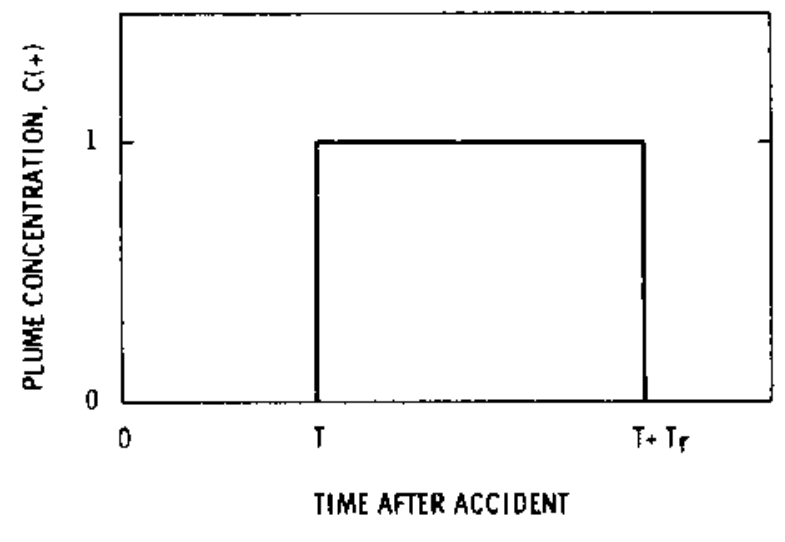

FIGURE 7.3-1. Normalized Plume Concentration Function 


\subsubsection{Inhalation of Contaminated Air}

The equations for normalized inhalation time integrals are the same as those presented above for external exposure, with the exception that the shielding factors $S_{n e}, S_{u e}$ and $S_{s e}$ are to be replaced by the inhalation reduction factors $S_{n i}, S_{u j}$ and $S_{s j}$, respectively. The inhalation reduction factors represent the reduction in inhalation exposure due to residing within structures. Under adverse situations the inhalation reduction factors may be greater than unity.

\subsubsection{External Exposure to Contaminated Ground}

The general expressions for external exposure to ground contaminated by the passing cloud are

$$
\begin{aligned}
& F_{n g}\left(T_{d}\right)=S_{n g} P_{n} \int_{T}^{T_{d}} G(t) d t \\
& F_{e g}\left(T_{d}\right)=s_{n g} \int_{T}^{T_{e l}} G(t) P_{e}(t) d t+s_{u g} \int_{T_{e l}}^{T_{e} 2} G(t) P_{e}(t) d t \\
& F_{s g}\left(T_{d}\right)=s \int_{n g}^{T s l} G(t) P_{s}(t) d t+s_{u g} \int_{T_{s}}^{T^{T} s 2} G(t) P_{s}(t) d t \\
& +S_{5 g} \int_{T_{s 1}}^{J d} G(t) P_{s}(t) d t
\end{aligned}
$$

A suggested normalized function for ground contamination is shown in Figure 7.3-2. An alternative definition would be to use the normalized release function $f q(t)$ to generate a nonuniformly increasing function. 


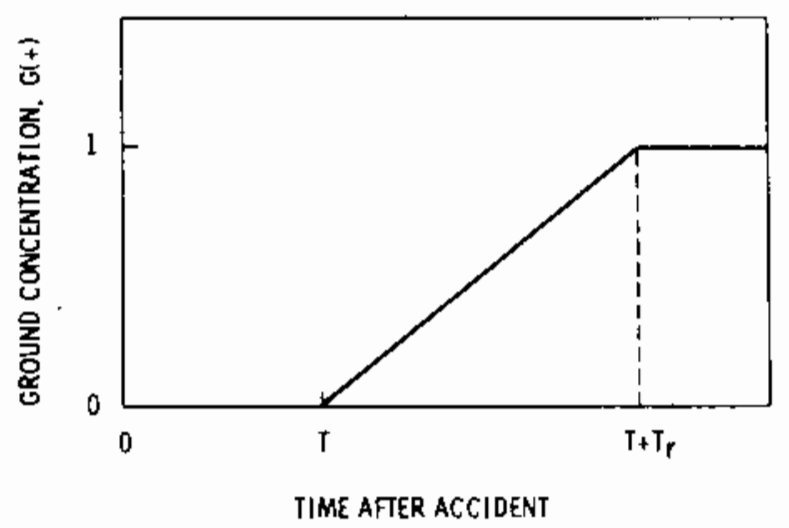

FIGURE 7.3-2. Nomalized Ground Concentration Function

\subsubsection{Direct Irradiation from Contained Materials}

The general equations for direct irradiation integrals for each population group are

$$
\begin{aligned}
& F_{n d}\left(T_{d}\right)=S_{n d} \int_{T_{c l}}^{T} c 2 \quad D(t) P_{n} d t \\
& F_{e d}\left(T_{d}\right)=s_{n d} \int_{T_{c l}}^{T^{e} e} D(t) P_{e}(t) d t+s_{u d} \int_{\left.T_{e}\right]}^{T_{e} 2} D(t) P_{e}(t) d t \\
& F_{s d}\left(T_{d}\right)=S_{n d} \int_{T_{c l}}^{T s 1} D(t) P_{s}(t) d t+S_{u d} \int_{T_{s} 1}^{T s} D(t) P_{s}(t) d t \\
& +s_{s d} \int_{T_{s}}^{T d} D(t) P_{s}(t) d t
\end{aligned}
$$


The normalized population time integrals for direct irradiation exposure are calculated using the direct irradiation dose rate function of Figure 7.3-3. The direct irradiation dose rate function is calculated as a function of distance and direction from the reactor site for selected time points. A numerical method is used to generate the time-population integrals. These time integrals have units of rem since they are only normalized to population and not dose rate.

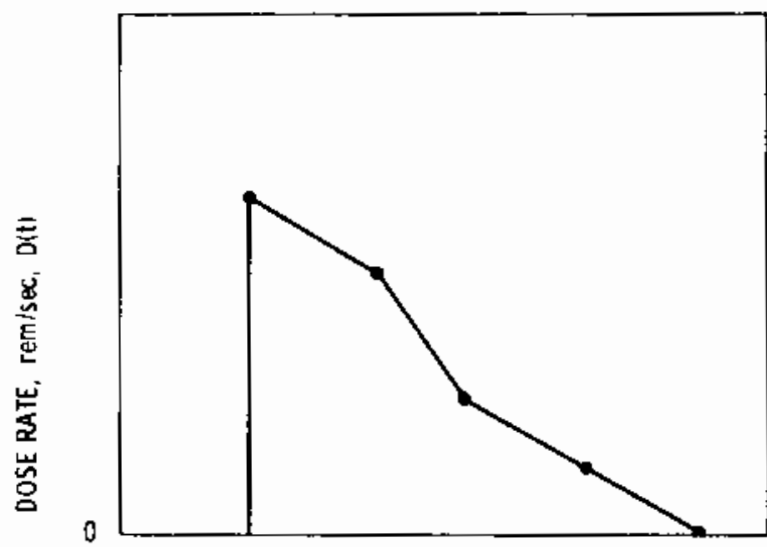

TIME SINCE START OF ACCIDENT

FIGURE 7.3-3. Direct Irradiation Dose Rate Function $D(t)$

\subsection{Interdiction and Decontamination}

The decision logic of Section 7.2 indicates situations where it may be desirable to interdict use of

- land for habitation,

- land for commercial activity,

- land for crop production,

- water for aquatic activities,

- water for human consumption,

- aquatic foods,

- food crops for human consumption,

- animal products,

- feed crops for animal consumption,

- water for animal consumption.

Land interdiction resulting from high external doses involves evacuation of people from the land and loss of use of the land. Rehabitation is only possible when radioactive decay and/or decontamination have reduced the dose rates to acceptable levels. Permanent interdiction results in evacuation and 
relocation costs. Interdiction of comercial land also involves costs due to loss of production. Farmland contamination above human occupancy levels (based on external exposure) may result in loss of crop production.

Contamination of water bodies from liquid effluent releases might require interdiction for aquatic recreation during the period of contamination. Shoreline interdiction may be reduced by cleanup procedures. Interdiction of drinking water would require replacement of contaminated water with clean water or additional decontamination at a water treatment plant leading to extra cost.

Aquatic foods harvested from contaminated water or sediment may give doses above acceptable limits. Interdiction will involve total loss of the aquatic product for human consumption unless facilities are available for frozen storage. However, some of the economic costs may be recovered by diversion of the aquatic products to other uses such as pet food or fertilizer production.

Farmland contaminated by airborne deposition might require interdiction of 1 and usage for crop production. Crops contaminated during the growing season might also be lost. Those crops that can be stored may be used after radioactive decay has reduced the contamination to acceptable levels. Also products such as grain may be diverted to other uses such as for animal feed (providing resulting animal product doses are not significant). When contamination occurs prior to the planting time, crop substitution may be made for production of food crops that resuit in less radiation dose to individuals.

Use of contaminated water for irrigation may result in unacceptably high concentrations in food crops. Such contamination would prohibit use of water for irrigation. Loss of crops will result. In some areas it may be possible to plant substitute crops that require less water. The substitute crops would be subject to airborne contamination from resuspension.

Animal products may be contaminated from airborne or waterborne releases through use of contaminated animal feed and drinking water. Animal product contamination might be avoided by use of clean feed and water imported from outside the area. Economic costs would be incurred for the value of the substitute feed and water. Some animal products may be stored or diverted for later use after radioactive decay has reduced the potential doses to acceptable levels. An example of such diversion would be use of milk for cheese production. 


\subsection{ECONOMIC COSTS}

This section describes the model selected for estimation of economic costs associated with a reactor accident. Equations and parameters are defined for each remedial action defined in the previous section. The selection of remedial actions and cost estimates is based on work by Nieves (1978). sections:

The following remedial action categories are discussed in the following

- contamination monitoring

- sheltering and evacuation

- food production loss

- nonfood production loss

- decontamination

- condemnation

- interdiction of land

- administration of potassium iodide tablets.

\subsection{CONTAMINATION MONITORING}

Contamination monitoring is necessary for all areas where contamination may potentially result. The cost-estimating model requires data relative to monitoring of 1) population, 2) aquatic environments, 3) terrestrial environment, 4) potable water supply and 5) farmlands and crops. Cost for monitoring are estimated by

$$
E_{m}=\left(M_{p} P_{m} T_{m p}+M_{w} N_{w} T_{m w}+M_{a} T_{m a}+M_{f} A_{f} T_{m f}+M_{t} A_{t} T_{m t}\right)+Q
$$

where

$E_{m} \cdot$ total monitoring costs for the accident, dollars

$T_{m p}$ - time period over which population monitoring is required, days

$M_{p}$. cost per person per day for population monitoring, dollars

$\mathrm{P}_{\mathrm{m}}$ - number of persons requiring monitoring

$M_{w}$ - cost per day per plant for monitoring water supplies, dollars

$N_{W}$ - number of water intake plants requiring monitoring

$T_{m w}$ - time period over which water monitoring is required, days

$\mathrm{M}_{\mathrm{a}}$ - cost per day for monitoring the aquatic environment, dollars 
$T_{\text {ma }}$ - time period for monitoring the aquatic environment, days

$M_{f}$ - cost per area per day to monitor farmlands and farm products, dollars $/$ day $/ m^{2}$

$A_{f} \cdot$ area of $f a r m l$ ands requiring general monitoring, $\mathrm{m}^{2}$

$T_{\mathrm{mf}}$ - time period for monitoring farmlands, days

$M_{t} \cdot$ cost per area per day for general terrestrial site monitoring, do 11 ars $/$ day $/ \mathrm{m}^{2}$

$A_{t} \cdot$ area requiring general monitoring, $\mathrm{m}^{2}$

$T_{m t}$ - time period for general site monitoring, days

Q - cost of providing additional site security and surveillance, dollars.

Costs are included for types of monitoring determined necessary by the remedial actions model. The site security and surveillance cost is assumed to be relatively independent of accident severity and is incurred whenever any monitoring is necessary.

\subsection{SHELTERING AND EVACUATION}

Sheltering and evacuation costs are based on the number of people moved and the time they must remain away. The equations are

$$
\begin{aligned}
& E_{s}=M_{s} P_{s} T_{s} \\
& E_{e}=M_{e} P_{e} T_{e}
\end{aligned}
$$

where

$E_{S} \cdot$ cost for sheltering

$M_{S} \cdot$ cost per person per day for sheltering

Ps - population sheltered

$T_{S}$ - duration of sheltering period

$\mathrm{E}_{\mathrm{e}} \cdot \cos \mathrm{t}$ for evacuation

$\mathrm{Me}_{\mathrm{e}}$ - cost per person per day for evacuation

Pe - population evacuated

$T_{e}$ - duration of evacuation period. 


\subsection{DECONTAMINATION}

Decontamination costs are determined for farmlands, residential lands and commercial lands. Decontamination is undertaken only if it is less costly than condemnation of the land. The costs are calculated by the following equations:

For farmlands,

$$
E_{d f}=K_{d f} A_{d f}
$$

where

$E_{d f} \cdot \cos t$ to decontaminate farmland, dollars

$\mathrm{K}_{\mathrm{df}} \cdot \cos \mathrm{t}$ per area to decontaminate farmland, dollars $/ \mathrm{m}^{2}$

$A_{d f}$ - area of $f a r m l$ and requiring decontamination, $\mathrm{m}^{2}$.

For residential lands,

$$
E_{d r}=K_{d r} A_{d r}
$$

where

$E_{d r} \cdot$ cost to decontaminate residential land, dollars

$\mathrm{K}_{\mathrm{dr}}$ - cost per area to decontaminate residential lands, dollars $/ \mathrm{m}^{2}$

$A_{d r}$ - area of residential land requiring decontamination, $\mathrm{m}^{2}$.

For commercial lands,

$$
E_{d c}=K_{d c} A_{d c}
$$

where

$E_{d c} \cdot$ cost to decontaminate commercial lands, dollars

$\mathrm{K}_{\mathrm{dc}} \cdot$ cost per area to decontaminate commercial lands, dollars $/ \mathrm{m}^{2}$

$A_{d c}$ - area of commercial land requiring decontamination, $\mathrm{m}^{2}$.

The cost per area values include the cost of both temporary onsite and long-term disposal of wastes generated during decontamination.

\subsection{INTERDICTION}

Interdiction costs are related to the loss of use of land, water and crops. Loss of land use may result in production losses for farmlands and commercial lands, plus population relocation costs for residential lands. The 
administration of potassium iodide (KI) tablets is also considered an act of interdiction.

The remedial action model may call for interdiction of land use for one or more years, after which decontanination will allow reuse of land. Interdiction involves loss of production, relocation of the population and loss of land value. The cost of interdiction is calculated as

$$
E_{i}=\sum_{j=f, r, c} T_{i j} M_{i j} A_{i j}+T_{i j} P_{r} M_{r}
$$

where

$E_{j} \cdot$ total interdiction costs, dollars

j - land type index: $f=f a r m l$ and, $r=$ resident $i a l, c=$ commercial

$M_{i j} \cdot$ cost per area of land interdicted, dollars/m2/year

$A_{i j} \cdot$ area of land interdicted, $m^{2}$

$\mathrm{P}_{\mathrm{r}}$ - population relocated

$M_{r} \cdot$ cost per person relocated, dollar/person/year

$T_{i j}$ - time interdiction and relocation lasts, years.

Costs associated with temporary site restriction are included in $M_{i j}$.

The costs for permanent interdiction (condemnation) are based on the purchase price of the property, costs for stabilization and restriction of the land and costs for relocation of the affected populations.

$$
E_{c}=R P_{r}+\sum_{i=f, r, c}\left(Z_{i}+Y_{j}+V_{j}\right) A_{t i}
$$

where

$E_{C} \cdot$ total cost of 1 and condemnation, dollars

$R$ - cost per person for permanent relocation, dollars

$P_{r}$ - number of persons requiring relocation

$i$ - land type index: $f=f a r m l a n d, r=$ residential and $c=$ commercial 


$$
\begin{aligned}
& Z_{i} \text { - condemnation value of } 1 \text { and, dollars } / \mathrm{m}^{2} \\
& Y_{i} \text { - cost of } 1 \text { and stabilizations, dollars } / \mathrm{m}^{2} \\
& V_{i} \text { - present value of site surveillance, dollars } / \mathrm{m}^{2} \\
& A_{t i} \text { - total area to be condemned, } \mathrm{m}^{2} \text {. }
\end{aligned}
$$

When permanent interdiction of land is necessary, the evacuation costs (Equation 8.2-2) are based on a one-month period, after which all people are relocated.

The costs for commercial production losses are based on the area of land under commercial use that must be evacuated, decontaminated or condemned. The equation is

$$
E_{C p}=T_{C p} K_{C p} A_{C p}
$$

where

$E_{c p}$ - total cost due to loss of commercial production, dollars

$T_{c p}$ - time period over which the loss occurs, days

$K_{C p} \cdot$ cost per day per area for all commercial production near the site, dollars/day/m²

$A_{C p}-$ area of commercial land affected, $\mathrm{m}^{2}$.

Food production losses are defined for four types of foods: aquatic foods, drinking water, food crops and animal products. The total costs are calculated by

$$
\begin{aligned}
& E_{f}=T_{p} E_{w} P_{w}+\sum_{j=1}^{N_{a q}} T_{a i} M_{a i}+\sum_{j=1}^{N_{c}} T_{c j} M_{c j} A_{f j} \\
&+T_{a p} \\
& \sum_{k=1}^{N} T_{a p k} M_{a p k} A_{f k}
\end{aligned}
$$

where

$E_{f}$ - total food interdiction costs, dollans 
$T_{p}$ - time period for interdiction of potable water supplies, days

$E_{W}$ - cost per person per day for interdiction of drinking water (including cost of replacement water), dollars

$P_{W}$ - total number of persons using contaminated water supply

$T_{a i}$ - time period for interdiction of aquatic food $i$, days

$M_{a i}$ - cost per day for interdiction of aquatic food $i$ for the site, dollars

$N_{a q} \cdot$ number of aquatic foods produced

$T_{c j} \cdot$ time period for interdiction of farm food crops, days

$\mathrm{N}_{\mathrm{C}}$ - number of food crops grown near the site

$M_{c j} \cdot$ cost per area per day for interdiction of food crop $j$, dollars/ day $/ \mathrm{m}^{2}$

$A_{f j} \bullet$ area interdicted for crop $j, m^{2}$

Tapk - time period for interdiction of animal products, days

$\mathrm{N}_{\text {ap }}$ - number of animal product types produced near the site

Mapk - cost per day per area for interdiction of animal product $k$, dollars $/$ day $/ \mathrm{m}^{2}$

$A_{f k}$ - farml and area interdicted for production of animal product $k, \mathrm{~m}^{2}$.

The cost for administration of potassium iodide tablets is calculated as $E_{K I}=P_{K I} M_{K I}$

where $E_{K I}$ - cost to administer potassium iodide tablets, dollars

PKI - population needing potassium iodide tablets, persons

MKI - cost per person for administration of potassium iodide tablets, dollars/person. 


\subsection{HEALTH EFFECTS}

Doses resulting from each accident are used to estimate health effects that would be expected to occur in the exposed population. Health effect est imations are based on doses from all pathways and exposure modes, reduced by any remedial actions deemed necessary according to criteria established for the remedial action model. The health effects models described here are essentially those presented in the Reactor Safety Study. They have been modified slightly by the addition of direct irradiation and waterborne exposure modes. Further modification of these models may be desirable after release of the third BEIR Committee report.

Three categories of health effects are considered here: early somatic, late somatic and genetic. Models for each of these effects are sumarized below.

\subsection{EARLY SOMATIC EFFECTS}

Early somatic effects include mortalities and morbidities that occur within days and up to one year after exposure. These effects generally involve doses of 100 rads or more. According to the Reactor Safety Study, the only body parts of significance for estimating early mortalities are bone marrow, lungs and the gastrointestinal tract. Health effect estimations are based on the dose received from the following pathways:

- External dose from the passing cloud

- External dose from ground contamination

- External dose from direct irradiation from contained activity

- External dose from exposure to contaminated water and shoreline

- Internal dose from inhalation of the passing cloud

- Internal dose from ingestion of contaminated foods and drinking water.

Average doses received by individuals during cloud passage, plus other doses received within 7 days after the start of the accident, are used. Special consideration for internal organ exposures extended this time in some cases.

The Class 9 accidents were of short duration, typically lasting less than one day. However, the accidents for the present study may involve activity releases lasting up to 30 days. Because of this difference, the early somatic effects are calculated from the dose received over the duration of the accident with a minimum time of seven days.

The time period for internal exposure depends on the organ being considered. For bone marrow, the internal dose received over the duration of the accident (minimum, 30 days), plus one-half of the dose received between the end of the accident and the thirtieth day after inhalation of radionuclides is used for early somatic effects. Dose to lungs is the internal dose received within one year from inhalation of radionuclides. Dose to the 
gastrointestinal tract is estimated by the internal dose received over the accident duration (minimum of seven days). below.

Early somatic effects are calculated using probability functions as shown

For bone marrow exposure :

$$
H_{b j}^{E}=P_{j} f_{b}^{E}\left(D_{b j}\right)
$$

where

$$
\begin{aligned}
& H_{b j}^{E} \text { - early deaths resulting from bone marrow exposure in spatial } \\
& P_{j} \text { - population (persons) in spatial interval } j \\
& f_{b}^{E}\left(D_{b j}\right) \text { - fraction of people expected to die from a bone marrow dose } \\
& \text { of } D_{b j} \text {, deaths/person } \\
& D_{b j} \text { - average individual bone marrow dose to people in spatial } \\
& \text { interval j, rem/person. }
\end{aligned}
$$

For lung exposure:

$$
H_{\ell_{j}}^{E}=P_{j}\left[l-f_{b}^{E}\left(D_{b j}\right)\right] f_{\ell}^{E}\left(D_{\ell j}\right)
$$

where

$$
\begin{aligned}
& H_{\ell j}^{E} \begin{array}{l}
\text { early deaths resulting from lung exposure in spatial } \\
\text { interval } j
\end{array} \\
& f_{\ell}^{E}\left(D_{\ell j}\right) \cdot \begin{array}{l}
\text { fraction of people expected to die from a lung dose of } \\
D_{\ell j} \text {, deaths/person }
\end{array} \\
& D_{\ell j} \cdot \begin{array}{l}
\text { average individual lung dose to people in spatial interval } \\
j, \text { rem/person. }
\end{array}
\end{aligned}
$$

For gastrointestinal tract exposure:

$$
H_{g j}^{E}=P_{j}\left[1-f_{b}^{E}\left(D_{b j}\right)\right]\left[1-f_{\ell}^{E}\left(D_{\ell j}\right)\right] f_{g}^{E}\left(D_{g j}\right)
$$

where

$\mathrm{H}_{\mathrm{g} j}^{\mathrm{E}}$ - early deaths resulting from gastrointestinal tract exposure 


$$
\begin{aligned}
& f_{g}\left(D_{g j}\right) \text { - fraction of people expected to die from a gastro } \\
& \text { intestinal tract dose of } D_{g j} \text {, deaths/person } \\
& D_{g j} \text { - average individual gastrointestinal tract dose to people in } \\
& \text { spatial interval } j \text {, rem/person. }
\end{aligned}
$$

The probability functions $f E$, $f$ and $f E$ are defined for use by the computer program in Table 9.1-1. Additional effects may also be considered by extending the above equations and defining corresponding probability functions. Nonfatal heal th effects may also be considered, but these must be based on the fraction of the population not dying from other effects. This fraction not dying from other effects is given by

\begin{tabular}{|c|c|c|c|c|c|}
\hline \multicolumn{2}{|c|}{ Bone Marrow } & \multicolumn{2}{|c|}{ Lung } & \multicolumn{2}{|c|}{ Gastrointestinal Tract } \\
\hline $\begin{array}{l}\text { Dose LeveT } \\
\text { (rem) }\end{array}$ & $\begin{array}{l}\text { Fraction of } \\
\text { Population }\end{array}$ & $\begin{array}{l}\text { Dose Level } \\
\text { (rem) }\end{array}$ & $\begin{array}{l}\text { Fraction of } \\
\text { Population }\end{array}$ & $\begin{array}{l}\text { Dose Leve1 } \\
\text { (rem) }\end{array}$ & $\begin{array}{l}\text { Fraction of } \\
\text { Population }\end{array}$ \\
\hline $\begin{array}{l}320 \\
400 \\
510 \\
615\end{array}$ & $\begin{array}{l}0.0 \\
0.03 \\
0.5 \\
1.0\end{array}$ & $\begin{array}{r}5,000 \\
14,800 \\
22,400 \\
24,000\end{array}$ & $\begin{array}{l}0.0 \\
0.24 \\
0.73 \\
1.0\end{array}$ & $\begin{array}{l}2,000 \\
5,000\end{array}$ & $\begin{array}{l}0.0 \\
1.0\end{array}$ \\
\hline
\end{tabular}

$$
\left(1-f E_{b}^{E}\right)\left(1-f \frac{f_{l}}{l}\right)\left(1-f_{g}^{E}\right) \text {. }
$$

TABLE 9.1-1. Early Death Probability Functions: Fraction of Population Expected to Die by Radionuclide Exposure to Various Organs

\subsection{LATE SOMATIC EFFECTS}

External exposure to radiation and intake of radionuclides may produce health effects that appear years after the initial exposure period. These are referred to as latent heal th effects from acute exposures. Internal contamination will continue until the radionuclides have decayed away or have been eliminated from the body. Latent effects are calculated for external exposure received during the first year and for internal doses from activity taken into the body during the first year. Also considered is the internal dose received during time periods following the first year.

The calculation of late somatic effects is limited to latent cancer fatalities plus benign and cancerous thyroid nodules. Because of the randomness of these effects, the Reactor Safety Study based the calculation of late somatic effects on population doses. 
The number of health effects for a given population group is estimated as follows:

time periods

where

$$
H_{\ell}^{L}=10^{-6} D_{x} H_{\ell 0}^{L}+10^{-6} \sum_{t=1} D_{\text {iot }} h_{\text {lot }}^{L}
$$

$H_{l}^{L}$ - total latent health effects of type $\ell$

$D_{x}$ - total external population dose during the first year for the exposed population, man-rem

$H_{\ell} L_{0}$ - health effect conversion factor for effect $\ell$ for the first year exposure of organ 0 , effects $/ 10^{6}$ man-rem

$D_{\text {iot }}$ - internal population dose received during time period $t$ by organ 0 , man-rem

$h_{\text {lot }}$ - health effect conversion factor for effect $\ell$ based on exposure of organ 0 during time period $t$, effects $/ 10^{6}$ man-rem.

Values for $h_{2}^{L}$ as defined for the Reactor Safety Study are shown in Table 9.2-1. Table 9.2-2 presents internal exposure health effect conversion factors, hlot.

TABLE 9.2-1. Expected Latent Cancer (Excluding Thyroid) Deaths per Million Man-rem of External Exposure

\begin{tabular}{lr} 
Iype of Cancer & \multicolumn{2}{c}{$\begin{array}{c}\text { Expected Dea } \\
\text { per } 10^{6} \text { Man-r }\end{array}$} \\
\cline { 2 - 2 } Leukemia & 28.4 \\
Lung & 22.2 \\
Stomach & 10.2 \\
Alimentary canal & 3.4 \\
Pancreas & 3.4 \\
Breast & 25.6 \\
Bone & 6.9 \\
All other & 21.6 \\
Total (excluding thyroid) & 121.6
\end{tabular}


Table 9.2-2. Expected Latent Cancer (Excluding Thyroid) Deaths per Million Man-rem from Internal Radionuclides Delivered During Specified Periods

\begin{tabular}{|c|c|c|c|c|c|c|c|c|c|}
\hline \multirow[b]{2}{*}{ Type of Cancer } & \multicolumn{9}{|c|}{ Expected Deaths per $10^{6}$ Man-rem } \\
\hline & $0-1$ & $1-10$ & $\begin{array}{c}\text { Time } \\
11-20 \\
\end{array}$ & $\begin{array}{l}\text { le Period } \\
21-30 \\
\end{array}$ & $\begin{array}{l}\text { (years) } \\
31-40\end{array}$ & $\begin{array}{l}\text { After } \\
41-50 \\
\end{array}$ & $\begin{array}{l}\text { Accide } \\
51-60\end{array}$ & $\begin{array}{l}\text { ent } \\
6 T-70\end{array}$ & $71-80$ \\
\hline $\begin{array}{l}\text { Leukemia } \\
\text { Lung } \\
\text { Gastrointestinal tract } \\
\text { Pancreas } \\
\text { Breast } \\
\text { Bone } \\
\text { All other }\end{array}$ & $\begin{array}{r}28.4 \\
22.2 \\
13.6 \\
3.4 \\
25.6 \\
6.9 \\
21.6\end{array}$ & $\begin{array}{r}27.2 \\
22.2 \\
13.6 \\
3.4 \\
25.6 \\
6.7 \\
19.8\end{array}$ & $\begin{array}{r}18.7 \\
22.2 \\
13.6 \\
3.4 \\
25.6 \\
5.0 \\
17.1\end{array}$ & $\begin{array}{r}13.8 \\
14.5 \\
8.9 \\
2.2 \\
16.8 \\
2.6 \\
11.2\end{array}$ & $\begin{array}{l}9.7 \\
8.1 \\
5.0 \\
1.3 \\
9.4 \\
1.6 \\
6.3\end{array}$ & $\begin{array}{l}6.8 \\
4.0 \\
2.5 \\
0.6 \\
4.6 \\
0.9 \\
3.1\end{array}$ & $\begin{array}{l}4.0 \\
1.5 \\
0.9 \\
0.2 \\
1.7 \\
0.4 \\
1.2\end{array}$ & $\begin{array}{l}1.7 \\
0.2 \\
0.1 \\
0 \\
0.3 \\
0.1 \\
0.2\end{array}$ & $\begin{array}{l}0.5 \\
0 \\
0 \\
0 \\
0 \\
0 \\
0\end{array}$ \\
\hline Total & 121.6 & 118.5 & 105.5 & 70.1 & 41.3 & 22.4 & 10.0 & 2.6 & 0.5 \\
\hline
\end{tabular}

The values in these tables are based on the following considerations as discussed in the Reactor Safety Study:

- The absolute risk basis is assumed to be appropriate for the evaluation of reactor risks.

- Late somatic effects are calculated on the basis of population dose (linear hypothesis).

- Late somatic effects are limited to latent cancer fatalities and morbidities, plus benign thyroid nodules.

- Latent cancers are calculated for a 30-year latent plateau period.

- The population age distribution (based $n n$ figures from 1970) is accounted for.

The latent health-effect conversion factors represent an upper bound estimate. A central estimate for latent cancer fatalities is calculated by modifying the given values by dose-effectiveness factors shown in Table 9.2-3. Use of these factors is based on the average dose and the average dose rate to the exposed population.

The Reactor Safety Study also calculated a lower bound estimate by assuming no health effects when the average exposure was below 10 or 25 rem. This option has not been retained in the present study. 
TABLE 9.2-3. Dose-Effectiveness Factors

\begin{tabular}{|c|c|c|c|}
\hline \multirow{2}{*}{$\begin{array}{l}\text { Total Dose } \\
\text { (rem) }\end{array}$} & \multicolumn{3}{|c|}{ Dose Rate (rem per day) } \\
\hline & 1 & $1-10$ & 1 \\
\hline $\begin{array}{c}10 \\
10-25 \\
25-300\end{array}$ & $\begin{array}{l}0.2 \\
0.2 \\
0.2\end{array}$ & $\begin{array}{l}0.2 \\
0.4 \\
0.4\end{array}$ & \\
\hline
\end{tabular}

The dose-effectiveness factors are applied to each organ except the breast, which shows no reduced cancer incidence for fractionated doses delivered at high dose rates.

The thyroid cancer death calculations are based on two assumptions: 1) a $10 \%$ mortality rate for thyroid cancer and 2) equivalence of all thyroid doses from sources other than 131 I to external $x$-ray irradiation. Under these assumptions, the thyroid cancer death calculations are based on the following exposures:

- external dose from passing cloud

- external dose from contaminated ground

- external dose from direct irradiation

- external dose from exposure to contaminated water and shoreline

- internal dose to thyroid from inhaled and ingested radionuclides other than $\{3$ I

- one tenth of the internal dose to thyroid from inhaled and ingested $131_{\mathrm{I}}$.

A11 doses are those received during the first 30 days after the accident. The health effect conversion factors for thyroid cancers are presented in Table 9.2-4. The number of thyroid cancer deaths is taken as $10 \%$ of the calculated number of cancerous nodules.

TABLE 9.2-4. Expected Thyroid NoduTes

\begin{tabular}{ccc} 
& \multicolumn{2}{c}{ Expected Nodules per $10^{6}$ Man-rem } \\
\cline { 2 - 3 } Dose Range (rem) & Benign & Cancerous \\
\cline { 2 - 3 } 1500 & 200 & 134 \\
15000 & 100 & 67 \\
5000 & 0 & 0
\end{tabular}




\subsection{GENETIC EFFECTS}

The Reactor Safety Study considers genetic effects (resulting from chronic exposure) of four types:

- autosomal dominant disorders

- multifactorial disorders

- disorders due to chromosomal aberrations

- spontaneous abortions.

Frequency factors are developed for external and internal radiation as a function of time of dose accumulation after the accident. The expected effects are also expressed as a broad function of time by considering two consecutive 30-year periods after the accident, plus all remaining time. The frequencies are developed from data in the BEIR Report (1972). Both the age and sex of the exposed population are considered because genetic effects are usually caused by irradiation of fathers. The organ of significance is therefore considered to be the male gonad.

Autosomal dominant disorders result from chromosomal mutations associated with dominant traits. Multifactorial disorders result from mutations at more than one genetic locus. These disorders include a variety of congenital malformations and degenerative diseases. The consequences of chromosomal aberrations result from having the wrong number of genetic material rather than from intrinsic changes. The majority of chromosomal aberrations result in spontaneous abortion.

Genetic effects are calculated separately for external and internal radiation. For external sources, the genetic effects are calculated as

$$
H_{x \ell}^{G}=10^{-6} \sum_{t=1}^{\text {time periods }} D_{x g t} h_{x \ell t}^{G}
$$

where

$$
\begin{aligned}
& H_{x \ell}^{G} \cdot \begin{array}{l}
\text { total genetic health effects of type } \ell \text { from external } \\
\text { exposure resulting over all time }
\end{array} \\
& D_{x g t} \text { - population dose received by testes in time period } t \\
& \text { from external sources, man-rem } \\
& h_{x \ell t}^{G} \text { - genetic health effect conversion factor for effect } \ell \text { from } \\
& \text { external sources during time period } t \text {, effects } / 10^{6} \text { man-rem. }
\end{aligned}
$$


Values of conversion factors for external exposure health effects, $h_{x \ell t}^{G}$, are given in Table 9.3-1. The values are given for health effects expressed during two 30-year periods following the accident and for all time. Multifactorial disorder factors are presented as a range due to uncertainty in their estimation. Equation 9.3-1 is described for use of the conversion factors for "all time" from Table 9.3-1. However, if the factors for $0-30$ or $30-60$ years are used, the resulting health effects will represent those expressed in the corresponding time period. by:

Exposure from internal radiation results in health effects as calculated

$$
H_{i \ell}^{9}=10^{-6} \sum_{t=1}^{\text {time periods }} \mathrm{D}_{\text {igt }} \mathrm{H}_{i \ell t}^{\mathrm{g}}
$$

where

$$
\begin{aligned}
& \mathrm{H}_{i \ell}^{g} \text { - total genetic health effects of type } \ell \text { from internal } \\
& \text { sources resulting over all time } \\
& \mathrm{D}_{\text {igt }} \text { - population dose received by testes in time period } t \\
& \text { from internal sources, man-ren } \\
& \mathrm{hg} \text { - genetic health effect conversion factor for effect } \ell \text { from } \\
& \text { internal sources during time period } t \text {. }
\end{aligned}
$$

Values for hg for the two 30-year periods and all times are given in Table 9.3-2. ilt 
TABLE 9.3-1. Disorders and Spontaneous Abortions Attributable to Radiation from External Sources Derived from Releases at the Time of the Hypothetical Accident

\begin{tabular}{|c|c|c|c|c|}
\hline \multirow{2}{*}{$\begin{array}{l}\text { Postaccident } \\
\text { Period over } \\
\text { Which Oose is } \\
\text { Accumulated } \\
\text { (Years) }\end{array}$} & \multicolumn{4}{|c|}{$\begin{array}{c}\text { Genet ic Effects (per } 10^{6} \text { man-rem) Expressed in the Two } 30-Y \text { ear } \\
\text { Periods After the Accident and Expressed over All Time }\end{array}$} \\
\hline & $\begin{array}{r}0-30 \\
\text { Years }\end{array}$ & $\begin{array}{l}31-60 \\
\text { Years }\end{array}$ & $\begin{array}{l}\text { Remaining to } \\
\text { Be Expressed }\end{array}$ & $\begin{array}{l}\text { Total (Over } \\
\text { All time) }\end{array}$ \\
\hline
\end{tabular}

$\begin{array}{ccccc}0-1 & 8.15 & 6.45 & 24.59 & 39.19 \\ 1-30 & 4.2 & 7.39 & 27.60 & 39.19 \\ 31-60 & -- & 8.15 & 31.04 & 39.19 \\ 61+ & -- & -- & 39.19 & 39.19\end{array}$

Multifactorial Disorders

$\begin{array}{ccccc}0-1 & 0.83-8.25 & 9.74-7.39 & 6.27-62.76 & 7.84-78.4 \\ 1-30 & 0.42-4.2 & 0.79-7.88 & 6.63-66.32 & 7.84-78.4 \\ 31-60 & -- & 0.83-8.25 & 7.01-70.15 & 7.84-78.4 \\ 61+ & -- & -- & 7.84-78.4 & 7.84-78.4\end{array}$

Disorders Oue to Chromosomal Aberrations

$\begin{array}{ccccc}0-1 & 4.8 & 0.8 & 0.6 & 6.2 \\ 1-30 & 2.7 & 2.7 & 0.8 & 6.2 \\ 3 i-60 & -- & 4.8 & 1.4 & 6.2 \\ 67+ & -- & -- & 6.2 & 6.2\end{array}$

Spontaneous Abortions

$\begin{array}{ccccc}0-1 & 31.8 & 5.1 & 3.6 & 40.6 \\ 1-30 & 18.0 & 17.6 & 5.0 & 40.6 \\ 31-60 & -- & 31.8 & 8.8 & 40.6 \\ 61+ & -- & -- & 40.6 & 40.6\end{array}$


TABLE 9.3-2. Disorders and Spontaneous Abortions Due to Radiation from Internal Sources Incorporated at the Time of the Hypothetical Accident

\begin{tabular}{|c|c|c|c|c|}
\hline \multirow{2}{*}{$\begin{array}{l}\text { Postaccident } \\
\text { Period over } \\
\text { Which Dose is } \\
\text { Accumulated } \\
\text { (Years) }\end{array}$} & \multicolumn{4}{|c|}{$\begin{array}{l}\text { Genet ic Effects (per } 10^{6} \text { man-rem) Expressed in the Two } 30 \text {-Year } \\
\text { Periods After the Accident and Expressed over All Time }\end{array}$} \\
\hline & $\begin{array}{r}0-30 \\
\text { Years }\end{array}$ & $\begin{array}{l}37-60 \\
\text { Years }\end{array}$ & $\begin{array}{l}\text { Remaining to } \\
\text { Be Expressed }\end{array}$ & $\begin{array}{l}\text { Total (Over } \\
\text { Alt time) }\end{array}$ \\
\hline
\end{tabular}

Autosomal Dominant Disorders

$\begin{array}{cclcr}0-1 & 8.15 & 6.45 & 24.59 & 39.19 \\ 1-10 & 6.18 & 5.27 & 20.76 & 32.21 \\ 11-20 & 3.12 & 2.46 & 12.47 & 18.23 \\ 21-30 & 0.68 & 0.88 & 4.45 & 6.01 \\ 31-40 & -- & 0.20 & 0.81 & 1.01 \\ 41-50 & -- & (\mathrm{a}) & (\mathrm{a}) & \text { (a) }\end{array}$

Multifactorial Disorders

\begin{tabular}{|c|c|c|c|c|}
\hline $\begin{array}{l}0-1 \\
1-10 \\
11-20 \\
21-30 \\
31-40 \\
41-50\end{array}$ & $\begin{array}{c}0.83-8.25 \\
0.62-6.22 \\
0.31-3.12 \\
0.07-0.68 \\
-- \\
=-\end{array}$ & $\begin{array}{c}0.74-7.39 \\
0.60-5.97 \\
0.29-2.92 \\
0.09-0.93 \\
0.02-0.22 \\
\text { (a) }\end{array}$ & $\begin{array}{c}6.27-62.76 \\
5.22-52.24 \\
3.05-30.42 \\
1.04-10.4 \\
0.18-1.80 \\
\text { (a) }\end{array}$ & $\begin{array}{c}7.84-78.4 \\
6.44-64.43 \\
3.65-36.46 \\
1.20-12.01 \\
0.20-2.02 \\
\text { (a) }\end{array}$ \\
\hline
\end{tabular}

Disorders Due to Chromosomal Aberrations

$\begin{array}{rrrrr}0-1 & 4.8 & 0.8 & 0.6 & 6.2 \\ 1-10 & 3.8 & 0.7 & 0.6 & 5.1 \\ 11-20 & 2.0 & 0.5 & 0.4 & 2.9 \\ 21-30 & 0.4 & 0.4 & 0.2 & 1.0 \\ 31-40 & -- & <0.1 & <0.1 & <0.2 \\ 41-50 & -- & (a) & (a) & (a)\end{array}$

Spontaneous Abortions

$\begin{array}{ccccc}0-1 & 31.8 & 5.2 & 3.6 & 40.6 \\ 1-10 & 25.5 & 4.7 & 3.2 & 33.4 \\ 11-20 & 13.4 & 3.5 & 2.0 & 19.0 \\ 21-30 & 2.9 & 2.5 & 0.9 & 6.3 \\ 31-40 & -- & 0.9 & 0.2 & 1.7 \\ 41-50 & -- & (a) & (a) & (a)\end{array}$

\footnotetext{
(a) Negligibly small in comparison with preceding row.
} 


\subsection{COMPARISON WITH REACTOR SAFETY STUDY MODELS}

The models presented in this report were selected for estimating health effects and economic costs for site-specific accident analyses. The models of the Reactor Safety Study were used as the basis for several of the modeling areas considered. However, the Reactor Safety Study only considered severe accidents for a generic site. Extension of the Reactor Safety Study models to less severe accidents and to site-specific cases has resulted in selection of models that are significantly different from the Reactor Safety Study models in some areas. These differences are discussed briefly in this section.

The general methodology of the selected models is very similar to the Reactor Safety Study methodology. Consequences are based on this sequence: release, transport, exposure pathway, remedial action, dosimetry, health effects and economic costs. The major differences between the two approaches are the addition of the direct irradiation from the contained activity pathway and the waterborne release pathway. These differences are obvious and will not be discussed further in this section. The comparison of models is presented below by major modeling area: source term, atmospheric transport, exposure pathway, dosimetry, remedial action, health effects and economic costs.

\subsection{SOURCE TERMS}

Definition of source terms for both models is essentially the same. The current study requires specification of additional stack parameters for momentum plume rise corrections when appropriate. Also, the radionuclides considered for a given run is variable up to a maximum of 60 .

\subsection{ATMOSPHERIC TRANSPORT}

The plume generation model of the Reactor Safety Study has been retained but modified for use on site-specific analysis. The main differences are

- use of hourly wind direction observations to calculate a weighted areal concentration pattern for a given start time

- use of hourly stability frequency data to generate the downwind straightline plume (rather than use of an average stability)

- updated equations for buoyancy plume rise

- addition of equations for momentum plume rise

- use of hourly precipitation rate data for wet deposition estimates

- extension of the model for release periods longer than eight hours

- addition of the option to include Pasquitl stability category $G$. unchanged.

other features of the atmospheric transport model are essentially 


\subsection{EXPOSURE PATHWAYS}

The exposure pathways considered in the Reactor Safety Study model were

- external exposure to the plume

- external exposure to contaminated ground

- inhalation exposure from the plume

- inhalation exposure from resuspended activity

- ingestion exposure from contaninated crops and animal products.

These same pathways are considered in the present study with some modification to the last two pathways. The resuspension model has been updated to reflect more recent recommendations of Anspaugh et al. (1975) and the ingestion exposure pathway model has been expanded to include

- definition of animal product and crop production by spatial interval about the site

- consideration of growing perjods for crops and animal products

- additional soil-crop-man pathways which were not explicitly included in the Reactor Safety Study

- transient behavior of radionuclides in the terrestrial food chain.

\subsection{DOSIMETRY}

External dosimetry calculations have been simplified by use of one dose rate conversion factor for all organs of the body for each radionuclide in accordance with recomendations in NCRP Publication 45 (1975). Also, the finite cloud correction factor model has been expanded to include effects of unsymmetrical plumes $\left(\sigma_{y} \neq \sigma_{z}\right)$. Internal dosimetry models are unchanged except for the recommendation to use a gastrointestinal tract model based on linear flow through the intestinal compartments rather than the exponential emptying model employed for the Reactor Safety Study.

\subsection{REMEDIAL ACTIONS}

The main difference in the remedial actions model is the use of a new evacuation and sheltering model. The new model uses local road network information to estimate evacuation rates and times as a function of distance and direction from the site. This evacuation model is used (with parameter modifications) to describe movement to shelters also. The Reactor Safety Study evacuation model considered all people to move together at a specified rate away from the site. Exposure was based on the time required to escape the cloud. The present model also allows for a stationary population fraction consisting of those people who either refuse or are not able to leave. The models for interdiction and decontamination are very similar; actions are based on exceeding dose criteria and potential reduction of dose. Decisions on decontamination also consider cost; if the decontamination cost is greater than the condemnation value, then decontamination is not performed. 


\subsection{HEALTH EFFECTS}

The Reactor Safety Study model for health effects has been selected for use in this study. Upon publication of the next BEIR Committee report, the model will be re-evaluated and modified as necessary.

\subsection{ECONOMIC COSTS}

The selected economic model considers costs for all remedial actions deemed necessary by the remedial action model. The major difference between the models is the inclusion of costs for contamination monitoring and added security after an accident. The costs associated with farmland interdiction are also based on specific crop values for which the farmland is used. 
. 


\section{REFERENCES}

Anspaugh, L. R., J. H. Shinn, P. L. Phelps and N. C. Kennedy. 1975. Resuspension and redistribution of plutonium in soils. Heaith Phys. 29:571-582.

BE IR Report. 1972. The Effects on Populations of Exposure to Low Levels of Ionizing Radiation, Report of the Advisory Committee on the Biological Effects of Ionizing Radiation. National Acadeny of Sciences National Research Council, Washington DC.

Bethe, H., and W. Heitler. 1934. On the stopping of fast particles and on the creation of positive electrons. Proc. Roy. Soc., Ai46:83.

Blizard, E. P., ed. 1962. Shielding, Reactor Handbook, Vol. III, Part B. Interscience Publishers, New York.

Briggs, G. A. 1969. Plume rise. AEC Critical Review Series. TID-25075, Clearinghouse for Federal Scient if ic and Technical Information, Springfield, Virginia.

Briggs, G. A. 1975. Plume Rise Predictions. National Oceanic and Atmospheric Administration, Oak Ridge, Tennessee.

Dana, M. T., N. A. Wogman and M. A. Wolf. 1978. Rain scavenging of tritiated water (HTO): A field experiment and theoretical considerations. Atmos. Env. I2: $1523-1529$.

Davis, W. E. 1979. The effect of using time-averaged precipitation for the estimation of wet deposition in a regional scale model. Preprint volume, Fourth Symposium on Turbulence, Diffusion and Air Pollution, Reno, Nevada, January 1979. Sponsored by American Meteorological Society, Boston, Mass achusetts.

Engle, R. L., J. Greenborg and M. M. Hendrickson. 1966. ISOSHLD--A Computer Code for General Purpose Isotope Shielding Analysis. BNWL-236, BatteTle, Pacific Northwest Laboratories, Richland, Washington.

Engleman, R. J. 1968. The calculation of precipjtation scavenging. In Meteorology and Atomic Energy - 1968, ed. D. H. Slade, pp. 208-221. USAEC TID-24T90.

EPA. 1975. Manual of Protective Action Guides and Protective Actions for Nuclear Incidents. EPA 520/1-75-001, Environmental Protection Agency, Washington, DC.

Eve, I. S. 1968. A review of the physiology of the gastrointestinil tract in relation to radiation doses from radioactive materials. Health Phys. $12: 131-162$. 
Federal Register. 1978. Vol. 43, No. 242, p. 58795.

FRC. 1964. 8ackground Material for the Development of Radiated Protection Standards, Federal Radiation Council Staff Report No. 5.

FRC. 1965. Background Material for the Development of Protective Action Guides for Strontium-89, Strontium-90 and Cesium-137. Federal Radiation Council, Staff Report No. 7.

Gifford, F. A., Jr. 1972. Atmospheric transport and dispersion over cities. Nuc. Safety 13(5):391-402.

Hans, J.F., Jr., and T. C. Sell. 1974. Evacuation Risks - An Evaluation. EPA-520/6-74-002, U.S. Environmental Protection Agency, National Environmental Research Center, Las Vegas, Nevada.

Hine, G. J. and G. L. Brownell, eds. 1956. Radiation Dosimetry. Academic Press, New York.

Hoffman, F. 0., and C. F. Baes, III, eds. 1979. A Statistical Analysis of Selected Parameters for Predicting Food Chain Transport and Internal Dose of Radionuclides. NUREG/CR-1004, ORNL/NUREG/TM-282, Oak Ridge National Laboratory, Oak Ridge, TN.*

Hoffman, F. 0., D. L. Schaeffer, C. W. Miller and C. T. Garten, Jr. 1977. Proceedings of a Workshop on the Evaluation of Models Used for the Environmental Assessment of Radionuclide Releases. CONF-770901, Oak Ridge National Laboratory, Oak Ridge, TN.

Horst, T. W. 1978. A simple correction to the source depletion model. In Pacif ic Northwest Laboratory Annual Report for 1978 to the DOE Assistant Secretary for Environment, Part 3: Atmospheric Sciences. PNL-2850, Pt 3, Pacific Northwest Laboratory, Richland, Washington.

Houston, J. R., D. L. Strenge and E. C. Watson. 1976. DACR IN - A Computer Program for Calculating Organ Doses from Acute or Chronic Radionuclide Inhalation. BNWL-B-389, Battelle, Pacific Northwest Laboratories, Richland, Washington.

Houston, R. W. 1976. Testimony in the Matter of Northern States Power. Docket No. 50-484, Nuclear Regulatory Comission, Washington, DC.

ICRP. 1959. Report of Committee II on Permissible Dose for Interna] Radiation. International Commission on Radiological Protection, ICRP Publication 2, Pergamon Press.

ICRP. 1966. Deposition and retention models for internal dosimetry of the human respiratory tract. Health Phys. 12: 173-207.

* Available for purchase from the NRC/GPO Sales Program, U.S. Nuclear Regulatory Comission, Washington, D.C. 20555, and the National Technical Information Service, Springfield, Virginia 22161. 
ICRP. 1972. The Metabolism of Compounds of PIutonium and Other Actinides. International Commission on Radiological Protection, ICRP Publication T9, Pergamon Press.

Jaeger, R. G., ed. 1968. Engineering Compendium on Radiation Sheilding, Vol. 1. Springer-Verlag, New York.

Knipp, J. K., and G. E. Uhlenbeck. 1936. Emission of gama radiation during the beta decay of nuclei. Physica 3:425.

Kovalev, E. E., and A. Foderaro. 1968. Surface sources. In Engineering Compendium on Radiation Shielding, ed. R. G. Jaeger, Section 6.3. SpringerVerTag, New York.

Little, C. A., and C. W. Miller. 1979. The Uncertainty Associated With Selected Environmental Transport Models. ORNL -5528 , Oak Ridge National Laboratory, Oak Ridge, TN.

NCRP. 1975. Natural Background Radiation in the United States. Report No. 45, National Council on Radiation Protection and Measurements, Washington, DC.

Nieves, L. A. 1978. Costs and Economic Impacts. In Estimate of Potential Costs and Hypothetical Contaminating Events, Subject to "Proposed Guidance on Dose Limits for Persons Exposed to Transuranium Elements in the General Environment." PNL-2574, Pacific Northwest Laboratory, Richland, Washington.

Powell, D. C., H. L. Wegley and T. D. Fox. 1977. MESODIF-II: A Variable Trajectory Plume Segment Model to Assess Ground-Level Air Concentrations and Deposition of Routine Eff luent Releases from Nuclear Power Facilities. PNL-2419, Pacific Northwest Laboratory, RichTand, Washington.

Sagendorff, J.F., and J. T. Gol1. 1977. XoQDox Program for the Meteorological Evaluation of Routine Effluent Releases at Nuclear Power Station. NUREG-0324, U.S. Nuclear Regulatory Commission, washington, D.C.*

Slade, D. H. 1968. Meteorology and Atomic Energy. U.S. Atomic Energy Comission, Washington, DC.

Slinn, W. A. N. 1975. Some approximations for the wet and dry removal of particles and gases from the atmosphere. BNWL-SA-5489, Battelle, Pacific Northwest Laboratories, Richland, Washington.

Strenge, D. L., E. C. Watson and J. R. Houston. 1975. SUBDOSA - A Computer Program for Calculating Individual External Doses from Accidental Atmospheric Releases of Radionuclides. BNWL-B-35I, Battelle, Pacific Northwest Laboratories, Richland, Washington.

Strenge, D. L., J. K. Soldat and E. C. Watson. 1978. A Review of Methodology for ACcident Conseguence Assessment. NUREG/CR-0545 (PNL-2633), U.S. Nuclear Regulatory Conmission, Washington, DC .*

Fuailable for purchase from the NRC/GPO Sales Program, U.S. Nuclear Regulatory Commission, Washington, D.C. 20555, and the National Technical Information Service, Springfield, Virginia 22161. 
USNRC. 1975. Reactor Safety Study; An Assessment of Accident Risks in U. S. Commercial Nuclear Power Plants, Appendix, VI, Calculation of Reactor Accident Consequences, WASH-1400 (NUREG 75/014), U. S. Nuclear Regulatory Commission, Washington, DC. *

USNRC. 1976. Preparation of Environmental Reports for Nuclear Power Stations. Regulatory Gujde 4.2, U. S. Nuclear Regulatory Comission, Washington, $D C$.

USNRC. 1977. Estimating Aquatic Dispersion of Effluents from Accidental and Routine Reactor Releases for the Purpose of Implementing Appendix I, Regulatory Guide 1.T13, Rev. 1. U.S. Nuclear Regulatory Commission, Washington, DC.

USNRC. 1978. Liquid Pathway Generic Study, NUREG-0440, U. S. Nuclear

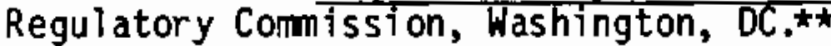

USNRC/EPA. 1978. Planning Basis for the Development of State and Local Government Radiological Emergency Response Plans in Support of Light Water Nuclear Power Plants. NUREG-0396, EPA 520/1-78-016, 0.S. Nuclear Regulatory Commission/Environmental Protection Agency, Washington, DC.**

Van Tuy1, H. H. 1964. BREMRAD -- A Computer Code for External and Internal Bremsstrahlung Calculations. HW-83784, General Electric, Richland, Washington.

* Available for free upon written request from the U.S. Nuclear Regulatory Commission, Division of Technical Information and Document Control, washington, D.C. 20555.

**Available for purchase from the NRC/GPO Sales Program, U.S. Nuclear Regulatory Commission, Washington, D.C. 20555, and the National Technical Information Service, Springfield, Virginia 22161. 
NUREG/CR-1021

PNL -3108

\section{DISTRIBUTION}

No. of

Copies

A. A. Churm

DOE Chicago Patent Group

Argonne, IL 60439

2 DOE Technical Information Center

oak Ridge, TN 37830

P. Donahoe

State of New Mexico

Environmental Improvement Division

P.0. Box 968

Sante Fe, NM 87503

6 Health and Safety Research Division

Oak Ridge National Laboratory PO BOX X

Oak Ridge, TN 37830

R. 0 . Chester

K. F. Eckerman

G. G. Killough

D. C. Kocher

L. M. McDowe 11-Boyer

P. S. Rohwer

J. McBride

Chemical Technology Division

Oak Ridge Nationai Laboratory

PO Box X

Oak Ridge, TN 37830

G. Schmidt

Bureau of Radiological Health HFX-460

5600 Fishers Lane

Rockville, MD 20857
No. of

Copies

D. Aldrich

Fuel Cycle Risk Analysis

Division 4413

Sandia Laboratories

A Ibuquerque, NM 87185

180 U.S. Nuclear Regulatory Commission

Division of Technical Information and Document Control

7920 Norfolk Avenue

Bethesda, MD 20014

P. Jackson

U.S. Nuclear Regulatory Commission Region I, I/E

631 Park Avenue

King of Prussia, PA 19406

41 U.S. Nuclear Regulatory Commission Washington, DC 20555

S. Acharya (2)

L. Andrews

W. Bivins

R. Bernero

$R$. Blond

W. Britz

R. Cordell

$\mathrm{F}$. Conge 1

E. Conti

T. Decker

C. Ferre 1

M. Fliegel

B. Grimes

R. Houston

F. Kantor

J. Kastner

R. Kornasiewicz

W. Kreger 
No. of

Copies

J. Long

0 . Lynch, Jr.

E. Markee

J. A. Martin

D. Martin

J. Meyer

D. Moeller

R. Muller

K. Murphy

T. Murphy

R. Neel

J. Norris

M. Parsont

W. Pasedag

F. Rowsome

H. Schierling

E. Shum

L. Soffer

T. Speis

F. Swanberg, Jr.

R. Waterfield

M. Young

R. B. McPherson

Battelle Memorial Institute $505 \mathrm{King}$ Avenue

Columbus, $\mathrm{OH} 43201$
No. of

Copies

Battelle Memorial Institute Pacific Northwest Laboratory PO Box 999

Richland, WA 99352

W. J. Bair

D. A. Baker

R. L. Drake

J. G. Droppo

L. G. Faust

W. A. Glass

G. R. Hoenes

W. E. Kennedy

B. A. Napier

L. A. Nieves

W. F. Sandusky

L. C. Schwendiman

J. K. Soldat

D. L. Strenge (26)

R. C. Thompson

C. M. Unruh

B. E. Vaughan

E. C. Watson

Technical Information (5)

Publishing Coordination (2) 


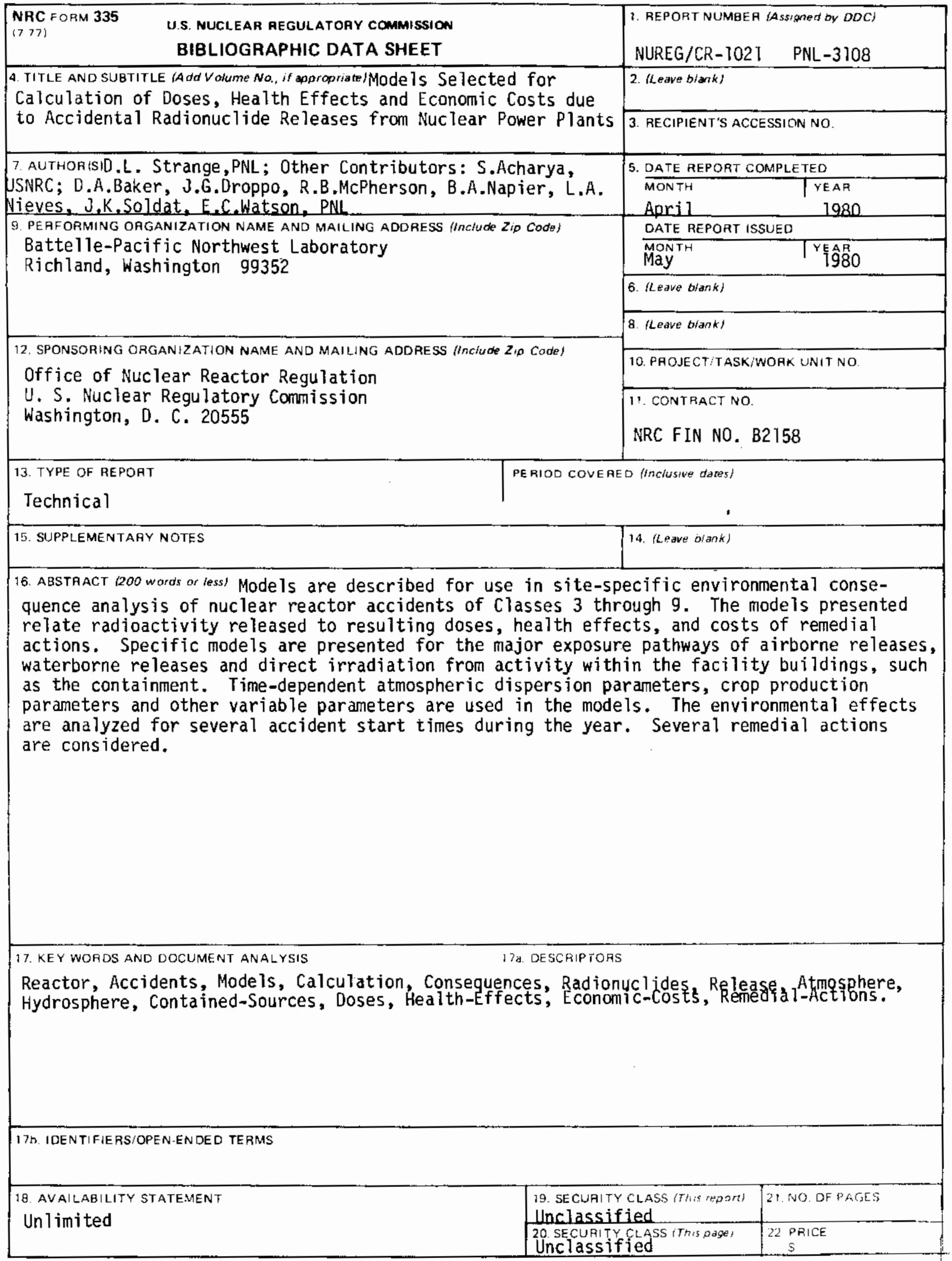


